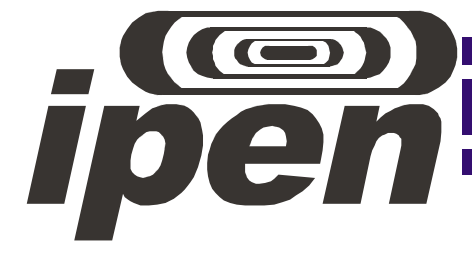

AUTARQUIA ASSOCIADA À UNIVERSIDADE DE SÃO PAULO

\title{
DESENVOLVIMENTO DE FERRAMENTA COMPUTACIONAL PARA PROJETO DE CANHÕES DE ELÉTRONS COM GRADE E SHADOW-GRID, PPM E COLETORES APLICADOS EM VÁLVULAS DE MICRO-ONDAS DE POTÊNCIA E CARACTERIZAÇÃO EXPERIMENTAL
}

\section{CÉSAR CANDIDO XAVIER}

\author{
Tese apresentada como parte \\ dos requisitos para obtenção do Grau \\ de Doutor em Ciências na Área \\ de Tecnologia Nuclear - Materiais \\ Orientador: \\ Prof. Dr. Cláudio Costa Motta
}


INSTITUTO DE PESQUISAS ENERGÉTICAS E NUCLEARES

Autarquia associada à Universidade de São Paulo

\title{
DESENVOLVIMENTO DE FERRAMENTA COMPUTACIONAL PARA PROJETO DE CANHÕES DE ELÉTRONS COM GRADE E SHADOW-GRID, PPM E COLETORES APLICADOS EM VÁLVULAS DE MICRO-ONDAS DE POTÊNCIA E CARACTERIZAÇÃO EXPERIMENTAL
}

\author{
CÉSAR CANDIDO XAVIER
}

Tese apresentada como parte dos requisitos para obtenção do Grau de Doutor em Ciências na Área de Técnologia Nuclear Materiais.

Orientador:

Dr. Cláudio Costa Motta 
Pois com o critério com que julgardes, sereis julgados; $e$, com a medida com que tiverdes medido, vos medirão também.

Mateus 7,2 


\section{Agradecimentos}

A Deus, por tudo de bom que fez e tem feito por mim.

Ao Ilmo. Sr. Vice-Almirante (EN) Carlos Passos Bezerril, Diretor do Centro Tecnológico da Marinha em São Paulo, por permitir que realizasse este curso.

Ao Capitão-de-Mar-e-Guerra (EN) Cláudio Costa Motta, pela orientação acadêmica, incentivo e oportunidade de aprender, um pouco, a fazer ciência, reconhecendo que ainda há muito o que aprender. Agradeço também pela forma saudável e instrutiva na condução de todo o trabalho desenvolvido.

Aos Capitães-de-Corveta (EN) Robson Keller e Silva Serra e ao Daniel Teixeira Lopes pela amizade, sugestões e, poucas mas enriquecedoras, discussões que tivemos ao longo deste trabalho.

Aos Primeiros-Tenentes (EN) Alleluia, Paulo e Thiago e ao Dr. Frank pela convivência amistosa e harmoniosa que mantivemos na Coordenadoria de Estudos e Projetos Espaciais.

Ao Primeiro-Sargento (ET) Cosme Ferreira da Silva e, em especial, ao Terceiro-Sargento (DT) Júlio dos Santos por todo o apoio e suporte que prestaram nas atividades laboratoriais.

A Sra. Selma Vilas Boas por todo o apoio nas atividades administrativas e incentivo.

Ao pessoal da biblioteca do IPEN, em especial o Sr. Valdir, a Srta. Edna, a Sra. Eneide e a Sra. Mery por todo apoio e força que me deram. Vocês não só foram muito prestativos como também competentes. Sempre foram comigo gentis e solícitos, seja no empenho na busca pelos diversos artigos/livros que solicitei em outras unidades da USP bem como no exterior. A vocês o meu sincero muito obrigado!

Aos professores que cordialmente aceitaram o convite para participar nas bancas do Plano de Trabalho, da Qualificação, do Seminário de Área e, finalmente, de Defesa de Tese. Todas as sugestões e correções apresentadas em muito enriqueceram este trabalho. Sou, portanto, grato à vocês: Dr. Josif Frenkel, Dr. Jiro Takahashi, Dr. Barroso, Dr. Angelo Pássaro e Dr. Valdir Sciane.

Não posso deixar de mencionar meu apreço, elevada estima e admiração pelo Professor Dr. Josif Frankel. Suas aulas foram o que de melhor um aluno pode aspirar: esclarecedoras, consisas, históricas e motivadoras. Com o senhor aprendi a gostar mais de aprender!

Aos meus sogros Sr. Geraldo e D. Cida e minhas cunhadas, Elisângela e Roberta pela torcida positiva!

Aos meus irmãos José, Alexandre e Eduardo. A vocês, o meu muito obrigado pela motivação incondicional ao longo desse trabalho!

Aos meus pais Xavier e Benedita. Saibam que sou eternamente grato a Deus por tê-los como pais dedicados e educadores pelo exemplo me apoiando em cada conquista da minha vida.

Ao meu filho Ítalo César. Desculpe-me por todos os momentos de ausência ao longo destes quatro anos, mas saiba que nunca deixei de lembrar e torcer por você!

Especialmente à minha esposa Ana Paula pelo carinho, paciência e amor. Mesmo em todos os momentos de ausência, ao meu lado torceu incondicionalmente pelo sucesso deste trabalho. Reconhecendo o que significava para mim, me motivou a superar todas as dificuldades e a conquintar mais este desafio. 


\title{
DESENVOLVIMENTO DE FERRAMENTA COMPUTACIONAL PARA PROJETO DE CANHÕES DE ELÉTRONS COM GRADE E SHADOW-GRID, PPM E COLETORES APLICADOS EM VÁLVULAS DE MICRO-ONDAS DE POTÊNCIA E CARACTERIZAÇÃO EXPERIMENTAL
}

\author{
César Candido Xavier
}

RESUMO

Neste trabalho analisa-se o problema do transporte do feixe de elétrons em canhões de elétrons, estruturas periódicas de ímãs permanentes e em coletores de simples e múltiplos estágios. Essa análise é de relevância em projetos de dispositivos de micro-ondas de potência dos tipos amplificador klystron e válvula TWT. Determina-se a dinâmica das partículas a partir da solução da equação da trajetória que é derivada da força de Lorentz e da conservação de energia. A equação da trajetória obtida é diferencial de segunda ordem, não-linear e independentemente do tempo para o potencial generalizado. Utiliza-se o método de RungeKutta de $4^{a}$ Ordem para integrar a equação da trajetória das partículas. Obtém-se o potencial escalar elétrico a partir da solução da equação de Poisson. Numericamente, obtêm-se os potenciais escalares elétricos e magnéticos, por meio do Método de Elementos Finitos (MEF). Ao longo do movimento de uma partícula, obtida a partir da solução da equação da trajetória, deposita-se carga elétrica. Utilizam-se macropartículas, uma vez que é praticamente impossível modelar cada partícula do problema, a partir do método Partícula na Célula (Particle in Cell - PIC). Neste caso, tem-se um problema acoplado para o potencial escalar elétrico e as trajetórias das macropartículas, uma vez que, as trajetórias das macropartículas dependem dos potenciais e estes, por sua vez, dependem das trajetórias. À convergência deste problema acoplado utiliza-se o Método das Aproximações Sucessivas (MAS). A plataforma desenvolvida, baseada nos métodos acima, compõe-se de duas ferramentas computacionais. A primeira, XMGUN, dedica-se ao projeto de: canhões de elétrons com grades e grades de sombreamento; e coletores de simples e múltiplos estágios considerando, ainda, a emissão de elétrons secundários. A segunda, XMAGUN, volta-se ao projeto de estruturas periódicas com ímãs permanentes. Afere-se o desempenho da ferramenta computacional XMGUN com o diodo plano de Pierce operando na condição em que a corrente é limitada pelas cargas espaciais. Por sua vez, verifica-se o desempenho do XMAGUN por meio de simulações com estruturas do tipo PPM separadas pelo vácuo e na presença de pole pieces. Os resultados obtidos em todas as simulações convergiram satisfatoriamente para as soluções analíticas. Utilizando o XMGUN, projeta-se um canhão de elétrons com $30 \mathrm{kV}$ de tensão de anodo e uma perveância de 1,37 $\mu$ Perv com capacidade de fornecer uma corrente elétrica de 7,1 $\mathrm{A}$. Esse canhão tem uma malha com 2796 elementos e 5057 nós. As principais características geométricas do canhão de elétrons são: raio do catodo $r_{c}=14,6 \mathrm{~mm}$; raio do disco do catodo $r_{k}=6,2 \mathrm{~mm}$; e ângulo do eletrodo de focalização $\theta=37^{\circ}$. Neste caso, a velocidade transversal normalizada $\sigma$ e o alcance do feixe $z_{w}$ observados são de 0,068 e 26,88 $\mathrm{mm}$ respectivamente. Obtém-se uma concordância superior a $93 \%$ em corrente e perveância com o EGUN. Utilizando, ainda, o XMGUN, são simulados coletores de simples e múltiplos estágios. O coletor de simples estágio apresenta 1612 nós e 2969 elementos, e o de 4 (quatro) estágios, 2496 nós e 4257 elementos. As tensões dos eletrodos do $1^{\circ}, 2^{\circ}, 3^{\circ}$ e $4^{\circ}$ estágio são de $9,45 \mathrm{kV}, 8,65$ 
$k V, 6,45 \mathrm{kV}$ e 3,45 $\mathrm{kV}$ respectivamente. Durante as simulações, devido à emissão de elétrons secundários, observa-se, para o coletor de simples estágio, macropartículas penetrando na região de deriva, fenômeno este indesejado, e não observado para o coletor de 4 (quatro) estágios. Considerando o XMAGUN, projeta-se um arranjo periódico com pole pieces e 5 (cinco) ímãs permanentes, capaz de fornecer um campo magnético, no centro da estrutura, de 0,42 $T$. Neste caso, a geometria do arranjo periódico obtida é: raio interno $r_{m 1}$ e externo $r_{m 2}$ do ímã permanente são iguais a $3,5 \mathrm{~mm}$ e $7,5 \mathrm{~mm}$ respectivamente; raio externo do pole piece $r_{3}=7,5 \mathrm{~mm}$; raio interno $r_{f 1}$ e externo $r_{f 2}$ da ponteira do pole piece são $1,6 \mathrm{~mm}$ e 3,05 $\mathrm{mm}$ respectivamente; espessura do ímã permanente $T=2,95 \mathrm{~mm}$; período magnético $L=8,5$ $m m$. A remanência do ímã permanente utilizada é de $B_{r}=0,85 \mathrm{~T}$. A malha dessa estrutura periódica magnética apresenta pouco mais de 20.000 nós e 40.000 elementos. 


\title{
COMPUTATIONAL DEVELOPMENT TOOL FOR PROJECT OF ELECTRON GUNS WITH GRIDS AND SHADOW-GRIDS, PPM AND COLECTORS FOR MICROWAVE POWER VALVES AND EXPERIMENTAL CHARACTERIZATION
}

\author{
César Candido Xavier
}

\begin{abstract}
In this paper we analyze the problem of transport of the electron beam in electron guns, periodic arrays of permanent magnets and collectors of simple and multiple stages. This analysis is of relevance in the design of power microwave devices such as klystron amplifier and TWT valve. The dynamics of particles is determined from the solution of the equation of the trajectory that is derived from the Lorentz force and energy conservation law. The equation of the trajectory obtained is differential of second-order, non-linear and time independent for the generalized potential. It is used the Runge-Kutta 4th order method to integrate the equation of the trajectory of the particles. The electric scalar potential is obtained from the solution of the Poisson equation. Numerically, we obtain the electric and magnetic scalar potentials, using the Finite Element Method (FEM). Throughout the motion of a particle, obtained from the solution of the equation of the trajectory, electrical charge it is deposited. Macroparticles are used, since it is virtually impossible to model each particle of the problem, based on Particle in Cell scheme (Particle in Cell - PIC). In this case, there is a coupled problem for the electric scalar potential and the trajectories of the macroparticles, since these trajectories depend on the potential and the potential, in turn, depends on the trajectories. In order to abtain the convergence of this coupled problem, it used the Method of Successive Approximations (MSA). The platform developed, based on the above methods, consists of two computational tools. The first, XMGUN, is dedicated to the project of: electron guns with grids and shadow-grids, and collectors of simple and multiple stages, where secondary electrons emission is considered. The second, XMAGUN, is used to the design of periodic permanent magnets structures. The XMGUN was benchmarked against the plan Pierce diode under space charge limited condiction. In turn, the XMAGUN was benchmarked against PPM like structures, separated by a vacuum and in the presence of pole pieces. The results, in all simulations, converged satisfactorily to the analytical solutions. Using XMGUN, it is designed an electron gun with $30 \mathrm{kV}$ anode voltage, $1.37 \mu$ Perv capable of supplying an electric current of $7.1 \mathrm{~A}$. This gun has a mesh with 2796 elements and 5057 nodes. The main geometric characteristics of the electron gun are: cathode radius $r_{c}=14.6 \mathrm{~mm}$; cathode disc radius $r_{k}=6.2 \mathrm{~mm}$; and half cone angle $\theta=37^{\circ}$. In this case, the normalized transverse velocity $\sigma$ and beam-waist distance from anode $z_{w}$ are 0.068 and $26.88 \mathrm{~mm}$ respectively. An agreement above 93\% in current and perveance is found when compared with EGUN. XMGUN is also used to simulate single and multi stage collectors. The single-stage collector has 1612 nodes and 2969 elements, while the 4 (four) stages collector has 2496 nodes and 4257 we elements. The collector electrode voltages of the $1 \mathrm{st}$, 2nd, 3rd and 4th stage are $9.45 \mathrm{kV} 8.65 \mathrm{kV} 3.45 \mathrm{kV} 6.45 \mathrm{kV}$, respectively. During the simulations, due to yield of secondary electrons, for the single stage collector, it is observed macroparticles entering into the drift region, a phenomenon unwanted, and not observed for the 4 (four) stage collector. Whereas XMAGUN is projected at a periodic arrangement with pole pieces and 5 (five) permanent magnets, capable of providing a magnetic field in the
\end{abstract}


center of the structure was $0.42 \mathrm{~T}$. In this case, the geometry of the periodic arrangement is obtained: inner and outer radius of the permanent magnet $r_{m 1}=3.5 \mathrm{~mm}$ and $7.5 \mathrm{~mm}$ respectively $r_{m 2}=$; outer radius of the pole piece $r_{3}=7.5 \mathrm{~mm}$, internal radius and external tip of the pole piece $r_{f 1}=r_{f 2}=1.6 \mathrm{~mm}$ and $3.05 \mathrm{~mm}$ respectively; permanent magnet thickness $\mathrm{T}=$ $2.95 \mathrm{~mm}$ magnetic period $\mathrm{L}=8.5 \mathrm{~mm}$. The remanence of the permanent magnet used is $\mathrm{Br}$ $=0.85 \mathrm{~T}$. The net periodic structure of magnetic features little more than 20,000 nodes and 40,000 elements. 


\section{Conteúdo}

1 Introdução 1

1.1 TWT - Princípio de Operação . . . . . . . . . . . . . . . . . . 3

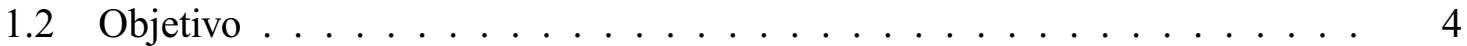

1.3 Descrição do Trabalho . . . . . . . . . . . . . . . . 5

2 O Problema do Canhão de Elétrons $\quad 7$

2.1 Componentes e Princípio de Funcionamento . . . . . . . . . . . . . . 8

2.2 Diodo de Pierce de Fluxo Paralelo . . . . . . . . . . . . . . . . . . . 9

2.3 Canhões de Pierce de Fluxo Convergente . . . . . . . . . . . . . . . . . . 17

2.3.1 Aplicação do resultado de Langmuir e Blodgett do diodo esférico para o problema do canhão de elétrons com fluxo convergente . . . 22

2.3.2 Fluxograma para projeto de um canhão de elétrons de Pierce com fluxo convergente . . . . . . . . . . . . . . 28

2.4 Controle do Feixe de Elétrons . . . . . . . . . . . . . . . . . . . . . . . 29

2.5 Conclusões do Capítulo . . . . . . . . . . . . . . . . . 31

3 O Problema do Transporte do Feixe - PPM 32

3.1 PPM - Componentes e Princípio de Funcionamento . . . . . . . . . . . . . 33

3.2 Teorema de Busch . . . . . . . . . . . . . . . . . . . . 34

3.3 Estrutura de Focalização - Solenóide . . . . . . . . . . . . . . . . . . . . 37

3.4 Estrutura de Focalização - PPM para um Fluxo de Brillouin . . . . . . . . . 40

3.5 Estrutura de Focalização - PPM para Ímãs toroidais separados pelo vácuo . 44

3.5.1 Determinação $B_{z}(\vec{r}): \ldots \ldots \ldots 4$. . . . . . . . . 45

3.5.2 Determinação $B_{\rho}(\vec{r}): \ldots \ldots \ldots$. . . . . . . . . 46

3.5.3 Determinação $B_{z}(\vec{r})$ no eixo de simetria de um PPM com $N$ ímãs permanentes ..................... 47

3.6 Estrutura de Focalização - PPM para Ímãs toroidais separados por Pole Piece 47

3.6.1 Potencial Escalar Magnético para $\rho<R_{1} \ldots \ldots$. . . . . . 49

3.6.2 Potencial Escalar Magnético para $\rho>R_{2} \ldots \ldots \ldots 50$

3.6 .3 Materiais com ímãs permanentes . . . . . . . . . . . . . . . 52

3.6.4 Modelos aprimorados de estruturas do tipo PPM . . . . . . . . . 52

3.7 Conclusões do Capítulo . . . . . . . . . . . . . . . . . 59

4 O problema do coletor de elétrons considerando a emissão de elétrons secundários 61

4.1 Recuperação de energia em coletores . . . . . . . . . . . . . . . 62

4.2 Emissão Simplificada de Elétrons Secundários em MDC . . . . . . . . . . 63

4.2.1 Emissão de Elétrons Secundários: modelo simplificado . . . . . . . 65

4.3 Modelo Aprimorado para o Número de Elétrons Secundários Emitidos . . . 67

4.4 Conclusões do Capítulo . . . . . . . . . . . . . . . . . . 69 
5 Materiais e Métodos $\quad 70$

5.1 Fundamentação Física . . . . . . . . . . . . . . . . . 71

5.1.1 Equações de Maxwell na condição FSCL . . . . . . . . . . . . . . 71

5.1.2 Inviabilidade Computacional na Determinação da Força Elétrica sobre uma Partícula . . . . . . . . . . . . . . . . . 72

5.2 Derivação das Equações de Movimento . . . . . . . . . . . . . . . 73

5.2.1 Equação da Trajetória - Coordenadas Cilíndricas . . . . . . . . . 73

5.3 Particle in Cell-PIC . . . . . . . . . . . . . . . . . . . . . . . 77

5.4 Método dos Elementos Finitos (MEF) . . . . . . . . . . . . . 78

5.4.1 Determinação do Potencial Escalar Elétrico: Método dos Resíduos Ponderados . . . . . . . . . . . . . . . . 80

5.4.2 Determinação do Potencial Vetor Magnético: Método Variacional . 83

5.5 Método de Aproximação Sucessiva (MAS) . . . . . . . . . . . . . . . . . 88

5.6 Sistemas Lineares Esparsos . . . . . . . . . . . . . . . . . . . . . . . 90

5.6.1 Método de armazenamento compacto por linha . . . . . . . . . . 91

5.6.2 Método do Gradiente Biconjugado (MGB) . . . . . . . . . . . . . 91

5.7 Conclusões do Capítulo . . . . . . . . . . . . . . . . . . . . . 92

6 Resultados e Discussão $\quad 94$

6.1 Simulações com o EGUN . . . . . . . . . . . . . . . . . . . . . . 95

6.1 .1 Procedimento do Projeto . . . . . . . . . . . . . . . 95

6.1 .2 Resultados ........................ 98

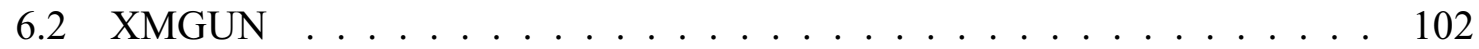

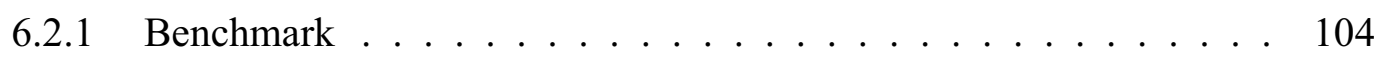

6.2 .2 Simulações com o XMGUN . . . . . . . . . . . . . . . . 111

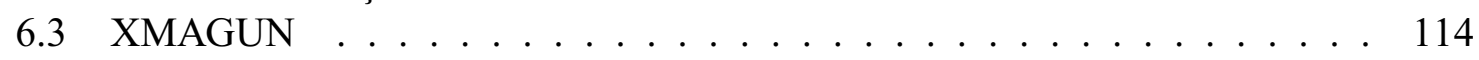

6.3.1 Benchmark \#1: PPM separados pelo vácuo . . . . . . . . . . . . 114

6.3.2 Benchmark \#2: PPM separados por pole pieces . . . . . . . . . . 117

6.3.3 Simulações com o XMAGUN . . . . . . . . . . . . . . . . . 119

6.4 Conclusões do Capítulo . . . . . . . . . . . . . . . . . . . . 124

7 Conclusão $\quad 126$

A Ferramentas Open Source 130

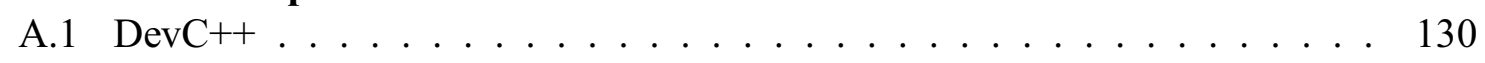

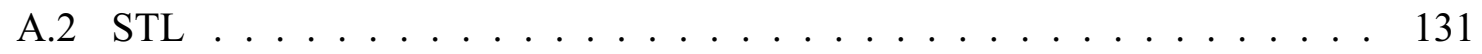

A.3 OpenGL . . . . . . . . . . . . . . . . . . . 132

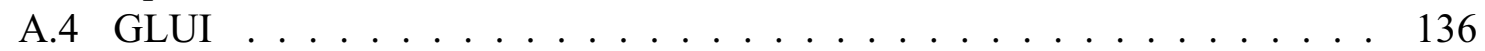

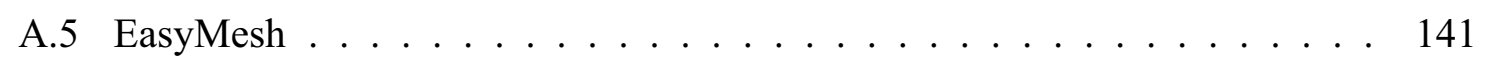

B Simuladores de Canhões de Elétrons 146

B.1 MICHELLE . . . . . . . . . . . . . . . . . . . . . . . . . . . . . . . . . . . . . 146

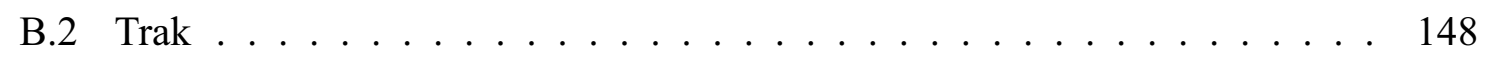

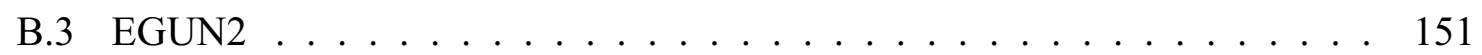

C Bancada Experimental $\quad \mathbf{1 5 2}$

C.1 Arranjo Experimental . . . . . . . . . . . . . . . . . . . . . . . 152

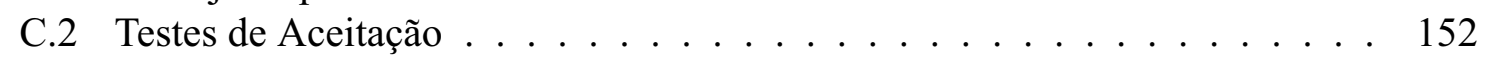

C.2.1 Vácuo . . . . . . . . . . . . . . . . . . 152 
C.2.2 Filamento . . . . . . . . . . . . . . . . . . 154

D Publicações

D.1 MOMAG $-2008 \ldots \ldots \ldots \ldots \ldots \ldots \ldots$

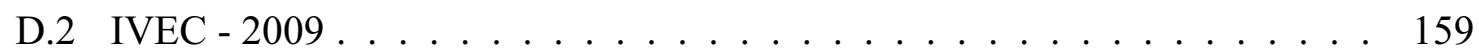

D.3 COMPUMAG $-2009 \ldots \ldots \ldots \ldots \ldots 16 \ldots \ldots \ldots$

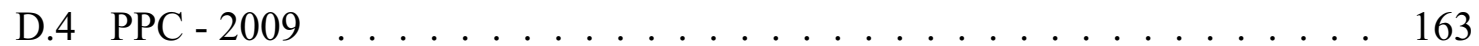

D.5 IEEE $-2010 \ldots \ldots \ldots \ldots \ldots \ldots \ldots$

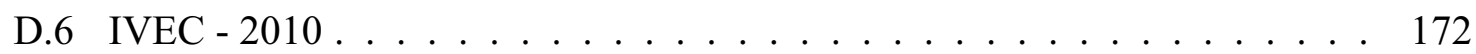

D.7 MOMAG $-2010 \ldots \ldots \ldots \ldots \ldots \ldots \ldots$

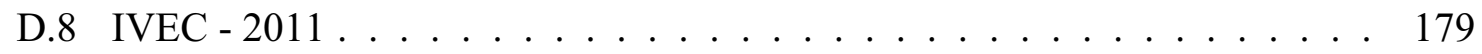

$\begin{array}{ll}\text { Bibliografia } & 181\end{array}$ 


\section{Lista de Tabelas}

2.1 Coordenadas da geometria do anodo para o problema do canhão de Pierce de feixe paralelo. . . . . . . . . . . . . . . . 17

2.2 Fluxograma de projeto do canhão de Pierce de fluxo convergente. . . . . . . 29

2.3 Parâmetros de entrada do canhão de elétron Litton L-2087. . . . . . . . . . 30

2.4 Parâmetros de saída do canhão de elétron Litton L-2087. . . . . . . . . . . 30

3.1 Propriedades de materiais magnéticos comerciais disponíveis. . . . . . . . 34

3.2 Parâmetros geométricos da estrutura do PPM cujos ímãs permanentes são separados pelo vácuo. . . . . . . . . . . . . 58

6.1 Faixas de utilização das variáveis geométricas do canhão de elétrons em simulações com o EGUN. . . . . . . . . . . . . . . . . . . . . . .

6.2 Valores para os Raios do Catodo e distâncias Grade-Catodo utilizadas em simulações com o EGUN obtidas a partir de componentes físicos existentes no laboratório. . . . . . . . . . . . . . . . . . . . . . .

6.3 Medidas dos Raios do Catodo e distâncias Grade-Catodo utilizadas em simulações com o EGUN obtidas a partir de componentes físicos existentes. . . 102

6.4 Dados das malhas, para o canhão de Pierce, utilizadas para validação da ferramenta computacional XMGUN. . . . . . . . . . . . . . 108

6.5 Parâmetros geométricos do feixe e da estrutura do PPM. . . . . . . . . . . 115

6.6 Parâmetros geométricos da estrutura do PPM com pole piece. . . . . . . . . . 117

B.1 Tensões do corpo e dos cinco estágios do coletor de uma válvula TWT da Boeing. . . . . . . . . . . . . . . . . . . 148 


\section{Lista de Figuras}

1.1 Modelo básico de uma válvula TWT do tipo hélice com seus principais componentes. . . . . . . . . . . . . . . .

2.1 Configuração típica de um canhão de elétrons e seus componentes. . . . . . 9

2.2 Vista geral de um canhão de Pierce de Fluxo Convergente. . . . . . . . . . 10

2.3 Feixe eletrônico paralelo de um catodo plano. . . . . . . . . . . . . 10

2.4 Perfis das equipotenciais na ausência (linhas tracejadas) e na presença (linhas contínuas) do feixe de elétrons. . . . . . . . . . . . . . . .

2.5 Novo perfil das equipotenciais em um catodo plano devido ao ajuste do eletrodo de focalização. . . . . . . . . . . . . . . . . . . . . .

2.6 Curvas da corrente pela temperatura observada entre os filamentos de uma lâmpada, observadas por Langmuir, para diferentes potenciais aplicados entre os filamentos [20]. . . . . . . . . . . . . . . . . .

2.7 Variação do potencial entre dois planos infinitos $A$ (catodo) e $B$ (anodo) considerando a densidade de cargas: nula (reta $P T$ ); constante (curva $P S T$ ); e FSCL [20]. . . . . . . . . . . . . . . . . . . . . .

2.8 Seção transversal do canhão de Pierce de feixe paralelo indicando o EFF, catodo, anodo bem como o sistema de coordenadas. . . . . . . . . . . . . .

2.9 Geometria do anodo, em verde, corrigida para o problema do canhão de Pierce de feixe paralelo. . . . . . . . . . . . . . . . . .

2.10 Parâmetros do canhão de fluxo convergente de Pierce. $d$ : separação entre o catodo e o anodo; $r_{c}$ e $r_{a}$ : raio das esferas do catodo e anodo respectivamente; $d_{m}$ : distância medida na direção do eixo do canhão entre a cintura do feixe e a esfera do anodo; $r_{M}$ : raio da cintura do feixe de elétrons; $r_{K} \mathrm{e}$ $r_{A}$ : raios limites do feixe de elétrons no catodo e anodo respectivamente; $\theta_{0}$ : ângulo do meio cone entre o eixo do canhão e a abertura do anodo. . . . . . .

2.11 Representação esquemática do caminho percorrido pelo elétron ao atravessar a abertura do anodo, causando desvio $\delta$ em sua trajetória face ao efeito de lente eletrostática e a magnitude da distância focal $f_{2} \ldots \ldots . \ldots 26$

2.12 Técnicas utilizadas no controle do feixe em canhões de elétrons. . . . . . . 31

3.1 Focalização de um feixe de elétrons utilizando uma estrutura do tipo PPM. . 35

3.2 Uso de um solenóide para focalização de um feixe de elétrons. . . . . . . . 38

3.3 Comportamento do feixe de elétrons focalizado por um PPM nos casos em que os parâmetros devido ao campo magnético e à carga espacial, $\alpha$ e $\beta$ variam $[18] \ldots \ldots \ldots \ldots \ldots \ldots$ 
3.4 Comportamento do ripple de um feixe de elétrons focalizado por um PPM tendo como parâmetros os coeficientes devido ao campo magnético $\alpha$ e à carga espacial $\beta$, considerando a primeira região com solução estável para $3.49 \ldots \ldots \ldots \ldots \ldots \ldots \ldots \ldots \ldots \ldots \ldots \ldots \ldots$

3.5 Esquema de uma estrutura de um PPM composto de ímãs permanentes toroidais de raios interno e externo $\mathrm{R}_{1}$ e $\mathrm{R}_{2}$, respectivamente, espessura externa de $2 \mathrm{~L}$ tendo uma separação entre os ímãs de $b$. A polaridade dos ímãs também está representada na figura [27]. . . . . . . . . . . . . . .

3.6 Geometria de um ímã permanente utilizada para se determinar o campo magnético $\vec{B}(\vec{r})$ [27].

3.7 Estrutura do PPM estudado por Chang. . . . . . . . . . . . . . . . . . .

3.8 Distribuição do potencial escalar magnético na superfície interna da estrutura do PPM apresentado na FIG. 3.7 . . . . . . . . . . . . . . . . . . . . . .

3.9 Modelo físico de uma estrutura do tipo PPM estudado por Sterzer (a) e a curva da intensidade do campo magnético em seu eixo de simetria (b). . . .

3.10 Representação dos três fluxos utilizados na determinação da permeância total do circuito magnético.

3.11 Método gráfico utilizado na determinação da intensidade de campo $H_{d}$ considerando um ímã permanente com características de desmagnetização linear.

3.12 Representação do modelo da estrutura do PPM estudado por Santra et al. . .

3.13 Variantes para as trajetórias dos fluxos da estrutura do PPM estudadas do Santra et al.: (a) raio interno do ímã permanente igual ao raio externo da ponteira do pole piece e raio externo ímã permanente igual ao raio externo do pole piece $\left(r_{m 1}=r_{f 2}\right.$ e $\left.r_{m 2}=r_{3}\right)$; (b) raio interno do ímã permanente maior que o raio externo da ponteira do pole piece e raio externo ímã permanente menor que o raio externo do pole piece $\left(r_{m 1}>r_{f 2}\right.$ e $\left.r_{m 2}<r_{3}\right)$; e (c) raio interno do ímã permanente maior que o raio externo da ponteira do pole piece e raio externo ímã permanente maior que o raio externo do pole piece $\left(r_{m 1}>r_{f 2}\right.$ e $\left.r_{m 2}>r_{3}\right) \ldots \ldots \ldots \ldots$

3.14 Perfil do campo magnético axial no eixo de simetria devido a 1 ímã permanente no vácuo. . . . . . . . . . . . . . . . . . .

3.15 Perfil do campo magnético axial no eixo de simetria devido a 3 ímãs permanentes separados pelo vácuo. . . . . . . . . . . . . . . .

3.16 Perfil do campo magnético axial no eixo de simetria devido a 10 ímãs permanentes separados pelo vácuo. . . . . . . . . . . . . .

4.1 Modelo simplificado de uma válvula tipo TWT em que o coletor está com o mesmo potencial do corpo do tubo. . . . . . . . . . . . . . . .

4.2 Modelo simplificado de uma válvula tipo TWT em que uma segunda fonte de alimentação de $10 \mathrm{kV}$ é utilizada no coletor. . . . . . . . . . . . . .

4.3 Modelo simplificado de uma válvula tipo TWT em que a segunda fonte de alimentação do coletor seja de $6 \mathrm{kV}$.

4.4 Espectro típico de energia de emissão de elétrons secundários. . . . . . . . . .

4.5 Representação da emissão de um elétron secundário verdadeiro devido a um elétron primário.

4.6 Representação da emissão de um elétron secundário espalhado devido a um elétron primário. 
5.1 Modelos de macropartículas: (a) modelo bidimensional para problemas que apresentam simetria axial com densidade de carga volumétrica $\rho_{i}$, raio inicial $r_{i}$, raio final $r_{i}+\Delta r$ e espessura $\Delta z$ e (b) modelo tridimensional. . . . .

5.2 Exemplo típico do ciclo, um passo no tempo, em um programa de simulação de partícula. As partículas são numeradas $i=1,2, \ldots, N P$; os índices da malha são $j$, os quais se tornarão vetores quando se referirem a 2 ou 3 dimensões.

5.3 Um elemento triangular da malha . . . . . . . . . . . . . . .

5.4 Modelo de discretização de um domínio retangular utilizando triângulos. Os elementos estão numerados em negrito. Os elementos que tem o nó $13 \mathrm{em}$ comum são os de número: $11,12,13,20,21$ e 22 . . . . . . . . . . . . . .

5.5 Trajetória da $j$-ésima macropartícula e, a respectiva, deposição de carga no $i$-ésimo elemento da malha. . . . . . . . . . . . . . . . . . .

5.6 Fluxograma do MAS utilizado em ferramentas computacionais para a solução de problemas de canhões de elétrons operando na condição FSCL. . . . . .

6.1 Geometria típica do canhão de elétrons e as variáveis geométricas utilizadas em simulações com o EGUN: raio do disco do catodo $r_{k}$; raio do catodo $r_{c}$; ângulo do eletrodo de focalização $\theta$; distância catodo-anodo $d$; e distância grade-catodo $g_{d} \ldots \ldots \ldots \ldots \ldots \ldots \ldots$

6.2 (a) Vista frontal da grade de controle e (b) aproximação da grade original, utilizada nas simulações com o EGUN, por meio de anéis concêntricos. . .

6.3 Componentes físicos de um canhão de elétrons: (a) catodo com shadow-grid e (b) eletrodo de focalização com a grade de controle. . . . . . . . . . . . .

6.4 Perveância como uma função da distância catodo-anodo tendo o raio do catodo como parâmetro. O ângulo do eletrodo de focalização é de $33,2^{\circ}$. . .

6.5 Perveância como uma função da distância catodo-anodo tendo o ângulo do eletrodo de focalização como parâmetro. $\mathrm{O}$ raio do catodo é de $11,9 \mathrm{~mm}$. .

6.6 Corrente do feixe como uma função da tensão da grade de controle tendo a separação catodo-anodo como parâmetro. A distância grade-catodo é de 1,0 mm. . . . . . . . . . . . . . . . . . .

6.7 Corrente do feixe como uma função da tensão da grade de controle tomandose como parâmetro a separação grade-catodo. A distância catodo é de 8,875 mm. . . . . . . . . . . . . . . . . . . .

6.8 Corrente do feixe como uma função da separação catodo-anodo tomando-se a tensão da grade de controle como parâmetro. A distância entre a gradecatodo é de $0,8 \mathrm{~mm} . \ldots \ldots \ldots \ldots$

6.9 Corrente do feixe de elétrons em função da separação catodo-anodo para os canhões GG2, G2A e G2Y. . . . . . . . . . . . . . . . . . . . . . . .

6.10 Canhão G2Y com shadow-grid modelado: (a) através de uma impressão sobre a superfície do catodo de uma região não emissora; (b) a partir de um modelo físico com altura . . . . . . . . . . . . . . . .

6.11 Amplificação visual da área de emissão do catodo do canhão G2Y. (a) A shadow-grid foi fisicamente modelada sobre a superfície do catodo enquanto que em (b) foram impressas áreas não emissoras. . . . . . . . . . . . . . . 
6.12 Interface com o usuário da ferramenta computacional desenvolvida. Está dividida em (a) Opções de visualização, (b) Dados da Malha, (c) Variáveis que podem ser alteradas pelo usuário, (d) Resultados Obtidos e (e) Visualização dos elementos da malha. . . . . . . . . . . . . . . . . .

6.13 Visualização das trajetórias de 20 partículas em um diodo plano de Pierce: em (a), as trajetórias foram traçadas como uma primeira aproximação do problema, onde os campos foram obtidos a partir da solução da equação de Laplace; em (b) as trajetórias das partículas após terem atingido o critério de convergência utilizando o MAS. Em (c) e (d) são apresentados o campo elétrico e a malha na condição inicial, sem a deposição de cargas, e após a convergência. . . . . . . . . . . . . . . . .

6.14 O gráfico em azul, que apresenta a razão da largura da área de emissão pelo erro percentual da densidade de corrente, indica que o erro diminui com o aumento da largura de emissão. O número de iterações para razão de largura de emissão superiores a 0,1 , (gráfico em vermelho), cresce e permanece praticamente constante para $d_{s} / d>0,5 \ldots \ldots \ldots \ldots$

6.15 Efeito da variação do coeficiente de sobre-relaxação $u$ sobre o número de iterações para a convergência.

6.16 Visualização, para até dez iterações necessárias para convergência, do erro percentual da densidade de corrente tomando-se como parâmetro o coeficiente de sobre-relaxação. . . . . . . . . . . . . . . . . . . . . .

6.17 Variação do número de iterações necessárias para se obter a convergência para o problema do diodo plano de Pierce em função de diferentes coeficientes de sobre-relaxação. . . . . . . . . . . . . . . . . . . . .

6.18 Variação percentual do erro da densidade de corrente pelo número de partículas utilizadas na simulação de um diodo plano de Pierce. . . . . . . . . . .

6.19 Erro percentual observado na posição final das partículas. Os maiores erros se referem às partículas que estão mais próximas do eixo de simetria. . . . . .

6.20 Erro comparativo para a posição final das partículas considerando a geometria do anodo plano e do anodo corrigido.

6.21 Comportamento típico observado para o tempo de trânsito das macropartículas. 111

6.22 Simulação de um canhão de elétrons, onde as trajetórias das partículas foram estabelecidas pela integração da equação diferencial de $2^{a}$ Ordem da Trajetória, considerando inexistir campo magnético na região simulada. . . . .

6.23 Geometria do canhão de elétrons com simetria axial, com grade e shadowgrid operando na condição limitado pela carga espacial. Equipotenciais de 1 $\mathrm{kV}$ e $r_{95}$ também são apresentados. Utilizando a equação da trajetória, este canhão fornece uma corrente de 4,58A.

Comportamento da posição $\left(z_{95}\right)$ e cintura $\left(r_{95}\right)$ do feixe e da velocidade transversal normalizada $(\sigma)$ para uma variação da tensão de grade de $420 \mathrm{a}$ 600 V. . . . . . . . . . . . . . . . . . .

6.25 Simulação da trajetória de 264 macropartículas em um coletor utilizando o XMGUN (a) e a malha de elementos triangulares utilizada na simulação com 2969 elementos triangulares e 1612 nós, (b). . . . . . . . . . . . . . .

6.26 Campo magnético de um ímã no eixo de simetria. É observado boa concordância entre as curvas que representa a solução numérica e exata. . . . . .

6.27 Campo magnético, devido a dois ímãs, no eixo de simetria. É observado boa concordância entre as curvas que representa a solução numérica e exata. . . 
6.28 Campo magnético, devido a vinte ímãs, no eixo de simetria. É observado boa concordância entre as curvas que representam as soluções numéricas, MEF-Gauss e MEF-MGC, e a exata e a obtida pela expressão integral. . .

6.29 Erro relativo observado para o campo magnético no eixo axial para um PPM composto de 20 ímãs. Os maiores erros acontecem quando o campo magnético axial se aproxima absolutamente de zero. . . . . . . . . . . . .

6.30 Vista ampliada e parcial do campo magnético gerado por um conjunto de 20 ímãs permanentes. . . . . . . . . . . . . . . . . . . . .

6.31 Vistas ampliadas da estrutura da malha gerada de um PPM com pole piece (a) e do perfil do campo magnético obtido (b). . . . . . . . . . . . . . .

6.32 Variação do valor de pico do campo magnético axial utilizando-se o XMGUN, o código ANSYS e a solução ANALÍTICA para distintos valores de

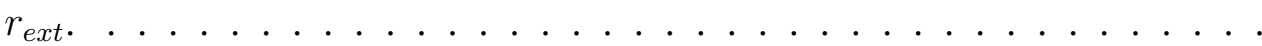

6.33 Perfil da intensidade do campo magnético axial ao longo do eixo para 5 (cinco) valores distintos de $r_{e x t}=r_{3}-r_{m 2} \ldots \ldots \ldots \ldots$

6.34 Um modelo típico de pole piece empregado entre dois ímãs permanentes e as linhas do campo magnético gerado. . . . . . . . . . . . . . . .

6.35 Um modelo diferenciado de pole piece empregado entre dois ímãs permanentes e as linhas do campo magnético gerado. . . . . . . . . . . . .

6.36 Comparação entre as intensidades do campo magnético gerado no eixo de simetria para três configurações de pole piece: (a) inexiste o pole piece; (b) modelo FIG. 6.34; (c) modelo FIG. 6.35 . . . . . . . . . . . . . . . . . .

6.37 Trajetória das macropartículas considerando um potencial de aceleração, corrente do feixe e campo magnético de $15 \mathrm{kV}, 4.6 \mathrm{~A} B_{p}=85 \mathrm{mT}$ respectivamente. Também é possível observar o $r_{95}$ e a intensidade do fluxo magnético axial, $B_{z}(\rho=0)$, devido à estrutura de um PPM. Neste caso $\alpha=0,08 \mathrm{e}$ $\beta=0,55$.

6.38 Trajetória das macropartículas considerando um potencial de aceleração, corrente do feixe e campo magnético de $20 \mathrm{kV}, 4.6 \mathrm{~A} B_{p}=85 \mathrm{mT}$ respectivamente. Também é possível observar o $r_{95}$. Neste caso $\alpha=0,06$ e $\beta=0,36$.

6.39 Trajetória das macropartículas considerando um potencial de aceleração, corrente do feixe e campo magnético de $40 \mathrm{kV}, 4.6 \mathrm{~A} B_{p}=85 \mathrm{mT}$ respectivamente. Também é possível observar o $r_{95}$. Neste caso $\alpha=0,03$ e $\beta=0,13$.

6.40 Trajetória das macropartículas considerando um potencial de aceleração, corrente do feixe e campo magnético de $60 \mathrm{kV}, 4.6 \mathrm{~A} B_{p}=85 \mathrm{mT}$ respectivamente. Também é possível observar o $r_{95}$. Neste caso $\alpha=0,02$ e $\beta=0,07$.

6.41 Trajetória das macropartículas considerando um potencial de aceleração, corrente do feixe e campo magnético de $80 \mathrm{kV}, 4.6 \mathrm{~A} B_{p}=85 \mathrm{mT}$ respectivamente. Também é possível observar o $r_{95}$. Neste caso $\alpha=0,01$ e $\beta=0,04$.

A.1 Vista do ambiente gráfico integrado do DevC++ . . . . . . . . . . . . . 131

A.2 Primitivas utilizadas pelo OpenGL para renderizar objetos. . . . . . . . . 133

A.3 Diversos tipos de recursos disponibilizados pela biblioteca GLUI. . . . . . 137

A.4 Modelo de uma típica janela para visualização de objetos em 3D utilizando a biblioteca GLUI. . . . . . . . . . . . . . . . . . .

A.5 Utilizando-se GLUI é possível construir janelas com diversos recursos de interface integrados para a visualização de modelos $3 \mathrm{D} \ldots$. . . . . . . . . 
A.6 (a) Interface com o usuário que permite ao usuário visualizar qualquer elemento da malha. Estabelecido o elemento, a interface indica os seus vizinhos e o potencial escalar elétrico associado a cada nó do elemento; (b) em destaque a visualização do elemento número 116 da malha. . . . . . . . . . 138

A.7 Exemplo de uma malha (a) regular e (b) não-regular. . . . . . . . . . . . . . . 142

A.8 Uma triangulação de Delaunay no plano e a representação das circunferências de cada triângulo da malha indicando que atender o critério exigido. . .

A.9 (a) Arquivo de entrada utilizado pelo EasyMesh de um diodo plano de Pierce de largura 2,5 mm, altura de 4,0 $\mathrm{mm}$ e área de emissão do catodo com uma altura de $1,04 \mathrm{~mm}$ e (b) a malha gerada apresentando 276 nós e 489 elementos. 144

B.1 Visualização final decorrente por meio de uma simulação com o MICHELLE de um canhão de elétrons de oito feixes. Os componentes do canhão multifeixe estão assim identificados: cor AZUL ESCURO: catodo - não totalmente visível; cor VERDE: eletrodo de focalização; MALHA: anodo; VERMELHO-AZUL CLARO: feixe de elétrons (o de menor energia tem a cor azul claro e, o de maior energia, vermelho). . . . . . . . . . . .

B.2 Coletor de cinco estágios de uma válvula tipo TWT da Boeing. Tensões do corpo e dos cinco estágios do coletor são $6,335 \mathrm{kV}, 3,44 \mathrm{kV}, 2,141 \mathrm{kV}, 1,223$ $k V, 0,589 \mathrm{kV}$ e $0,133 \mathrm{kV}$ respectivamente. As duas figuras apresentam a geometria do coletor. (a) Coletor com apenas 77,2 $\mathrm{mA}$ de corrente devido aos elétrons primários do feixe. (b) Elétrons primários e cinco gerações de elétrons secundários emitidos. . . . . . . . . . . . . . . . . . . 148

B.3 Simulação de um canhão de elétrons utilizando o Trak. . . . . . . . . . . . 149

B.4 Distribuição no espaço de fase de um feixe anular. . . . . . . . . . . . . . . 150

B.5 Distribuição radial da densidade de corrente avaliada em cinco diferentes posições. . . . . . . . . . . . . . . . . 150

B.6 Exemplo de resposta do EGUN de uma simulação de um canhão de elétrons submetido a um campo magnético externo. . . . . . . . . . . . . 151

C.1 Bancada de teste de canhões de elétrons em fase final de montagem. . . . . 153

C.2 Comportamento do vácuo ao longo de três dias. O aquecimento produzido pelo filamento melhorou significativamente a qualidade do vácuo. . . . . . 153

C.3 Comportamento da potência do filamento pela variação de temperatura. . . 154 


\section{Lista de Símbolos}

\section{Latinos}

Maiúsculos

E - Vetor intensidade do campo elétrico.

J - Vetor densidade de corrente de convecção.

B - Vetor densidade de fluxo magnético ou indução magnética.

$E_{c_{e}}$ - Energia cinética do elétron.

$I_{0} \quad$ - Corrente de convecção do feixe.

L - Linha do programa

Minúsculos

$r_{m}$ - Distância entre o catodo e a cintura do feixe.

$e \quad$ - Carga do elétron.

$q_{i} \quad$ - Carga da $i$-ésima partícula

r - Vetor posição.

$r_{a} \quad$ - Raio da esfera do anodo.

$r_{c} \quad$ - Raio da esfera do catodo.

$r_{K}$ - Distância entre a cintura do feixe de elétrons do canhão de Pierce e a esfera do anodo.

$r_{M}$ - Raio da cintura do feixe de elétrons.

$t \quad$ - Variável tempo.

v - Vetor velocidade.

X - Vetor posição.

\section{Gregos}

$\theta_{0} \quad$ - Ângulo do semicone entre o eixo do canhão e a abertura do anodo.

$\rho \quad$ - Densidade de corrente volumétrica.

$\epsilon_{0} \quad$ - Permissividade elétrica do vácuo.

$\mu_{0} \quad$ - Permeabilidade magnética do vácuo.

$\eta \quad$ - Razão carga massa do elétron.

\section{Especiais}

$\nabla \quad$ - Operador diferencial vetorial( em coordenadas cartesianas $\nabla \equiv\left(\frac{\partial}{\partial x} \hat{\mathbf{a}}_{\mathbf{x}}+\frac{\partial}{\partial y} \hat{\mathbf{a}}_{\mathbf{y}}+\frac{\partial}{\partial z} \hat{\mathbf{a}}_{\mathbf{z}}\right)$.

$\Delta t \quad$ - Intervalo de tempo.

$\Delta \rho \quad$ - Tamanho finito na direção do vetor unitário $\hat{a}_{\rho}$ em coordenadas cilíndricas.

$\Delta z \quad$ - Tamanho finito na direção do vetor unitário $\hat{\mathbf{a}}_{\mathbf{z}}$ em coordenadas cilíndricas.

$\Delta \phi \quad$ - Tamanho finito na direção do vetor unitário $\hat{\mathbf{a}}_{\phi}$ em coordenadas cilíndricas.

$\vec{r} \quad$ - Vetor posição. 


\section{Capítulo 1}

\section{Introdução}

O Centro Tecnológico da Marinha em São Paulo (CTMSP) vem, desde 1999, buscando o domínio da tecnologia para construção de dispositivos ativos de micro-ondas de potência, com feixe de elétrons, do tipo válvulas de ondas progressivas, denominadas Traveling-Wave Tube - TWT [1]. Estas válvulas são utilizadas para a operação na Banda-X, com potência média de saída superior a $320 \mathrm{~W}$, nos radares das fragatas classe Greenhalgh da Marinha do Brasil (MB). Os fatos que motivaram o domínio dessa tecnologia relacionam-se com o elevado custo para reposição e o longo tempo para entrega desses dispositivos, uma vez que são fabricados no exterior e, via de regra, fornecidos somente por encomenda.

Dentre os institutos de pesquisa da MB, o CTMSP foi escolhido em função de: (a) ter instalações laboratoriais especializadas em tecnologia de alto-vácuo; (b) laboratórios para caracterização de materiais; e (c) usinagem mecânica de precisão. O CTMSP conta, atualmente, com cooperação do Laboratório de Acelerador Linear do Instituto de Física da Universidade de São Paulo (IFUSP), onde existe capacitação de pessoal e laboratorial em dispositivos de micro-ondas de potência destinados aos aceleradores de elétrons. Desde seu início, o projeto de fabricação de válvulas para TWT vem obtendo resultados satisfatórios. O primeiro resultado relevante foi o perfeito funcionamento, desde agosto de 2001, de um protótipo de um amplificador para operação pulsada na Banda-X, com potência média de $320 \mathrm{~W}$ e, desde então, outras válvulas foram desenvolvidas e aplicadas nos meios navais da $\mathrm{MB}$, sendo que, mais de duas dezenas de canhões para a TWT já foram construídos e testados. O CTMSP conta com fomentos na capacitação de recursos humanos e industrial do processo de construção deste modelo de TWT da Fundação de Amparo à Pesquisa do Estado de São Paulo (FAPESP) e da Financiadora de Estudos e Projetos (FINEP) respectivamente.

Uma TWT é constituída, basicamente, de um canhão de elétrons, de uma região de deriva e de um coletor. O canhão de elétrons é utilizado para formar um feixe, a partir do catodo, por efeito termiônico, com uma geometria e intensidade adequadas, de forma que possa ser utilizado na região de deriva como um amplificador de um sinal de radiofrequência (RF). Ao atravessar a região de deriva, esse feixe de elétrons é finalmente coletado no coletor, fechando o circuito.

Em relação ao canhão de elétrons, o projetista deve estabelecer qual a geometria do canhão, ou seja: qual o raio do catodo; a inclinação do eletrodo de focalização; a sepa- 
ração catodo-anodo; a geometria do anodo; e o raio do disco do catodo, a fim de atender os parâmetros do projeto, também denominados parâmetros de entrada, que são: tensão do anodo $\left(V_{0}\right)$; corrente do feixe $\left(I_{0}\right)$; cintura do feixe $\left(r_{M}\right)$; e densidade de corrente $\left(J_{o p}\right)$,. Os parâmetros do projeto só são conhecidos para algumas geometrias em que existem soluções analíticas. Para os demais casos, a determinação dos parâmetros de projeto só é possível por meio do uso de ferramentas computacionais dedicadas. $\mathrm{O}$ uso destas ferramentas permite a redução do tempo de projeto e experimentação e, portanto, do custo de concepção.

As ferramentas computacionais para modelar e projetar canhões de elétrons vêm, ao longo de mais de três décadas, sendo desenvolvidas e aprimoradas. Neste caso, como hipótese, considera-se que, para o canhão de elétrons, o fluxo esteja na condição Fully-Space Charge Limited (FSCL) ${ }^{1}$ - limitado pela carga espacial, onde se tem uma situação invariante no tempo e as trajetórias das partículas são muito bem definidas. A elaboração de uma ferramenta computacional que permita desenvolver canhões de elétrons de alta perveância ${ }^{2}$, ou seja, elevada corrente de convecção e energia do feixe, é imprescindível, pois uma vez desenvolvida reduziria o tempo de projeto dos mesmos e a quantidade de experimentação necessária para validá-los. Os códigos voltados para projeto de canhões em duas dimensões (2D), foram desenvolvidos com sucesso para dispositivos que possuem simetria axial tais como o EGUN [2], o TRAK [3] e o ULTRASAM [4]. Entretanto, vem crescendo o interesse em modelar canhões de elétrons cuja geometria da fonte é mais complicada, tais como os canhões multifeixe, com grade de controle e shadow-grid. O uso de grade de controle permite que o canhão de elétrons opere na forma pulsada. Um agravante, entretanto, decorrente do uso da grade, é a formação de aberrações do feixe, onde estudos são feitos no sentido de minimizar este efeito [5]-[8]. A necessidade de melhor entender o comportamento do feixe de partículas em modelos de válvulas com elevado grau de complexidade, levou ao desenvolvimento de códigos tridimensionais (3D), como o MICHELLE [9], o COLLGUN [10], o AVGUN [11], o COCA [12], o OMINITRAK [13], o MTSS [14] e o EOS [15].

Atualmente, o método numérico amplamente utilizado para se obter o potencial escalar elétrico $\varphi$ no domínio do problema do canhão de elétrons operando na condição FSCL, é o Finite Element Method (FEM) - Método de Elementos Finitos (MEF). As trajetórias das partículas do feixe de elétrons são bem definidas e unicamente determinadas, sendo possível estabelecê-las resolvendo-se o problema acoplado (uma vez que os campos eletromagnéticos dependem das trajetórias das partículas e estas, por sua vez, dependem dos campos) por meio do uso de um procedimento iterativo denominado Método das Aproximações Sucessivas (MAS). O MAS consiste basicamente em determinar, inicialmente, o potencial escalar elétrico (não existem cargas depositadas - solução da equação de Laplace). Em seguida, as partículas são emitidas, a partir do catodo, e, ao longo de suas trajetórias, as cargas

\footnotetext{
${ }^{1}$ Sejam dados uma temperatura fixa de aquecimento do catodo e uma diferença de potencial (ddp) constante entre o catodo e o anodo. A condição limitada pela carga espacial é caracterizada pelo fato de não ser possível extrair mais elétrons de um catodo devido à ação de forças de repulsão dos próprios elétrons do feixe sobre os elétrons da superfície do catodo.

${ }^{2}$ Perveância (perv) é definida como uma grandeza física que caracteriza um canhão de elétrons na condição Fully-Space Charge Limited (FSCL) onde, fixada uma tensão de anodo, qual é a máxima corrente que pode ser drenada do catodo.
} 
são depositadas nos elementos, normalmente triângulos, da malha do problema. Assim, resolve-se o problema de Poisson, e os novos potenciais escalares elétricos são determinados. Sendo esta distribuição de potenciais uma melhor aproximação, novamente as partículas são lançadas, as cargas são depositadas e o ciclo se repete. O critério para se estabelecer a convergência é variado, podendo ser, por exemplo, uma diferença relativa entre as posições para cada uma das partículas em um determinado plano ou entre a corrente fornecida pelo canhão de elétrons seja inferior a um determinado $\delta$, entre duas iterações consecutivas.

Partindo da Lei de Coulomb, demonstra-se que computacionalmente é, praticamente impossível, com os recursos computacionais atualmente existentes, resolver o problema de muitas partículas, tipicamente elétrons, em quantidade na ordem de $10^{13}$. Sendo impossível, nos dias atuais, modelar todas as partículas de um canhão de elétrons na condição FSCL, faz-se uso do Método Célula na Partícula - Particle in Cell (PIC) [16]. A estratégia é baseada na representação do comportamento de grandes distribuições de cargas em um número limitado de partículas denominadas macropartículas. Esta representação computacional das partículas visa caracterizar o comportamento médio de toda a distribuição de cargas. Uma macropartícula, portanto, possui a carga de $N$ partículas. Entretanto, $N$ não deve ser pequeno de modo a inviabilizar computacionalmente a solução do problema e, nem tão grande, de forma que não possa ser uma representação física adequada do problema.

Uma vez obtido um feixe de elétrons conforme as condições de projeto, observa-se que, devido à carga espacial, o feixe de elétrons diverge na região de deriva. Para que este fenômeno não aconteça, o feixe de elétrons deve ser mantido confinado em toda a região de deriva. O projeto adequado de estruturas de focalização permite manter o feixe de elétrons confinado em toda a região de deriva. Nesta região há conversão de energia cinética do feixe de elétrons em energia eletromagnética quando ocorre o sincronismo, aumentando-se a potência do sinal de entrada de RF. Em seguida, o feixe de elétrons é coletado em estruturas denominadas de coletores, os quais podem ser simples ou de múltiplos estágios.

Os códigos, atualmente existentes, determinam as posições das partículas, uma vez conhecidos os campos que atuam sobre as mesmas, a partir da integração no tempo da força de Lorentz. Este trabalho, entretanto, propõe uma nova abordagem para conhecer a dinâmica da partícula a partir da equação da trajetória, a qual é independente do tempo.

Este trabalho foi desenvolvido nas instalações do Laboratório de micro-ondas de Potência da Coordenadoria de Estudos e Projetos Especiais do CTMSP.

A seguir, são apresentados os princípios de funcionamento de uma válvula do tipo TWT, o objetivo e a organização deste trabalho.

\subsection{TWT - Princípio de Operação}

As válvulas do tipo TWT têm a função de amplificar sinais de micro-ondas por meio de uma desaceleração contínua dos elétrons que se movem em sincronia com uma onda eletromagnética. Existem TWT que operam em frequências na faixa abaixo de $1 \mathrm{GHz}$ até $100 \mathrm{GHz}$ e, sobre a maior parte desta faixa, as TWT operam com potências médias de transmissão 
entre alguns watts a centenas de quilowatts. Observa-se também que as eficiências das TWT variam entre $30 \%$ a $70 \%$ [17]. Para transmissores embarcados em satélites a elevada eficiência é crucial para o sucesso do projeto. As válvulas tipo TWT representam mais de $50 \%$ das vendas de dispositivos de micro-ondas de alta potência [17].

Existem basicamente dois tipos de válvulas TWT: a hélice e a cavidade acoplada. As TWT do tipo cavidade acoplada são capazes de operar com energias de transmissão na ordem de megawatts, porém apresentam limitada largura de banda de operação, tipicamente de $10 \%$ a $20 \%$ [18].

A FIG. 1.1 apresenta os principais componentes de uma TWT do tipo hélice.

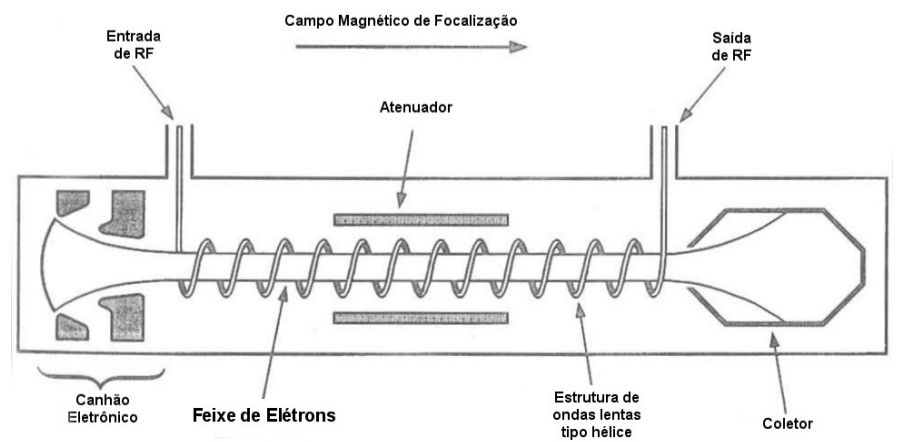

Figura 1.1: Modelo básico de uma válvula TWT do tipo hélice com seus principais componentes.

As válvulas TWT possuem em comum o canhão de elétrons, o feixe de elétrons e o coletor, sendo que as diferenças significativas estão nos circuitos de radiofrequência (RF) utilizados. Apesar destas diferenças os princípios de funcionamento são os mesmos.

A estrutura de ondas lentas, ilustrada na FIG. 1.1, tem a função de reduzir a velocidade de fase do sinal para uma próxima à velocidade do feixe de elétrons. Nessa condição, denominada sincronismo, ocorre a transferência da energia cinética do feixe para o sinal de RF.

Após sair do circuito de RF o feixe de elétrons deposita sua energia no coletor, sendo que parte desta energia é convertida em calor devido a colisão dos elétrons do feixe com o coletor. Vale salientar que um projeto adequado de coletor deve, primordialmente, procurar reduzir a velocidade do feixe antes de se chocar com o coletor e, neste caso, recuperar energia do feixe, devolvendo esta energia para o circuito. Atualmente coletores são desenvolvidos em multiestágios, Multistage Depressed Collectors (MDC) onde, cada um, promove uma desaceleração contínua do feixe, proporcionando aos sistemas uma maior eficiência.

\subsection{Objetivo}

O objetivo deste trabalho é desenvolver uma ferramenta computacional capaz de simular com boa exatidão, a partir da equação da trajetória, a dinâmica das partículas: (a) em canhões de elétrons operando na condição FSCL, com grades de controle e shadow-grid; (b) na região 
de deriva com arranjo periódico com ímãs permanentes, Periodic Permanent Magnet (PPM); e (c) em coletores simples e de múltiplos estágios, Multistage Deppreseed Collectors (MDC).

\subsection{Descrição do Trabalho}

O Capítulo 2 discute detalhadamente: (a) a formação de um feixe de elétrons entre planos paralelos; (b) o canhão de Pierce de fluxo paralelo; e, finalmente, (c) o canhão de Pierce de fluxo convergente. Estes modelos são estudados uma vez que, além de permitirem uma melhor compreensão da física dos problemas, possuem soluções analíticas as quais serão confrontadas posteriormente com as soluções numéricas.

No Capítulo 3 são estudados o campo magnético gerado por estruturas do tipo PPM e seu efeito sob a trajetória do feixe de elétrons ao atravessar a região de deriva. Em seguida, no Capítulo 4, são apresentados dois modelos que descrevem a emissão de elétrons secundários decorrentes da colisão entre os elétros primários do feixe com a superfície do coletor. $\mathrm{O}$ primeiro modelo, mais simples, foi adotado pela NASA em 1986 e, o segundo, é utilizado por MICHELLE e o EOS. Neste trabalho o primeiro modelo foi implementado.

Descreve-se no Capítulo 5, inicialmente, partindo das Equações de Maxwell, o sistema de equações acoplado a ser resolvido para o problema do canhão de elétrons operando na condição FSCL. Em seguida, a equação da trajetória não-relativística, para as partículas do feixe, é deduzida e os métodos utilizados pela ferramenta computacional MEF, PIC e MAS são abordados. Finalmente este capítulo é concluído com a descrição dos métodos utilizados para o armazenamento da matriz esparsa e para a obtenção da solução do sistema de equações a partir do método do gradiente conjugado.

No Capítulo 6 a ferramenta computacional é validada, confrontando os resultados numéricos para os diodos de Pierce, uma vez que estes possuem solução analítica. Ainda neste capítulo são apresentados os resultados obtidos em simulações: (a) de canhões de elétrons com grade e sem grade de controle; (b) do comportamento do feixe de elétrons na região de deriva com estruturas para focalização do feixe do tipo PPM; e (c) de coletores simples ou de múltiplos estágios. Finalmente, é relatado o procedimento utilizado na caracterização dos canhões de elétrons, descrevendo a bancada experimental e os resultados obtidos.

Finalmente, no Capítulo 7, apresentam-se as conclusões obtidas no desenvolvimento deste trabalho e algumas sugestões para trabalhos futuros.

A linguagem $\mathrm{C} / \mathrm{C}++$ foi empregada no desenvolvimento das ferramentas computacionais. Buscou-se paralelamente utilizar fontes que disponibilizavam pacotes livres (open sources) no desenvolvimento do código para as atividades subsidiárias tais como: a geração de malha; a interface gráfica com o usuário; e o uso de algoritmos eficientes e robustos na manipulação das estruturas de dados desenvolvidas. Neste sentido, o Apêndice A apresenta, de maneira sucinta, uma descrição de todos os pacotes livres integrados à ferramenta computacional, a saber:

- DevC++: disponibilizado pela Bloodshed Dev-C++ é um ambiente integrado de desenvolvimento para a linguagem de programação $\mathrm{C} / \mathrm{C}++$; 
- OpenGL: é um programa que faz a interface com a placa gráfica, permitindo criar programas iterativos com imagens coloridas em $2 \mathrm{D}$ ou $3 \mathrm{D}$;

- GLUI: é uma biblioteca que dá suporte ao programador no desenvolvimento de uma interface gráfica com o usuário facilitando a criação de janelas, botões de controle, menus, etc.;

- STL: trata-se de uma biblioteca $\mathrm{C}++$ que disponibiliza soluções no gerenciamento de coleções de dados por meio do uso de algoritmos modernos e eficientes; e

- EasyMesh: gerador de malha 2D, não estruturada, baseado na triangulação de Delaunay.

O Apêndice B faz uma breve descrição de três softwares científicos voltados para simulações de canhões de elétrons: o EGUN, o TRAK e o MICHELLE.

É apresentada, brevemente, a bancada experimental que está em fase de conclusão de montagem nas instalações do CTMSP no Apêndice C.

Finalmente, consta no Apêndice D todos os trabalhos publicados em Congressos nacionais e internacionais e periódicos frutos da realização deste trabalho. 


\section{Capítulo 2}

\section{O Problema do Canhão de Elétrons}

O dispositivo responsável pela formação de um feixe de elétrons, com características adequadas para a utilização em válvulas de micro-ondas do tipo TWT, é denominado de canhão de elétron. Tendo em vista a necessidade de focalização ou confinamento do feixe de elétrons, este dispositivo pode estar tanto sob o efeito exclusivo de campos elétricos quanto de campos magnéticos ou de ambos. Em termos gerais, o problema para a geração do feixe de elétrons pode ser formulado como:

"Sejam dados os requisitos: a tensão do anodo $\left(V_{0}\right)$; a corrente do feixe $\left(I_{0}\right)$; a cintura do feixe $\left(r_{M}\right)$; e a densidade de corrente de operação $\left(J_{o p}\right)$, qual será a geometria do catodo e dos eletrodos de focalização e do anodo do canhão de elétrons de forma que estes sejam atendidos?"

Dentre os vários modelos de emissão, aquele de relevância para este trabalho é o limitado pela carga espacial. Neste Capítulo serão desenvolvidas soluções analíticas para o problema acima, em ordem crescente de complexidade, considerando a emissão limitada pela carga espacial e, são eles: o diodo plano de Pierce; duas esferas concêntricas; e o canhão de Pierce de fluxo convergente. A solução proposta por Pierce para o canhão de fluxo convergente é relevante, pois estabelece um ponto de partida para o projeto de canhões de elétrons na condição FSCL.

Este Capítulo está organizado da seginte forma: a seção 2.1 apresenta os principais componentes de um canhão de elétrons e o seu princípio de funcionamento. Em seguida, na seção 2.2 estuda-se o diodo plano de Pierce. É apresentado, ainda, naquela seção o método utilizado na determinação da geometria do eletrodo de focalização e do anodo. A seção 2.3 estuda os canhões de fluxo convergente. Inicialmente descreve-se a solução de Langmuir e Blodgett para um diodo esférico. Em seguida, estuda-se como a interpretação de Pierce, para o diodo esférico, foi fundamental para o projeto de um canhão de elétrons cuja região emissora tem a forma de uma calota esférica. Neste estudo mostra-se que Pierce considerou, ainda, o problema da cintura do feixe e o efeito de lente eletrostática, observado na abertura do anodo. Esta análise leva a determinação analítica da cintura do feixe e seu alcance, parâmetros relevantes na caracterização de um canhão de elétrons. Como resultado, obtem-se uma expressão para a determinação da perveância do canhão, grandeza esta que depende 
somente de suas características geométricas. Finalmente, na seção 2.4 descreve-se, sucintamente, quatro modelos utilizados para o controle da corrente do feixe de elétrons em um canhão.

\subsection{Componentes e Princípio de Funcionamento}

Nesta seção apresenta-se, inicialmente, os principais componentes de um canhão de elétrons, sejam eles: o catodo; o filamento; o eletrodo de formação; o anodo; a grade de interceptação; e a grade de sombreamento. Em seguida, para um canhão de fluxo convergente operando na condição FSCL é apresentado o seu princípio de funcionamento.

A geração do feixe, a partir de um canhão de elétrons, se dá por meio dos seguintes componentes básicos representados na FIG. 2.1:

- Catodo: um protótipo característico de catodo é constituído de uma pastilha de tungstênio porosa cujo corpo é impregnado com aluminato de bário e cálcio. Tem a função de emitir elétrons por efeito termiônico;

- Filamento: construído com fios de tungstênio ou tungstênio com uma pequena porção de rênio, tendo o formato espiral, tem a função de aquecer, por efeito joule, a superfície do catodo, de maneira que este possa fornecer a densidade de elétrons adequada à formação do feixe;

- Eletrodo de Formação: também conhecido como eletrodo de focalização, é um eletrodo não emissor de elétrons e é responsável por produzir superfícies equipotenciais com o mesmo centro de curvatura do catodo;

- Anodo: uma estrutura condutora que tem a função de acelerar os elétrons, mantendo uma diferença de potencial positiva em relação ao catodo;

- Grade de Interceptação/Controle: eletrodo adicional, constituído de molibdênio ou níquel, posicionado entre o catodo e o anodo para controlar a operação pulsada do canhão de elétrons permitindo ou não a passagem do feixe; e

- Grade de Sombreamento: construída sobre a superfície do catodo. Tem a forma da projeção da grade de controle sobre o catodo, e tem como finalidade impedir o impacto de elétrons sobre a superfície da grade de controle, aumentando sua durabilidade.

Dentre as diversas configurações possíveis para contruir-se um canhão de elétrons, sejam aquelas com as seguintes características:

- ausência de campos magnéticos no canhão de elétrons, ou seja, o canhão é totalmente blindado magneticamente;

- os elétrons do feixe partem com velocidade inicial nula; e 


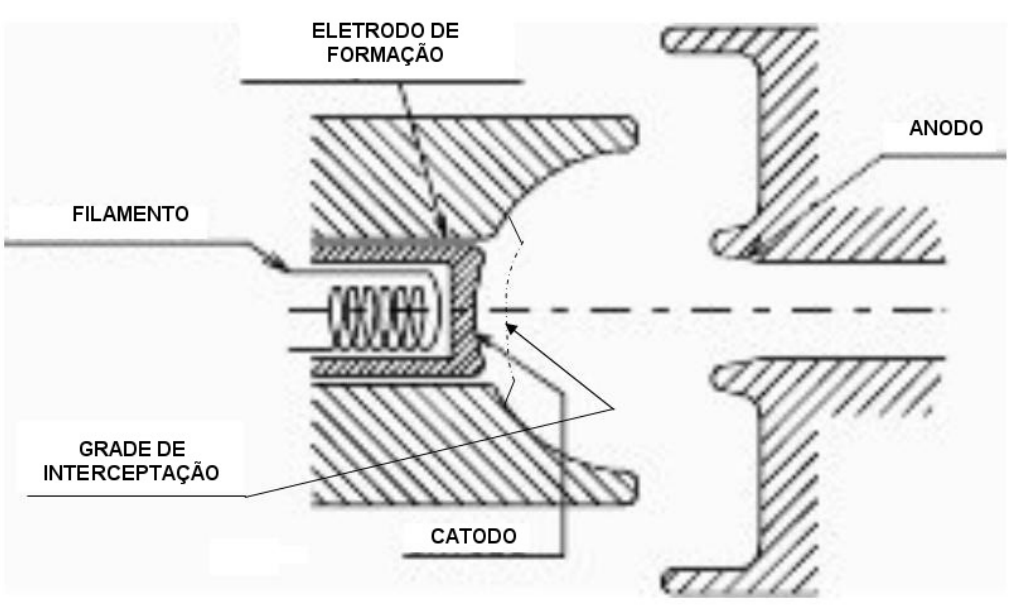

Figura 2.1: Configuração típica de um canhão de elétrons e seus componentes.

- o fluxo do feixe de elétrons é laminar.

Os canhões de elétrons que possuem as características acima relacionadas são denominados de canhões de Pierce. Os canhões de Pierce podem ser de feixe paralelo ou convergente [19]. Ao se modelar o canhão de elétrons tipo Pierce, de feixe convergente, o catodo tem a forma de uma calota esférica, FIG. 2.2. Nestas condições os elétrons do feixe atravessam três regiões distintas. Na Região 1, os elétrons são acelerados devido ao anodo, que mantém uma diferença de potencial positiva em relação ao catodo. O eletrodo de formação, também denominado de focalização, é projetado de forma que as superfícies equipotenciais tenham o mesmo centro de curvatura do catodo. Este fato garante que os elétrons irão fluir para o centro de curvatura do catodo. Devido às forças de repulsão entre os elétrons do feixe, observa-se que esta convergência ao centro do catodo é limitada pela própria carga espacial. $\mathrm{Na}$ Região 2, face à abertura do anodo, as superfícies equipotenciais se curvam para o interior do anodo e os elétrons do feixe experimentam o efeito de uma lente eletrostática divergente, levando-os, por sua vez, a divergirem. Na Região 3, os elétrons do feixe não mais sentem a influência aceleradora do anodo, mas tão somente das forças devido à carga espacial que, mais uma vez, promovem a divergência do feixe.

O princípio físico que norteia o funcionamento dos canhões de elétrons das TWT são, essencialmente, os mesmos. As diferenças residem, basicamente, no tamanho, tensão e corrente de operação, decorrentes dos pré-requisitos de potência do projeto do canhão.

\subsection{Diodo de Pierce de Fluxo Paralelo}

Nesta seção é apresentado o método desenvolvido por Pierce para a formação de um feixe retangular de elétrons considerando uma superfície de emissão plana conforme indicado na FIG. 2.3. A solução obtida por Pierce para este problema foi fundamentada no trabalho de Child-Langmuir, no qual foi desenvolvida uma solução para o problema de um diodo plano 


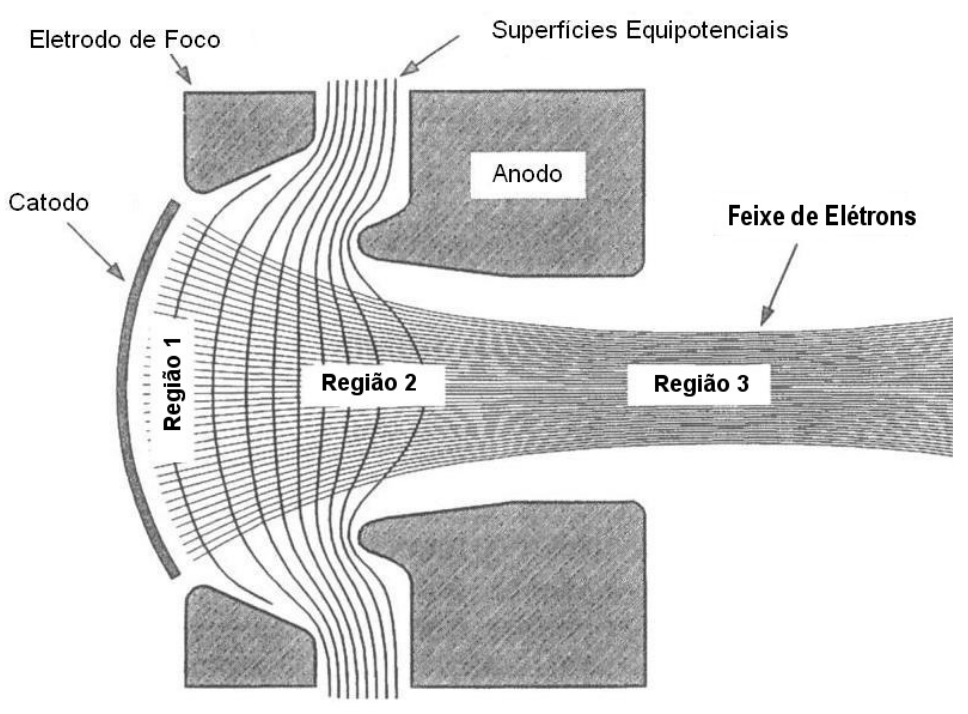

Figura 2.2: Vista geral de um canhão de Pierce de Fluxo Convergente.

infinito. Encerra-se esta seção apresentado-se um método para a obtenção das geometrias do eletrodo de focalização e do anodo que garantem a produção de um feixe retangular, de forma que, os elétrons da fronteira do feixe não percebem que a região fora do feixe está ausente de carga elétrica.

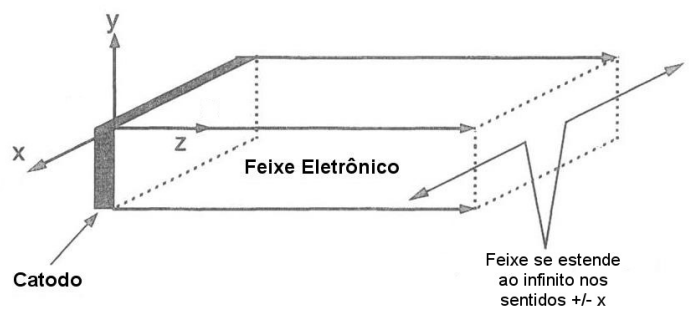

Figura 2.3: Feixe eletrônico paralelo de um catodo plano.

Considerando-se, inicialmente, dois planos paralelos separados com uma diferença de potencial elétrica entre os mesmos e ainda, que inexistem cargas elétricas nesta região, podese verificar que as equipotenciais são paralelas e igualmente espaçadas para um mesmo incremento na tensão, conforme indicado na FIG. 2.4.

$\mathrm{Na}$ presença de um feixe de elétrons as equipotenciais, solução do problema sem carga, tendem a defletirem à direita, representadas pelas linhas contínuas da FIG. 2.4. Uma vez que os elétrons tendem a se mover perpendicularmente às equipotenciais, as trajetórias dos elétrons do feixe divergem. Desta forma, pode-se imaginar ser possível alterar a estrutura do eletrodo de focalização de modo a corrigir a deflexão acima, mesmo na presença das cargas espaciais e, portanto, tornar a trajetória do feixe de elétrons paralela. Neste caso, a solução consiste em promover uma deflexão dos eletrodos adjacentes ao catodo na direção do anodo, conforme indicado na FIG. 2.5. Assim, considerando inicialmente ausência de cargas, 


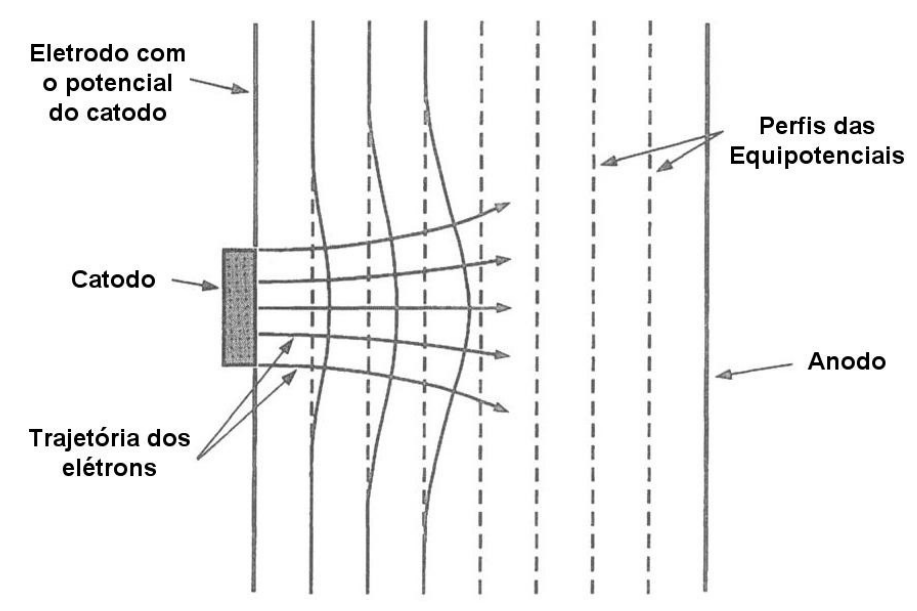

Figura 2.4: Perfis das equipotenciais na ausência (linhas tracejadas) e na presença (linhas contínuas) do feixe de elétrons.

observa-se que as equipotenciais se curvam na direção do catodo, linha tracejada. Entretando, o feixe de elétrons, emitido pelo catodo e acelerado sob a ação do anodo, promove o deslocamento das superfícies equipotenciais em direção ao anodo, FIG. 2.5.

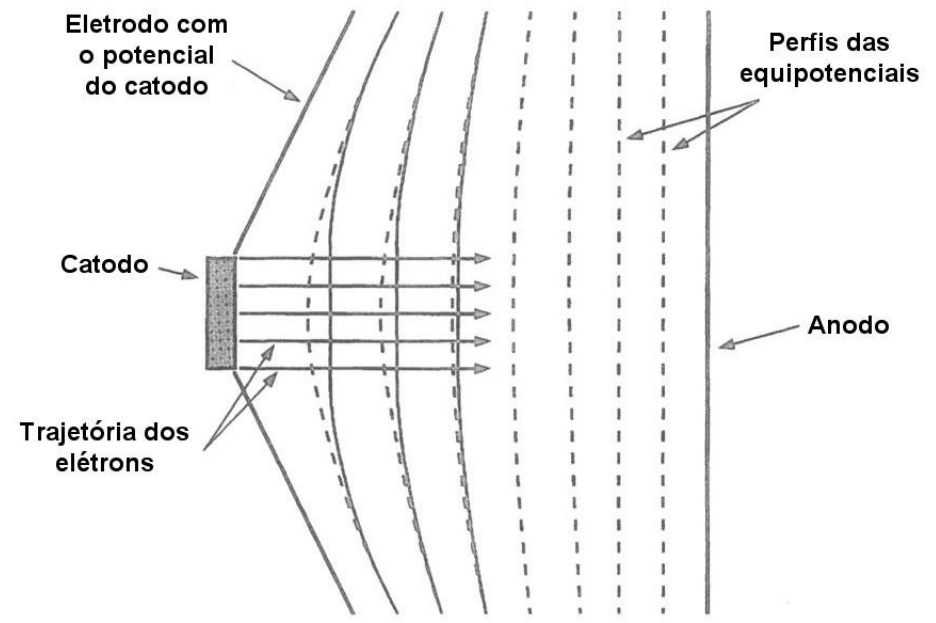

Figura 2.5: Novo perfil das equipotenciais em um catodo plano devido ao ajuste do eletrodo de focalização.

A discussão, a seguir apresentada para o problema do transporte de elétrons entre dois planos infinitos, $A$ (catodo - superfície emissora) e $B$ (anodo), foi realizada cuidadosamente e com bastante rigor, inicialmente, por Langmuir que considerou ausência de moléculas ou íons positivos (vácuo) nessa região. Langmuir [20] interessou-se por este problema onde experimentalmente observou que, fixada uma diferença de potencial entre os filamentos de uma lâmpada de tungstênio, era constatado um crescimento da corrente do filamento com o aumento da temperatura até um determinado valor onde, a partir da qual, não importando o quanto era aumentada a temperatura, a corrente do filamento não mais crescia, FIG. 2.6. 
Este experimento foi realizado para diversas diferenças de potenciais entre os filamentos considerando ainda ausência e presença no interior da lâmpada de diferentes tipos gases (hidrogênio, vapor de água, oxigênio, nitrogênio e argônio) e pressões internas.

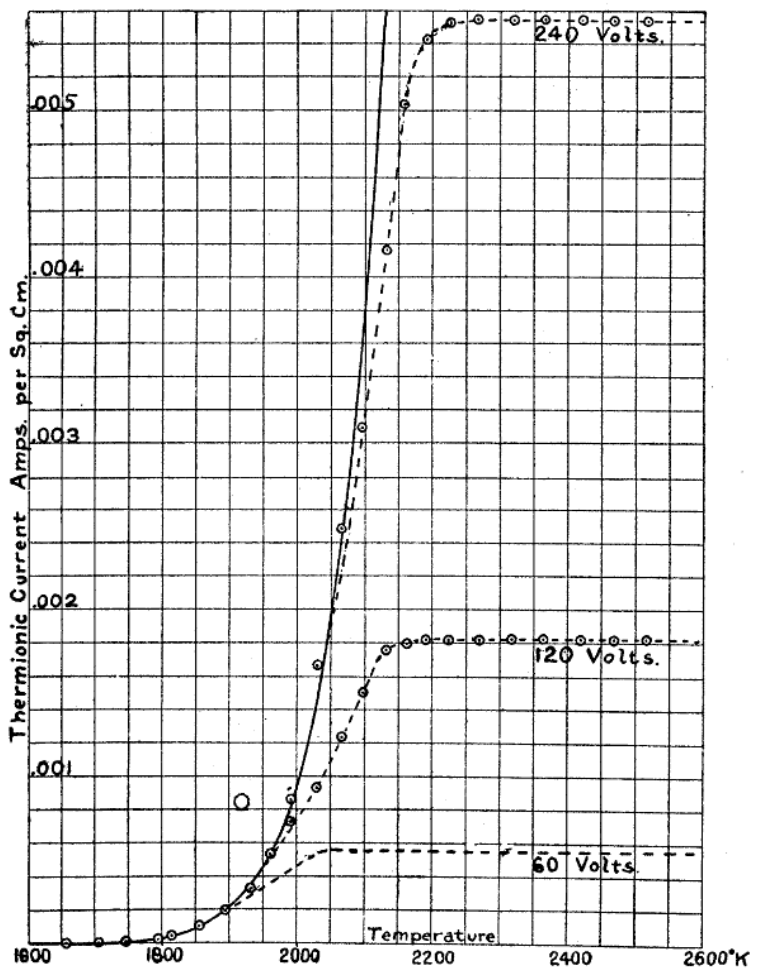

Figura 2.6: Curvas da corrente pela temperatura observada entre os filamentos de uma lâmpada, observadas por Langmuir, para diferentes potenciais aplicados entre os filamentos [20].

Considere, inicialmente, que a temperatura do catodo é baixa o suficiente de forma que não há emissão de elétrons. Assim, o potencial escalar eletrostático $\varphi$, na região entre o catodo e o anodo, é obtido a partir da equação de Laplace. É possível mostrar, neste caso, que $\varphi$ varia linearmente entre o catodo e o anodo, reta $P T$, conforme FIG. 2.7. Entretanto, à medida em que a temperatura do catodo aumenta, inicia-se emissão de elétrons. Neste caso, $\varphi$ é obtido a partir da solução da equação de Poisson:

$$
\nabla^{2} \varphi=-\frac{\rho}{\epsilon_{0}}
$$

onde: $\rho$ é densidade de carga e $\epsilon_{0}$ é a permissividade do vácuo.

Como uma primeira aproximação, para a solução de 2.1, considerando-se uma densidade de carga constante entre os planos, é possível demonstrar que o potencial escalar elétrico $\varphi$, neste caso, terá a forma de uma parábola, curva PST, FIG. 2.7.

Caso a temperatura do catodo continue a aumentar, a corrente elétrica aumentará até que a curva do potencial escalar elétrico torna-se uma parábola cuja tangente em $P$ seja nula. $\mathrm{Na}$ condição FSCL, a corrente elétrica não mais cresce além do ponto em que a curva do potencial $\varphi$ torna-se horizontal em $P$, uma vez que, qualquer aumento na corrente tornará a 


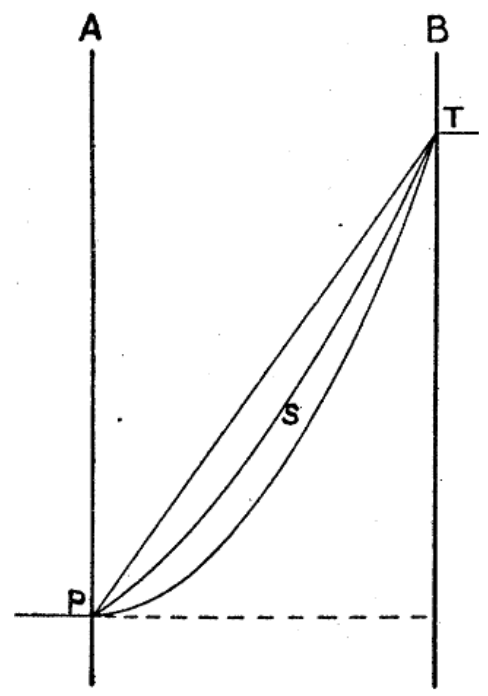

Figura 2.7: Variação do potencial entre dois planos infinitos $A$ (catodo) e $B$ (anodo) considerando a densidade de cargas: nula (reta PT); constante (curva PST); e FSCL [20].

inclinação da curva do potencial $\varphi$ negativa e, assim, os elétrons não se moverão contra esse gradiente de potencial negativo.

Uma vez que o catodo e o anodo são planos paralelos, não deverá existir variação do campo elétrico nas direções $x$ e $y$, e, neste caso, pode-se escrever $\varphi=f(z)$ e,

$$
\frac{\partial \varphi}{\partial x}=\frac{\partial \varphi}{\partial y}=0
$$

Considerando que o catodo está sob potencial nulo, e que, o elétron emitido do mesmo tenha velocidade inicial nula, segue que, segundo a conservação da energia, $\frac{1}{2} m v^{2}=|e| \varphi$ ou, $v=\sqrt{2 \eta \varphi}$. Sejam $\eta(=|e| / m)$ a relação entre a carga do elétron e sua massa; $J$ é a densidade de corrente, valor negativo, que se relaciona com a densidade de carga $\rho$ como $J=v \rho$ e, por hipótese, é constante; e $v$ é a velocidade do elétron. Assim, 2.1 pode ser reescrita como:

$$
\nabla^{2} \varphi=\frac{\partial^{2} \varphi}{\partial z^{2}}=\frac{d^{2} \varphi}{d z^{2}}=\frac{|J|}{\epsilon_{0} \sqrt{2 \eta \varphi}} .
$$

Multiplicando ambos os lados por $2 d \varphi / d z$ :

$$
2 \frac{d \varphi}{d z} \frac{d^{2} \varphi}{d z^{2}}=\frac{d}{d z}\left[\left(\frac{d \varphi}{d z}\right)^{2}\right]=\frac{2|J| \varphi^{-1 / 2}}{\epsilon_{0} \sqrt{2 \eta}} \frac{d \varphi}{d z},
$$

ou seja:

$$
d\left[\left(\frac{d \varphi}{d z}\right)^{2}\right]=\frac{2|J|}{\epsilon_{0} \sqrt{2 \eta}} \varphi^{-1 / 2} d \varphi
$$

Integrando a equação acima tem-se: 


$$
\left(\frac{d \varphi}{d z}\right)^{2}-\left(\frac{d \varphi}{d z}\right)_{p}^{2}=\frac{4|J|}{\epsilon_{0} \sqrt{2 \eta}} \varphi^{1 / 2}+\varphi_{p}
$$

onde $p, \varphi_{p} \mathrm{e}\left(\frac{d \varphi}{d z}\right)_{p}$ correspondem a um ponto na região entre os planos infinitos paralelos, ao potencial escalar e ao gradiente escalar em $p$ respectivamente.

Considere o ponto $p$ no catodo. Neste caso, o catodo está sob potencial nulo, ou seja:

$$
\varphi(0)=0
$$

Caso o gradiente do potencial escalar elétrico na superfície do catodo, $\varphi$, fosse negativo, ou seja, $d \varphi / d z<0$, neste caso, não há corrente elétrica. Caso o gradiente do potencial escalar elétrico na superfície seja positivo, ou seja, $d \varphi / d z>0$, todos os elétrons que deixam a superfície do catodo alcançaram o anodo, de forma que a intensidade de corrente elétrica obedece a equação de Richardson ${ }^{1}$. O caso de interesse é aquele em que a corrente é menor que a corrente de saturação sendo determinada pela tensão do anodo. Neste caso o gradiente do potencial $\varphi$ é nulo, ou seja:

$$
\frac{d \varphi(z=0)}{d z}=0
$$

Utilizando 2.7 e 2.8 em 2.6:

$$
\left(\frac{d \varphi}{d z}\right)^{2}=\frac{4|J|}{\epsilon_{0} \sqrt{2 \eta}} \varphi^{1 / 2}
$$

Extraindo a raiz quadrada da equação acima tem-se:

$$
\frac{d \varphi}{\varphi^{1 / 4}}=\left(\frac{4|J|}{\epsilon_{0} \sqrt{2 \eta}}\right)^{1 / 2} d z
$$

Integrando 2.10 utilizando 2.7 tem-se, finalmente, a solução de Child-Langmuir para um diodo plano infinito para o potencial escalar elétrico:

$$
\varphi(z)=\left(\frac{9|J|}{4(2 \eta)^{\frac{1}{2}} \epsilon_{0}}\right)^{\frac{2}{3}} z^{\frac{4}{3}}=\left(\frac{|J|}{2,33 \times 10^{-6}}\right)^{\frac{2}{3}} z^{\frac{4}{3}} .
$$

Por outro lado, 2.11 pode ser resolvida para a densidade de corrente $|J|$, se o potencial $\varphi(z)$ para $z=d_{a}$, onde é $d_{a}$ é a separação catodo-anodo. Considerando-se que o potencial na superfície do anodo $\varphi\left(d_{a}\right)$ é $V_{a}$, assim, a densidade de corrente $|J|$ é dada por:

$$
|J|=\frac{4(2 \eta)^{\frac{1}{2}} \epsilon_{0}}{9} \frac{V_{a}^{3 / 2}}{d_{a}^{2}}
$$

Utilizando-se o valor da densidade decorrente acima, o potencial escalar elétrico pode ser escrito como:

\footnotetext{
${ }^{1}$ A equação de Richardson estabelece precisamente a relação entre a densidade de corrente termiônica $(J)$ e a temperatura da superfície do metal $(T)$ como sendo: $J=a T^{2} e^{-\frac{b}{T}}$, onde $a$ e $b$ são constantes.
} 


$$
\varphi(z)=V_{a}\left(\frac{z}{d_{a}}\right)^{4 / 3} .
$$

Considere agora um modelo mais próximo da realidade de um canhão de elétrons, representado na FIG. 2.8. Neste caso há limitação na região de emissão na direção $y$ e, além do mais, deseja-se que o fluxo do feixe de elétrons seja paralelo em relação a direção $z$. $\mathrm{O}$ canhão de elétrons que atende a estes requisitos é denominado de canhão de Pierce de fluxo paralelo. A seguir é apresentado a solução para a geometria dos eletrodos de focalização e do anodo, de forma que, a densidade decorrente seja constante para o canhão de Pierce de fluxo paralelo.

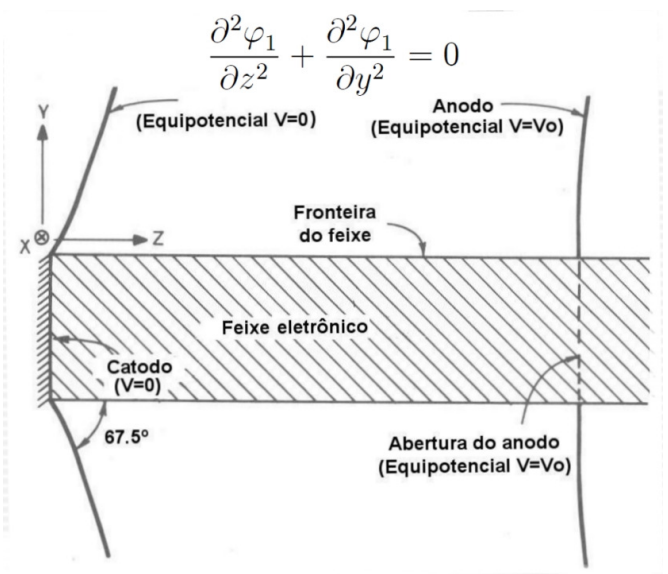

Figura 2.8: Seção transversal do canhão de Pierce de feixe paralelo indicando o Eletrodo de Focalização (EFF), catodo, anodo bem como o sistema de coordenadas.

As geometrias dos eletrodos de focalização e do anodo, neste caso, devem simular condições tais que, os elétrons da fronteira do feixe não percebam a ausência de cargas elétricas fora do mesmo. Portanto, deve-se garantir condições tais que (a) no interior e na fronteira do feixe o potencial varia de acordo com a lei de Child-Langmuir e (b) não há força transversal atuando sobre os elétrons da fronteira do feixe. Estas condições são obtidas tipicamente por meio do uso de dois eletrodos, um no catodo e outro no anodo tais que as posições deles coincidam com as superfícies equipotenciais naqueles potenciais.

Assim, fora da região de emissão, FIG. 2.8, não existem cargas elétricas e, portanto, a equação a ser resolvida para o potencial escalar elétrico $\varphi_{1}$ é a de Laplace:

$$
\frac{\partial^{2} \varphi_{1}}{\partial z^{2}}+\frac{\partial^{2} \varphi_{1}}{\partial y^{2}}=0
$$

Para garantir a condição (a) acima, na fronteira $(y=0)$ o potencial deve obedecer à lei de Child-Langmuir, portanto:

$$
\varphi_{1}(z, y=0)=\left(\frac{9|J|}{4(2 \eta)^{\frac{1}{2}} \epsilon_{0}}\right)^{\frac{2}{3}} z^{\frac{4}{3}}
$$


Já a condição (b) acima, impõe que não deve existir força eletrostática atuando sobre o feixe de elétrons ao longo de sua fronteira, a qual seria responsável pelo espalhamento. Desta forna, na fronteira, o potencial esclar elétrico deve satisfazer:

$$
\frac{\partial \varphi_{1}(z, y=0)}{\partial y}=0
$$

Para iniciar a solução deste problema, deve-se lembrar que toda função analítica $f(z+y j)$ satisfaz a equação de Laplace [1]. Diz-se que a função $f(z+y j)=u_{r}+u_{i} j$ é analítica em uma região $R$ se ela for diferenciável em todo o ponto de $R$, ou seja, ela satisfaz as condições de Cauchy-Riemann (vide [1]):

$$
\begin{aligned}
\frac{\partial u_{r}}{\partial z} & =\frac{\partial u_{i}}{\partial y}, \mathrm{e} \\
\frac{\partial u_{r}}{\partial y} & =-\frac{\partial u_{i}}{\partial z} .
\end{aligned}
$$

Utilizando-se a técnica de mapeamento conforme, é possível mostrar que o potencial $\varphi_{1}(z, y)$ é dado por [18]:

$$
\varphi_{1}(z, y)=\operatorname{Re} f(z+y j)=\operatorname{Re}\left[\left(\frac{9|J|}{4(2 \eta)^{\frac{1}{2}} \epsilon_{0}}\right)^{\frac{2}{3}}(z+y j)^{4 / 3 .}\right] .
$$

Assim, a equação acima pode ser escrita como:

$$
\varphi_{1}(z, y)=\operatorname{Re}\left(\frac{9|J|}{4(2 \eta)^{\frac{1}{2}} \epsilon_{0}}\right)^{\frac{2}{3}}\left[\left(z^{2}+y^{2}\right)^{\frac{2}{3}}(\cos \theta+j \sin \theta)^{\frac{4}{3}}\right]
$$

ou,

$$
\varphi_{1}(z, y)=\left(\frac{9|J|}{4(2 \eta)^{\frac{1}{2}} \epsilon_{0}}\right)^{\frac{2}{3}}\left(z^{2}+y^{2}\right)^{\frac{2}{3}} \cos \frac{4}{3} \theta
$$

onde $\theta=\tan ^{-1} y / z$.

\section{Geometria do Eletrodo de Focalização e do Anodo}

A partir da interpretação de 2.19 pode-se obter a geometria do eletrodo de focalização e do anodo correspondente ao problema resolvido por Pierce. Para a determinação da geometria do eletrodo de focalização (EF), considera-se, a partir de 2.19 , os pontos em que o potencial é nulo, ou seja, $\varphi_{1}(z, y)=0$. Neste caso, tem-se que a única solução para qualquer par $z$ e $y$ é $\cos \frac{4}{3} \theta=0$, ou seja:

$$
\theta=\tan ^{-1} y / z=3 \pi / 8=67,5^{\circ}
$$

sugerindo que o eletrodo de focalização deve formar um ângulo de $67,5^{\circ} \mathrm{com}$ a fronteira do feixe conforme indicado na FIG. 2.8. 
De modo similar, a geometria do anodo é estabelecida considerando que, desta vez $\varphi(z, y)=V_{a}$, onde $V_{a}$ é o potencial do anodo. Neste caso, a solução é não trivial e técnicas numéricas para solução de equações não-lineares devem ser utilizadas, tais como o método de bissecção sucessiva ou o de ponto fixo. A posição inicial da geometria do anodo é $\left(z_{a}, y_{a}\right)$, onde $z_{a}$ é a separação catodo-anodo e $y_{a}$ é altura do catodo. A idéia é, a partir de um incremento $d z$ na posição inicial $z_{1}=z_{a}+d z$, utilizando-se um dos métodos acima, determinar-se o valor da ordenada $y_{1}$ que satisfaz 2.19. Em seguida, busca-se o valor de ordenada $y_{2}$ para um novo incremento, que corresponde a nova posição $z_{2}=z_{1}+d z=z_{a}+2 d z$ e, assim, sucessivamente. Desta forma é possível construir a superfície do anodo unindo o conjunto de pares ordenados $\left(z_{a}, y_{a}\right),\left(z_{1}, y_{1}\right),\left(z_{2}, y_{2}\right), \ldots$. Como exemplo, para o diodo plano de Pierce, utilizado como Benchmark, FIG. 2.9, o catodo tem 1,5mm de altura de emissão e a separação catodo-anodo é de $2,5 \mathrm{~mm}$. A superfície do anodo construída a partir dos pontos, solução de 2.19, para $\varphi(z, y)=V_{a}$, estão apresentados na TAB. 2.1. A FIG. 2.9(a) apresenta a geometria corrigida para o anodo, a trajetória do feixe de elétrons e as equipotenciais e, a FIG. 2.9(b), a malha utilizada na simulação e o vetor campo elétrico que, embora não facilmente observável, praticamente se anula nas proximidades da superfície do catodo.

Tabela 2.1: Coordenadas da geometria do anodo para o problema do canhão de Pierce de feixe paralelo.

\begin{tabular}{cc}
\hline$z$ & $y$ \\
\hline 2,5000000000 & 1,5 \\
2,5060546875 & 1,8 \\
2,5237304688 & 2,1 \\
2,5525390625 & 2,4 \\
2,5914550781 & 2,7 \\
2,6394592285 & 3,0 \\
2,6955078125 & 3,3 \\
2,7584228516 & 3,6 \\
2,8274414063 & 3,9 \\
2,8515869141 & 4,0 \\
\hline
\end{tabular}

\subsection{Canhões de Pierce de Fluxo Convergente}

O canhão de elétrons de fluxo paralelo tem limitações, uma vez que, para se obter valores elevados de corrente só é possível mediante acréscimo significativo da área transversal do feixe. Em particular, uma elevada densidade de corrente é, geralmente, essencial para a operação de válvulas do tipo TWT. Um método alternativo utilizado para contornar este problema é por meio do uso de um catodo curvo, na forma de uma calota esférica, a qual emite elétrons radialmente e perpendicular a sua superfície, conforme FIG. 2.10, promovendo um aumento da densidade de corrente. Um parâmetro relevante utilizado em canhões de elétrons deste tipo é a razão de compressão do feixe. A razão de compressão do feixe de elétrons de 


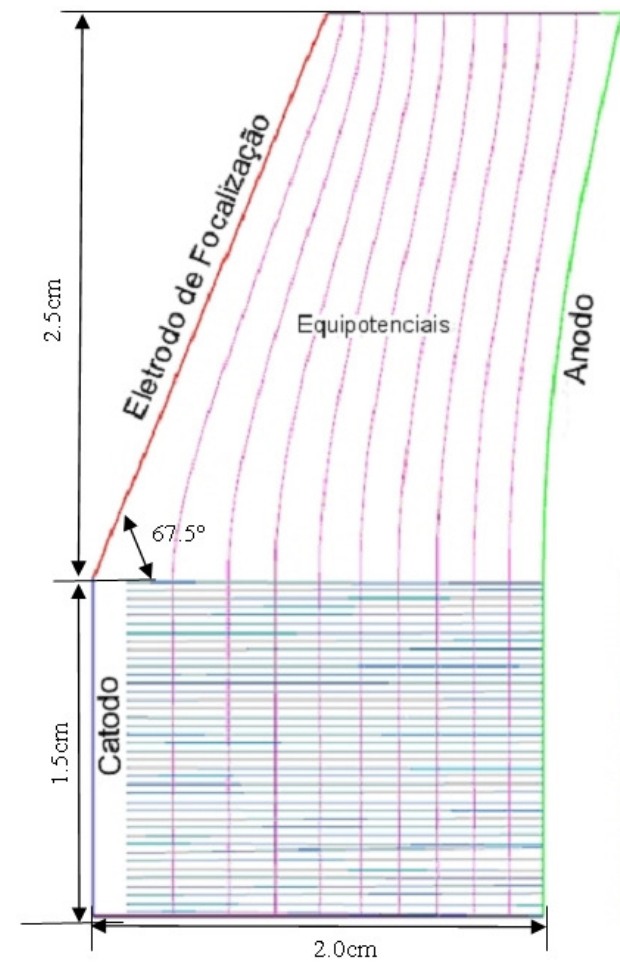

(a)

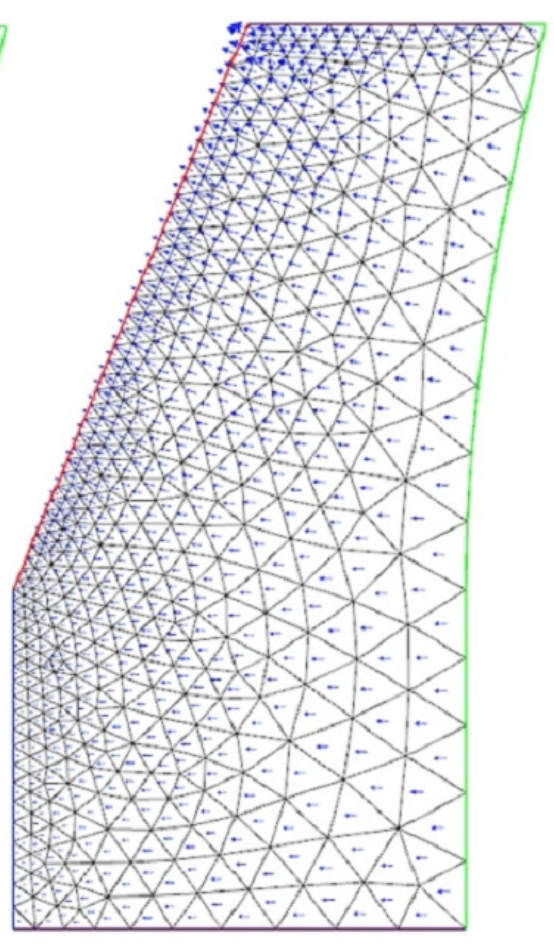

(b)

Figura 2.9: Geometria do anodo, em verde, corrigida para o problema do canhão de Pierce de feixe paralelo.

um canhão de elétrons é definida como sendo a razão entre o raio de abertura do catodo $r_{K}$ e o raio da cintura do feixe, $r_{M}$.

Nesta seção é apresentado, inicialmente, a solução proposta por Langmuir e Blodgett para o problema do diodo esférico. Neste caso considera-se o catodo e o anodo como sendo duas esferas concêntricas. Devido a simetria do problema, o potencial escalar elétrico $\varphi$ só apresenta variação radial, assim $\varphi=\varphi(r)$ e, a equação de Poisson a ser resolvida, é em coordenadas esféricas, portanto:

$$
\frac{d^{2} \varphi}{d r^{2}}+\frac{2}{r} \frac{d \varphi}{d r}=-\frac{\rho}{\epsilon_{0}} .
$$

Em seguida, decreve-se a interpretação de Pierce para o resultado de Langmuir e Blodgett para um projeto de canhão de elétrons de fluxo convergente cuja região emissora é uma calota esférica, considerando ainda o problema da cintura do feixe e o efeito de lente eletrostática existente na abertura do anodo. Encerra-se esta seção com o procedimento para projeto de um canhão de elétrons de fluxo convergente de Pierce a partir dos quatro parâmetros de projeto, a saber: tensão do anodo $\left(V_{0}\right)$; corrente do feixe $\left(I_{0}\right)$; cintura do feixe $\left(r_{M}\right)$; e densidade de corrente de operação $\left(J_{o p}\right)$. 


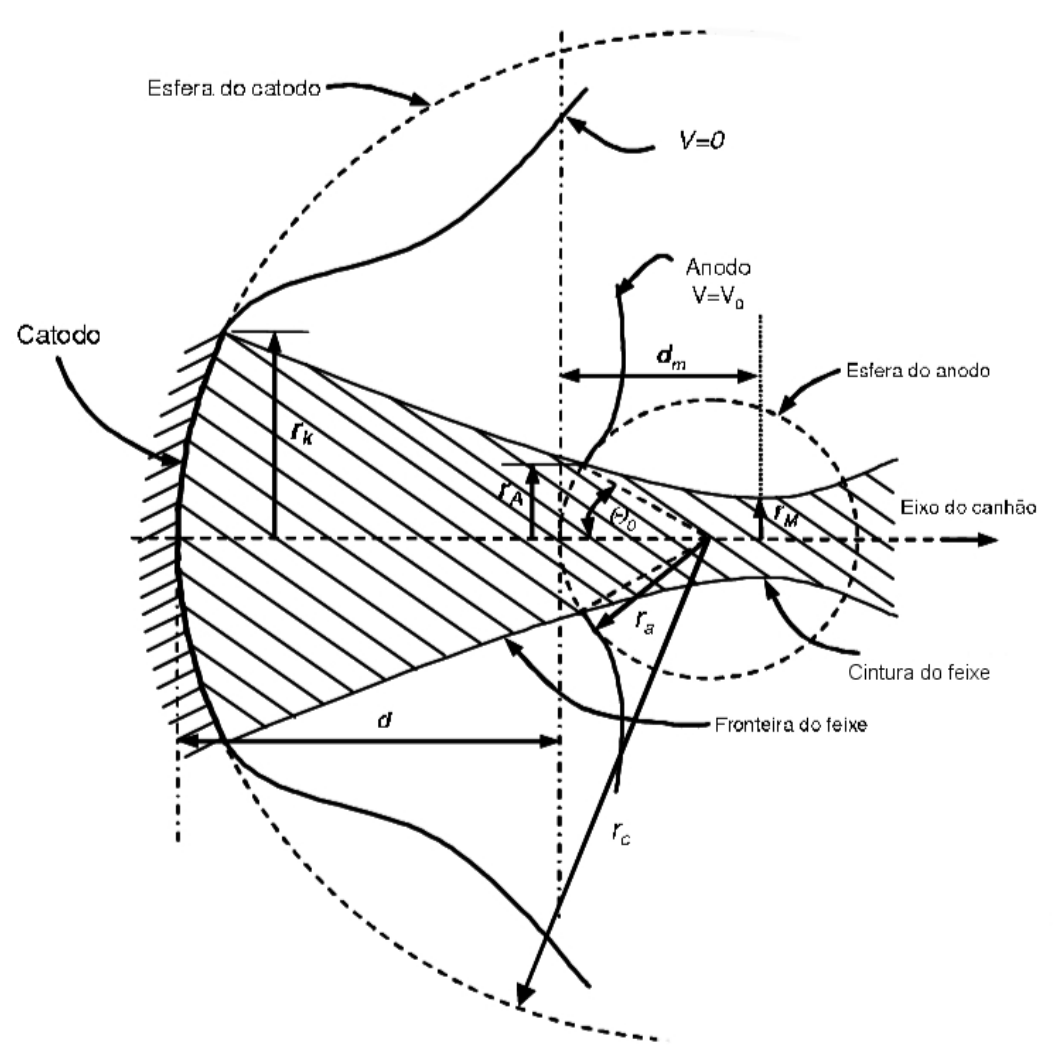

Figura 2.10: Parâmetros do canhão de fluxo convergente de Pierce. $d$ : separação entre o catodo e o anodo; $r_{c}$ e $r_{a}$ : raio das esferas do catodo e anodo respectivamente; $d_{m}$ : distância medida na direção do eixo do canhão entre a cintura do feixe e a esfera do anodo; $r_{M}$ : raio da cintura do feixe de elétrons; $r_{K}$ e $r_{A}$ : raios limites do feixe de elétrons no catodo e anodo respectivamente; $\theta_{0}$ : ângulo do meio cone entre o eixo do canhão e a abertura do anodo.

\section{Solução proposta por Langmuir e Blodgett}

Será apresentado a seguir a solução de Langmuir e Blodgett para o problema de um canhão de elétrons, sob a condição de emissão limitada pela carga espacial, cuja região emissora tem a forma de calota esférica. Neste caso, sabe-se que a densidade de cargas $\rho$ pode ser escrita como $\rho=J / v$, onde $|J|=I_{0} /\left(4 \pi r^{2}\right)$ é a densidade de corrente e $v(r)$ é a velocidade do elétron. Considerando a conservação de energia, a velocidade $v$ do elétron é dada por $v(r)=\sqrt{2 \eta \varphi(r)}$ e 2.21 pode ser reescrita como:

$$
\frac{d^{2} \varphi}{d r^{2}}+\frac{2}{r} \frac{d \varphi}{d r}=\frac{I_{0}}{4 \pi r^{2} \epsilon_{0} \sqrt{2 \eta}} \frac{\varphi(r)}{r^{2}}=K^{\prime} \frac{\varphi(r)}{r^{2}},
$$

onde $K^{\prime}$ é dado por:

$$
K^{\prime}=\frac{I_{0}}{4 \pi r^{2} \epsilon_{0} \sqrt{2 \eta}}
$$

Langmuir e Blodgett [21] propuseram para a equação 2.22, a seguinte solução em série: 


$$
\varphi(u)=\left[\frac{9 I_{0}}{4(2 \eta)^{\frac{1}{2}} \epsilon_{0} A_{c}}\right]^{2 / 3} r_{c}^{\frac{4}{3}}[G(u)]^{\frac{4}{3}}=\left(\frac{9}{4} K^{\prime}\right)^{\frac{2}{3}}[G(u)]^{\frac{4}{3}},
$$

onde $r_{c}$ é o raio de curvatura do catodo, que se relaciona com a área do catodo $A_{c}$ por:

$$
A_{c}=4 \pi r_{c}^{2}
$$

e $G(u)$ é uma série adimensional em

$$
u=\ln \left(r / r_{c}\right),
$$

cuja expansão em série de Taylor em torno da origem:

$$
G(u)=G(0)+u G^{\prime}(0)+\frac{u^{2}}{2 !} G^{\prime \prime}(0)+\frac{u^{3}}{3 !} G^{\prime \prime \prime}(0)+\frac{u^{4}}{4 !} G^{\prime \prime \prime \prime}(0)+\ldots,
$$

onde $G^{\prime}, G^{\prime \prime}, G^{\prime \prime \prime}, \ldots$ etc. são, respectivamente, a primeira, segunda e terceira derivada de $G$ em relação à $u$ avaliada na origem, ou seja, para $r=r_{c}$. Neste caso $G(u=0)=0$ uma vez que o potencial no catodo é nulo.

Substituindo-se 2.24 em 2.21 tem-se a seguinte equação diferencial em $G$ :

$$
3 r^{2} \frac{d^{2} G}{d r^{2}}+r^{2}\left(\frac{d G}{d r}\right)^{2}+6 r G \frac{d G}{d r}-1=0 .
$$

Para que se possa determinar os coeficientes $G^{n}(0)$, faz-se necessário, inicialmente, escrever a equação diferencial em $G$, anterior, em relação a a variável $u=\ln \left(r / r_{c}\right)$. Assim, determina-se $d G / d r$ e $d^{2} G / d r^{2}$ considerando-se que $G(u)=G\left(\ln \left(r / r_{c}\right)\right)$, e a primeira derivada $d G / d r$ pode ser reescrita como:

$$
\frac{d G}{d r}=\frac{d G}{d u} \frac{d u}{d r}=G^{\prime} \frac{1}{r} .
$$

A derivada segunda, $d^{2} G / d r^{2}$, é assim determinada:

$$
\frac{d^{2} G}{d r^{2}}=\frac{d}{d r}\left(\frac{G^{\prime}}{r}\right)=\frac{r G^{\prime \prime} \frac{d u}{d r}-G^{\prime}}{r^{2}}=\frac{G^{\prime \prime}-G^{\prime}}{r^{2}} .
$$

Substituindo 2.29 e 2.30 em 2.28 obtém-se, finalmente, uma equação diferencial de $G$ na variável $u$ :

$$
3 G \frac{d^{2} G}{d u^{2}}+3 G \frac{d G}{d u}+\left(\frac{d G}{d u}\right)^{2}-1=3 G G^{\prime \prime}+3 G G^{\prime}+\left(G^{\prime}\right)^{2}-1=0 .
$$

Avaliando-se 2.31 em $u=0$,tem-se:

$$
\left.\left(G^{\prime}\right)^{2}\right\rfloor_{u=0}=1
$$

ou seja: 


$$
G^{\prime}(0)= \pm 1 .
$$

$G^{\prime}(0)=1$ indica que o canhão de elétrons tem fluxo convergente e, $G^{\prime}(0)=-1$, um fluxo divergente.

Considerando um fluxo convergente, onde toda esfera externa é emissora de elétrons, determina-se $G^{\prime \prime}(0)$ derivando-se uma vez 2.31 e, neste caso, obtém-se a seguinte equação diferencial:

$$
3 G^{\prime} G^{\prime \prime}+3 G G^{\prime \prime \prime}+3\left(G^{\prime}\right)^{2}+3 G G^{\prime \prime}+2 G^{\prime} G^{\prime \prime}=0 .
$$

Avaliando a expressão $2.34 \mathrm{em} u=0$, utilizando-se $G^{\prime}(0)=1$ obtém-se $G^{\prime \prime}(0)$ :

$$
G^{\prime \prime}(0)=3 / 5 \text {. }
$$

A determinação dos outros coeficientes é realizada por meio de derivações contínuas de 2.34 substituindo nestas os valores anteriormente determinados das derivadas de $G$ avaliadas em $u=0$. Assim, para um feixe convergente, 2.27 é unicamente determinada e dada por:

$$
G(u)=-u+\frac{3}{10} u^{2}-\frac{3}{40} u^{3}+\frac{63}{4400} u^{4}-\frac{13311}{6160000} u^{5}+\frac{280557}{1047200000} u^{6}+\ldots
$$

ou,

$G\left[\ln \left(\frac{r}{r_{c}}\right)\right]=\ln \left(\frac{r_{c}}{r}\right)+\frac{3}{10} \ln ^{2}\left(\frac{r_{c}}{r}\right)+\frac{3}{40} \ln ^{3}\left(\frac{r_{c}}{r}\right)+\frac{63}{4400} \ln ^{4}\left(\frac{r_{c}}{r}\right)+\frac{13311}{6160000} \ln ^{5}\left(\frac{r_{c}}{r}\right)+\ldots$.

Considerando um fluxo convergente em que o potencial no anodo $\varphi=V_{0}$ em $r=r_{a}$, a máxima corrente que pode ser drenada do catodo pode ser determinada. Substituindo $\varphi=V_{0}$ em $r=r_{a}$ em 2.24

$$
V_{0}=\left[\frac{9 I_{0}}{16 \pi(2 \eta)^{\frac{1}{2}} \epsilon_{0}}\right]^{2 / 3}\left[G_{0}(u)\right]^{\frac{4}{3}},
$$

onde $G_{0}(u)$ é dado por:

$$
G_{0}\left[\ln \left(\frac{r_{a}}{r_{c}}\right)\right]=\ln \left(\frac{r_{c}}{r_{a}}\right)+\frac{3}{10} \ln ^{2}\left(\frac{r_{c}}{r_{a}}\right)+\frac{3}{40} \ln ^{3}\left(\frac{r_{c}}{r_{a}}\right)+\frac{63}{4400} \ln ^{4}\left(\frac{r_{c}}{r_{a}}\right)+\ldots
$$

Um parâmetro importante de projeto de um canhão de elétrons é a perveância perv. Para o diodo esfério a perveância é:

$$
\text { perv }=\frac{\left(\frac{4}{9}\right)\left[4 \pi \epsilon_{0}(2 \eta)^{\frac{1}{2}}\right]}{\left[G_{0}(u)\right]^{2}} .
$$


As expressões 2.12 e 2.40 indicam que a perveância é um parâmetro que depende unicamente da geometria.

Uma consequencia importante da definição de perveância é que, a máxima corrente $I_{0}$ que pode ser extraída do canhão esférico na condição FSCL depende da perveância como:

$$
I_{0}=\operatorname{perv} V_{0}^{\frac{3}{2}}
$$

\subsubsection{Aplicação do resultado de Langmuir e Blodgett do diodo esférico para o problema do canhão de elétrons com fluxo convergente}

Pierce interpretou o resultado de Langmuir e Blodgett e utilizando-o no projeto de um canhão de elétrons de fluxo convergente. Considerando a região emissora como sendo uma calota esférica, a corrente será reduzida de seu valor total (2.41), por um fator proporcional à área emissora, $2 \pi r_{c}^{2}\left(1-\cos \theta_{0}\right)$, em relação à área total do catodo, $4 \pi r_{c}^{2}$, ou seja:

$$
I_{0}=\left\{\frac{\left(\frac{4}{9}\right)\left[4 \pi \epsilon_{0}(2 \eta)^{\frac{1}{2}}\right]}{\left[G_{0}(u)\right]^{2}} V_{0}^{\frac{3}{2}}\right\}\left[\frac{2 \pi r_{c}^{2}\left(1-\cos \theta_{0}\right)}{4 \pi r_{c}^{2}}\right],
$$

ou:

$$
I_{0}=\left\{\frac{\left(\frac{4}{9}\right)\left[4 \pi \epsilon_{0}(2 \eta)^{\frac{1}{2}}\right]}{\left[G_{0}(u)\right]^{2}} V_{0}^{\frac{3}{2}}\right\}\left[\frac{\left(1-\cos \theta_{0}\right)}{2}\right],
$$

que pode ser reescrita como:

$$
I_{0}=14,67 \times 10^{-6} \frac{\left(1-\cos \theta_{0}\right)}{\left[G_{0}(u)\right]^{2}} V_{0}^{\frac{3}{2}}
$$

onde $\theta_{0}$ é o ângulo de meio cone, FIG. 2.10. A expressão (2.43) representa a máxima corrente que se pode extrair da superfície emissora de um diodo na forma de uma calota cônica. Podese agora determinar, também, a máxima densidade de corrente, para uma tensão de anodo $V_{0}$ :

$$
J_{\max }=\frac{I_{0}}{\pi r_{k}^{2}} .
$$

Desta última equação, define-se a perveância do feixe do canhão de elétrons de Pierce de fluxo convergente, perv como:

$$
\text { perv }=2 \pi \epsilon_{0}(2 \eta)^{\frac{1}{2}} k^{2}
$$

onde $k$ é dado por:

$$
k=\left\{\left(\frac{4}{9}\right) \frac{\left(1-\cos \theta_{0}\right)}{\left[G_{0}(u)\right]^{2}}\right\}^{1 / 2} .
$$


Observa-se que, para o canhão de elétrons de fluxo convergente, a perveância é um parâmetro que depende exclusivamente da sua geometria. Uma vez mais, observa-se que, a máxima corrente $I_{0}$ que pode ser extraída do canhão esférico de fluxo convergente na condição FSCL depende da perveância como:

$$
I_{0}=\operatorname{perv} V_{0}^{\frac{3}{2}}
$$

\section{O problema da Cintura do Feixe}

Para que haja uma utilização prática de um canhão de elétrons do tipo Pierce, faz-se necessário introduzir um orifício no anodo. Assim, os elétrons que forem acelerados em direção ao anodo, passarão por esta abertura e continuarão seus movimentos. Devido à existência de forças de carga espacial sobre feixe de elétrons, que é convergente na região entre o catodo e o anodo, este começará a divergir na região além do anodo, uma vez que além do anodo, por hipótese, é livre da ação de campo elétrico externo. Deste modo, o raio da seção transversal do feixe atingirá um valor mínimo a certa distância do anodo. Este raio mínimo é denominado cintura do feixe. A seguir é estimado o quanto este feixe se espalha além da abertura do anodo.

Considere, inicialmente, um feixe cilíndrico de elétrons com raio $r$. Pode-se mostrar, segundo a Lei de Gauss, que a intensidade do campo elétrico experimentado por um elétron na superfície da fronteira do feixe é:

$$
E_{s}=\frac{\rho r}{2 \epsilon_{0}}
$$

A equação da força atuando sobre este elétron na fronteira é descrita como:

$$
\frac{d^{2} r}{d t^{2}}=\eta E_{s}=\eta\left(\frac{\rho r}{2 \epsilon_{0}}\right) .
$$

Com o objetivo de se conhecer a trajetória, deve-se relacionar a derivada do lado esquerdo da equação acima em termos da derivada em relação à $z$. Assim,

$$
\frac{d^{2} r}{d t^{2}}=\frac{d}{d t}\left(\frac{d r}{d t}\right)=\frac{d}{d t}\left[\left(\frac{d r}{d z}\right)\left(\frac{d z}{d t}\right)\right] .
$$

Levando-se em consideração que $v=d z / d t$ é possível reescrever 2.49 como:

$$
\begin{gathered}
\frac{d^{2} r}{d t^{2}}=\frac{d}{d t}\left(\frac{d r}{d z} v\right)=v \frac{d}{d t}\left(\frac{d r}{d z}\right)= \\
=v\left[\frac{d}{d z}\left(\frac{d r}{d z}\right)\right]\left(\frac{d z}{d t}\right)=v \frac{d^{2} r}{d z^{2}} v= \\
=v^{2} \frac{d^{2} r}{d z^{2}}
\end{gathered}
$$


Fazendo uso de 2.3.1, 2.48 pode ser escrita como:

$$
v^{2} \frac{d^{2} r}{d z^{2}}=\left(\frac{\eta \rho}{2 \epsilon_{0}}\right) r
$$

Utilizando-se as relações $J=\rho v=I_{0} /\left(\pi r^{2}\right)$ e $v=\sqrt{2 \eta V}$ em 2.52 tem-se:

$$
\frac{d^{2} r}{d z^{2}}=\frac{k^{2}}{2 r}
$$

onde $k$ é dado por (2.46).

Normalizando as variáveis, simplificações podem ser obtidas na predição da trajetória. Assim, sejam:

$$
R=r / r_{0}
$$

e,

$$
Z=k\left(z / r_{0}\right)
$$

onde $r_{0}$ é um valor de referência de $r$.

A equação da trajetória (2.53), em termos das quantidades normalizadas, passa a ser escrita como:

$$
\frac{d^{2} R}{d Z^{2}}=\frac{1}{2 R}
$$

Entretanto, 2.54 pode ser reescrita como:

$$
\frac{d}{d Z}\left[\left(\frac{d R}{d Z}\right)^{2}\right]=\left(\frac{d R}{d Z}\right) \frac{1}{R} .
$$

a qual pode ser integrada, apresentando como resultado:

$$
\left(\frac{d R}{d Z}\right)^{2}=\ln R+A .
$$

A constante de integração $A$ pode ser tomada como sendo zero se a referência for escolhida de forma que $d R / d Z=0$, ou $d r / d z=0$. Neste caso, $\ln R=0$, ou seja, $R=1$ e, portanto, $r=r_{0}$. Desta forma, quando se considera $A=0 \mathrm{em} 2.55$ e avalia-se no ponto de mínimo da trajetória, ou seja, $d R / d Z=d r / d z=0$.Neste caso, a referência é na posição de mínimo, e é aqui denominada de $r_{0}$. Assim, 2.55 tem-se duas soluções possíveis:

$$
\left(\frac{d R}{d Z}\right)= \pm(\ln R)^{1 / 2}
$$

onde os sinais positivo e negativo referem-se à inclinação da trajetória à direita e à esquerda de $r_{0}$.

É esperado que o feixe de elétrons, embora mantenha convergência ao ser emitido pelo catodo com ângulo de semicone $\theta_{0}$ até o anodo, deverá divergir devido às forças de cargas 
espaciais além da abertura do anodo. Assim, em lugar de haver convergência para o centro das esferas do catodo e anodo, o feixe apresentará um raio mínimo $r_{M}$, veja FIG. 2.10, e a inclinação da trajetória, neste ponto, é nula, isto é, $d r / d z=0$. Seja $r_{M}=r_{0}$, o raio de referência da cintura do feixe, então pode-se utilizar (2.56) para obter $d_{m}$, a distância da cintura do feixe até o anodo, utilizando-se, neste caso, o sinal negativo:

$$
d Z=-\left(\frac{1}{\ln R}\right)^{1 / 2} d R
$$

A equação 2.57 pode ser integrada entre os limites inferiores: $Z=0$ (integral à esquerda que corresponde a $z=0$ ), $R=1$ (integral à direita correspondendo a $r=r_{0}=r_{M}$ ); e limites superiores na cintura do feixe: $Z=-k d_{m} / r_{M}$ (integral à esquerda correspondendo a $z=-d_{m}$ ), $R=r / r_{0}=r_{A} / r_{M}$ (integral à direita que corresponde a $r=r_{A}$ na abertura do anodo). Integrando 2.57 nesses limites:

$$
\int_{0}^{-k\left(d_{m} / r_{M}\right)} d Z=-\int_{1}^{r_{A} / r_{M}} \frac{d R}{(\ln R)^{1 / 2}}
$$

ou seja,

$$
d_{M}=\left(r_{M} / k\right) \int_{1}^{r_{A} / r_{M}} \frac{d R}{(\ln R)^{1 / 2}} .
$$

Utilizando a mudança de variável $\zeta=(\ln R)^{1 / 2}$ e fazendo a expansão em série de Taylor de $\exp \left(\zeta^{2}\right)$, a integral acima pode ser escrita como:

$$
d_{M}=\left(2 \frac{r_{M}}{k}\right)\left[\ln ^{1 / 2}\left(\frac{r_{A}}{r_{M}}\right)+\frac{\ln ^{3 / 2}\left(\frac{r_{A}}{r_{M}}\right)}{3(1 !)}+\frac{\ln ^{5 / 2}\left(\frac{r_{A}}{r_{M}}\right)}{5(2 !)}+\frac{\ln ^{7 / 2}\left(\frac{r_{A}}{r_{M}}\right)}{7(3 !)}+\ldots\right]
$$

Utilizando o ângulo de semicone $\theta_{0}$, a inclinação da trajetória do feixe $d r / d z$ avaliada no anodo, pode ser escrita como

$$
\left(\frac{d r}{d z}\right)_{A}=-\tan \theta_{0}
$$

onde o subscrito $A$ refere-se ao cálculo da derivada tomada no anodo. Como $d r / d z=$ $k(d R / d Z)$, a equação acima pode ser reescrita como:

$$
k\left(\frac{d R}{d Z}\right)_{A}=-\tan \theta_{0} .
$$

Utilizando-se (2.56) com o sinal negativo na região entre o anodo e a cintura do feixe, tem-se que

$$
k\left(\log R_{A}\right)^{1 / 2}=\tan \theta_{0},
$$


onde $R_{A}$ é o valor de $R$ no anodo, ou seja, $R_{A}=r_{A} / r_{0}=r_{A} / r_{M}$. Elevando ao quadrado e, em seguida, a exponencial, a equação acima, se obtém:

$$
\frac{r_{A}}{r_{M}}=\exp \left(\frac{\tan ^{2} \theta_{0}}{k^{2}}\right)
$$

que é a expressão para a razão entre o raio de abertura do anodo e o raio da cintura do feixe em termos do ângulo de semicone.

\section{Efeito de lente eletrostática na abertura do anodo}

Para que se possa extrair elétrons do diodo esférico de setor cônico fez-se necessário introduzir uma abertura na superfície do anodo. A presença desta abertura forma uma lente eletrostática sobre o feixe de elétrons, o qual é acelerado pelo potencial do anodo $V_{0}$. Essa lente eletrostática atua sobre o feixe promovendo a divergência do mesmo, conforme FIG. 2.11 .

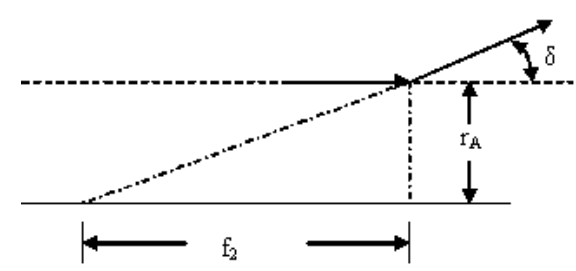

Figura 2.11: Representação esquemática do caminho percorrido pelo elétron ao atravessar a abertura do anodo, causando desvio $\delta$ em sua trajetória face ao efeito de lente eletrostática e a magnitude da distância focal $f_{2}$.

É possível demonstrar que a distância focal $f_{2}$, decorrente do efeito de lente eletrostática, é dada por [1]:

$$
f_{2}=\frac{4 V_{0}}{E_{1}-E_{2}},
$$

onde $E_{1}$ e $E_{2}$ representam a intensidade do campo elétrico nas vizinhanças da abertura do anodo, à esquerda e à direita do anodo, respectivamente. A lente poderá ser convergente ou divergente de acordo com o sinal de $f$ é positivo ou negativo. Em razão de o anodo estar com um potencial positivo em relação ao catodo $E_{1}$ é negativo e, $E_{2}=0$. Portanto, se o feixe de elétrons for lançado à região livre do campo elétrico as lentes produzirão sobre o feixe um efeito divergente e, como resultado, a trajetória dos elétrons sofrerá um desvio na abertura do anodo de um ângulo $\delta$, que levaria a alteração do ângulo de $\theta_{0}$ para $\theta_{0}^{\prime}$, ou seja:

$$
\theta_{0}=\theta_{0}^{\prime}+\delta=\theta_{0}^{\prime}+\frac{r_{A}}{\left|f_{2}\right|},
$$

para pequenos valores de $\delta$. É possível mostrar (vide [1]) que: 


$$
\theta_{0}^{\prime}=\theta_{0}\left[1-\left(\frac{1}{6}\right)\left(\frac{r_{c}}{r_{a}}\right)\left(\frac{1}{G_{0}^{2}}\right)\left|\frac{d G^{2}}{d\left(r_{c} / r\right)}\right|_{0}\right]
$$

onde $\left|\frac{d G^{2}}{d\left(r_{c} / r\right)}\right|_{0}$ é avaliado no anodo e a função $G^{2}$ é calculada utilizando (2.37), de forma que a modificação do ângulo da trajetória de $\theta_{0}$ para $\theta_{0}^{\prime}$ leva a correção de (2.59) para:

$$
\frac{r_{A}}{r_{M}}=\exp \left(\frac{\tan ^{2} \theta_{0}^{\prime}}{k^{2}}\right)
$$

onde $\theta_{0}^{\prime}$ é dado por (2.60).

Pode-se escrever a razão de convergência como $\frac{r_{k}}{r_{M}}=\left(\frac{r_{k}}{r_{A}}\right)\left(\frac{r_{A}}{r_{M}}\right)$ e, de acordo com a FIG. 2.10, $\frac{r_{k}}{r_{M}}=\frac{r_{A}}{r_{a}}$, portanto vale a expressão:

$$
\frac{r_{k}}{r_{M}}=\left(\frac{r_{c}}{r_{a}}\right)\left(\frac{r_{A}}{r_{M}}\right)
$$

Utilizando (2.61) na equação acima, e considerando $\theta_{0}^{\prime}$ pequeno, de forma que se pode tomar $\tan \theta_{0}^{\prime} \approx \theta_{0}^{\prime}$, tem-se:

$$
\frac{r_{k}}{r_{M}}=\left(\frac{r_{c}}{r_{a}}\right) \exp \left(\frac{\theta_{0}^{\prime}}{k}\right)^{2}
$$

Substituindo $\theta_{0}^{\prime}$ de (2.60) acima,

$$
\frac{r_{k}}{r_{M}}=\left(\frac{r_{c}}{r_{a}}\right) \exp \left\{\left(\frac{\theta_{0}}{k}\right)^{2}\left[1-\left(\frac{1}{6}\right)\left(\frac{r_{c}}{r_{a}}\right)\left(\frac{1}{G_{0}^{2}}\right)\left|\frac{d G^{2}}{d\left(r_{c} / r\right)}\right|_{0}\right]^{2}\right\}
$$

Avaliando a derivada acima no anodo, substituindo $G_{0}, 2.39$, e, levando-se em consideração que $\frac{\theta_{0}^{2}}{k^{2}}=(9 / 2) G_{0}^{2}$, pode-se mostrar, finalmente, que [1]:

$$
\frac{r_{k}}{r_{M}}=\left(\frac{r_{c}}{r_{a}}\right) \exp \left\{\frac{1}{2}\left[-1+\left(\frac{12}{5}\right) \ln \left(\frac{r_{c}}{r_{a}}\right)+\left(\frac{27}{40}\right) \ln ^{2}\left(\frac{r_{c}}{r_{a}}\right)+\left(\frac{369}{2200}\right) \ln ^{3}\left(\frac{r_{c}}{r_{a}}\right)+\ldots\right]^{2}\right\}
$$

Elevando ao quadrado a série, obtém-se:

$$
\frac{r_{k}}{r_{M}}=\left(\frac{r_{c}}{r_{a}}\right) \exp \left\{\frac{1}{2}\left[1-\left(\frac{24}{5}\right) \ln \left(\frac{r_{c}}{r_{a}}\right)+\left(\frac{441}{100}\right) \ln ^{2}\left(\frac{r_{c}}{r_{a}}\right)+\left(\frac{639}{220}\right) \ln ^{3}\left(\frac{r_{c}}{r_{a}}\right)+\ldots\right]\right\}
$$

Aplicando o logarítmo nos dois lados da equação anterior tem-se: 


$$
\ln \left(\frac{r_{k}}{r_{M}}\right)=\frac{1}{2}-\left(\frac{7}{5}\right) \ln \left(\frac{r_{c}}{r_{a}}\right)+\left(\frac{441}{200}\right) \ln ^{2}\left(\frac{r_{c}}{r_{a}}\right)+\left(\frac{639}{440}\right) \ln ^{3}\left(\frac{r_{c}}{r_{a}}\right)+\ldots
$$

Esta última equação pode ser escrita da seguinte forma:

$$
y=a_{0}+a_{1} \gamma+a_{2} \gamma^{2}+a_{3} \gamma^{3}+a_{4} \gamma^{4}+\ldots
$$

onde $y=\ln \left(\frac{r_{k}}{r_{M}}\right), \gamma=\ln \left(\frac{r_{c}}{r_{a}}\right)$ e $a_{n}$ são os coeficientes de série 2.67. Esta série pode ser invertida (vide, por exemplo, [1]) da seguinte forma:

$$
\gamma=b_{0}+b_{1} y+b_{2} y^{2}+b_{3} y^{3}+b_{4} y^{4}+\ldots
$$

Considerando as seguintes razões $\frac{r_{c}}{r_{a}}=[1,41 ; 1,76 ; 1,91 ; 2,10 ; 2,60]$ adotadas por Langmuir [21], é possível resolver o sistema linear para os parâmetros $b_{0}, \ldots, b_{4} \mathrm{e} b_{5}$. Considerando $\gamma_{0}=-\gamma=\ln \left(r_{a} / r_{c}\right)$, resolvendo o sistema [22], obtém-se:

$$
\begin{aligned}
\gamma_{0}= & 0,099493-1,820707 \ln \left(\frac{r_{k}}{r_{M}}\right)+1,925535 \ln ^{2}\left(\frac{r_{k}}{r_{M}}\right)+ \\
& -1,133440 \ln ^{3}\left(\frac{r_{k}}{r_{M}}\right)+0,326941 \ln ^{4}\left(\frac{r_{k}}{r_{M}}\right)-0,036137 \ln ^{5}\left(\frac{r_{k}}{r_{M}}\right),
\end{aligned}
$$

e

$$
\frac{r_{c}}{r_{a}}=\exp \left(-\gamma_{0}\right)
$$

Assim, todos os parâmetros para o projeto de um canhão de elétrons estão determinados. O procedimento para obtê-los estão sistematizados na próxima subseção.

\subsubsection{Fluxograma para projeto de um canhão de elétrons de Pierce com fluxo convergente}

De modo a tornar claro o procedimento anterior, é apresentado na TAB. 2.2 as etapas à síntese de um canhão de elétrons de Pierce, que tem como parâmetros de projeto: tensão do anodo $\left(V_{0}\right)$, corrente do feixe $\left(I_{0}\right)$, cintura do feixe $\left(r_{M}\right)$ e densidade de corrente de operação $\left(J_{o p}\right)$.

A título de exemplo, considere os parâmetros de entrada do canhão de elétron Litton L2087 [23] apresentado na TAB. 2.3. A TAB. 2.4 apresenta os parâmetros de saída obtidos, a partir do procedimento acima, para o canhão Littion L-2087. 
Tabela 2.2: Fluxograma de projeto do canhão de Pierce de fluxo convergente.

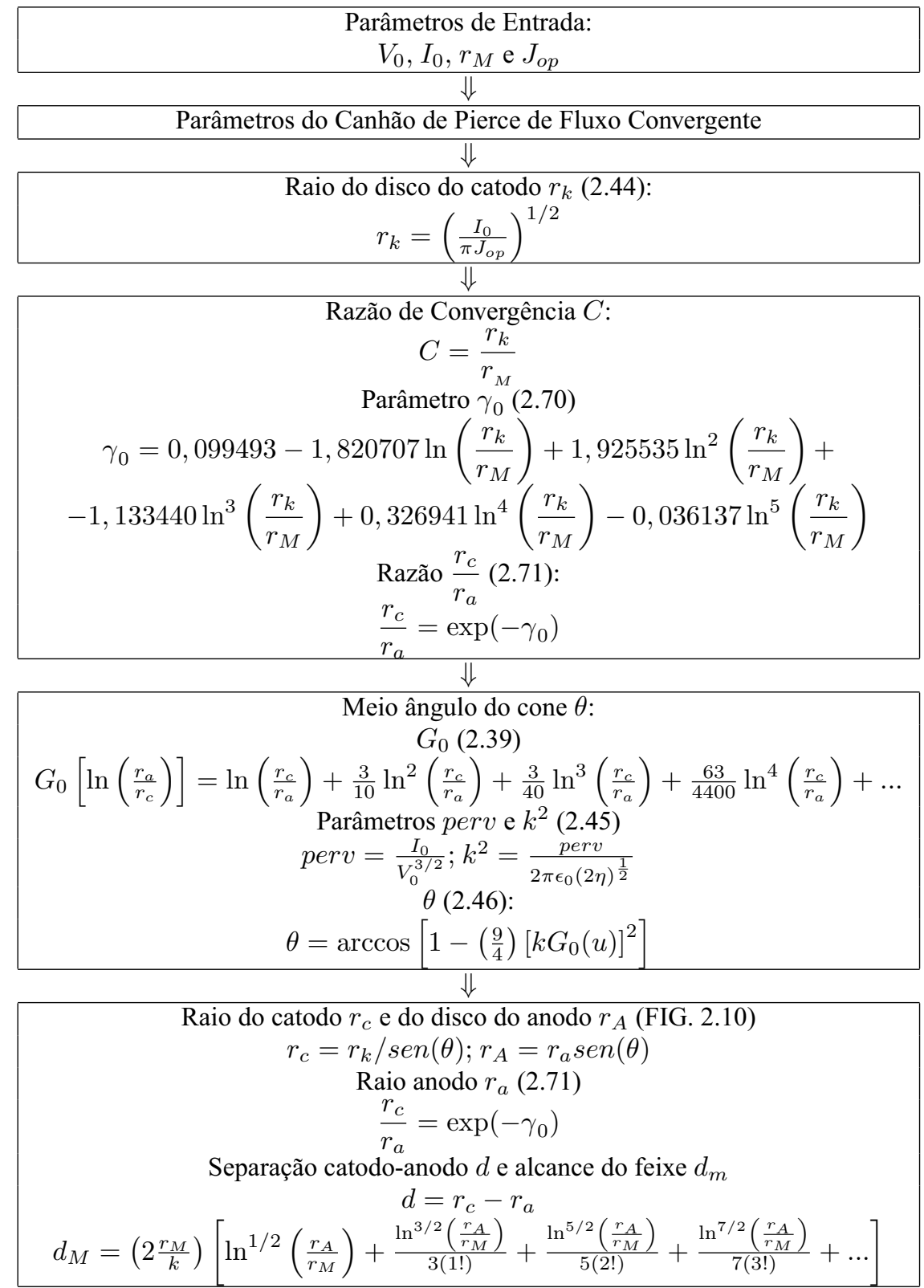

\subsection{Controle do Feixe de Elétrons}

Tipicamente, as válvulas do tipo TWT operam na forma pulsada e, para tanto, faz-se necessário controlar a corrente do feixe de elétrons. Esta seção descreve, sucintamente, quatro modelos comumente utilizados que permitem o controle da corrente do feixe de elétrons [18].

- a FIG. 2.12(a) ilustra o modo de controle da corrente do feixe utilizando-se uma fonte de tensão entre o catodo e o anodo. Em função da potência fornecida por esta fonte de tensão o seu projeto pode ser complexo e, tipicamente, seu modulator é grande, pesado e ineficiente;

- pode-se utilizar um segundo anodo, denominado anodo modulador, entre o catodo e o 
Tabela 2.3: Parâmetros de entrada do canhão de elétron Litton L-2087.

\begin{tabular}{ccc}
\hline Parâmetro de Entrada & Valor & Unidade \\
\hline$V_{0}$ & 10,0 & $\mathrm{kV}$ \\
$I_{0}$ & 0,55 & $\mathrm{~A}$ \\
$r_{M}$ & 0,09398 & $\mathrm{~cm}$ \\
$J$ & 1,737 & $\mathrm{Acm}^{-2}$ \\
\hline
\end{tabular}

Tabela 2.4: Parâmetros de saída do canhão de elétron Litton L-2087.

\begin{tabular}{ccc}
\hline Parâmetro de Saída & Valor & Unidade \\
\hline Perveância & 0,55 & $\mu$ Perv \\
$r_{k}$ & 3,175 & $\mathrm{~mm}$ \\
$\left(\frac{r_{k}}{r_{M}}\right)$ & 3,378 & \\
$\left(\frac{r_{c}}{r_{a}}\right)$ & 1,987 & \\
$\theta$ & 13,46 & $\left(^{\circ}\right)$ \\
$r_{c}$ & 13,635 & $\mathrm{~mm}$ \\
$r_{a}$ & 6,861 & $\mathrm{~mm}$ \\
$r_{A}$ & 1,5975 & $\mathrm{~mm}$ \\
$d_{m}$ & 12,82 & $\mathrm{~mm}$ \\
\hline
\end{tabular}

anodo final para o controle da corrente conforme apresentado na FIG. 2.12(b). Embora a faixa de tensão do anodo modulator utilizado para modular a corrente do feixe seja grande, tipicamente a corrente interceptada por este modulador é baixa e, portanto, a potência da fonte também é baixa;

- os canhões de elétrons com baixa perveância podem utilizar o eletrodo de focalização para controlar a corrente como indicado na FIG. 2.12(c). Este sistema, entretanto, não é recomendado para aplicações em que se exije um controle intermediário de corrente devido ao elevado grau de desfocalização que é produzido no feixe de elétrons; e

- para a maioria das aplicações, grades de controle são introduzidas nas proximidades da superfície de emissão do catodo, FIG. 2.12(d). Embora as trajetórias dos elétrons são afetadas, de modo que a focalização do feixe é degradada e a dinâmica do feixe é afetada, ainda assim, o controle do feixe de elétrons, por meio de grades de controle, é largamente utilizado, uma vez que sua fonte de alimentação tem um modulador de menor dimensão quando comparado com os modelos acima citados.

O maior problema observado no uso da grade de controle está na corrente interceptada por ela. Em alguns casos este valor representa até $15 \%$ ou mais da corrente do catodo interceptada. O efeito resultante da interceptação da corrente do catodo na grade é o aumento do calor da grade, o qual, não raramente, promove a diminuição do tempo de vida da grade de controle. A solução, largamente empregada atualmente, consiste em utilizar uma segunda grade, denominada shadow-grid. A shadow-grid fica localizada entre a grade de controle e o coletor. Tipicamente a shadow-grid é construída sob ou próxima a superfície do catodo, de forma que o aquecimento devido a corrente de interceptação seja pequeno e, alinhada com a grade de controle, funcionando assim como um escudo, reduzindo a corrente de interceptação pela grade de controle. 
(a)

Catodo

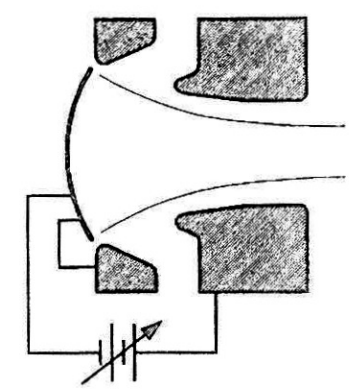

(c)

Eletrodo de Focalização

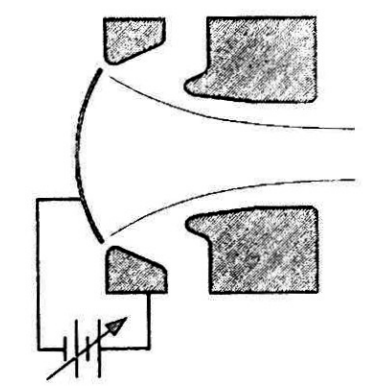

(b)

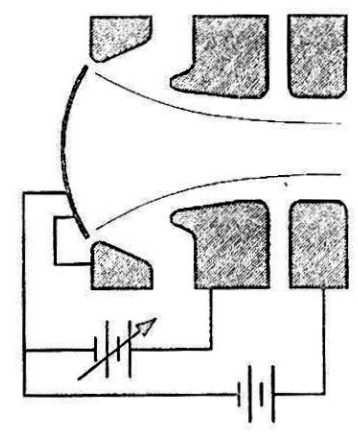

(d)

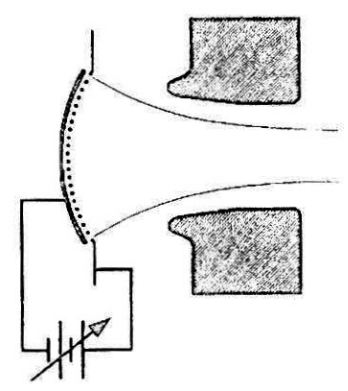

Figura 2.12: Técnicas utilizadas no controle do feixe em canhões de elétrons.

\subsection{Conclusões do Capítulo}

Neste Capítulo foram, inicialmente, descritos os principais componentes de um canhão de elétrons e seu funcionamento. Em seguida, foram apresentados, em ordem crescente de complexidade, os canhões de elétrons que possuem solução analítica: planos de Pierce de feixe paralelo, esférico de fluxo convergente e de Pierce de fluxo convergente. Para o diodo plano de Pierce foi demonstrado ser possível obter um feixe retilíneo de elétrons. Para que as trajetórias sejam retilíneas o eletrodo de focalização deve-se ter um ângulo de $67.5^{\circ}$ entre o eletrodo de focalização e a direção axial do feixe de elétrons e uma geometria adequada para o anodo. Foi ainda mostrado que a máxima densidade de corrente extraída varia diretamente com o potencial do anodo elevado a razão $3 / 2$ e inversamente com o quadrado da separação entre o anodo e o coletor. Para o canhão de Pierce de fluxo convergente, toda a dinâmica do feixe foi resolvida levando-se em consideração a condição em que a emissão é limitada pela carga espacial. Conceitos importantes como perveância, cintura e alcance do feixe de elétrons foram apresentados. Finalmente, para o canhão de Pierce de fluxo convergente, foi apresentado o procedimento de projeto tendo como parâmetros de entrada a tensão do anodo $\left(V_{0}\right)$, a corrente do feixe $\left(I_{0}\right)$, a cintura do feixe $\left(r_{M}\right)$ e densidade de corrente de operação $\left(J_{o p}\right)$ seguido de um exemplo numérico. 


\section{Capítulo 3}

\section{O Problema do Transporte do Feixe - PPM}

O Capítulo anterior tratou do problema de formação de um feixe de elétrons de modo a atender aos requisitos de projeto. Para aplicações em TWT, após o feixe de elétrons ser acelerado pelo anodo, ele deverá atravessar a região de deriva e interagirá com a estrutura de ondas-lentas. Nesta região a energia cinética do feixe é convertida em energia eletromagnética, amplificando o sinal de RF. Devido às cargas espaciais, o feixe de elétrons tende a divergir. Para que se possa garantir a propagação do feixe de elétrons com um diâmetro praticamente constante, aplica-se um campo magnético nesta região na direção axial. A interação entre as partículas do feixe com o campo magnético fazem com que as mesmas ganhem velocidade radial. Por sua vez, a interação entre esta componente da velocidade com o a componente longitudinal do campo magnético produz uma força que age comprimindo o feixe, o qual deve ser projetada de forma a contrabalancear a força devido às cargas espaciais.

O campo magnético que atende aos requisitos de confinamento acima, pode ser obtido por meio do uso de solenóides ou ímãs permanentes. Um método largamente utilizado, baseado no uso de ímãs permanentes para manter o feixe confinado, é o uso de estruturas denominas de Estruturas Periódicas de Ímãs Permanentes, usualmente conhecidas como $\mathrm{Pe}$ riodic Permanent Magnet - PPM. A utilização de PPM permite obter estruturas de focalização que minimizam tanto o peso quanto o tamanho de uma TWT, sendo que a redução de peso do sistema de focalização, quando comparada com a de um solenóide, chega a ser de uma a duas ordens de magnitude [24]. Esta redução de peso é essencial em sistemas de comunicações embarcadas em satélite e radares que utilizam válvulas do tipo TWT.

Assim, o problema do transporte do feixe pode ser formulado como:

"Dados a energia, o diâmetro e a corrente do feixe de elétrons qual será a geometria de uma estrutura do tipo PPM com pole piece e a magnetização dos ímãs permanentes que garantirá o confinamento do feixe na região de deriva?"

Ao longo deste Capítulo são abordados os princípios teóricos que norteiam a descrição do campo magnético no interior de diferentes estruturas. A primeira estrutura analisada é aquela 
baseada em um solenóide e, em seguida, estruturas do tipo PPM que apresentam solução analítica. Estes modelos serão utilizados como referência para a validação da ferramenta computacional XMAGUN. Uma vez validada, estruturas com arranjos complexos podem ser modelados e simulados visando otimizar o desempenho de um PPM.

Neste capítulo é descrito, inicialmente, na seção 3.1, o princípio de funcionamento de uma estrutura do tipo PPM com pole piece utilizado para focalização de um feixe de elétrons. Na seção 3.2 é demonstrado o teorema de Busch, amplamente utilizado em campos que apresentam simetria axial. O teorema de Busch estabelece a relação entre a velocidade angular de uma partícula com a variação do fluxo magnético atravessado por ela. Em seguida, na seção 3.3, é estudada a estrutura de focalização baseada em um solenóide. A seção 3.4 descreve os parâmetros de projeto de um PPM considerando um fluxo de Brillouin ${ }^{1}$. A seção 3.5 estabelece analiticamente os campos magnéticos axial e radial no interior de três distintas estruturas do tipo PPM com pole pieces, a partir de um modelo simplificado até o mais próximo da realidade. Vale salientar, entretanto, que na maioria dos modelos estudados, são considerados modelos de PPM infinito os quais, embora não realizáveis fisicamente, são largamente utilizado para modelar estruturas finitas.

\subsection{PPM - Componentes e Princípio de Funcionamento}

Um PPM é composto basicamente de um arranjo de ímãs permanentes em forma de anéis concêntricos separados por pole pieces, conforme FIG. 3.1. Os ímãs permanentes são dispostos de forma que a imantação está na direção longitudinal e, entre ímãs permanentes adjacentes, ela tem sentido opostos. A utilização de ímãs permanentes construídos a partir de terras-raras tem larga aplicação em estruturas do tipo PPM uma vez que suas propriedades magnéticas têm sofrido constantes melhorias, superando os ímãs permanentes construídos a partir de ferrite e Alnico. Destacam-se as seguintes propriedades magnéticas referentes aos ímãs permanentes com aplicações em estruturas do tipo PPM [17]:

- produto de energia $(B H)_{\max }$ : é relevante em sistemas que exigem minimização em volume e peso uma vez que o ímã permanente trabalhando no ponto que fornece a maior energia, neste caso, o produto entre os campos $B$ e $H$ é máximo, tem-se o maior fluxo utilizando o mínimo do material magnético;

- força coercitiva $H_{c}$ : indica a intensidade do campo magnético externo $H_{c}$ que, quando aplicado sobre o ímã permanente, é capaz de anular a magnetização residual $B_{r}$ do ímã permanente. Quanto maior $H_{c}$ melhor a estrutura do PPM, pois assim se evita a desmagnetização entre ímãs adjacentes; e

- temperatura de Curie $T_{c}$ : é a temperatura em que, acima desta, os momentos magnéticos elementares não mais terão um sentido predominante e, portanto, o material perde

\footnotetext{
${ }^{1}$ Um fluxo de elétrons e dito ser de Brillouin quando: (a) os elétrons do feixe entram em um campo magnético cuja componente radial da velocidade é nula; (b) e a força magnética, devido ao campo magnético, se equilibra exatamente com a força devido à carga espacial.
} 
suas propriedades magnéticas e, comumente, passa a apresentar um comportamento paramagnético ${ }^{2}$. As temperaturas máximas de operação, dependendo do material do ímã permanente, estão entre $0,35 T_{c}$ e $0,9 T_{c}[17]$.

A TAB. 3.1 apresenta as propriedades magnéticas de seis tipos de materiais utilizados como ímãs permanentes [17].

Tabela 3.1: Propriedades de materiais magnéticos comerciais disponíveis.

\begin{tabular}{ccccc}
\hline Material & $B_{r}(T)$ & $H_{c}(A / m)$ & $(B H)_{\max }$ & $\begin{array}{c}\text { Temperatura } \\
\text { Máxima de } \\
\text { Operação }\left({ }^{\circ} C\right)\end{array}$ \\
\hline Ferrite (Cerâmica \#10) & 0,42 & 37,1 & 33,4 & 300 \\
Alnico 8 & 0,83 & 20,7 & 43,8 & 540 \\
SmCo (27H) & 1,1 & 129,4 & 223,0 & 350 \\
NdFeB (39H) & 1,3 & 154,6 & 302,0 & 150 \\
NdFeB (48) & 1,4 & 162,1 & 382,0 & 80 \\
\hline
\end{tabular}

O motivo pelo qual a estrutura do tipo PPM mantém a trajetória do feixe de elétrons de acordo com o envelope apresentado na FIG. 3.1, é assim sintetizado: à medida que o feixe de elétrons entra na estrutura, decorrente da ação das cargas espaciais, o feixe de elétrons começa a divergir, apresentando uma velocidade radial $\left(+\widehat{a_{r}}\right)$. As partículas do feixe passam a sofrer ação de uma força (resultado do produto vetorial da força de Lorentz, $\mathbf{v} \times \mathbf{B}$ ) que promove a rotação do mesmo (velocidade azimutal $+\widehat{a_{\varphi}}$ ). Desta forma, o feixe começa a sofrer rotação e a interação resultante deste movimento rotacional com o campo magnético axial produz uma força radial que comprime o feixe $\left(-\widehat{a_{r}}\right)$.

Estruturas do tipo PPM são largamente empregadas na focalização do feixe de elétrons em válvulas do tipo klystron e TWT. O peso de estruturas do tipo PPM é substancialmente menor quando comparadas com estruturas que utilizam solenóides que produzem campos uniformes. Outros problemas associados ao uso de solenóides estão na necessidade de uma fonte de alimentação e, em alguns casos, de sistemas de refrigeração à ar ou à água.

\subsection{Teorema de Busch}

Uma importante relação que caracteriza o movimento de partículas em campos que apresentam simetria cilíndrica, é conhecida como teorema de Busch e é demonstrada nesta seção.

Inicialmente, considere a representação do campo magnético $\vec{B}$ em termos do vetor potencial magnético $\vec{A}$ em coordenadas cilíndricas:

\footnotetext{
${ }^{2}$ Diz-se que um material tem um comportamento paramagnético quando, na ausência de campo externo, os seus dipolos magnéticos estão orientados aleatoriamente apresentando momento magnético líquido nulo.
} 


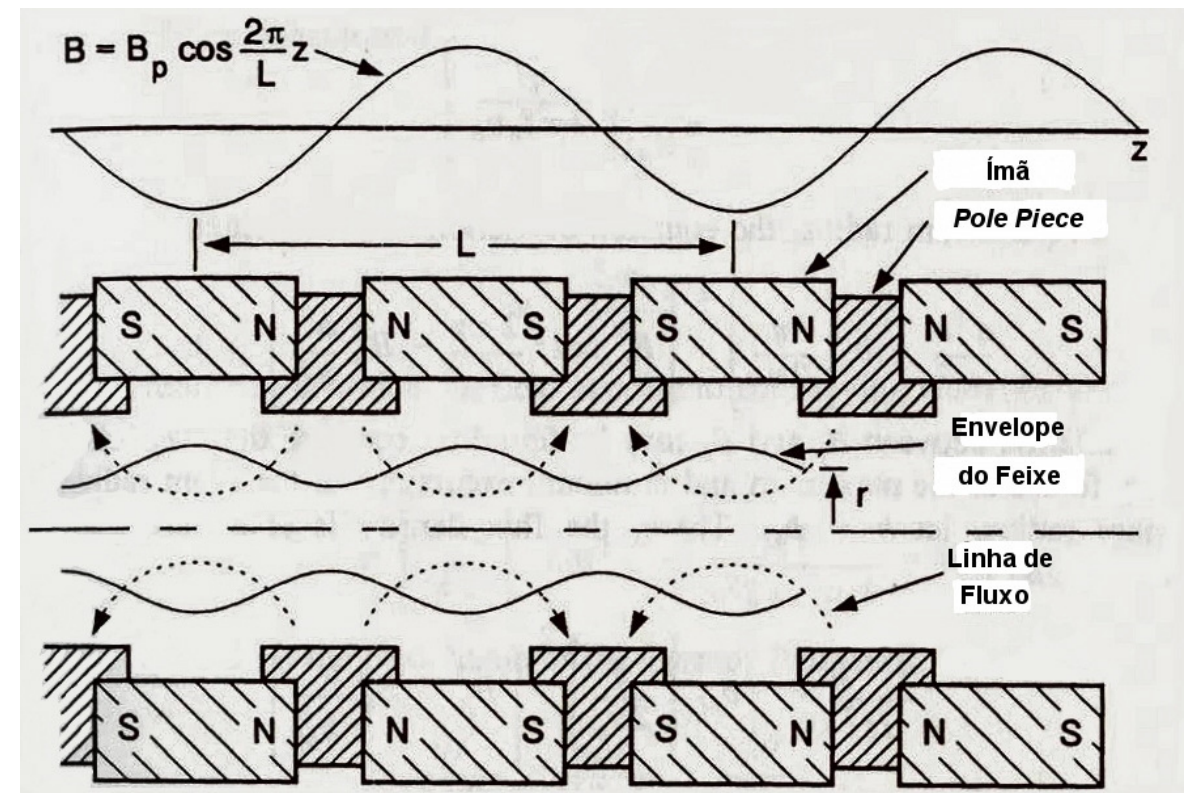

Figura 3.1: Focalização de um feixe de elétrons utilizando uma estrutura do tipo PPM.

$$
\begin{aligned}
\vec{B} & =\nabla \times \vec{A}= \\
& =\left[\frac{1}{\rho} \frac{\partial A_{z}}{\partial \theta}-\frac{\partial A_{\theta}}{\partial z}\right] \widehat{\rho}+\left[\frac{\partial A_{\rho}}{\partial z}-\frac{\partial A_{z}}{\partial \rho}\right] \widehat{\theta}+\frac{1}{\rho}\left[\frac{\partial\left(\rho A_{\theta}\right)}{\partial \rho}-\frac{\partial A_{\rho}}{\partial \theta}\right] \widehat{z}
\end{aligned}
$$

Em problemas de óptica de elétrons, com simetria cilíndrica, os campos magnéticos são similares com o de uma espira circular. E, neste caso, há tão somente a componente $\theta$ da corrente e, portanto, somente a componente $\theta$ de $A$. E ainda, a componente $\theta$, tanto da corrente quanto de $A$ não variam $\operatorname{com} \theta$. Assim:

$$
\begin{aligned}
A_{r} & =A_{z}=0, \\
\vec{A} & =A_{\theta} \widehat{\theta}, \mathrm{e} \\
\frac{\partial A_{\theta}}{\partial \theta} & =0 .
\end{aligned}
$$

Levando-se em consideração as restrições acima, as relações componente a componente entre $B$ e $A$ são:

$$
\begin{gathered}
B_{\theta}=0, \\
B_{z}=\frac{1}{\rho} \frac{\partial\left(\rho A_{\theta}\right)}{\partial \rho}
\end{gathered}
$$

e, 


$$
B_{\rho}=-\frac{\partial A_{\theta}}{\partial z} .
$$

Será demonstrado na seção 5.2, que a componente azimutal da equação de movimento de um elétron, derivada da força de Lorentz, é dada por:

$$
2 \dot{\rho} \dot{\theta}+\ddot{\rho} \ddot{\theta}=\frac{1}{\rho} \frac{d\left(\rho^{2} \dot{\theta}\right)}{d t}=-\eta\left(E_{\theta}+\dot{z} B_{\rho}-\dot{\rho} B_{z}\right) .
$$

Devido a simetria do problema, $E_{\theta}=0$. Substituindo 3.6 e 3.7 acima tem-se:

$$
\frac{d\left(\rho^{2} \dot{\theta}\right)}{d t}=\eta\left(\dot{\rho} \frac{\partial\left(\rho A_{\theta}\right)}{\partial \rho}+\rho \dot{z} \frac{\partial A_{\theta}}{\partial z}\right) .
$$

Avaliando-se o diferencial de $\rho A_{\theta}$, onde $A_{\theta}=A_{\theta}(\rho, z)$ :

$$
d\left(\rho A_{\theta}\right)=\frac{\partial\left(\rho A_{\theta}\right)}{\partial \rho} d \rho+\frac{\partial\left(\rho A_{\theta}\right)}{\partial z} d z .
$$

Diferenciando-se em relação ao tempo a equação acima:

$$
\frac{d\left(\rho A_{\theta}\right)}{d t}=\dot{\rho} \frac{\partial\left(\rho A_{\theta}\right)}{\partial \rho}+\dot{z} \frac{\partial\left(\rho A_{\theta}\right)}{\partial z}=\dot{\rho} \frac{\partial\left(\rho A_{\theta}\right)}{\partial \rho}+\rho \dot{z} \frac{\partial A_{\theta}}{\partial z} .
$$

Utilizando-se a equação acima em 3.9 tem-se:

$$
\frac{d\left(\rho^{2} \dot{\theta}\right)}{d t}=\eta \frac{d\left(\rho A_{\theta}\right)}{d t} .
$$

Integrando esta última equação obtém-se:

$$
\rho^{2} \dot{\theta}-\eta \rho A_{\theta}=C .
$$

$\mathrm{O}$ valor da constante $C$ pode ser determinado conhecendo-se os valores iniciais, em um ponto $l$, por exemplo, e, neste caso: $C=\rho_{l}^{2} \dot{\theta}_{l}-\eta \rho_{l} A_{\theta l}$. Assim:

$$
\rho^{2} \dot{\theta}-\rho_{l}^{2} \dot{\theta}_{l}=\eta\left(\rho A_{\theta}-\rho_{l} A_{\theta l}\right) .
$$

O fluxo magnético $\Phi$ devido ao campo magnético $\vec{B}$ é dado por:

$$
\Phi=\int_{S} \vec{B} \cdot \widehat{n} d A=\int_{S}(\nabla \times \vec{A}) \cdot \widehat{n} d A .
$$

Utilizando o teorema de Stokes acima,

$$
\int_{S}(\nabla \times \vec{A}) \cdot \widehat{n} d A=\oint_{C} \vec{A} \cdot \overrightarrow{d l}
$$

portanto, 


$$
\Phi_{\vec{B}}=\int_{S} \vec{B} \cdot \widehat{n} d A=\oint_{C} \vec{A} \cdot \overrightarrow{d l} .
$$

$A_{\theta}$ é a componente do vetor potencial magnético para um raio $\rho$, o qual pode ser expresso em termos do fluxo magnético $\Phi$ que atravessa a região da circunferência de mesmo raio. Assim,

$$
\Phi=\oint_{C} \vec{A} \cdot \overrightarrow{d l}=\oint_{C} A_{\theta} \widehat{\theta} \cdot \rho d \theta \widehat{\theta}=\oint_{C} A_{\theta} \rho d \theta=2 \pi \rho A_{\theta}
$$

portanto:

$$
A_{\theta}=\frac{\Phi}{2 \pi \rho}
$$

Substituindo esta última equação em 3.14 leva a:

$$
\rho^{2} \dot{\theta}-\rho_{l}^{2} \dot{\theta_{l}}=\frac{\eta}{2 \pi}\left(\Phi-\Phi_{l}\right)
$$

onde: $\Phi$ e $\Phi_{l}$ são os fluxos magnéticos que atravessam as superfícies limitadas pelos círculos de raios $\rho$ e $\rho_{l}$ respectivamente.

Esta expressão é conhecida como teorema de Busch. Ela estabelece que a variação no momento angular é proporcional à variação do fluxo magnético.

Se uma partícula inicia sua trajetória com velocidade angular nula, a expressão para o momento angular pode ser escrita como:

$$
\rho^{2} \dot{\theta}=\frac{\eta}{2 \pi}\left(\Phi-\Phi_{l}\right)
$$

Considerando o movimento das partículas próximas ao eixo de simetria, onde $\partial B_{z} / \partial \rho \approx$ 0 e portanto:

$$
\Phi=\pi \rho^{2} B_{z}
$$

e,

$$
\Phi_{l}=\pi \rho_{l}^{2} B_{z l} .
$$

Neste caso o teorema de Busch pode ser escrito como:

$$
\dot{\theta}=\frac{\eta}{2}\left(B_{z}-\frac{\rho_{l}^{2}}{\rho^{2}} B_{z l}\right)
$$

\subsection{Estrutura de Focalização - Solenóide}

Nesta seção é estudado o solenóide como estrutura de focalização. É apresentado, inicialmente, o seu modelo físico e em seguida é estabelecido a intensidade do campo magnético $B$ 
necessária para confinar um feixe de elétrons que transporta uma corrente $I$ com velocidade $v_{z}$ e cintura $a$.

A FIG. 3.2 ilustra uma representação típica de um solenóide utilizado para focalizar um feixe de elétrons em uma TWT. O solenóide é blindado magneticamente de modo a minimizar/anular o campo magnético produzido pelo solenóide na região do canhão de elétrons.

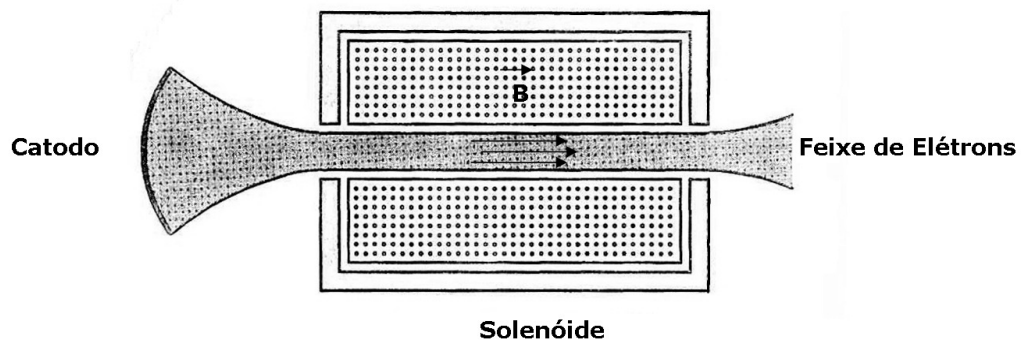

Figura 3.2: Uso de um solenóide para focalização de um feixe de elétrons.

Considere que o feixe de elétrons transporta uma corrente elétrica $I$ com velocidade $v_{z}$. É possível demonstrar, a partir da Lei de Gauss, que o campo radial $E_{\rho}$, na fronteira do feixe, é dado por:

$$
E_{\rho}=-\frac{I}{2 \pi \rho \varepsilon_{0} v_{z}}
$$

A equação de movimento de um elétron, derivada da força de Lorentz é:

$$
m \frac{d(\vec{v})}{d t}=-e(\vec{E}+\vec{v} \times \vec{B}) .
$$

A componente radial do movimento do elétron, a partir de 3.26, é:

$$
\ddot{\rho}-\rho \dot{\theta}=-\eta\left(E_{\rho}+\rho \dot{\theta} B_{z}-\dot{z} B_{\theta}\right)
$$

onde $\eta=e / m$.

Considerando nulas as componentes azimutais dos campos elétrico e magnético, $E_{\theta}=$ $B_{\theta}=0$, esta última equação é simplificada e tem a forma:

$$
\ddot{\rho}-\dot{\theta}^{2}=-\eta\left(E_{\rho}+\rho \dot{\theta} B_{z}\right)
$$

Isolando $\ddot{\rho}$ tem-se:

$$
\begin{aligned}
\ddot{\rho} & =-\eta\left(E_{\rho}+\rho \dot{\theta} B_{z}\right)+\dot{\rho} \dot{\theta}^{2}= \\
& =-\eta E_{\rho}+\rho \dot{\theta}\left(-\eta B_{z}+\dot{\theta}\right) .
\end{aligned}
$$


Utilizando 3.25 e 3.24 em 3.29, levando-se em consideração que o catodo está blindado magneticamente, ou seja $B_{z l}=0$, tem-se:

$$
\ddot{\rho}=\frac{\eta I}{2 \pi \rho \varepsilon_{0} v_{z}}+\rho \frac{\eta B_{z}}{2}\left(-\eta B_{z}+\frac{\eta B_{z}}{2}\right)
$$

ou seja:

$$
\ddot{\rho}=\left(\frac{\eta I}{2 \pi \varepsilon_{0} v_{z}}\right) \frac{1}{\rho}-\left(\frac{\eta B_{z}}{2}\right)^{2} \rho .
$$

Para se obter a equação da trajetória, utiliza-se nesta última expressão o fato de que $z=v_{z} t$, ou seja, $d t=d z / v_{z}$, assim:

$$
\frac{d^{2} \rho}{d z^{2}}=\frac{C_{1}}{\rho}-C_{2} \rho
$$

onde:

$$
C_{1}=\frac{\eta I}{2 \pi \varepsilon_{0} v_{z}^{3}}
$$

e,

$$
C_{2}=\left(\frac{\eta B_{z}}{2 v_{z}}\right)^{2}
$$

Considere que o raio do feixe de elétrons $\rho$ variará como: $\rho=a+\delta$, onde $\delta<<a$. Substituindo $\rho$ em 3.31 tem-se que:

$$
\frac{d^{2} \delta}{d z^{2}}=\frac{C_{1}}{a+\delta}-C_{2}(a+\delta)=\frac{C_{1}}{a\left(1+\frac{\delta}{a}\right)}-a C_{2}-\delta C_{2} .
$$

Considerando, $1 /\left(1+\frac{\delta}{a}\right) \approx 1-\frac{\delta}{a}$, a equação acima é reescrita como:

$$
\frac{d^{2} \delta}{d z^{2}}=\left(\frac{C_{1}}{a}-a C_{2}\right)-\left(\frac{C_{1}}{a^{2}}+C_{2}\right) \delta .
$$

Se, $C_{1} / a=a C_{2}$, isolando $C_{2}$ e substituindo na expressão acima se obtém:

$$
\frac{d^{2} \delta}{d z^{2}}=-2 C_{2} \delta=-m^{2} \delta
$$

que tem como solução:

$$
\delta=A \operatorname{sen}(m z)+B \cos (m z),
$$

onde $A$ e $B$ são constantes a serem determinadas. Se for levado em consideração que as trajetórias das partículas ao entrarem no solenóide estão paralelas ao eixo de simetria, então, neste caso, $\delta=0$ em $z=0$, e portanto, $B=0$. Assim o feixe possui uma oscilação cujo raio varia como: 


$$
r=a+A \operatorname{sen}(m z) .
$$

Se, entretanto, considera-se que $d \delta / d z=0$ em $z=0$, tem-se que $A=0$, e o feixe não mais tem a oscilação indesejada. Assim, as condições necessárias para que haja focalização do feixe de elétrons com mínima oscilação são:

- o catodo deve ser blindado magneticamente;

- $C_{1} / a=a C_{2}$, e neste caso:

$$
\frac{\eta I}{2 a \pi \varepsilon_{0} v_{z}^{3}}=a\left(\frac{\eta B_{z}}{2 v_{z}}\right)^{2},
$$

e isolando $B_{z}$ desta última expressão:

$$
B_{z}=B_{B}=\frac{1}{a}\left(\frac{2 I}{\pi \varepsilon_{0} \eta v_{z}}\right)^{1 / 2} ;
$$

- o feixe de elétrons deve entrar no campo magnético da estrutura de focalização solenoidal com o seu raio igual ao valor desejado $(\rho=a)$; e

- o feixe de elétrons deve entrar no campo magnético da estrutura de focalização solenoidal paralelo ao eixo axial e com sua componente de velocidade radial nula.

Para um feixe de elétrons que apresenta densidade de corrente uniforme de carga, a intensidade do campo magnético que produz uma força magnética que exatamente contrabalanceia a força devido à carga espacial, é denominado de Brillouin e, comumente, representado por $B_{B}$.

\subsection{Estrutura de Focalização - PPM para um Fluxo de Bril- louin}

Nesta seção é apresentada a primeira aproximação de projeto de um PPM, elaborado por Mendel, para confinar um feixe de elétrons que transporta uma corrente $I$ com velocidade $v_{z}$ e cintura $a$ em uma estrutura do tipo PPM. São apresentadas, ainda, nesta seção, as definições dos parâmetros $\alpha$ e $\beta$, devido ao campo magnético e à carga espacial, os quais são relevantes para o projeto do PPM.

O trabalho seminal [25] desenvolvido por Mendel, utilizando um PPM para confinar o feixe de elétrons, considera que a componente axial do campo magnético é uniforme e tem a forma:

$$
B_{z}(z)=B_{p} \cos \left(\frac{2 \pi z}{L}\right)
$$

onde: $B_{p}$ é o valor de pico do campo; e $L$ é o período magnético, vide FIG. 3.1. 
Seja $B_{B}, 3.38$, a intensidade do campo magnético para o fluxo de Brillouin que produza o raio de equilíbrio $a$. Estudando o movimento dos elétrons que se encontram na fronteira do feixe, $\rho=b, 3.31$ pode ser reescrita como:

$$
\frac{d^{2} b}{d z^{2}}=\frac{C_{1}}{b}-C_{2} b
$$

ou,

$$
\ddot{b}+b\left(\frac{\eta B_{z}}{2 v_{z}}\right)^{2}-\frac{1}{b} \frac{\eta I}{2 \pi \varepsilon_{0} v_{z}^{3}}=0 .
$$

Substituindo 3.39 e 3.38 acima, rearranjando os termos tem-se a seguinte equação diferencial de segunda ordem não-linear:

$$
\ddot{b}+b\left(\frac{\eta}{2 v_{z}}\right)^{2}\left[B_{p}^{2} \cos ^{2}\left(\frac{2 \pi z}{L}\right)-B_{B}^{2} \frac{a^{2}}{b^{2}}\right]=0 .
$$

Quando $\cos \left(\frac{2 \pi z}{L}\right)=1$, tem-se o raio máximo do feixe e, neste caso, tomando $b=b_{M}$ tem-se que:

$$
\ddot{b_{M}}=-b_{M}\left(\frac{\eta}{2 v_{z}}\right)^{2}\left(B_{p}^{2}-B_{B}^{2} \frac{a^{2}}{b_{M}^{2}}\right) .
$$

Por sua vez, quando $\cos \left(\frac{2 \pi z}{L}\right)=0$, tem-se o raio mínimo do feixe e, neste caso, $b=b_{m}$ e:

$$
\ddot{b_{m}}=b_{m}\left(B_{B}^{2} \frac{a^{2}}{b_{m}^{2}}\right) .
$$

Igualando as intensidades das forças restauradoras, tem-se:

$$
b_{m}\left(B_{B}^{2} \frac{a^{2}}{b_{m}^{2}}\right)=b_{M}\left(\frac{\eta}{2 v_{z}}\right)^{2}\left(B_{p}^{2}-B_{B}^{2} \frac{a^{2}}{b_{M}^{2}}\right) .
$$

Quando a amplitude do ripple do feixe é pequena, $b_{m} \approx b_{M} \approx a$ e neste caso:

$$
\begin{gathered}
B_{B}^{2}=\left(B_{p}^{2}-B_{B}^{2}\right) \\
B_{p}=\sqrt{2} B_{B},
\end{gathered}
$$

ou seja, o valor eficaz do campo magnético gerado pelo PPM deve ser igual ao campo magnético de Brillouin.

É possível, ainda, expressar 3.40 de forma normalizada. Para isso, sejam os parâmetros de normalização da cintura do feixe e da distância axial normalizada $\sigma$ e $T$, respectivamente, definidos como:

$$
\sigma=\frac{b}{a}
$$

e, 


$$
T=\frac{2 \pi z}{L}
$$

Utilizando as expressões acima é possível mostrar que:

$$
\ddot{b}=\left(\frac{4 \pi^{2} a}{L^{2}}\right)\left(\frac{d^{2} \sigma}{d T^{2}}\right) .
$$

Substituindo 3.46, 3.47 e a expressão acima em 3.40 obtém-se a seguinte equação diferencial de segunda ordem em termos dos parâmetros de normalização $\sigma$ e $T$ :

$$
\frac{d^{2} \sigma}{d T^{2}}+\alpha[1+\cos (2 T)] \sigma-\frac{\beta}{\sigma}=0
$$

onde os parâmetros $\alpha$ e $\beta$, devidos ao campo magnético e à carga espacial, respectivamente, são definidos como:

$$
\alpha=\frac{1}{2}\left(\frac{\eta B_{p} L}{4 \pi v_{z}}\right)^{2}
$$

e,

$$
\beta=\frac{\eta I L^{2}}{8 \pi^{3} v_{z}^{3} a^{2} \varepsilon_{0}} .
$$

As frequências de plasma e de Larmor são definidas respectivamente como:

$$
\omega_{p}=\frac{1}{a}\left(\frac{\eta I}{\pi \varepsilon_{0} v_{z}}\right)^{1 / 2}
$$

e,

$$
\omega_{L}=\frac{\eta B_{p}}{2}
$$

Utilizando as definições de frequências de plasma e de Larmor é possível expressar 3.49 como:

$$
\frac{d^{2} \sigma}{d T^{2}}=\frac{1}{2}\left(\frac{\omega_{L}}{\omega}\right)^{2}[1+\cos (2 T)] \sigma-\frac{1}{2}\left(\frac{\omega_{p}}{\omega}\right)^{2} \frac{1}{\sigma}=0
$$

onde:

$$
\omega=\frac{2 \pi v_{z}}{L}
$$

Observa-se que, quando as intensidades dos parâmetros $\alpha$ e $\beta$, devido ao campo magnético e à carga espacial são iguais, ocorre ripple mínimo do feixe de elétrons na região de deriva. Quando $\alpha<\beta$, observa-se que o campo magnético não é forte o suficiente para garantir que a cintura do feixe ao longo da região de deriva seja menor que a cintura de entrada. Finalmente, quando $\alpha>\beta$, por ter um campo magnético excessivo, observa-se ripple do feixe, sendo que a cintura do feixe ao longo do PPM será menor que a cintura do feixe ao entrar na estrutura. A FIG. 3.3 sintetiza cada um destes três casos.

A equação 3.49 tem a forma da equação diferencial de Mathieu, cuja solução é conhecida 
(a)

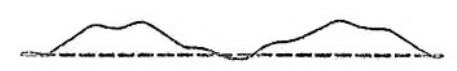

Campo Magnétlco

Insuflclente

$\alpha=0.15, \beta=0.2$

(b)

Campo Magnétlco

Correto

$\alpha=0.2, \beta=0.2$

(c)

Campo Magnétlco

em Excesso

$\alpha=0.4, \beta=0.2$
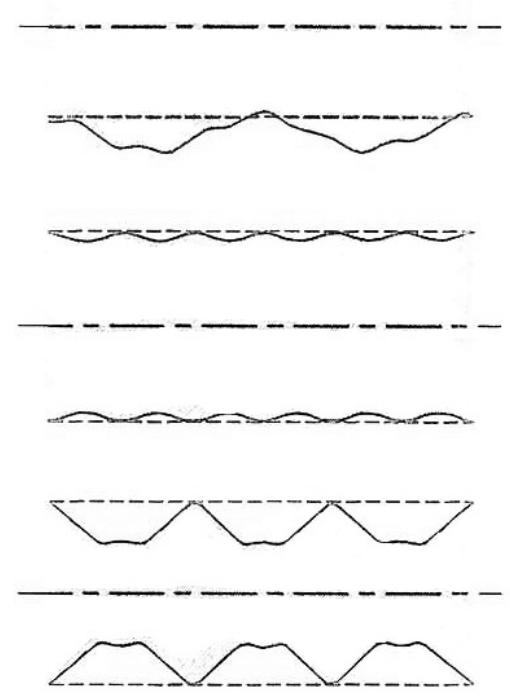

Figura 3.3: Comportamento do feixe de elétrons focalizado por um PPM nos casos em que os parâmetros devido ao campo magnético e à carga espacial, $\alpha$ e $\beta$ variam [18].

por apresentar soluções em apenas algumas regiões [26]. A primeira região com solução estável corresponde a $0 \leq \alpha \leq 0,66$, vide FIG. 3.4

Para que haja estabilidade no transporte do feixe de elétrons na região de deriva, a seguinte relação deve ser satisfeita:

$$
\beta=\alpha<0,66
$$

ou,

$$
\frac{1}{2}\left(\frac{\eta B_{p} L}{4 \pi v_{z}}\right)^{2}<0,66
$$

Assim, o período $L$ e o campo magnético $B_{p}$, da estrutura de um PPM, utilizada para que um feixe de elétrons que transporta uma corrente $I$, com cintura do feixe $a$ e velocidade $v_{z}$ seja confinado na região de deriva, são assim estabelecidos:

- Determinação de $B_{B}(3.38)$ :

$$
B_{B}=\frac{1}{a}\left(\frac{2 I}{\pi \varepsilon_{0} \eta v_{z}}\right)^{1 / 2}
$$

- Determinação de $B_{p}(3.45)$ :

$$
B_{p}=\sqrt{2} B_{z}
$$

- Determinação de $L$ (3.54): 


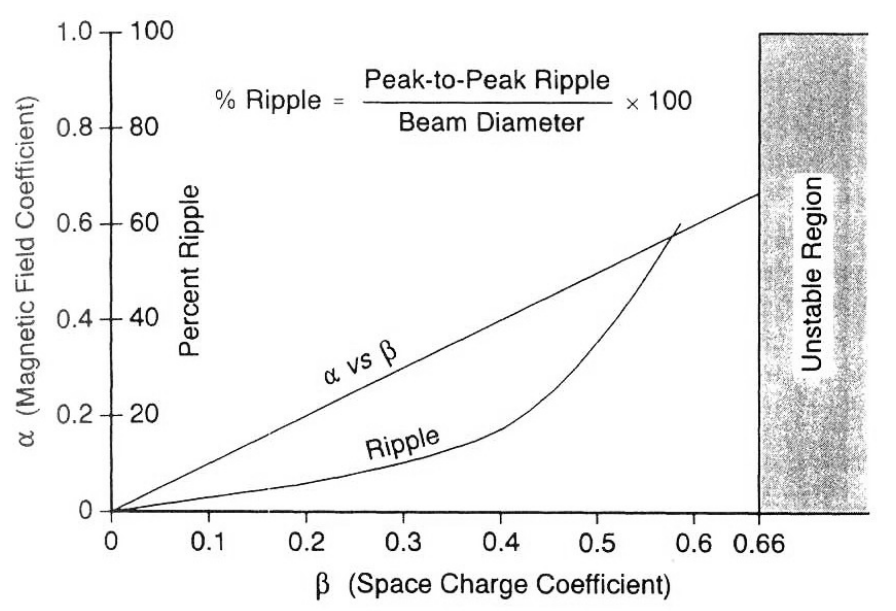

Figura 3.4: Comportamento do ripple de um feixe de elétrons focalizado por um PPM tendo como parâmetros os coeficientes devido ao campo magnético $\alpha$ e à carga espacial $\beta$, considerando a primeira região com solução estável para 3.49.

$$
L<14,44 \frac{v_{z}}{\eta B_{p}}
$$

\subsection{Estrutura de Focalização - PPM para Ímãs toroidais separados pelo vácuo}

Nesta seção é apresentada a solução para os campos magnéticos axial e radial a partir de uma estrutura de focalização finita do tipo PPM em que os ímãs permanentes são toroidais e separados pelo vácuo, conforme sintetizado na FIG. 3.5, por meio de um conjunto analíticointegral de expressões [27].

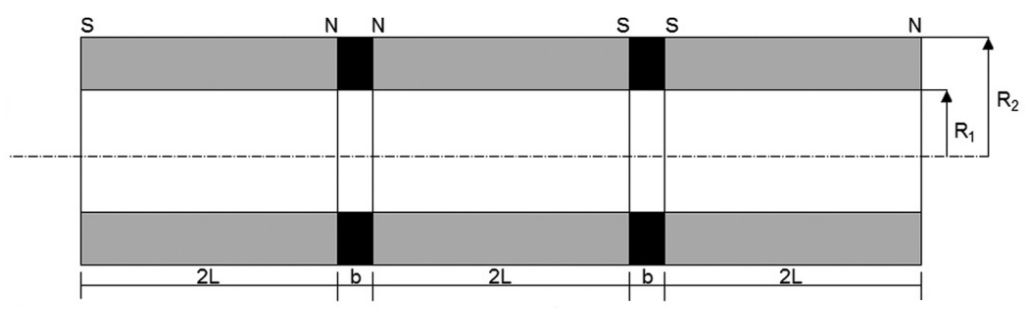

Figura 3.5: Esquema de uma estrutura de um PPM composto de ímãs permanentes toroidais de raios interno e externo $\mathrm{R}_{1}$ e $\mathrm{R}_{2}$, respectivamente, espessura externa de $2 \mathrm{~L}$ tendo uma separação entre os ímãs de $b$. A polaridade dos ímãs também está representada na figura [27].

Os parâmetros de entrada do PPM são: o raio interno $R_{1}$, o raio externo $R_{2}$, a espessura $2 L$, a magnetização $M$ de cada ímã permanente e o vetor posição, em coordenadas cilíndricas, é dado por $\vec{r}(t)=\rho \widehat{\rho}+z \widehat{k}$. 
A geometria utilizada para se determinar o campo magnético devido a apenas um ímã permanente é apresentada na FIG. 3.6.

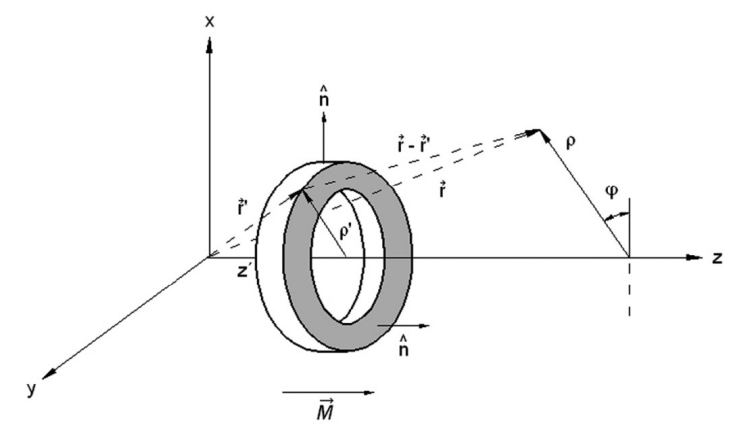

Figura 3.6: Geometria de um ímã permanente utilizada para se determinar o campo magnético $\vec{B}(\vec{r})$ [27].

O campo magnético $\vec{B}(\vec{r})$ pode ser obtido a partir do potencial magnético $\psi(\vec{r})$, sabendo-se que $\vec{B}(\vec{r})=-\nabla \psi(\vec{r})$ e

$$
\psi(\vec{r})=\frac{1}{4 \pi} \int \frac{\vec{M}(\vec{r}) \cdot \widehat{n}}{|\vec{r}-\vec{r}|} d S^{\prime}
$$

onde: $M$ é a magnetização, $\vec{r}$ é a posição onde se deseja determinar o potencial magnético, $\vec{r}$ 'é a posição do termo fonte, $\widehat{n}$ é o vetor unitário normal à superfície do ímã permanente $\mathrm{e}$ $d S^{\prime}=\rho^{\prime} d \rho^{\prime} d \varphi^{\prime}$. O termo $|\vec{r}-\vec{r}|$ pode ser expresso como [28]:

$$
\begin{aligned}
\frac{1}{|\vec{r}-\vec{r}|}= & \frac{4}{\pi} \int_{0}^{\infty} d k \cos [k(z-z)]\left\{\frac{1}{2} I_{o}\left(k \rho_{<}\right) K_{o}\left(k \rho_{>}\right)+\right. \\
& \left.+\sum_{m=0}^{\infty} \cos [m(\varphi-\varphi)] I_{m}\left(k \rho_{<}\right) K_{m}\left(k \rho_{>}\right)\right\}
\end{aligned}
$$

onde : $I_{m}$ e $K_{m}$ são as funções de Bessel modificadas de ordem $m$ do primeiro e segundo tipo respectivamente. Substituindo a expressão acima em 3.55, utilizando as propriedades de ortogonalidade, é possível demonstrar para a face à direita do ímã (em destaque na FIG. 3.6), que o potencial escalar magnético, $\psi_{d}(\vec{r})$, é dado por:

$$
\psi_{d}(\vec{r})=\frac{M}{\pi} \int_{0}^{\infty} d k \cos [k(z-z)] \int_{R_{1}}^{R_{2}} I_{o}\left(k \rho_{<}\right) K_{o}\left(k \rho_{>}\right) \rho^{\prime} d \rho^{\prime}
$$

\subsubsection{Determinação $B_{z}(\vec{r})$ :}

Neste caso, a partir de 3.57, demonstra-se que a componente axial do campo magnético é dada por: 


$$
\begin{aligned}
B_{z}(\vec{r})= & \frac{M}{\pi} \int_{0}^{\infty} d k \operatorname{sen}[k(z-L)] I_{0}(k \rho) \times\left[\left(R_{2}\right) K_{1}\left(k R_{2}\right)-\left(R_{1}\right) K_{1}\left(k R_{1}\right)\right] \\
& -\frac{M}{\pi} \int_{0}^{\infty} d k \operatorname{sen}[k(z+L)] I_{0}(k \rho) \times\left[\left(R_{2}\right) K_{1}\left(k R_{2}\right)-\left(R_{1}\right) K_{1}\left(k R_{1}\right)\right] .
\end{aligned}
$$

O campo magnético no eixo de simetria é obtido a partir de 3.58 considerando $\rho=0$, assim:

$$
\begin{aligned}
B_{z}(0, z)= & \frac{M}{\pi} \int_{0}^{\infty} d k\{\operatorname{sen}[k(z-L)]-\operatorname{sen}[k(z+L)]\} \times \\
& {\left[\left(R_{2}\right) K_{1}\left(k R_{2}\right)-\left(R_{1}\right) K_{1}\left(k R_{1}\right)\right], }
\end{aligned}
$$

uma vez que $I_{0}(0)=1$. A equação acima pode ser resolvida a partir do resultado da integral [29]:

$$
\int_{0}^{\infty} K_{1}(k a) \operatorname{sen}(k z) d k=\frac{\pi}{2 a} \frac{z}{\sqrt{z^{2}+a^{2}}} .
$$

Ajustando os termos e substituindo, essa última expressão em 3.59, tem-se que a intensidade do campo magnético axial no eixo de simetria é dado por:

$$
\begin{aligned}
B_{z}(0, z)= & \frac{M}{2}\left\{\left[\frac{z+L}{\sqrt{(z+L)^{2}+R_{2}^{2}}}-\frac{z-L}{\sqrt{(z-L)^{2}+R_{2}^{2}}}\right]-\right. \\
& {\left.\left[\frac{z+L}{\sqrt{(z+L)^{2}+R_{1}^{2}}}-\frac{z-L}{\sqrt{(z-L)^{2}+R_{1}^{2}}}\right]\right\} . }
\end{aligned}
$$

\subsubsection{Determinação $B_{\rho}(\vec{r})$ :}

A partir de 3.57 se obtém a componente radial do campo magnético:

$$
\begin{aligned}
B_{\rho}(\vec{r})= & \left.\frac{M}{\pi}\left\{\int_{0}^{\infty} d k \cos [k(z-L)] I_{1}(k \rho) \times\left[\left(R_{2}\right) K_{1}\left(k R_{2}\right)-\left(R_{1}\right) K_{1}\left(k R_{1}\right)\right](3.6)\right] I_{1}(k \rho) \times\left[\left(R_{2}\right) K_{1}\left(k R_{2}\right)-\left(R_{1}\right) K_{1}\left(k R_{1}\right)\right]\right\} \\
& -\int_{0}^{\infty} d k \cos [k(z+L)
\end{aligned}
$$

O campo magnético radial no eixo de simetria, é obtido a partir de 3.62 considerando $\rho=0$, o qual é nulo pois $I_{1}(0)=0$. 


\subsubsection{Determinação $B_{z}(\vec{r})$ no eixo de simetria de um PPM com $N$ ímãs permanentes}

Pode-se, utilizando o princípio de superposição, mostrar que a componente do campo magnético na direção axial para um conjunto de $N$ ímãs permanentes é dada por:

$$
\begin{aligned}
B_{z}(0, z)= & \frac{M}{2} \sum_{i=0}^{N-1}(-1)^{i}\left\{\left[\frac{z+L-i(2 L+b)}{\sqrt{[z+L-i(2 L+b)]^{2}+R_{2}^{2}}}-\frac{z-L-i(2 L+b)}{\sqrt{[z-L-i(2 L+b)]^{2}+R_{2}^{2}}}\right]\right. \text { (3.63) } \\
& \left.-\left[\frac{z+L-i(2 L+b)}{\sqrt{[z+L-i(2 L+b)]^{2}+R_{1}^{2}}}-\frac{z-L-i(2 L+b)}{\sqrt{[z-L-i(2 L+b)]^{2}+R_{1}^{2}}}\right]\right\},
\end{aligned}
$$

onde $b$ é a separação entre dois ímãs permanentes adjacentes.

Baseado no mesmo princípio, a partir da expressão integral do campo magnético $B_{z}(\vec{r})$ para um ímã permanente 3.58, pode-se estabelecer o campo de um PPM com $N$ ímãs permanentes em qualquer ponto em seu interior, $\rho<R_{1}$, como sendo:

$$
\begin{aligned}
B_{z}(\vec{r})= & \frac{M}{\pi} \sum_{i=0}^{N-1}(-1)^{i} \int_{0}^{\infty} d k\{\operatorname{sen}[k(z-L-i(2 L+b))] \\
& -\operatorname{sen}[k(z+L-i(2 L+b))]\} \times\left[\left(R_{2}\right) K_{1}\left(k R_{2}\right)-\left(R_{1}\right) K_{1}\left(k R_{1}\right)\right] .
\end{aligned}
$$

\subsection{Estrutura de Focalização - PPM para Ímãs toroidais separados por Pole Piece}

É possível, utilizando pole piece, obter intensidades maiores do campo magnético no interior de um PPM que aquele com ímãs permanentes separados pelo vácuo. O pole piece oferece um caminho de menor relutância ao fluxo magnético, concentrando-o e direcionandoo ao interior da estrutura do PPM. Pole pieces que apresentam elevada permeabilidade são utilizados em estruturas do tipo PPM uma vez que, construir ímãs permanentes com formas complexas, é difícil. Neste seção são apresentados três modelos de estruturas infinitas do tipo PPM com pole piece. Estes modelos apresentam evoluções no entendimento do problema, os quais foram continuamente aprimorados. É apresentado, inicialmente, os principais resultados obtidos por Chang, em seguida por Sterzer e, finalmente, por Santra.

Chang [30] estudou o problema de um PPM de acordo com o modelo representado na FIG. 3.7. $M$ representa os ímãs permanentes os quais possuem forma anular e são magnetizados na direção axial. Os ímãs são montados entre os pole pieces de acordo com as polaridades indicadas na figura.

A abordagem adotada por Chang considera que, para a região interna da estrutura do PPM, $R<R_{1}$, os pole pieces servem como uma fronteira cujo potencial escalar magnético na superfície, para $\rho=R_{1}$, varia de acordo com o ilustrado na parte inferior da FIG. 3.8. Neste caso, considerando uma estrutura infinita com espessura desprezível, as superfícies 


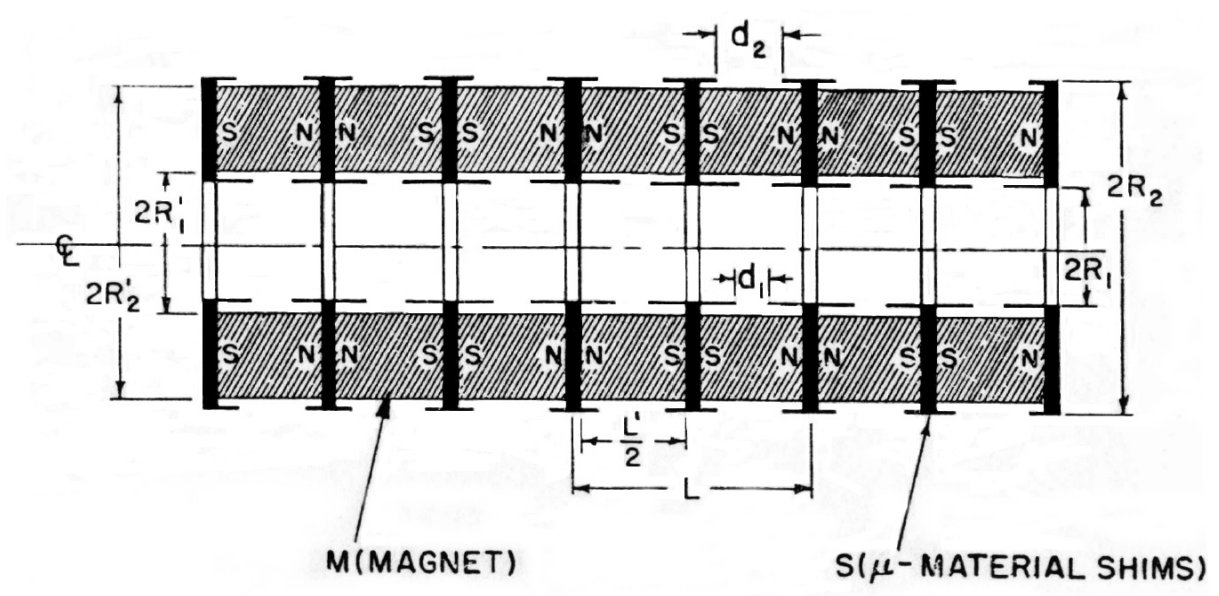

Figura 3.7: Estrutura do PPM estudado por Chang.

equipotenciais magnéticas do pole piece são periódicas. Considera-se ainda que o potencial escalar magnético varia linearmente entre pole pieces adjacentes.

A análise para o caso $R>R_{2}$ é similar. A separação entre os pole pieces e o raio da superfície externa do PPM, representados na parte inferior da FIG. 3.8, devem ser substituídos: onde se lê $d_{1} / 2$ e $R_{1}$, lê-se $d_{2} / 2$ e $R_{2}$ respectivamente.

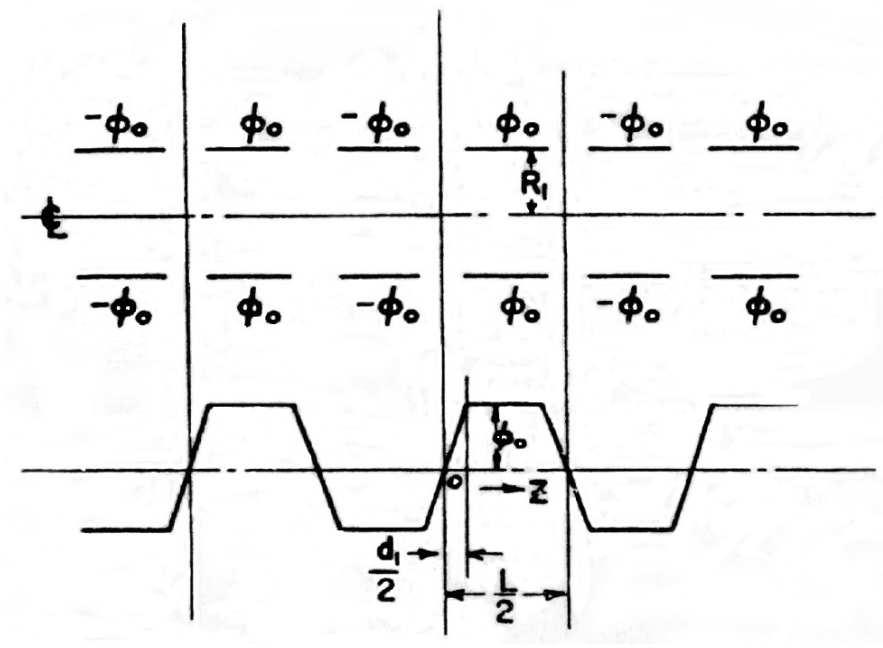

Figura 3.8: Distribuição do potencial escalar magnético na superfície interna da estrutura do PPM apresentado na FIG. 3.7.

Considerando a simetria axial e a geometria cilíndrica do PPM, o potencial escalar magnético é obtido resolvendo-se a equação de Laplace (em coordenadas cilíndricas):

$$
\nabla^{2} \phi(\rho, z)=\frac{1}{\rho} \frac{\partial}{\partial \rho}\left(\rho \frac{\partial \phi}{\partial \rho}\right)+\frac{\partial^{2} \phi}{\partial z^{2}}=0 .
$$




\subsubsection{Potencial Escalar Magnético para $\rho<R_{1}$}

Utilizando o método de separação de variáveis é possível mostrar que o potencial escalar magnético $\phi_{1}(\rho, z)$, solução de 3.65 para $\rho<R_{1}$, tem a forma:

$$
\phi_{1}(\rho, z)=\sum_{n=1}^{\infty} A_{n 1} \operatorname{sen}\left(\frac{2 n \pi}{L} z\right) I_{0}\left(\frac{2 n \pi}{L} \rho\right) .
$$

O potencial escalar magnético $\phi_{1}(z, \rho)$ pode ser expandido em uma série de Fourier para $\rho=R_{1}$. Neste caso:

$$
\phi_{1}\left(R_{1}, z\right)=\frac{a_{0}}{2}+\sum_{n=1}^{\infty}\left[a_{n} \cos \left(\frac{2 n \pi}{L} z\right)+b_{n} \operatorname{sen}\left(\frac{2 n \pi}{L} z\right)\right] .
$$

Uma vez que $\phi_{1}\left(R_{1}, z\right)$ é ímpar, $a_{0}=a_{n}=0$. O coeficiente de Fourier $b_{n}$ é obtido a partir de:

$$
b_{n}=\frac{2}{L} \int_{0}^{L} \phi\left(R_{1}, z\right) \operatorname{sen}\left(\frac{2 n \pi}{L} z\right) d z
$$

Portanto,

$$
\begin{aligned}
b_{n}= & \frac{2}{L} \int_{0}^{d_{1} / 2} \frac{2 \phi_{0}}{d} z \operatorname{sen}\left(\frac{2 n \pi}{L} z\right) d z+ \\
& \int_{d_{1} / 2}^{\left(L-d_{1}\right) / 2} \phi_{0} \operatorname{sen}\left(\frac{2 n \pi}{L} z\right) d z+\int_{\left(L-d_{1}\right) / 2}^{\left(L+d_{1}\right) / 2} \frac{-2 \phi_{0}}{d}\left(z-\frac{L}{2}\right) \operatorname{sen}\left(\frac{2 n \pi}{L} z\right) d z+ \\
& \left.\int_{\left(L+d_{1}\right) / 2}^{L-\frac{d}{2}}-\phi_{0} \operatorname{sen}\left(\frac{2 n \pi}{L} z\right) d z+\int_{L-\frac{d}{2}}^{L} \frac{2 \phi_{0}}{d}(z-L) \operatorname{sen}\left(\frac{2 n \pi}{L} z\right) d z\right]
\end{aligned}
$$

Integrando todos os termos acima, o coeficiente $b_{n}$ é dado por:

$$
b_{n}=\frac{2 \phi_{0} L}{d_{1}(n \pi)^{2}}\left[(1-\cos n \pi) \sin \left(\sigma_{1} n \pi\right)\right],
$$

onde:

$$
\sigma_{1}=\frac{d_{1}}{L}
$$

e, $d_{1}$ e $L$ são a separação ente os pole pieces e o período magnético respectivamente.

Tomando $\rho=R_{1}$ em 3.66 e comparando termo a termo com 3.67 determina-se o coeficiente $A_{n 1}$ : 


$$
A_{n 1}=\frac{2 \phi_{0}}{I_{0}\left(\frac{2 n \pi}{L} R_{1}\right)} \frac{(1-\cos n \pi) \sin \left(\sigma_{1} n \pi\right)}{\sigma_{1}(n \pi)^{2}} .
$$

A componente axial do campo magnético $B_{z 1}(z, \rho)$, para $0 \leqslant \rho<R_{1}$, por definição é obtida considerando:

$$
\begin{aligned}
B_{z 1}(z, \rho)= & \mu_{0} \frac{\partial \phi_{1}}{\partial z} \\
= & \mu_{0} \sum_{n=1}^{\infty} \frac{4 \phi_{0}}{L I_{0}\left(\frac{2 n \pi}{L} R_{1}\right)} \frac{(1-\cos n \pi) \sin \left(\sigma_{1} n \pi\right)}{\sigma_{1}(n \pi)^{2}} \times \\
& \cos \left(\frac{2 n \pi z}{L}\right) I_{0}\left(\frac{2 n \pi}{L} \rho\right) .
\end{aligned}
$$

Pode-se também determinar o fluxo magnético $\psi_{1}$ que atravessa o plano $z=0$, para $0 \leqslant \rho<R_{1}$, que neste caso é:

$$
\begin{aligned}
\psi_{1} & =\int_{0}^{R_{1}} B_{z 1} 2 \pi \rho d \rho \\
& =\frac{4 \mu_{0} \phi_{0} R_{1}}{\sigma_{1} \pi} \sum_{n=1}^{\infty} \frac{I_{1}\left(\frac{2 n \pi}{L} R_{1}\right)}{I_{0}\left(\frac{2 n \pi}{L} R_{1}\right)} \frac{(1-\cos n \pi) \sin \left(\sigma_{1} n \pi\right)}{n^{2}} .
\end{aligned}
$$

\subsubsection{Potencial Escalar Magnético para $\rho>R_{2}$}

É possível mostrar [30] que o potencial escalar magnético $\phi_{2}(z, \rho)$ para $\rho>R_{2}$ é igual a:

$$
\phi_{2}(\rho, z)=\sum_{n=1}^{\infty} A_{n 2} \operatorname{sen}\left(\frac{2 n \pi}{L} z\right)\left[i H_{0}^{(1)}\left(\frac{i 2 n \pi}{L} \rho\right)\right],
$$

onde: $H_{0}^{(1)}$ é a função de Hankel do primeiro tipo de ordem zero.

O coeficiente $A_{n 2}$ é determinado de modo similar ao coeficiente $A_{n 1}$ e, neste caso, é igual a:

$$
A_{n 2}=\frac{2 \phi_{0}}{i H_{0}^{(1)}\left(\frac{i 2 n \pi}{L} R_{2}\right)} \frac{(1-\cos n \pi) \sin \left(\sigma_{2} n \pi\right)}{\sigma_{2}(n \pi)^{2}},
$$

onde $\sigma_{2}=d_{2} / L$.

O campo axial externo $B_{z 2}(z, \rho)$ é obtido pela diferenciação de 3.75 em relação à distância axial $z$ : 


$$
\begin{aligned}
B_{z 2}(z, \rho)= & \mu_{0} \frac{\partial \phi_{2}}{\partial z} \\
= & \mu_{0} \sum_{n=1}^{\infty} \frac{4 \phi_{0}}{L i H_{0}^{(1)}\left(\frac{i 2 n \pi}{L} R_{2}\right)} \frac{(1-\cos n \pi) \sin \left(\sigma_{2} n \pi\right)}{\sigma_{2} n \pi} \times \\
& \cos \left(\frac{2 n \pi z}{L}\right) i H_{0}^{(1)}\left(\frac{i 2 n \pi}{L} \rho\right)
\end{aligned}
$$

para $R_{2}<\rho<\infty$.

O fluxo magnético $\psi_{2}$ que atravessa o plano $z=0$, fora do PPM é:

$$
\begin{aligned}
\psi_{2} & =\int_{R_{2}}^{\infty} B_{z 2} 2 \pi \rho d \rho \\
& =-\frac{4 \mu_{0} \phi_{0} R_{2}}{\sigma_{2} \pi} \sum_{n=1}^{\infty} \frac{H_{1}^{(1)}\left(\frac{i 2 n \pi}{L} R_{2}\right)}{i H_{0}^{(1)}\left(\frac{i 2 n \pi}{L} R_{2}\right)} \frac{(1-\cos n \pi) \sin \left(\sigma_{2} n \pi\right)}{n^{2}} .
\end{aligned}
$$

Seja a igualdade [31]:

$$
K_{\nu}(x)=\frac{\pi}{2} i^{\nu+1} H_{\nu}^{(1)}(i x),
$$

onde $K_{\nu}$ é a função de Bessel modificada do segundo tipo de ordem $\nu$. Assim:

$$
i H_{0}^{(1)}\left(\frac{i 2 n \pi}{L} \rho\right)=\frac{2}{\pi} K_{0}\left(\frac{2 n \pi}{L} \rho\right)
$$

$\mathrm{e}$

$$
-H_{1}^{(1)}\left(\frac{i 2 n \pi}{L} R_{2}\right)=\frac{2}{\pi} K_{1}\left(\frac{2 n \pi}{L} \rho\right) .
$$

Desta forma, 3.75, 3.76, 3.77 e 3.78 podem ser reescritas e são iguais respectivamente a:

$$
\begin{gathered}
\phi_{2}(\rho, z)=\sum_{n=1}^{\infty} \frac{2 \phi_{0}}{K_{0}\left(\frac{2 n \pi}{L} R_{2}\right)} \frac{(1-\cos n \pi) \sin \left(\sigma_{2} n \pi\right)}{\sigma_{2}(n \pi)^{2}} \times \\
\operatorname{sen}\left(\frac{2 n \pi}{L} z\right)\left[K_{0}\left(\frac{2 n \pi}{L} \rho\right)\right] \\
A_{n 2}=\frac{\pi \phi_{0}}{K_{0}\left(\frac{2 n \pi}{L} R_{2}\right)} \frac{(1-\cos n \pi) \sin \left(\sigma_{2} n \pi\right)}{\sigma_{2}(n \pi)^{2}} \\
B_{z 2}(z, \rho)=\frac{4 \mu_{0} \phi_{0}}{\pi \sigma_{2} L} \sum_{n=1}^{\infty} \frac{\cos \left(\frac{2 n \pi z}{L}\right) K_{0}\left(\frac{2 n \pi}{L} \rho\right)}{K_{0}\left(\frac{2 n \pi}{L} R_{2}\right)} \frac{(1-\cos n \pi) \sin \left(\sigma_{2} n \pi\right)}{n}
\end{gathered}
$$




$$
\psi_{2}=\frac{4 \mu_{0} \phi_{0} R_{2}}{\pi \sigma_{2}} \sum_{n=1}^{\infty} \frac{K_{1}\left(\frac{2 n \pi}{L} R_{2}\right)}{K_{0}\left(\frac{2 n \pi}{L} R_{2}\right)} \frac{(1-\cos n \pi) \sin \left(\sigma_{2} n \pi\right)}{n^{2}} .
$$

\subsubsection{Materiais com ímãs permanentes}

É importante conhecer as características de operação dos ímãs permanentes que produzam os campos acima para que a análise de uma estrutura baseada em ímãs permanentes esteja completa. O tamanho do ímã permanente (neste caso igual a $L^{\prime} / 2$ ) capaz de fornecer o potencial magnético $\phi_{0}$ é [32]:

$$
\frac{L^{\prime}}{4}=\frac{\phi_{0}}{H_{m}}
$$

onde $H_{m}$ é igual à força de magnetização de operação obtida a partir da curva característica de desmagnetização do material do ímã permanente. Levando em consideração que o fluxo de cada ímã é totalmente axial, a área da seção transversal do ímã permanente é dada pelo quociente entre o fluxo total $\psi_{1}+\psi_{2}$ e o campo magnético $B_{m}$ correspondente à $H_{m}$, obtido a partir da curva característica de desmagnetização do material do ímã permanente. Assim:

$$
\pi\left(R_{2}^{\prime 2}-R_{1}^{\prime 2}\right)=\frac{\psi_{1}+\psi_{2}}{B_{m}}
$$

\subsubsection{Modelos aprimorados de estruturas do tipo PPM}

A seguir são apresentados dois modelos aprimorados de estruturas do tipo PPM propostos por Sterzer et al. e Santra et al.

\section{Estrutura de Sterzer et al.}

Sterzer [33] propôs, a partir do modelo do PPM abaixo representado, FIG. 3.9, utilizando pole piece, um aprimoramento da teoria acima considerando o fluxo I entre os pole pieces, FIG. 3.10, não contabilizado no modelo anterior estudado, vide equação 3.87 .

A componente axial do campo magnético na região $0 \leqslant \rho<d_{1} / 2$, utilizando 3.73 pode ser reescrita como:

$$
B(z, \rho)=\sum_{n=1,3,5, \ldots}^{\infty} \frac{4 B_{g} \sin \left(\frac{n \pi g}{L}\right)}{n \pi I_{0}\left(\frac{n \pi}{L} d_{1}\right)} \cos \left(\frac{2 n \pi z}{L}\right) I_{0}\left(\frac{2 n \pi}{L} \rho\right),
$$

onde $B_{g}$ é o campo no entreferro do pole piece. Neste caso $B_{g}$ é dado aproximadamente por:

$$
B_{g}=\frac{F}{g}=\frac{H_{d} T}{g}
$$

onde $F$ e $T$ são a força magnetomotriz produzido pelo ímã permanente e o comprimento do ímã permanente na direção da magnetização, respectivamente. Assim, o valor máximo do campo magnético $B_{m}$ no eixo de simetria do PPM, a partir de 3.88, é: 
(a)

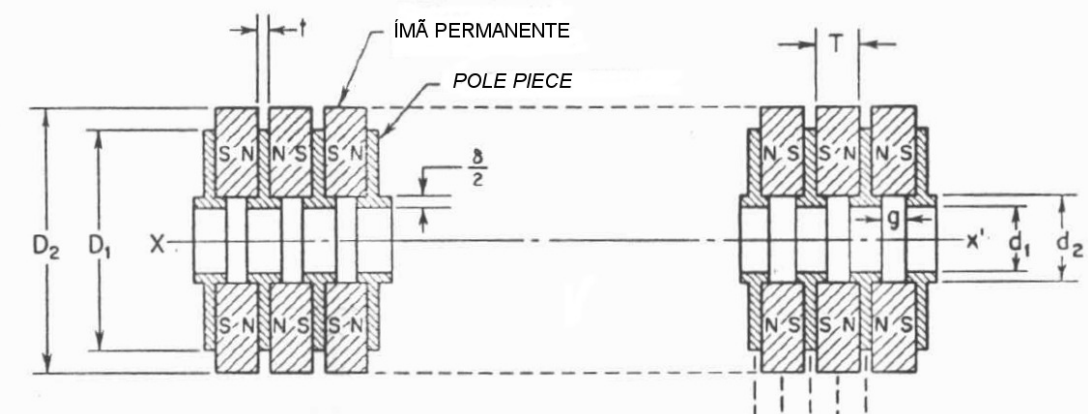

(b)

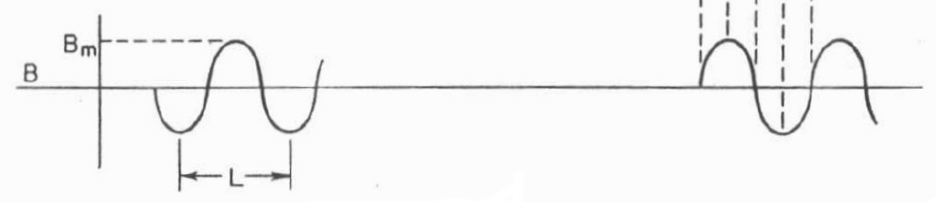

Figura 3.9: Modelo físico de uma estrutura do tipo PPM estudado por Sterzer (a) e a curva da intensidade do campo magnético em seu eixo de simetria (b).

$$
B_{m}=B_{g} \sum_{n=1,3,5, \ldots}^{\infty} \frac{4 \sin \left(\frac{n \pi g}{L}\right)}{n \pi I_{0}\left(\frac{n \pi}{L} d_{1}\right)}
$$

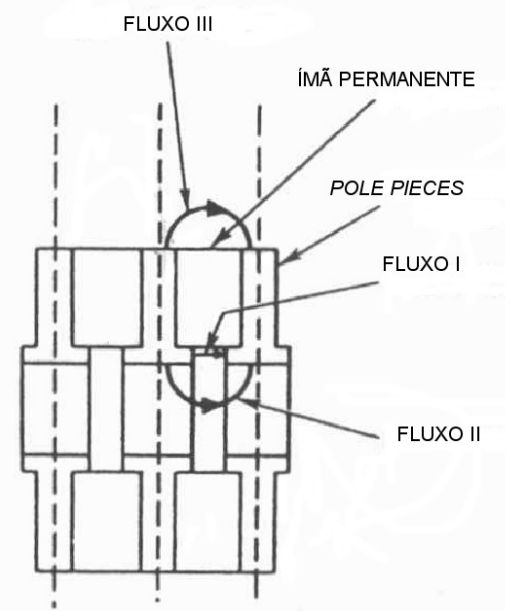

Figura 3.10: Representação dos três fluxos utilizados na determinação da permeância total do circuito magnético.

A força magnetomotriz produzida por um ímã permanente é

$$
F=H_{d} T
$$

O fluxo total produzido por um ímã permanente é, aproximadamente, dado por:

$$
\psi=B_{g} A^{\prime}
$$


onde $A^{\prime}$ é a área do ímã permanente perpendicular à direção da magnetização. A permeância $P$ de um circuito magnético é definida como:

$$
P=\frac{\psi}{F} \text {. }
$$

Para essa estrutura de PPM, utilizando 3.91 e 3.92 em 3.93, tem-se que:

$$
\frac{\psi}{F}=\frac{B_{g} A^{\prime}}{H_{d} T}=P_{T}
$$

onde $P_{T}$ é a permeância total do circuito externo ao ímã permanente. Conhecido $P_{T}$, a razão $B_{g} / H_{d}$ pode ser calculada utilizando-se 3.94. O ponto de operação é determinado pela reta de carga com inclinação $K$ :

$$
K=\frac{-T P_{T}}{A^{\prime}}
$$

obtida a partir da curva $B-H$ no segundo quadrante do material que compõe o ímã permanente.

Para ímãs permanentes que possuem características lineares de desmagnetização, FIG. 3.11, $H_{d}$ é determinado por:

$$
H_{d}=\frac{B_{r}}{\left(K+B_{r} / H_{c}\right)},
$$

onde $B_{r}$ e $H_{c}$ são a remanência e a coercividade do material magnético utilizado respectivamente.

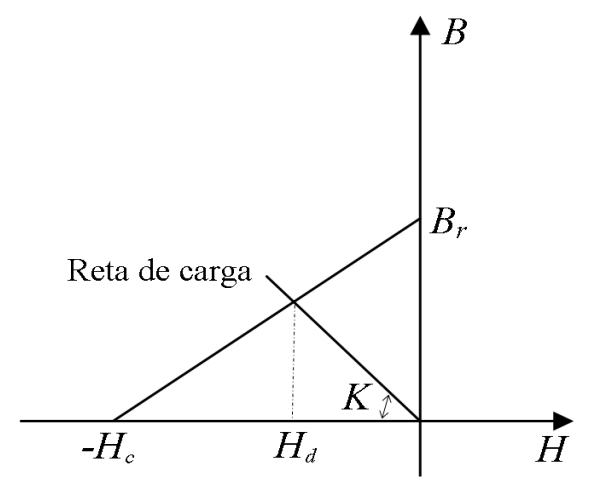

Figura 3.11: Método gráfico utilizado na determinação da intensidade de campo $H_{d}$ considerando um ímã permanente com características de desmagnetização linear.

A seguir é apresentada a metodologia utilizada para se determinar a permeância total da estrutura do PPM estudada por Sterzer et al.

\section{Determinação de $P_{T}$ para a estrutura de PPM estudada por Sterzer et al.}

A permeância total, $P_{T}$, externa ao circuito magnético é determinada a partir dos fluxos 
I, II e III, de acordo com o apresentado na FIG. 3.10. Assim,

$$
P_{T}=P_{1}+P_{2}+P_{3}
$$

A permeância no entreferro, $P_{1}$ é:

$$
P_{1}=\frac{A_{g}}{L_{g}}
$$

onde $A_{g}$ é área da seção do pole piece na região do entreferro e $L_{g}$ é a separação do entreferro. Neste caso:

$$
P_{1}=\frac{\pi\left(d_{2}^{2}-d_{1}^{2}\right)}{4 g} \approx 0,785 \frac{\left(d_{2}^{2}-d_{1}^{2}\right)}{g} .
$$

Para a determinação de $P_{2}$ e $P_{3}$, em função do novo modelo da estrutura do PPM, FIG. 3.9, sejam as mudanças de variáveis:

$$
\begin{aligned}
R_{1} & =d_{1} / 2, \\
\sigma_{1} & =g / L, \\
R_{2} & =d_{2} / 2, \\
\sigma_{2} & =T / L,
\end{aligned}
$$

e

$$
\phi_{0}=\frac{T}{2 \mu_{0}} H_{d} .
$$

Assim, $P_{2}$ é determinado a partir do fluxo na região interna da estrutura do PPM, neste caso $\psi_{1}, 3.74$. Utilizando as mudanças de variáveis acima, $\psi_{1}$ é reescrita como:

$$
\psi_{1}=\frac{2 T L d_{1}}{\pi g} \sum_{n=1,3,5, \ldots}^{\infty} \frac{I_{1}\left(\frac{n \pi}{L} d_{1}\right)}{I_{0}\left(\frac{n \pi}{L} d_{1}\right)} \frac{\sin \left(\frac{n \pi}{L} g\right)}{n^{2}} H_{d} .
$$

Desta forma,

$$
P_{2}=\frac{\psi_{1}}{F}=\frac{\psi_{1}}{H_{d} T}=\frac{2 L d_{1}}{\pi g} \sum_{n=1,3,5, \ldots}^{\infty} \frac{I_{1}\left(\frac{n \pi}{L} d_{1}\right)}{I_{0}\left(\frac{n \pi}{L} d_{1}\right)} \frac{\sin \left(\frac{n \pi}{L} g\right)}{n^{2}} .
$$

Para se determinar $P_{3}$, faz-se uso do fluxo $\psi_{2}$, existente na região externa da estrutura do PPM. Fazendo uso das mudanças de variáveis acima estabelecidas, 3.100-3.104, o fluxo $\psi_{2}$ é:

$$
\psi_{2}=\frac{2 L D_{2}}{\pi} \sum_{n=1,3,5, \ldots}^{\infty} \frac{K_{1}\left(\frac{n \pi}{L} D_{2}\right)}{K_{0}\left(\frac{n \pi}{L} D_{2}\right)} \frac{\sin \left(\frac{n \pi}{L} T\right)}{n^{2}} H_{d}
$$

Assim, 


$$
P_{3}=\frac{\psi_{2}}{F}=\frac{\psi_{2}}{H_{d} T}=\frac{2 L D_{2}}{\pi T} \sum_{n=1,3,5, \ldots}^{\infty} \frac{K_{1}\left(\frac{n \pi}{L} D_{2}\right)}{K_{0}\left(\frac{n \pi}{L} D_{2}\right)} \frac{\sin \left(\frac{n \pi}{L} T\right)}{n^{2}} .
$$

A permeância total $P_{T}$ pode ser determinada a partir da soma de 3.99, 3.106 e 3.108 . Utilizando-se, 3.95, 3.96 e 3.89, o campo magnético no interior da estrutura do PPM está completamente definido utilizando-se 3.88 para modelos em que os ímãs permanentes possuam características de desmagnetização lineares.

\section{Estrutura de Santra et al.}

Observa-se que aplicações práticas de estruturas do tipo PPM aplicadas em válvulas do tipo TWT com estruturas de ondas lentas que utilizam hélice, o raio interno do ímã permanente é aproximadamente igual ao raio externo da ponteira do pole piece $\left(r_{m 1} \sim r_{f 2}\right)$. Para válvulas do tipo TWT com cavidades acopladas, o raio interno do ímã permanente é muito maior que o raio externo do pole piece $\left(r_{m 1} \sim r_{f 2}\right)$, FIG.3.12. Estes casos foram estudados por Santra et al. [34]. O modelo abordado por Santra et al. compreende o caso particular estudado por Sterzer et al., no qual o raio interno do ímã permanente $\left(r_{m 1}\right)$ é igual ao raio externo da ponteira do pole piece $\left(r_{f 2}\right)$ e, o raio externo do ímã permanente $\left(r_{m 2}\right)$ é igual ao raio externo do pole piece $\left(r_{3}\right)$, FIG.3.12(a).

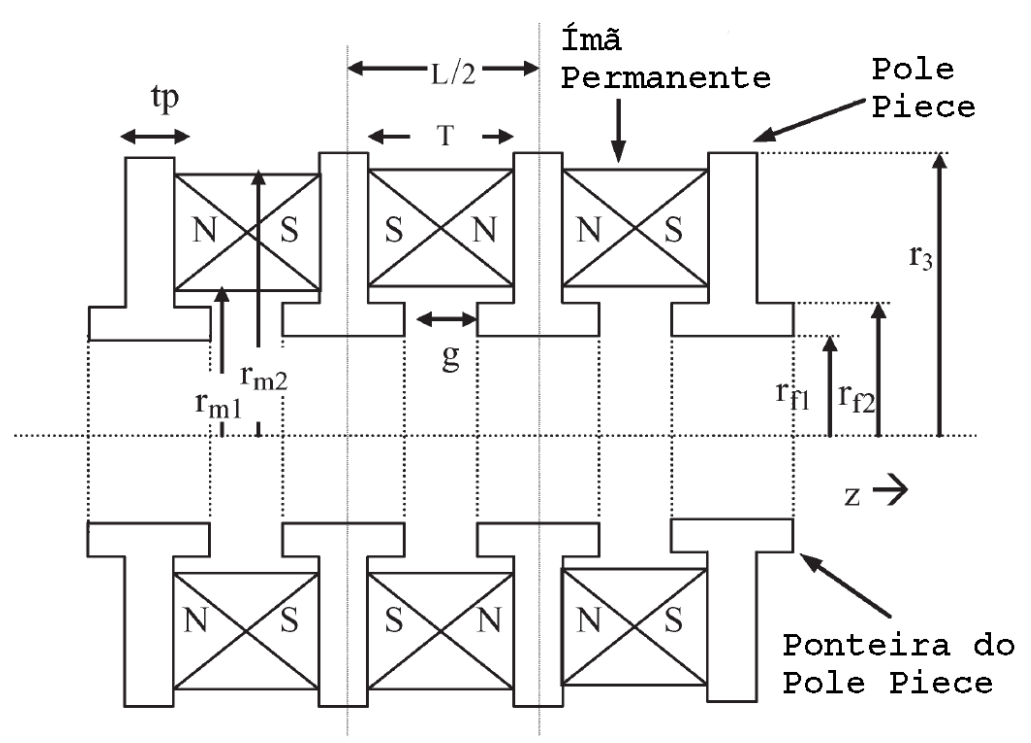

Figura 3.12: Representação do modelo da estrutura do PPM estudado por Santra et al.

A determinação da $P_{T}$ é analisada para os seguintes casos apresentados na FIG.3.13. As permeâncias $P_{1}, P_{2}$ e $P_{3}$ são comuns nos modelos estudados, sendo determinados pela abordagem de Sterzer et al., e são dados por 3.99, 3.106 e 3.108 respectivamente correspondendo ao modelo apresentado na FIG.3.13(a).

Para estruturas representadas pelo modelo da FIG.3.13(b) há dois novos fluxos cujas permeâncias $P_{4}$ e $P_{5}$ são dadas por: 


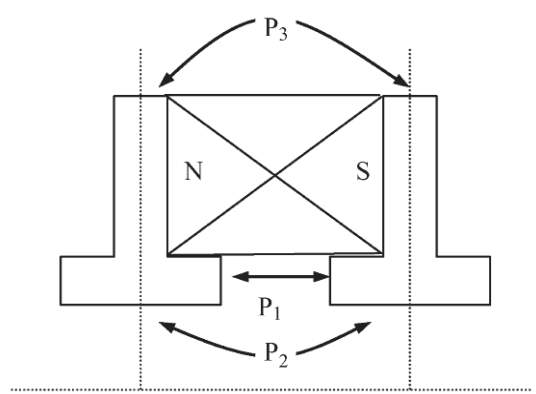

(a)

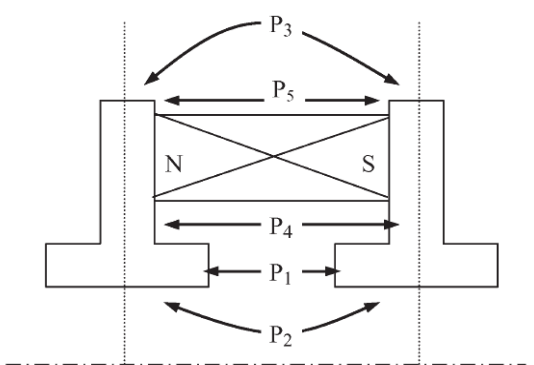

(b)

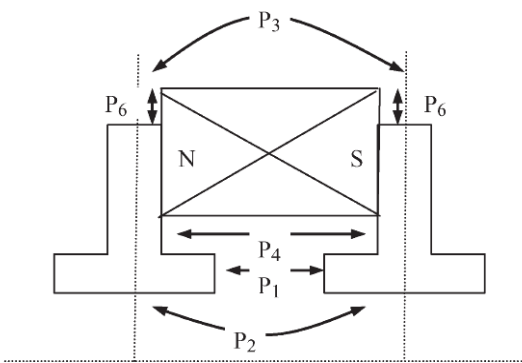

(c)

Figura 3.13: Variantes para as trajetórias dos fluxos da estrutura do PPM estudadas do Santra et al.: (a) raio interno do ímã permanente igual ao raio externo da ponteira do pole piece e raio externo ímã permanente igual ao raio externo do pole piece $\left(r_{m 1}=r_{f 2}\right.$ e $\left.r_{m 2}=r_{3}\right)$; (b) raio interno do ímã permanente maior que o raio externo da ponteira do pole piece e raio externo ímã permanente menor que o raio externo do pole piece $\left(r_{m 1}>r_{f 2}\right.$ e $\left.r_{m 2}<r_{3}\right)$; e (c) raio interno do ímã permanente maior que o raio externo da ponteira do pole piece e raio externo ímã permanente maior que o raio externo do pole piece $\left(r_{m 1}>r_{f 2}\right.$ e $\left.r_{m 2}>r_{3}\right)$. 


$$
P_{4}=\frac{\pi\left(r_{m 1}^{2}-r_{f 2}^{2}\right)}{T}
$$

e,

$$
P_{5}=\frac{\pi\left(r_{3}^{2}-r_{m 2}^{2}\right)}{T}
$$

onde: $r_{m 1}$ é o raio interno do ímã permanente, $r_{f 2}$ é o raio externo da ponteira do pole piece, $r_{3}$ é o raio externo do pole piece, $r_{m 2}$ é o raio externo do ímã permanente e $T$ é a espessura do ímã permanente. Assim, para esta estrutura, FIG.3.13(b), a permeância total é dada por:

$$
P_{T}=P_{1}+P_{2}+P_{3}+P_{4}+P_{5} .
$$

O modelo apresentado na FIG.3.13(c) possui uma estrutura na qual há um entalhe pole piece, ou seja, o raio externo do ímã permanente é maior que o raio externo do pole piece e, neste caso, a permeância $P_{5}$ não é considerada e a permeância $P_{3}$ é modificada devido à endentação do pole piece. Assim, neste caso em particular, $P_{3}$ verá duas permeâncias idênticas $P_{6}$ em série, a partir dos dois lados do ímã permanente, onde $P_{3}$ e $P_{6}$ estão em paralelo. Considerando o caso em que o entalhe no pole piece é pequeno, $P_{6}$ é dado por:

$$
P_{6}=\frac{\pi\left(r_{m 2}+r_{3}\right)}{\left(r_{m 2}-r_{3}\right)} t_{p} / 2
$$

onde $t_{p}$ é a espessura do pole piece. Assim a permeância $P_{3}$ é modificada:

$$
P_{3 m}=\frac{P_{3} \cdot 2 P_{6}}{P_{3}+2 P_{6}}
$$

Neste caso a permeância total do modelo apresentado na FIG.3.13(c) é:

$$
P_{T}=P_{1}+P_{2}+P_{3 m}+P_{4}
$$

Mais uma vez, determinando a permeância total, $P_{T}$, em função do modelo utilizado, por meio das equações 3.95, 3.96 e 3.89, o campo magnético no interior da estrutura do PPM está completamente definido utilizando-se 3.88 para modelos nos quais os ímãs permanentes possuam características de desmagnetização lineares.

A título de exemplo, considere a geometria de um PPM em que os ímãs permanentes são separados pelo vácuo, FIG. 3.5, com a geometria indicada na TAB. 3.2.

Tabela 3.2: Parâmetros geométricos da estrutura do PPM cujos ímãs permanentes são separados pelo vácuo.

\begin{tabular}{ccc}
\hline Parâmetro & Valor & Unidade \\
$R_{1}$ & 9,0 & $\mathrm{~mm}$ \\
$R_{2}$ & 16,0 & $\mathrm{~mm}$ \\
$2 L$ & 10,0 & $\mathrm{~mm}$ \\
$b$ & 2,0 & $\mathrm{~mm}$ \\
\hline
\end{tabular}


Utilizando 3.63 é apresentado, a seguir, nas FIG. 3.14-3.16, a intensidade do campo magnético na direção axial para um conjunto de 1, 3 e 10 ímãs permanentes com a geometria da TAB. 3.2 considendo a magnetização $M$ dos ímãs permanentes como sendo de $1,3 \mathrm{~A} / \mathrm{m}$.

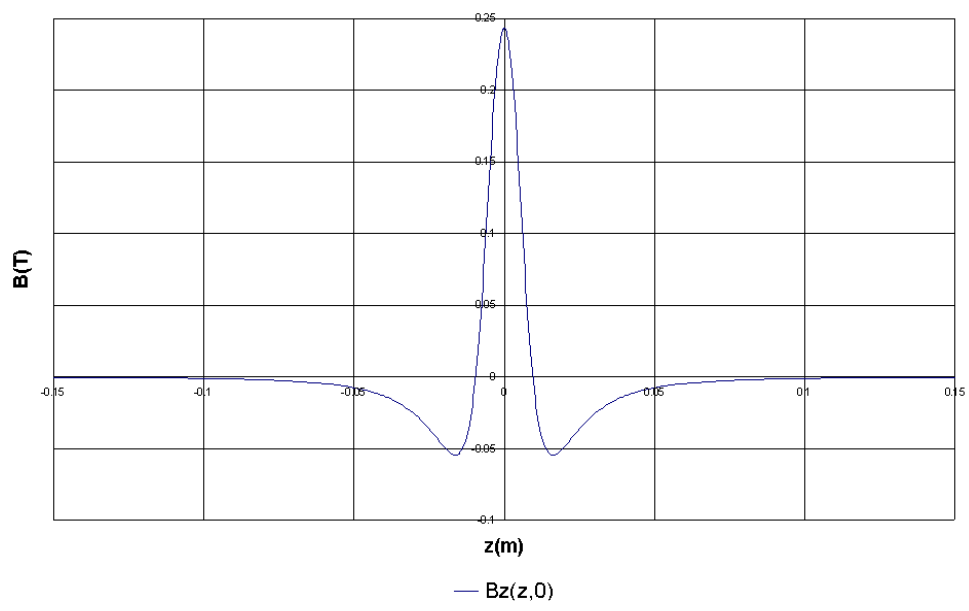

Figura 3.14: Perfil do campo magnético axial no eixo de simetria devido a 1 ímã permanente no vácuo.

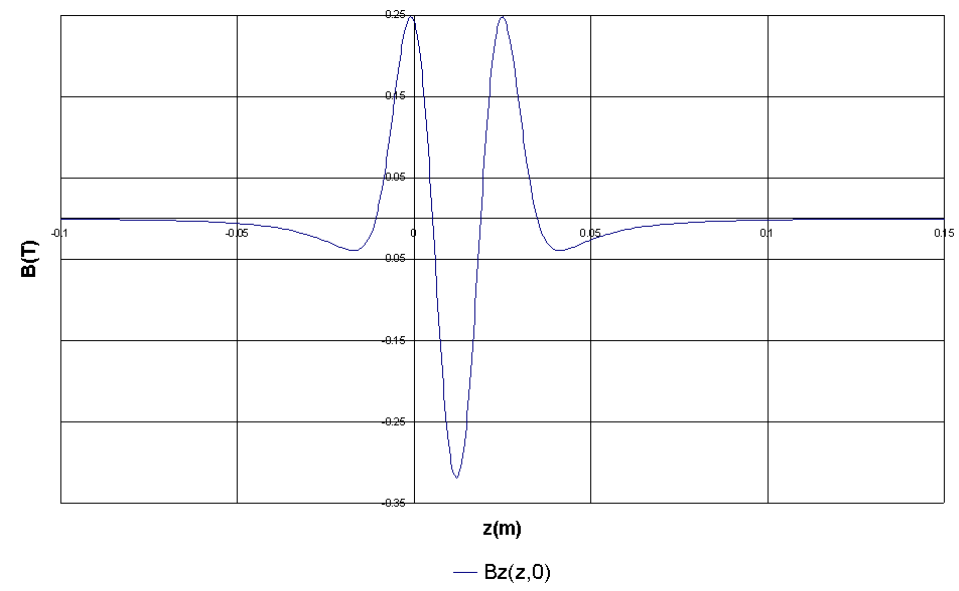

Figura 3.15: Perfil do campo magnético axial no eixo de simetria devido a 3 ímãs permanentes separados pelo vácuo.

\subsection{Conclusões do Capítulo}

Este Capítulo abordou estruturas do tipo PPM para confinar um feixe de elétrons na região de deriva. Inicialmente foi descrito o princípio de funcionamento e os componentes de um PPM típico. Em seguida, foi demonstrado que, para uma estrutura de focalização do tipo solenóide, a intensidade do campo magnético necessário para confinar um feixe de elétrons, com comportamento de um fluxo de Brillouin, transportando uma corrente $I$, cintura $a$ e velocidade axial $v_{z}$ é proporcional a $B_{z} \propto(1 / a)\left(I / v_{z}\right)^{1 / 2}$. Já, em uma estrutura 


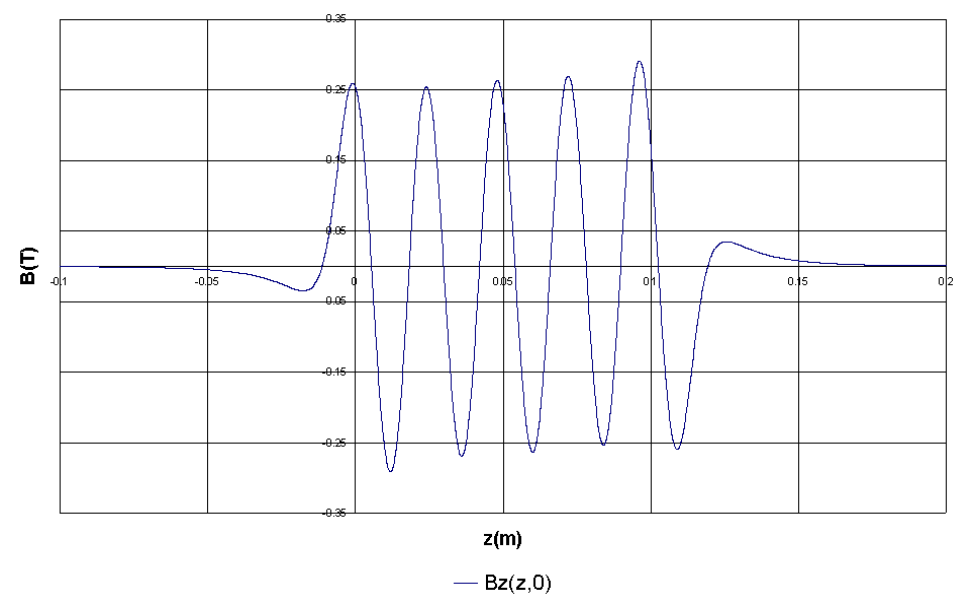

Figura 3.16: Perfil do campo magnético axial no eixo de simetria devido a 10 ímãs permanentes separados pelo vácuo.

do tipo PPM, o campo magnético $B_{p}$, deve ser, no mínimo, $B_{p}=\sqrt{2} B_{z}$ cujo período magnético $L$ deve ser $L<14,44\left(v_{z} / \eta B_{p}\right)$. Em seguida foram estudadas estruturas do tipo PPM separados pelo vácuo e com pole piece. Para o PPM com $N$ ímãs permanentes separados pelo vácuo foram determinados os campos magnéticos axial e radial em todo o domínio do problema. Para o PPM com pole piece, os campos no interior da estrutura foram determinados considerando uma estrutura infinita de pole pieces e ímãs permanentes. Este Capítulo é encerrado apresentando os resultados do comportamento do campo magnético axial no eixo de simetria devido a um arranjo de PPM com 1, 3 e 10 ímãs permanentes separados pelo vácuo. 


\section{Capítulo 4}

\section{O problema do coletor de elétrons considerando a emissão de elétrons secundários}

Nos Capítulos anteriores foram apresentados os problemas de formação (canhão de elétrons) e de transporte do feixe de elétrons na região de deriva (PPM). A estrutura responsável por coletar o feixe de elétrons após deixar a região de deriva, bem como, completar o circuito elétrico é denominada de coletor. No coletor, o feixe de elétrons diverge, uma vez que o campo magnético gerado pela estrutura de focalização não mais atua sobre o feixe de elétrons, desta forma, ele está sujeito, tão somente, à ação das cargas espaciais. Os elétrons do feixe irão colidir com a superfície do coletor com uma velocidade relativamente elevada. Boa parte da energia do feixe de elétrons, com a colisão, é disperdiçada e convertida em calor sendo disperdiçada. Neste caso, tipicamente, $50 \%$ da potência do feixe é dissipada no coletor em forma de calor [18]. Atualmente, boa parte dos esforços, para o projeto de válvulas do tipo TWT, estão voltados para o desenvolvimento de coletores que promovam uma melhor eficiência do sistema.

Presentemente, os coletores são desenvolvidos, de modo geral, com 3 (três) ou 4 (quatro) estágios. Cada estágio é projetado para capturar um determinado espectro de energia do feixe de elétrons. Um efeito decorrente da colisão dos elétrons do feixe, denominados de primários, com a superfície do coletor é a emissão de elétrons secundários. Há emissão de dois tipo de elétrons secundários: primários (emitidos com baixa energia) e secundários (energia, aproximadamente, igual a energia de incidência do elétron primário). O ruído balístico é resultado da emissão aleatória de elétrons, ou a partir do catodo ou a patir da colisão dos elétrons primários com a superfície do coletor. A produção de corrente entre os eletrodos do coletor, devido a emissão de elétrons secundários, aquece os eletrodos reduzindo a eficiência do sistema. Caso parte da corrente, devido aos elétrons secundários, escape do coletor em direção à região de deriva, haverá geração de ruído no circuito de RF, seja pela interceptação com a estrutura de ondas lentas ou pela interação com o sinal de RF [18]. Desta forma o problema do coletor de simples ou múltiplos estágios é definido como sendo:

"Dado um feixe de elétrons, transportando uma corrente $I_{o}$, com veloci- 
dade $v_{z}$, qual a geometria e tensão/tensões do(s) eletrodo(s) do coletor que promoverão a máxima eficiência de conversão com a menor produção de elétrons secundários?"

Neste Capítulo são apresentados, de forma simplificada, (a) um coletor de simples estágio, que exemplifica de que forma o coletor pode ser utilizado para melhoria do desempenho de uma válvula de micro-ondas e (b) dois modelos de emissão de elétrons secundários. $\mathrm{O}$ primeiro, ainda que de fácil compreensão, foi adotado pela NASA em 1986 [35] o qual considera para cada elétron primário, a emissão de um elétron secundário verdadeiro de baixa energia (tipicamente de $10 \mathrm{eV}$ ) e um elétron secundário espalhado cuja energia é, aproximadamente, a mesma do elétron primário. O segundo, proposto por Vaughan [36]-[37] e por Reimer [40], é utilizado pelos códigos MICHELLE [9] e Electron Optics Simulator (EOS) [38], no desenvolvimento de coletores do tipo MDC para válvulas do tipo TWT. Neste modelo o número de elétrons secundários emitidos não é constante, mas função do material, da energia e do ângulo do elétron primário de incidência. Este modelo considera ainda dois tipos de elétrons secundários espalhados: os elétrons secundários espalhados elasticamente e os inelásticamente.

\subsection{Recuperação de energia em coletores}

Define-se a eficiência global $\eta_{e g}$ de uma válvula como sendo a razão entre a potência de saída do sinal de $\mathrm{RF}\left(P_{s}\right)$ pela potência elétrica total de entrada $\left(P_{e}\right)$. A melhoria da eficiência pode ser explicada considerando o seguinte exemplo [18]: seja o modelo simplificado de uma válvula TWT, FIG. 4.1. O coletor tem o mesmo potencial do tubo, $-10 \mathrm{kV}$, sendo drenada uma corrente do catodo de $1 \mathrm{~A}$ e produzido um sinal cuja potência de RF de saída é de $P_{s}=2$ kW. Neste caso, a eficiência global é: $\eta_{e g}=P_{s} / P_{e}=2 \mathrm{~kW} /(10 \mathrm{kV} \times 1 \mathrm{~A})=20 \%$.

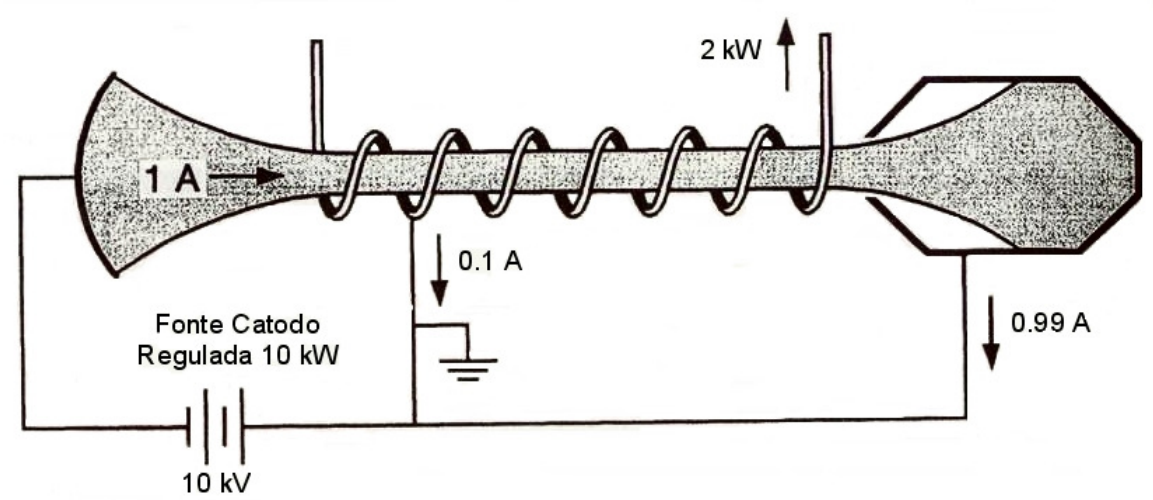

Figura 4.1: Modelo simplificado de uma válvula tipo TWT em que o coletor está com o mesmo potencial do corpo do tubo.

Considere agora um modelo em que uma segunda fonte de alimentação é ligada ao coletor, FIG. 4.2. Neste caso, a potência total fornecida à válvula é a mesma do exemplo anterior, 
portanto a eficiência também é de $20 \%$. Porém, neste caso, para a geração do sinal de RF a fonte do catodo pode ser regulada para fornecer apenas $100 \mathrm{~W}$. Este aspecto é relevante para as válvulas que operam no modo pulsado, uma vez que a complexidade do projeto da fonte do catodo de $100 \mathrm{~W}$ é menor quando comparada com aquela de $10 \mathrm{~kW}$. Assim, embora não seja observado ganho de eficiência, uma redução significativa de complexidade para o projeto da fonte do catodo é conseguida.

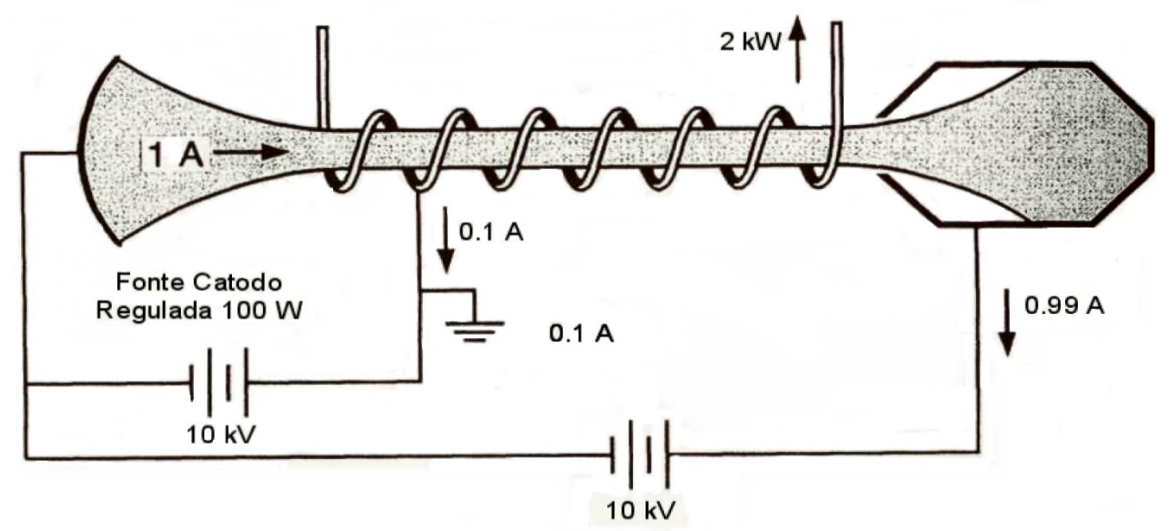

Figura 4.2: Modelo simplificado de uma válvula tipo TWT em que uma segunda fonte de alimentação de $10 \mathrm{kV}$ é utilizada no coletor.

Se, entretanto, o valor nominal da tensão da fonte de alimentação do coletor for reduzida (depressed) para um valor abaixo do valor nominal da tensão do corpo da válvula, as velocidades dos elétrons que colidem com o coletor e o calor emitido serão reduzidos. Considerase, neste caso, que o coletor recuperou alguma energia do feixe de elétrons. Portanto, caso a tensão da fonte do coletor seja reduzida para $6 \mathrm{kV}$, FIG. 4.3, a potência fornecida pela fonte é reduzida para $5940 \mathrm{~W}$. Sendo a potência do sinal de RF de $2 \mathrm{~kW}$ a eficiência global passa a ser de $\eta_{\text {eg }}=2 \mathrm{~kW} /(100 \mathrm{~W}+5940 \mathrm{~W})=33 \%$, ou seja, uma melhoria superior em mais de $50 \%$ em relação ao modelo anterior.

Atualmente, coletores com elevada eficiência, fazem uso de diversos eletrodos com diferentes potenciais os quais, seletivamente, coletam os elétrons em diferentes níveis de energia. Estes coletores, mais complexos, são denominados de Multistage Depressed Collectors (MDC).

\subsection{Emissão Simplificada de Elétrons Secundários em MDC}

O objetivo principal de um MDC é recuperar a energia do feixe de elétrons. Existem basicamente duas formas de aprimorar a eficiência de uma válvula do tipo TWT: melhorando, ou o sistema em que ocorre a iteração do feixe de elétrons com a estrutura de ondas lentas, ou o sistema de recuperação de energia do feixe para uso posterior. Para as válvulas do tipo TWT, a busca para melhoria em eficiência é centralizada na minimização do calor dissipado 


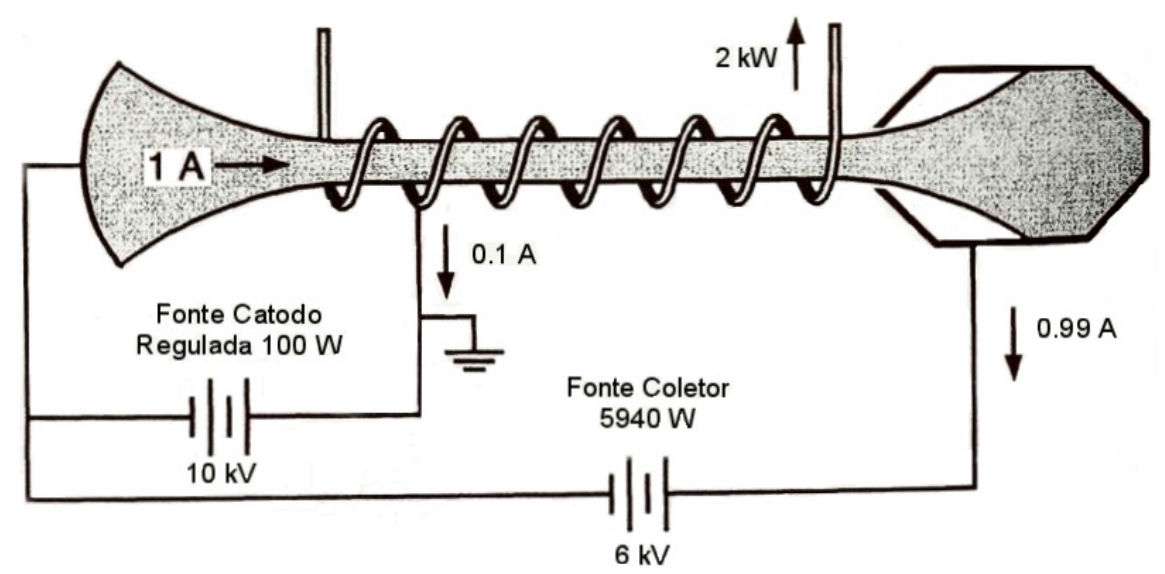

Figura 4.3: Modelo simplificado de uma válvula tipo TWT em que a segunda fonte de alimentação do coletor seja de $6 \mathrm{kV}$.

pelo coletor do tipo MDC [39]. Um bom projeto de um MDC proporciona uma considerável melhoria da eficiência de toda a válvula de micro-ondas do tipo TWT [18].

$O$ feixe de elétrons, ao deixar a região de deriva, ainda possui boa parte da energia cinética inicial, a qual deve ser recuperada para a obtenção de eficiência máxima. A recuperação desta energia se dá por meio do uso de coletores do tipo MDC, nos quais os eletrodos do coletor estão com potenciais negativos relativos ao da região de deriva, e promovem uma desaceleração do feixe de elétrons. O objetivo desta desaceleração é minimizar a energia perdida em forma de calor, decorrente da colisão dos elétrons do feixe com os eletrodos do coletor e, portanto, melhorar a eficiência global. Tendo o feixe de elétrons uma faixa variável de energia cinética, atualmente são utilizados de 3 (três) a 5 (cinco) estágios com diferentes potenciais, que permitem recuperar mais energia que aquele coletor com apenas um estágio. Faz-se necessário, ainda, projetar o coletor do tipo MDC de modo que impeça/minimize os elétrons secundários de fluírem do coletor de volta para a região de deriva. Este fluxo, além de poder danificar a estrutura de ondas lentas interage com o sinal de RF que viaja em sentido contrário produzindo ruído [18].

Elétrons secundários são tipicamente gerados a partir da colisão entre os elétrons primários do feixe com a superfície do eletrodo do coletor. É possível gerar também elétrons secundários a partir da colisão de elétrons secundários, sendo aqueles denominados de elétrons secundários de segunda geração. $\mathrm{O}$ uso de ferramentas computacionais capazes de simular com boa precisão coletores do tipo MDC, considerando a emissão de elétrons secundários, levam a projetos com melhor desempenho, minimizando o número de experimentação física, o custo e o tempo de projeto.

O modelo típico do espectro de energia para a emissão de elétrons secundários é apresentado na FIG. 4.4.

Um modelo preciso para a emissão de elétrons secundários, leva em consideração três tipos de partículas. O primeiro tipo é o elétron secundário verdadeiro, denominado de SSE (true secondary electron). Os elétrons secundários verdadeiros são emitidos com energias 


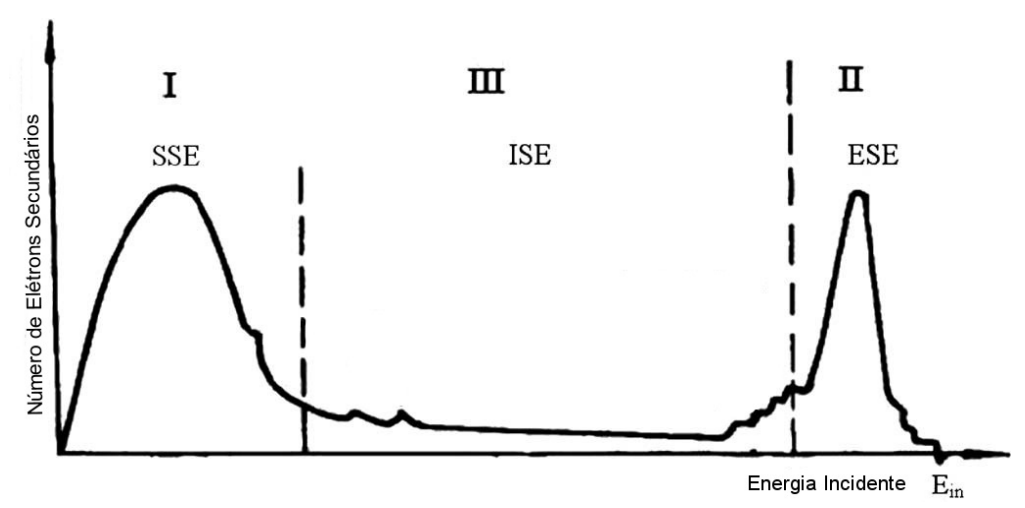

Figura 4.4: Espectro típico de energia de emissão de elétrons secundários.

inferiores, tipicamente, à $50 \mathrm{eV}$. Os outros dois tipos são derivados dos elétrons secundários espalhados BSE (backscattered secondary electrons): (a) os elétrons espalhados elasticamente, ESE (elastically scattered electron), e (b) os elétrons espalhados inelasticamente, ISE (inelastically scattered electron). A seguir são apresentados os dois modelos estudados para as emissões de elétrons secundários. O primeiro utilizado pela NASA em 1986 [35] e o segundo proposto por Vaughan [36]-[37] em 1993. Ao se referir, nas seções deste Capítulo, à corrente transportada por um elétron secundário/primário, subentende-se que se trata, na verdade, da corrente transportada pela macropartícula secundária/primária.

\subsubsection{Emissão de Elétrons Secundários: modelo simplificado}

Toda a superfície ao sofrer o bombardeamento de elétrons primários, podem produzir elétrons secundários. O número de elétrons secundários, resultante da incidência de um elétron primário é denominado de produto de elétron secundário $\delta$ (secondary electron yield - $S E Y$ ). Os elétrons secundários são emitidos em uma larga faixa de ângulos e energias. Uma boa aproximação inicial, entretanto, considera dois tipos de emissão: (a) elétrons secundários verdadeiros, os quais deixam a superfície de colisão com energia inferior a $50 \mathrm{eV}$, e (b) elétrons secundários espalhados que deixam a superfície de colisão com, aproximadamente, a mesma energia dos elétrons primários incidentes conforme apresentado a seguir.

\section{Modelo de Emissão para os Elétrons Secundários Verdadeiros}

Os parâmetros para emissão dos elétrons secundários verdadeiros são tomados a partir das posições e direções dos elétrons primários do feixe antes de se chocarem com o coletor. $\mathrm{O}$ ângulo de reflexão do elétron secundário verdadeiro é igual ao ângulo de incidência formado entre a trajetória final do elétron primário com o eixo $z$, FIG. 4.5.

A energia cinética de emissão é considerada como sendo de $10 \mathrm{eV}$. Sendo baixa a energia de emissão do elétron secundário verdadeiro, a direção inicial, na verdade, tem pouca influência na trajetória do mesmo. A corrente transportada por um elétron secundário verdadeiro é dada por: 


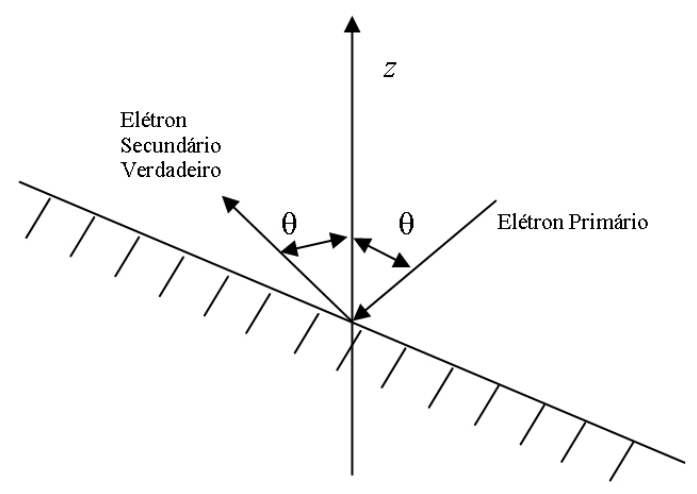

Figura 4.5: Representação da emissão de um elétron secundário verdadeiro devido a um elétron primário.

$$
I_{s}=I_{p} C_{s}\left(1+0.5 \theta^{2}\right)
$$

onde:

- $I_{s}$ : corrente elétrica transportada pelo elétron secundário verdadeiro $(A)$;

- $I_{p}$ : corrente elétrica transportada pelo elétron primário $(A)$;

- $C_{s}$ : coeficiente superficial de emissão de elétron secundário (valores típicos são 0,8 para o $\mathrm{Cu}, 0,4$ para o grafite e, 0,2 para superfícies texturizadas com carbono); e

- $\theta$ : ângulo de incidência do elétron primário com a normal da superfície em radianos.

\section{Modelo de Emissão para os Elétrons Secundários Espalhados}

A determinação das trajetórias para os elétrons secundários espalhados é realizada de modo similar à adotada para os elétrons secundários verdadeiros. Este modelo, entretanto, diverge nos seguintes aspectos: (a) a direção do elétron secundário espalhado é igual à direção refletida do elétron primário com a normal à superfície, FIG.4.6; (b) a energia cinética do elétron secundário espalhado é igual à energia final do elétron primário; e (c) a corrente a ser transportada pelo elétron secundário espalhado é dada por:

$$
I_{r}=0,005 I_{p}
$$

onde: $I_{r}$ é a corrente do elétron secundário espalhado $(A)$ e $I_{p}$ é corrente do elétron primário $(A)$.

Geralmente, o problema observado devido à emissão de elétrons secundários verdadeiros, sob as trajetórias dos elétrons primários, aqui não é verificado uma vez que os elétrons secundários espalhados transportam uma corrente baixa. Entretanto, observa-se que boa parte dos problemas relativos à degradação do sinal de RF amplificado e aos danos estruturais 


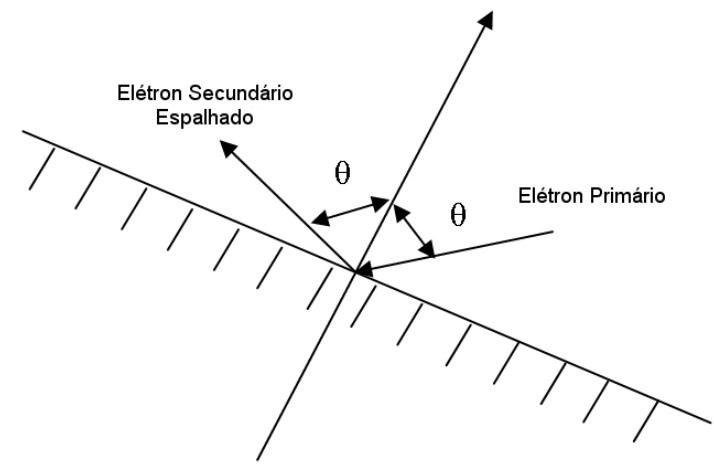

Figura 4.6: Representação da emissão de um elétron secundário espalhado devido a um elétron primário.

observados na região de deriva são decorrentes da corrente reversa, na região de deriva, dos elétrons secundários espalhados.

\subsection{Modelo Aprimorado para o Número de Elétrons Se- cundários Emitidos}

O modelo simplificado para emissão de elétrons secundários, acima descrito, leva à geração de no máximo 2 (duas) partículas após a colisão do elétron primário com a superfície do eletrodo do coletor. Um modelo mais próximo da realidade física foi proposto por Vaughan [36]-[37] para o número de elétrons secundários verdadeiros emitidos e por Reimer [40] para o número de elétrons secundários espalhados.

A seguir é apresentado o modelo utilizado tanto no MICHELLE [9] quanto pelo Electron Optics Simulator (EOS) [38], proposto por Vaughan [36]-[37] e por Reimer [40] para e emissão de elétrons secundários $\delta$, que é a soma do número das emissões de elétrons secundários verdadeiros (SSE) $\sigma$ e dos elétrons secundários espalhados (BSE) $\eta$ ou seja:

$$
\delta=\sigma+\eta
$$

Neste modelo valem as seguintes relações:

$$
\delta(\theta)=\delta_{\max }(\theta)\left(\nu e^{1-\nu}\right)^{k}
$$

onde:

$$
\begin{aligned}
\nu & =\frac{E_{i}-E_{0}}{E_{\max }(\theta)-E_{0}}, \\
k & =0,56, \text { para } \nu<1, \\
k & =0,25, \text { para } 1<\nu \leq 3,6,
\end{aligned}
$$




$$
\delta(\theta)=\delta_{\max }(\theta) \frac{1,125}{\nu^{0,35}}, \text { para } \nu>3,6
$$

e,

$$
\begin{aligned}
& E_{\max }(\theta)=E_{\max }(0)\left(1+k_{s} \theta^{2} / \pi\right), \\
& \delta_{\max }(\theta)=\delta_{\max }(0)\left(1+k_{s} \theta^{2} / \pi\right),
\end{aligned}
$$

onde: $E_{i}$ é a energia do elétron incidente; $E_{0}$ é a energia limiar de emissão (tipicamente é adotado o valor de $12,5 \mathrm{eV}$ ) sendo que, caso a energia do elétron incidente seja inferior a $E_{0}$, nenhum elétron secundário é emitido; $\theta$ é o ângulo de incidência da partícula em relação à normal da superfície; $\delta_{\max }(0)$ e $E_{\max }(0)$ são o coeficiente de emissão de um SSE e a sua correspondente energia de incidência do elétron na direção normal à superfície, respectivamente. Estes valores são constantes experimentais, sendo que, para o cobre [38], $\delta_{\max }(0) \approx 1,3$ e $E_{\max }(0) \approx 600$. $k_{s}$ é a emissividade da superfície, variando de 0 para uma superfície com textura de carbono, para 1,5 ou 2,0 para uma superfície metálica polida ou cristalina.

A produção de BSE está diretamente relacionada com o ângulo de incidência dos elétrons primários, porém modelada de uma maneira diferente do modelo para os SSEs. Este modelo, utilizado nos programas MICHELLE e EOS, foi proposto por Reimer [40] com resultados satisfatórios para todos os modelos de coletores tipo MDC com superfícies metálicas. Neste caso:

$$
\eta(Z, \theta)=B\left(\frac{\eta_{0}}{B}\right)^{\cos \theta}
$$

sendo que:

$$
\begin{gathered}
\eta_{0}(E, Z)=E^{m(Z)} C(Z), \\
m(Z)=0,13182-\frac{0,9211}{Z^{0,5}}
\end{gathered}
$$

e,

$$
\begin{aligned}
C(Z)= & 0,1904-0,2236 \ln Z \\
& +0,1292(\ln Z)^{2}-0,01491(\ln Z)^{3}
\end{aligned}
$$

onde: $Z$ é o número atômico do material do eletrodo; $\theta$ é o ângulo de incidência da partícula em relação à normal da superfície; e $B=0,89$ é uma constante.

A relação $\varepsilon$, entre a produção de elétrons espalhados elasticamente $\left(\eta_{e l}\right)$ e inelasticamente $\left(\eta_{\text {inel }}\right)$, é dada por: 


$$
\varepsilon=\frac{\eta_{\text {inel }}}{\eta_{e l}}
$$

sendo característica para cada tipo de material do coletor, de maneira que vale a relação:

$$
\eta=\eta_{\text {inel }}+\eta_{e l} .
$$

Tanto o MICHELLE quanto o EOS foram desenvolvidos com a capacidade de os elétrons secundários produzirem outros elétrons secundários, denominados de segunda geração, e, estes por sua vez, gerarem uma nova geração, assim sucessivamente. Variáveis de controle são introduzidas para limitar o número de novas gerações, reduzindo o esforço computacional na determinação e armazenamento das trajetórias de todas as gerações evitando, assim, um ciclo infinito.

É de fundamental importância ressaltar que os modelos de emissão dos elétrons secundários são, na verdade, de macropartículas secundárias.

Como exemplo para o modelo simplificado, considere uma macropartícula, $1 \mathrm{keV}$, transportando uma corrente elétrica de $0,05 \mathrm{~mA}$, que se choca com um coletor cujo material é o cobre $\left(C_{s}=0,4\right)$ e forma um ângulo de $30^{\circ}$ com a normal à superfície. Neste caso, o elétron secundário verdadeiro transportará, utilizando 4.1, uma corrente de $0,023 \mathrm{~mA}$. Já, a corrente transportada pela macropartícula que representa o elétron secundário espalhado, utilizando 4.2 , é de $0,25 \mu \mathrm{A}$. Utilizando o modelo aprimorado de emissão, demonsta-se que a produção de elétrons secundários $\delta$ é de $\delta=1,44$, e o número de elétrons secundários espalhados $\eta$ de $\eta=0,3$ e, portanto, o número de elétrons secundários verdadeiros $\sigma$ de $\sigma=1,14$. Ou seja, neste caso, considerando o modelo aprimorado para o número de elétrons secundários emitidos, a emissão do elétron secundário espalhado seria descartada.

\subsection{Conclusões do Capítulo}

Após uma breve descrição do modo em que coletores são utilizados para a recuperação de energia, foram apresentados dois modelos utilizados para se modelar elétrons secundários. No primeiro, adotado pela NASA em 1986, considera-se a emissão de elétrons secundários verdadeiros e espalhados. Os elétrons secundários primários transportam praticamente a mesma corrente do elétron primário, porém com energia baixa, tipicamente $50 \mathrm{eV}$. Os elétrons secundários espalhados, por sua vez, transportam uma corrente muito baixa mas com a mesma energia do elétron primário. O segundo modelo de emissão, utilizado tanto por MICHELLE quanto pelo EOS, não considera a emissão de apenas dois elétrons secundários. Nesse modelo, um número maior de elétrons secundários pode ser emitidos, valor este que depende do material do coletor, da energia do elétron primário ao se chocar com o coletor e do ângulo de incidência. Outra diferença, em relação ao modelo anterior, é o fato de considerar dois subtipos de elétrons secundários espalhados: os espalhados elasticamente e os inelasticamente. Finalmente, um exemplo numérico relativo aos dois modelos de emissão foram apresentados. 


\section{Capítulo 5}

\section{Materiais e Métodos}

O uso de computadores voltados à solução do problema autoconsistente, que envolve a determinação dos campos elétrico e magnético e a trajetória de elétrons em canhões, remontam a criação dos mesmos [41]-[42]. Desde então, os códigos vêm sendo continuamente aprimorados e novos modelos que melhor descrevem a física do problema são continuamente integrados aos mesmos. Elevado poder computacional dos processadores, baixo custo de memória, paralelização do processamento, etc., permitiram desenvolver ferramentas computacionais capazes de modelar dispositivos com aplicações em válvulas do tipo TWT com geometrias complexas. A utilização destas ferramentas em simulações nos dias atuais é imprescindível. Atualmente, dispositivos com elevado grau de complexidade são simulados e otimizados proporcionando sistemas mais eficientes e redução de custo de projeto. Este Capítulo descreve a metodologia adotada para o desenvolvimento de uma ferramenta computacional capaz de resolver o problema acoplado entre o potencial e a dinâmica das partículas, a partir da equação da trajetória, em canhões de elétrons com grade e shadow-grid, em estruturas do tipo PPM e em coletores.

Inicialmente, na seção 5.1, é abordada a fundamentação física do problema de canhões de elétrons que operam na condição FSCL a partir das Equações de Maxwell. Em seguida, uma aproximação é feita para se determinar a quantidade de memória física necessária para se computar a força que age sobre uma partícula em movimento em uma válvula do tipo TWT, onde é demonstrado ser inexequível computacionalmente devido à limitação física de memória. Em seguida, na seção 5.2, descreve-se a equação da trajetória de uma partícula em coordenadas cilíndricas devido a ação dos campos magnético e elétrico. São apresentados, a seguir, os métodos utilizados no desenvolvimento da ferramenta computacional, a saber:

- PIC (seção 5.3): largamente utilizado em problemas físicos que envolvem muitas partículas;

- MEF (seção 5.4): tem aplicações em diversas áreas da engenharia. Trata-se de uma técnica numérica que apresenta uma solução aproximada para problemas que envolvem equações diferenciais parciais; e

- MAS (seção 5.5): descreve o modo de se conseguir convergência em problemas acoplados envolvendo a determinação dos campos e de trajetórias de partículas elétricas. 
A seção 5.6, descreve o método adotado pela ferramenta computacional desenvolvida para a resolução do sistema linear esparso. A sistemática de armazenamento, baseada no método compacto por linha é descrita e exemplificada. Finalmente, o algoritmo baseado no método do gradiente biconjugado, para solução de sistemas esparsos, é apresentado.

\subsection{Fundamentação Física}

\subsubsection{Equações de Maxwell na condição FSCL}

O conjunto de expressões matemáticas que descrevem completamente os campos eletromagnéticos, conhecidas como Equações de Maxwell, é

$$
\begin{aligned}
\nabla \cdot \mathbf{E} & =\frac{\rho}{\epsilon_{0}} \text { (Lei de Gauss) } \\
\nabla \cdot \mathbf{B} & =0 \text { (Lei de Gauss Magnética) } \\
\nabla \times \mathbf{E} & =-\frac{\partial \mathbf{B}}{\partial t} \text { (Lei de Faraday) e, } \\
\nabla \times \mathbf{B} & =\mu_{0} \mathbf{J}+\mu_{0} \epsilon_{0} \frac{\partial \mathbf{E}}{\partial t} \text { (Lei de Ampère-Maxwell). }
\end{aligned}
$$

Considerando-se o problema do canhão de elétrons, operando na condição FSCL, os campos eletromagnéticos são invariantes no tempo, assim as equações que descrevem este quadro físico são:

$$
\begin{aligned}
\nabla \cdot \mathbf{E} & =\frac{\rho}{\epsilon_{0}}, \\
\nabla \cdot \mathbf{B} & =0, \\
\nabla \times \mathbf{E} & =\mathbf{0}, \mathrm{e} \\
\nabla \times \mathbf{B} & =\mu_{0} \mathbf{J} .
\end{aligned}
$$

Sendo o campo elétrico conservativo, ele pode ser obtido a partir do gradiente de um campo escalar, neste caso o potencial $\varphi$, ou seja

$$
\mathbf{E}=-\nabla \varphi
$$

Substituindo a expressão acima na equação 5.5 tem-se

$$
\nabla \cdot \nabla \varphi=\nabla^{2} \varphi=-\frac{\rho}{\epsilon_{0}} \text { (Equação de Poisson) }
$$

Devido à inexistência de monopolos magnéticos (5.6), o campo magnético pode ser escrito como

$$
\mathbf{B}=\nabla \times \mathbf{A},
$$


onde A é o potencial vetor magnético. Substituindo a expressão acima na equação 5.8 tem-se que

$$
\nabla \times \nabla \times \mathbf{A}=\mu_{0} \mathbf{J}
$$

Utilizando-se o método PIC, a trajetória para cada uma das macropartículas é determinada pela integração da equação de movimento. Considerando-se que a força resultante, não-relativística, sobre cada macropartícula é do tipo Lorentz, para a $i$-ésima macropartícula $M_{i}$, de massa $m_{M_{i}}$, vale a equação

$$
\begin{gathered}
m_{M_{i}} \frac{d\left(\mathbf{v}_{i}\right)}{d t}=q_{M_{i}}\left(\mathbf{E}_{i}+\mathbf{v}_{i} \times \mathbf{B}_{i}\right), \mathrm{e} \\
\frac{d \mathbf{x}_{i}}{d t}=\mathbf{v}_{i}
\end{gathered}
$$

onde $\mathbf{x}_{i}$ e $\mathbf{v}_{i}$ são a posição e velocidade da $i$-ésima macropartícula e $\mathbf{E}_{i}$ e $\mathbf{B}_{i}$ os campos elétrico e magnético que atuam sobre a $i$-ésima macropartícula.

Assim, o problema para o canhão de elétrons na condição FSCL está totalmente determinado: os campos devem satisfazer 5.10 e 5.12 e as trajetórias das partículas, 5.13 e 5.14 .

\subsubsection{Inviabilidade Computacional na Determinação da Força Elétrica sobre uma Partícula}

Para determinar a equação do movimento de cada elétron, faz-se necessário conhecer a força resultante atuando sobre cada um deles. Como exemplo, considere a força que atua sob cada elétron devido ao campo elétrico. Neste caso, a Força $\mathbf{F}$ atuando sob uma partícula é dada por:

$$
\mathbf{F}=q \mathbf{E}
$$

Considerando o movimento típico de elétrons em um canhão, acelerados devido à diferença de potencial entre o catodo e o anodo, a força total que atua sobre cada partícula pode ser determinada como segue. A força resultante $\mathbf{F}_{\mathbf{T i}}$, sobre cada elétron, será devida à força elétrica $\mathbf{F}_{\mathrm{Ei}}$ e à força externa $\mathbf{F}_{\text {ext }}$ decorrente da diferença de potencial. Então, para $\mathbf{o}$ $i$-ésimo elétron de carga $q_{i}$, a força resultante $\mathbf{F}_{\mathbf{T i}}$ pode ser escrita:

$$
\mathbf{F}_{\mathbf{T i}}=\mathbf{F}_{\mathrm{Ei}}+\mathbf{F}_{\mathbf{e x t}}=q_{i} \sum_{j \neq i}^{N} \frac{q_{j}}{4 \pi \epsilon_{0}} \frac{\mathbf{r}_{\mathbf{i j}}}{r_{i j}^{3}}+\left.q_{i} \nabla V\right|_{i},
$$

onde $N$ representa o número de partículas, neste caso elétrons, $\mathbf{r}_{\mathbf{i j}}$ corresponde ao vetor posição entre a carga $q_{i}$ e $q_{j}$, e $\left.\nabla V\right|_{i}=-E_{i}$, o campo elétrico avaliado na posição da carga $q_{i}$ devido à diferença de potencial catodo-anodo, $\epsilon_{0}$ é a permissividade elétrica do vácuo.

Levando-se, ainda, em consideração que a potência média dos amplificadores de microondas tipo TWT, utilizados pelas Fragatas Classe Greenhalgh da MB, é de $320 \mathrm{~W}$ com duração do pulso de $2 \mu s$ e uma corrente do feixe de $4 A$, pode-se estimar uma transferência de 
carga, em cada pulso do canhão, de $Q=-8 \mu C$, que corresponde, aproximadamente, à passagem de $N=5 \cdot 10^{13}$ elétrons. Como para cada elétron deve-se armazenar sua posição e velocidade no espaço $3 \mathrm{D}$, têm-se um total de $6 N$ variáveis. Considerando $N$ na ordem de $10^{14}$, para o exemplo acima citado, o número total de variáveis a serem utilizadas é da ordem de $10^{15}$. De acordo com IEEE Standard for Binary Floating-Point Arithmetic (ANSI/IEEE Std 754-1985), um número em ponto flutuante de simples precisão tem 4 bytes. A necessidade de memória de armazenamento destas informações são, portanto, na ordem de $10^{6}$ Gbytes. Este valor, atualmente, está fora das atuais capacidades de armazenamento e processamento, inviabilizando a adoção do procedimento acima para o cálculo da força resultante sobre cada uma das partículas. Uma aproximação largamente utilizada é o uso de PIC, onde se constrói uma super partícula, ou macropartícula, que é na verdade um conjunto de partículas cuja densidade de carga é distribuída uniformemente sobre um volume. Se uma macropartícula é composta de $n$ elétrons, a massa da macropartícula $m_{M}$ será $m_{M}=n \cdot m_{e}$, onde $m_{e}$ é a massa do elétron $m_{e} \simeq 9,109 \cdot 10^{-31} \mathrm{~kg}$ com uma carga $q_{M}=n \cdot q$, onde $q \simeq 1,602 \cdot 10^{-19} \mathrm{C}$.

\subsection{Derivação das Equações de Movimento}

\subsubsection{Equação da Trajetória - Coordenadas Cilíndricas}

A equação de movimento, não-relativístico, derivada da força de Lorentz, aqui reescrita para um elétron é dada por:

$$
m \frac{d(\mathbf{v})}{d t}=-e(\mathbf{E}+\mathbf{v} \times \mathbf{B})
$$

onde:

- $m$ : massa do elétron;

- v: vetor velocidade do elétron;

- $e$ : carga do elétron;

- E: campo elétrico sobre o elétron; e

- B: campo magnético sobre o elétron.

Considerando baixas velocidades para os elétrons e o interesse em observar o fenômeno apenas no plano $r \times z$, o vetor posição é, em coordenas cilíndricas, dado por:

$$
\mathbf{r}(t)=\rho(t) \widehat{\rho}+z(t) \widehat{k}
$$

Os vetores unitários $\widehat{\rho}$ e $\widehat{\theta}$ variam com o tempo. Para $\widehat{\rho}$, sabe-se que:

$$
\widehat{\rho}=\cos \theta \widehat{i}+\sin \theta \widehat{j}
$$


assim:

$$
\frac{d \widehat{\rho}}{d t}=(-\sin \widehat{\theta}+\cos \theta \widehat{j}) \frac{d \theta}{d t}=\dot{\theta} \widehat{\theta}
$$

Utilizando-se o mesmo raciocínio, para $\widehat{\theta}$ tem-se que:

$$
\widehat{\theta}=-\sin \hat{\theta i}+\cos \hat{\theta j}
$$

e

$$
\frac{d \widehat{\theta}}{d t}=-(\cos \theta \widehat{i}+\sin \theta \widehat{j}) \frac{d \theta}{d t}=-\dot{\theta} \widehat{\rho}
$$

A velocidade da partícula é:

$$
\mathbf{v}(t)=\frac{d \mathbf{r}(t)}{d t}=\frac{d \rho}{d t} \widehat{\rho}+\rho \frac{d \widehat{\rho}}{d t}+\frac{d z}{d t} \widehat{z}=\dot{\rho} \widehat{\rho}+\rho \dot{\theta} \widehat{\theta}+\dot{z} \widehat{k}
$$

Já a aceleração pode ser obtida derivando-se a equação acima em relação ao tempo:

$$
\mathbf{a}(t)=\frac{d \mathbf{v}(t)}{d t}=\frac{d(\dot{\rho} \widehat{\rho}+\rho \dot{\theta} \widehat{\theta}+\dot{z} \widehat{k})}{d t}=\ddot{\rho} \widehat{\rho}+\dot{\rho} \dot{\theta} \widehat{\theta}+\frac{d(\rho \dot{\theta} \widehat{\theta})}{d t}+\ddot{z} \widehat{k}
$$

O terceiro termo do lado direito é igual à:

$$
\frac{d(\rho \dot{\theta} \widehat{\theta})}{d t}=\frac{d(\rho \dot{\theta})}{d t} \widehat{\theta}+\rho \dot{\theta} \frac{d(\widehat{\theta})}{d t} .
$$

Utilizando-se 5.20 e 5.22 acima se obtém:

$$
\frac{d(\dot{\rho} \widehat{\theta})}{d t}=(\dot{\rho} \dot{\theta}+\ddot{\rho}) \widehat{\theta}-\rho \dot{\theta} \widehat{\rho} .
$$

Substituindo a equação acima em 5.24 e agrupando os termos obtém-se:

$$
\mathbf{a}(t)=\left(\ddot{\rho}-\dot{\rho}^{2}\right) \widehat{\rho}+(2 \dot{\rho} \dot{\theta}+\ddot{\rho} \dot{\theta}) \widehat{\theta}+\ddot{z} \widehat{k}
$$

Considerando $\mathbf{E}=E_{\rho} \widehat{\rho}+E_{\theta} \widehat{\theta}+E_{z} \widehat{k}, \mathbf{B}=B_{\rho} \widehat{\rho}+B_{\theta} \widehat{\theta}+B_{z} \widehat{k}$ e fazendo uso de 5.23, a equação 5.15 pode ser escrita como:

$$
m \vec{a}(t)=-e\left[E_{\rho} \widehat{\rho}+E_{\theta} \widehat{\theta}+E_{z} \widehat{k}+(\dot{\rho} \widehat{\rho}+\rho \dot{\theta} \widehat{\theta}+\dot{z} \widehat{k}) \times\left(B_{\rho} \widehat{\rho}+B_{\theta} \widehat{\theta}+B_{z} \widehat{k}\right)\right]
$$

O produto vetorial $\mathbf{v} \times \mathbf{B}$ é igual a:

$$
\mathbf{v} \times \mathbf{B}=\left(\dot{\rho \theta} B_{z}-\dot{z} B_{\theta}\right) \widehat{\rho}+\left(\dot{z} B_{\rho}-\dot{\rho} B_{z}\right) \widehat{\theta}+\left(\dot{\rho} B_{\theta}-\rho \dot{\theta} B_{\rho}\right) \widehat{k}
$$


Substituindo a equação acima em 5.28 e agrupando componente a componente tem-se:

$$
\begin{gathered}
\ddot{\rho}-\dot{\rho} \dot{\theta}=-\eta\left(E_{\rho}+\dot{\theta} \dot{\theta} B_{z}-\dot{z} B_{\theta}\right), \\
2 \dot{\rho} \dot{\theta}+\ddot{\rho} \theta=\frac{1}{\rho} \frac{d\left(\rho^{2} \dot{\theta}\right)}{d t}=-\eta\left(E_{\theta}+\dot{z} B_{\rho}-\dot{\rho} B_{z}\right), \\
\ddot{z}=-\eta\left(E_{z}+\dot{\rho} B_{\theta}-\rho \dot{\theta} B_{\rho}\right),
\end{gathered}
$$

onde $\eta=e / m$.

Devido a simetria axial do problema, as componentes azimutais dos campos elétrico e magnético são nulas, ou seja, $E_{\theta}=B_{\theta}=0$. Assim o sistema acima é simplificado:

$$
\begin{gathered}
\ddot{\rho}-\dot{\rho} \dot{\theta}=-\eta\left(E_{\rho}+\rho \dot{\theta} B_{z}\right) \\
2 \dot{\rho} \dot{\theta}+\ddot{\rho}=\frac{1}{\rho} \frac{d\left(\rho^{2} \dot{\theta}\right)}{d t}=-\eta\left(\dot{z} B_{\rho}-\dot{\rho} B_{z}\right) \\
\ddot{z}=-\eta\left(E_{z}-\rho \dot{\theta} B_{\rho}\right)
\end{gathered}
$$

A primeira equação de 5.31 pode ser escrita como:

$$
\begin{aligned}
& \ddot{\rho}=-\eta\left(E_{\rho}+\rho \dot{\theta} B_{z}\right)+\rho \dot{\theta}, \text { ou } \\
& \ddot{\rho}=-\eta E_{\rho}+\rho \dot{\theta}\left(-\eta B_{z}+\dot{\theta}\right) .
\end{aligned}
$$

Utilizando-se 3.21 acima:

$$
\begin{gathered}
\ddot{\rho}=-\eta E_{\rho}+\rho \frac{\eta}{2 \pi \rho^{2}}\left(\Phi-\Phi_{l}\right)\left(-\eta B_{z}+\frac{\eta}{2 \pi \rho^{2}}\left(\Phi-\Phi_{l}\right)\right) \\
\ddot{\rho}=-\eta E_{\rho}-\frac{\eta^{2}}{4 \pi^{2} \rho}\left(\Phi-\Phi_{l}\right)\left(2 \pi B_{z}-\frac{\left(\Phi-\Phi_{l}\right)}{\rho^{2}}\right)
\end{gathered}
$$

A terceira equação de 5.31 é escrita utilizando-se 3.21 como:

$$
\begin{gathered}
\ddot{z}=-\eta E_{z}+\frac{\eta^{2}}{2 \pi \rho}\left(\Phi-\Phi_{l}\right) B_{\rho} \\
\ddot{z}=-\eta E_{z}-\frac{\eta^{2}}{2 \pi \rho}\left(\Phi-\Phi_{l}\right) \frac{\partial A_{\theta}}{\partial z} \\
\ddot{z}=-\eta E_{z}-\frac{\eta^{2}}{2 \pi \rho}\left(\Phi-\Phi_{l}\right) \frac{\partial \frac{\Phi}{2 \pi \rho}}{\partial z} \\
\ddot{z}=-\eta E_{z}-\frac{\eta^{2}}{4 \pi^{2} \rho^{2}}\left(\Phi-\Phi_{l}\right) \frac{\partial \Phi}{\partial z}
\end{gathered}
$$

Levando-se em consideração que $\mathbf{E}=-\nabla \phi$, um novo sistema pode ser construído, 
utilizando-se 3.21, 5.34 e 5.35:

$$
\left.\begin{array}{c}
\dot{\theta}=\frac{\eta}{2 \pi \rho^{2}}\left(\Phi-\Phi_{l}\right), \\
\ddot{\rho}=\eta \frac{\partial \phi}{\partial \rho}-\frac{\eta^{2}}{4 \pi^{2} \rho}\left(\Phi-\Phi_{l}\right)\left(2 \pi B_{z}-\frac{\left(\Phi-\Phi_{l}\right)}{\rho^{2}}\right) \text { e } \\
\ddot{z}=\eta \frac{\partial \phi}{\partial z}-\frac{\eta^{2}}{4 \pi^{2} \rho^{2}}\left(\Phi-\Phi_{l}\right) \frac{\partial \Phi}{\partial z} .
\end{array}\right\}
$$

O sistema acima ainda pode ser reescrito como:

$$
\left.\begin{array}{c}
\dot{\theta}=\frac{\eta}{2 \pi \rho^{2}}\left(\Phi-\Phi_{l}\right) \\
\ddot{\rho}=\eta \frac{\partial \phi}{\partial \rho}-\frac{\eta^{2}}{8 \pi^{2}} \frac{\partial}{\partial \rho}\left(\frac{\Phi-\Phi_{l}}{\rho}\right)^{2} \\
\ddot{z}=\eta \frac{\partial \phi}{\partial z}-\frac{\eta^{2}}{8 \pi^{2}} \frac{\partial}{\partial z}\left(\frac{\Phi-\Phi_{l}}{\rho}\right)^{2}
\end{array}\right\}
$$

Segue-se de 5.37 que o movimento de uma partícula em campos com simetria axial pode ser descrito em termos do potencial generalizado $Q$ :

$$
\left.\begin{array}{c}
\ddot{\rho}=\eta \frac{\partial Q}{\partial \rho}, \mathrm{e} \\
\ddot{z}=\eta \frac{\partial Q}{\partial z}, \text { onde: } \\
=\phi-\frac{\eta}{8 \pi^{2}}\left(\frac{\Phi-\Phi_{l}}{\rho}\right)^{2} .
\end{array}\right\}
$$

As duas primeiras equações de 5.38 podem ser reescritas como:

$$
\frac{d^{2} \rho}{d t^{2}}=\eta \frac{\partial Q}{\partial \rho}
$$

$\mathrm{e}$

$$
\frac{d^{2} z}{d t^{2}}=\eta \frac{\partial Q}{\partial z}
$$

Levando-se em consideração a conservação de energia:

$$
\begin{gathered}
\frac{1}{2} m v^{2}=q Q \\
\frac{1}{2} m\left(v_{\rho}^{2}+v_{z}^{2}\right)=\frac{1}{2} m\left[\left(\frac{d \rho}{d t}\right)^{2}+\left(\frac{d z}{d t}\right)^{2}\right]=\frac{1}{2} m\left(\frac{d z}{d t}\right)^{2}\left[\left(\frac{d \rho}{d z}\right)^{2}+1\right]=q Q
\end{gathered}
$$

a qual pode ser reescrita como:

$$
\left(\frac{d z}{d t}\right)^{2}\left[\left(\frac{d \rho}{d z}\right)^{2}+1\right]=2 \frac{q}{m} Q=2 \eta Q
$$

Sabe-se que:

$$
\frac{d \rho}{d t}=\frac{d \rho}{d z} \frac{d z}{d t}, \mathrm{e}
$$




$$
\frac{d^{2} \rho}{d t^{2}}=\frac{d}{d t}\left(\frac{d \rho}{d t}\right)=\frac{d}{d t}\left(\frac{d \rho}{d z} \frac{d z}{d t}\right)=\frac{d \rho}{d z} \frac{d^{2} z}{d t^{2}}+\frac{d z}{d t} \frac{d}{d t}\left(\frac{d \rho}{d z}\right)
$$

O segundo termo do lado direito da equação pode ainda ser reescrito como:

$$
\begin{gathered}
\frac{d z}{d t} \frac{d}{d t}\left(\frac{d \rho}{d z}\right)=\frac{d z}{d t} \frac{d}{d z}\left(\frac{d \rho}{d t}\right)=\frac{d z}{d t} \frac{d}{d z}\left(\frac{d \rho}{d z} \frac{d z}{d t}\right) \\
\frac{d z}{d t} \frac{d}{d z}\left(\frac{d \rho}{d z} \frac{d z}{d t}\right)=\left(\frac{d z}{d t}\right)^{2} \frac{d^{2} \rho}{d z^{2}}+\frac{d z}{d t} \frac{d \rho}{d z} \frac{d}{d z}\left(\frac{d z}{d t}\right)=\left(\frac{d z}{d t}\right)^{2} \frac{d^{2} \rho}{d z^{2}} \\
\text { ou seja: } \\
\frac{d^{2} \rho}{d t^{2}}=\frac{d \rho}{d z} \frac{d^{2} z}{d t^{2}}+\left(\frac{d z}{d t}\right)^{2} \frac{d^{2} \rho}{d z^{2}}
\end{gathered}
$$

Substituindo 5.47 em 5.39 tem-se:

$$
\frac{d \rho}{d z} \frac{d^{2} z}{d t^{2}}+\left(\frac{d z}{d t}\right)^{2} \frac{d^{2} \rho}{d z^{2}}=\eta \frac{\partial Q}{\partial \rho}
$$

Isolando $\left(\frac{d z}{d t}\right)^{2}$ em 5.47 e substituindo juntamente com 5.40 acima, tem-se finalmente a equação da trajetória:

$$
\begin{gathered}
\frac{d \rho}{d z}\left(\eta \frac{\partial Q}{\partial z}\right)+\left[\frac{2 \eta Q}{\left(\frac{d \rho}{d z}\right)^{2}+1}\right] \frac{d^{2} \rho}{d z^{2}}=\eta \frac{\partial Q}{\partial \rho} \\
\frac{d^{2} \rho}{d z^{2}}=\left[\frac{1+\left(\frac{d \rho}{d z}\right)^{2}}{2 Q}\right]\left(\frac{\partial Q}{\partial \rho}-\frac{\partial Q}{\partial z} \frac{d \rho}{d z}\right)
\end{gathered}
$$

\subsection{Particle in Cell-PIC}

Conforme discutido na seção 5.1.2 mostrou-se que é inviável resolver o problema autoconsistente das trajetórias de todas as partículas do feixe de elétrons. Uma proposta de solução para este problema, voltado à simulação de plasmas, foi apresentada no trabalho de J. M. Dawson [43, 44], onde o plasma foi modelado usando o conceito de macropartículas. Uma questão importante que se deve levar em consideração diz respeito ao número de macropartículas, uma vez que não se deseja uma quantidade muito elevada, de modo a inviabilizar computacionalmente a realização da simulação e, ao mesmo tempo, que não seja muito reduzido, de maneira que o modelo não seja representativo para o problema em análise. A idéia é inicialmente preencher o espaço $2 D$ ou $3 D$ com as macropartículas de acordo com os modelos apresentados na FIG. 5.1. 

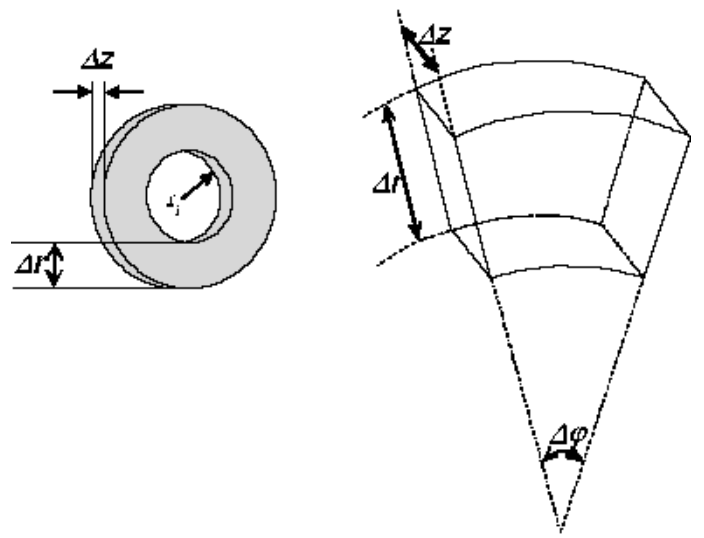

(a)

(b)

Figura 5.1: Modelos de macropartículas: (a) modelo bidimensional para problemas que apresentam simetria axial com densidade de carga volumétrica $\rho_{i}$, raio inicial $r_{i}$, raio final $r_{i}+\Delta r$ e espessura $\Delta z$ e (b) modelo tridimensional.

A partir das posições e velocidades das macropartículas, em um determinado instante de tempo, calcula-se a corrente elétrica de convecção e a densidade de carga, obtidas a partir da distribuição das partículas na grade espacial que é construída no domínio do problema. Em função da densidade de cargas e de correntes de convecção, calculam-se os campos elétricos e magnéticos autoconsistentes, uma vez que, na condição de regime permanente, os campos gerados dependem das posições e velocidades das macropartículas (que possuem cargas) sendo que estas, por sua vez, têm suas velocidades e posições dependendo dos campos, os quais são gerados por elas mesmas e pela diferença de potencial catodo/anodo. Este esquema está representado na FIG. 5.2.

\subsection{Método dos Elementos Finitos (MEF)}

Existem diversos métodos numéricos utilizados na busca de uma solução aproximada para problemas físicos, em particular, os descritos por equações diferenciais parciais. Entre estes métodos destacam-se o MEF e o Método das Diferenças Finitas (MDF). É possível destacar as seguintes diferenças entre o MEF e o MDF:

- o MDF faz uso, comumente, de células retângulares (2D) ou paralelepipedais (3D), enquanto que o MEF utiliza elementos de forma arbitrária, cujas arestas, não necessariamente são retas (2D) ou planas (3D);

- os objetos/sistemas modelados não necessariamente possuem uma geometria regular, sendo estas, na verdade, exceções. Nestes casos, as geometrias dos objetos modelados utilizando o MDF não apresentam uma aproximação satisfatória; e

- o MEF permite refinar localmente uma ou várias regiões do domínio do problema, em particular, aquelas onde o gradiente sofre grandes variações. É possível, utilizando-se 


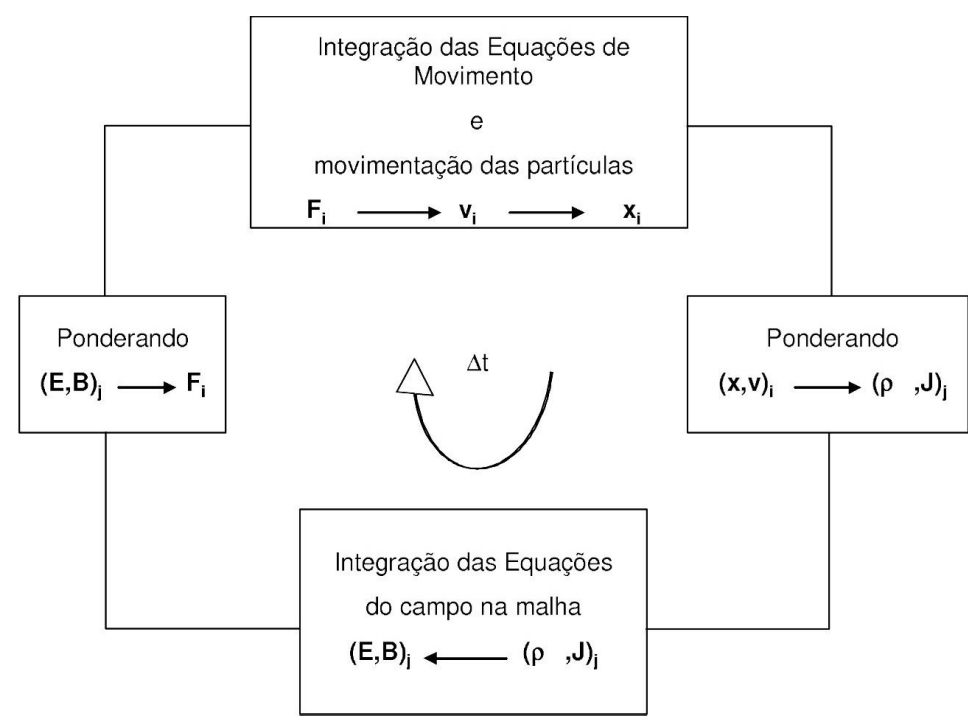

Figura 5.2: Exemplo típico do ciclo, um passo no tempo, em um programa de simulação de partícula utilizando PIC. As partículas são numeradas $i=1,2, \ldots, N P$; os índices da malha são $j$, os quais se tornarão vetores quando se referirem a 2 ou 3 dimensões.

o MDF, realizar o refinamento local, sendo que, neste caso, o refinamento é propagado por toda a geometria.

Por esses motivos o MDF terá que utilizar, de modo geral, um número bem maior de células. O uso de um número maior de células implica em um esforço computacional elevado para se obter a mesma precisão que seria alcançada pelo MEF.

Existe atualmente uma vasta bibliografia que trata do MEF, em particular, voltadas aos problemas eletromagnéticos, [45, 46, 47] e às Equações Diferenciais Parciais, [48]. Em problemas eletromagnéticos, o MEF é normalmente associado com os métodos variacionais e aos métodos residuais. O procedimento numérico utilizado pelos métodos variacionais é baseado na minimização de um funcional. Embora sejam bem conhecidos os funcionais para problemas clássicos em $2 \mathrm{D}$, a determinação dos mesmos para fenômenos menos usuais não é uma tarefa trivial. Além disso, não se trabalha diretamente com a equação que descreve o fenômeno físico mas, sim, o correspondente funcional. Diferentemente, o método baseado em resíduos é mais fácil, uma vez que as equações que regem este método são estabelecidas a partir da equação que descreve o problema físico que se deseja resolver.

O método de Galerkin é amplamente utilizado em problemas eletromagnéticos. Esta formulação, além de ser simples, é de fácil implementação e apresenta, normalmente, resultados precisos e com boa exatidão.

A solução aproximada dos problemas que utilizam o MEF de forma sistemática é obtida em quatro etapas:

- discretização do domínio do problema em um número finito de regiões denominadas elementos finitos; 
- derivação da equação que governa o elemento (método variacional ou de residuos ponderados);

- reunião de todos os elementos do domínio, que corresponde à montagem da matriz global; e

- resolução do sistema de equações.

\subsubsection{Determinação do Potencial Escalar Elétrico: Método dos Resídu- os Ponderados}

Considere o problema em 2D, com simetrial axial, no qual os elementos da região discretizada são triângulos $^{1}$ tal como aquele representado na FIG. 5.3. Os pontos que definem os triângulos são os nós ou graus de liberdade, enquanto que, o triângulo, em si, é o elemento finito. A reunião de todos os elementos finitos, compõem a malha do domínio.

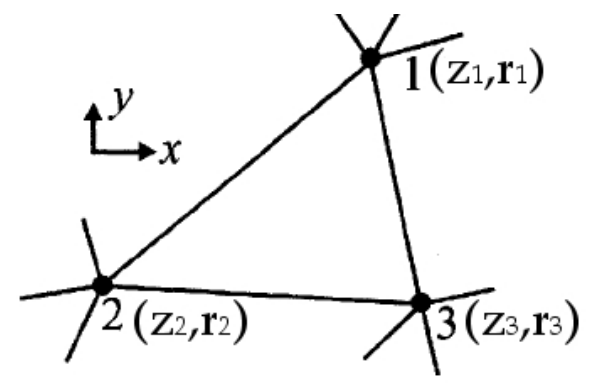

Figura 5.3: Um elemento triangular da malha.

Tomando-se uma variação linear do potencial no elemento, o potencial é escrito como

$$
V(z, r)=a_{1}+a_{2} z+a_{3} r .
$$

Sendo $V_{1}, V_{2}$ e $V_{3}$ os potenciais nos nós 1,2 e 3, respectivamente, desconhecidos, utilizando (5.51) tem-se

$$
\begin{aligned}
& V_{1}=a_{1}+a_{2} z_{1}+a_{3} r_{1} ; \\
& V_{2}=a_{1}+a_{2} z_{2}+a_{3} r_{2} ; \mathrm{e} \\
& V_{3}=a_{1}+a_{2} z_{3}+a_{3} r_{3} .
\end{aligned}
$$

Este sistema pode ser resolvido e o potencial $V(z, r)$ é dado por

\footnotetext{
${ }^{1}$ É possível ter elementos em forma de triângulo com 6 nós (3 nós nos vértices do triângulo e os outros 3 nos pontos médios de cada aresta). São também modelos 2D o quadrilátero de 4 nós e o retângulo de 5 nós (um nó em cada vértice e o outro, no centro do quadrilátero). Modelos 3D de elementos são o tetraedro com 4 nós ou o hexaedro de 8 nós.
} 


$$
V(z, r)=\sum_{i=1}^{3} \frac{1}{D}\left(p_{i}+q_{i} z+r_{i} r\right) V_{i}
$$

onde:

$$
\begin{aligned}
& p_{1}=z_{2} r_{3}-z_{3} r_{2} \quad q_{1}=r_{2}-r_{3} \quad r_{1}=z_{3}-z_{2}, \\
& p_{2}=z_{3} r_{1}-z_{1} r_{3} \quad q_{2}=r_{3}-r_{1} \quad r_{2}=z_{1}-z_{3}, \\
& p_{3}=z_{1} r_{2}-z_{2} r_{1} \quad q_{3}=r_{1}-r_{2} \quad r_{3}=z_{2}-z_{1},
\end{aligned}
$$

e,

$$
D=\left|\begin{array}{lll}
1 & z_{1} & r_{1} \\
1 & z_{2} & r_{2} \\
1 & z_{3} & r_{3}
\end{array}\right|
$$

O campo elétrico pode então ser facilmente obtido a partir de 5.53:

$$
\begin{aligned}
\mathbf{E} & =-\nabla V=-\left(\frac{\partial V}{\partial z} \widehat{k}+\frac{\partial V}{\partial r} \widehat{\rho}\right) \\
& =-\frac{1}{D}\left[\left(q_{1} V_{1}+q_{2} V_{2}+q_{3} V_{3}\right) \widehat{k}+\left(r_{1} V_{1}+r_{2} V_{2}+r_{3} V_{3}\right) \widehat{\rho}\right]
\end{aligned}
$$

É ainda possível escrever (5.53) como

$$
V(z, r)=\phi_{1}(z, r) V_{1}+\phi_{2}(z, r) V_{2}+\phi_{3}(z, r) V_{3}
$$

onde:

$$
\phi_{i}(z, r)=\frac{1}{D}\left(p_{i}+q_{i} z+r_{i} r\right), 1 \leq i \leq 3 .
$$

As funções $\phi_{i}$, acima, são denominadas funções de forma (shape functions). Pode-se facilmente mostrar que

$$
\phi_{i}\left(z_{i}, r_{j}\right)=\delta_{i j}
$$

onde $\delta_{i j}$ é o delta de Kronecker.

A etapa seguinte consiste em aplicar o Método de Resíduos Ponderados e, para tanto, deve-se distinguir a solução exata $V_{e}$ da solução aproximada obtida pelo MEF, $V$. Para o problema do canhão de elétrons, a solução dos campos passa pela solução da equação de Poisson (5.10), $\nabla^{2} V_{e}=-\frac{\rho}{\epsilon_{0}}$. Utilizando-se o MEF a solução obtida é aproximada, e portanto, tem-se um resíduo $R$ dado por

$$
R=\nabla^{2} V+\frac{\rho}{\epsilon_{0}}
$$


O procedimento baseado no MEF exige que, no domínio, $R$ se torne zero:

$$
\int_{\Omega} W R d \Omega=0
$$

onde a função $W$, não nula, é denominada função peso (weighting function) e, $\Omega$, representa o domínio do problema. A equação acima pode ser reescrita como:

$$
\int_{\Omega} W\left(\nabla^{2} V+\frac{\rho}{\epsilon_{0}}\right) d \Omega=\int_{\Omega} W\left(\nabla \cdot \nabla V+\frac{\rho}{\epsilon_{0}}\right) d \Omega=0 .
$$

Considerando as igualdades,

$$
U \nabla \cdot \mathbf{A}=\nabla \cdot U \mathbf{A}-\mathbf{A} \cdot \nabla U
$$

e,

$$
\int_{\Omega} U \nabla \cdot \mathbf{A} d \Omega=\int_{\Omega} \nabla \cdot U \mathbf{A} d \Omega-\int_{\Omega} \mathbf{A} \cdot \nabla U d \Omega
$$

aplicando o teorema do divergente no primeiro termo do lado direito, assim a igualdade acima é reescrita,

$$
\int_{\Omega} U \nabla \cdot \mathbf{A} d \Omega=\oint_{S} U \mathbf{A} \cdot \mathbf{d} \mathbf{S}-\int_{\Omega} \mathbf{A} \cdot \nabla U d \Omega
$$

onde $S$ é a superfície que envolve o domínio $\Omega$.Tomando-se $U=W$ e $\mathbf{A}=\nabla V$ a integral (5.64) torna-se

$$
\begin{aligned}
\int_{\Omega} W\left(\nabla \cdot \nabla V+\frac{\rho}{\epsilon_{0}}\right) d \Omega & =\oint_{S} W \nabla V \cdot \mathbf{d} \mathbf{S}+ \\
-\int_{\Omega} \nabla V \cdot \nabla W d \Omega+\int_{\Omega} W \frac{\rho}{\epsilon_{0}} d \Omega & =0 .
\end{aligned}
$$

A equação (5.68) é comumente denominada de forma fraca da formulação por elementos finitos, pois esta contém derivadas de primeira ordem, diferentemente da (5.64) que contém derivadas de segunda ordem.

A equação (5.63) deve ser válida para todos os elementos do domínio, portanto, ela deve ser minimizada em todo o domínio. Assim

$$
\sum_{k=1}^{K} \int_{\Omega} W_{k} R_{k} d \Omega_{k}=0
$$

onde $W_{k}$ é a função peso para o $k$-ésimo nó, $K$ é o número total de nós incógnitas e $\Omega_{k}$ é o domínio do $k$-ésimo nó. Tem-se, com isso, um sistema de $K$ equações para os $K$ potenciais desconhecidos que correspondem aos $K$ nós do domínio, na forma:

$$
[S][V]+[g]=0,
$$


onde:

$$
S_{i j}=\int_{\Omega} \nabla V_{i} \cdot \nabla W_{j} d \Omega
$$

e,

$$
g_{i}=\frac{1}{\epsilon_{0}} \int_{\Omega} W_{i} \rho_{i} d \Omega
$$

onde: $1 \leq i, j \leq K$.

Se as funções peso $W_{k}$ forem iguais às funções de forma $\phi_{i}(z, r)$, diz-se que o método é o de Galerkin.

As integrais sobre o domínio $\Omega$ da equação 5.68 quando se faz a discretização do domínio torna-se:

$$
\sum_{n=1}^{N} \int_{\Omega_{n}}\left[\varepsilon_{0} \nabla V \cdot \nabla \phi_{n}-\rho \phi_{n}\right] d \Omega=0,
$$

onde $n$ representa cada um dos elementos do domínio $\Omega$ que foi discretizado e $N$ é o número de elementos da discretização. Observa-se ainda que, tipicamente, não há variação do potencial escalar elétrico na direção normal à superfície do problema e, neste caso, a integral sobre a superfície se anula.

Como há simetria axial, o elemento de área $d \Omega$ é aproximado por $d \Omega=2 \pi r_{0} d \rho d z$, onde $r_{0}$ é o baricentro do triângulo. Assim, a equação acima é reescrita como:

$$
\sum_{n=1}^{N} 2 \pi r_{0} \int_{\Omega_{n}}\left[\varepsilon_{0} \nabla V \cdot \nabla \phi_{n}-\rho \phi_{n}\right] d \rho d z=0 .
$$

Portanto, para problemas que apresentam simetria axial, as contribuições são multiplicadas pelo fator $2 \pi r_{0}$ na determinação do potencial escalar elétrico.

\subsubsection{Determinação do Potencial Vetor Magnético: Método Variacional}

Aplicação do método variacional em problemas eletromagnéticos pode ser encontrada em [47], e é aqui sintetizada, para a determinação do potencial vetor magnético. Inicialmente, quando se utiliza o método variacional em problemas cujo domínio $\Omega$ é discretizado, considera-se que o funcional $F$ deste domínio é dado por:

$$
F=\sum_{i=0}^{N} F_{i},
$$

onde os $F_{i}$ funcionais, associados a cada elemento $i$ da discretização do domínio $\Omega$, são somados. Considerando que existam $K$ nós nesta discretização, o funcional $F$ deve ser minimizado para cada um dos potenciais dos nós $V_{k}$ da malha, assim: 


$$
\frac{\partial F}{\partial V_{k}}=\sum_{i=0}^{N} \frac{\partial F_{i}}{\partial V_{k}}=0
$$

Observa-se que, embora a soma seja sobre todos os elementos da malha, $F_{i}$ será não nulo somente para os elementos que tem em comum o $k$-ésimo nó. Para a malha triangular do domínio representado na FIG. 5.4, a soma dos funcionais para o nó 13 é:

$$
\sum_{i=1}^{32} \frac{\partial F_{i}}{\partial V_{13}}=\frac{\partial F_{11}}{\partial V_{13}}+\frac{\partial F_{12}}{\partial V_{13}}+\frac{\partial F_{13}}{\partial V_{13}}+\frac{\partial F_{20}}{\partial V_{13}}+\frac{\partial F_{21}}{\partial V_{13}}+\frac{\partial F_{22}}{\partial V_{13}}
$$

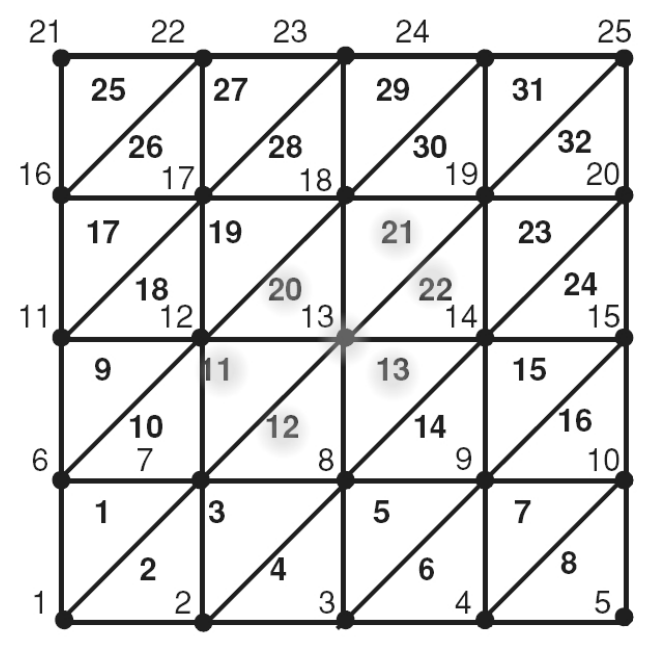

Figura 5.4: Modelo de discretização de um domínio retangular utilizando triângulos. Os elementos estão numerados em negrito. Os elementos que tem o nó 13 em comum são os de número: $11,12,13,20,21$ e 22 .

Pode-se mostrar [47] que o funcional utilizado para se determinar o vetor potencial magnético é dado por:

$$
F_{i}=\int_{\Omega i}\left[\int_{0}^{B} H d B-J A\right] d \Omega_{i}
$$

Considerando simetria axial, e que o campo magnético relaciona-se com o vetor potencial magnético por $\vec{B}=\nabla \times \vec{A}$, as componentes $B_{\rho}$ e $B_{z}$ são dadas por:

$$
B_{\rho}=\frac{1}{\rho} \frac{\partial A_{z}}{\partial \theta}-\frac{\partial A_{\theta}}{\partial A_{z}}
$$

$\mathrm{e}$

$$
B_{z}=\frac{1}{\rho} \frac{\partial\left(r A_{\theta}\right)}{\partial \rho}-\frac{1}{\rho} \frac{\partial A_{\rho}}{\partial A_{\theta}}
$$

Devido à simetria axial, $\mathbf{A}$ é perpendicular ao plano de estudo e, portanto, $A=A_{\theta}$, $A_{z}=0$ e $A_{\rho}=0$. Assim, as expressões acima são simplificadas: 


$$
B_{\rho}=-\frac{\partial A}{\partial z}
$$

e

$$
B_{z}=\frac{A}{\rho}+\frac{\partial A}{\partial \rho} .
$$

O primeiro termo de 5.77 , denominado $F_{i 1}$ é dado por:

$$
F_{i 1}=2 \pi r_{0} \int_{\Omega i}\left[\int_{0}^{B} H d B\right] d \rho d z .
$$

Calculando $\partial F_{i 1} / \partial A_{k}$ :

$$
\frac{\partial F_{i 1}}{\partial A_{k}}=2 \pi r_{0} \int_{\Omega i} \frac{\partial}{\partial B}\left[\int_{0}^{B} H d B\right] \frac{\partial B}{\partial A_{k}} d \rho d z .
$$

Considerando $\vec{H}=\left(1 / \mu_{0}\right) \vec{B}=\nu_{0} \vec{B}$, e que os elementos da malha são de primeira ordem, assim o potencial magnético, de maneira similar a 5.53 é escrito como:

$$
A(\rho, z)=\frac{1}{D} \sum_{l=1}^{3}\left(p_{l}+s_{l} \rho+q_{l} z\right) A_{l} .
$$

Portanto, o campo magnético é constante em seu interior, assim, a última expressão tornase:

$$
\frac{\partial F_{i 1}}{\partial A_{k}}=2 \pi r_{0} \frac{D}{2} \nu_{0} B \frac{\partial B}{\partial A_{k}}=\frac{\pi r_{0} D \nu_{0}}{2} \frac{\partial B^{2}}{\partial A_{k}} .
$$

Uma vez que o módulo do campo magnético é dado por:

$$
B^{2}=B_{\rho}^{2}+B_{z}^{2}
$$

o termo $\partial B^{2} / \partial A_{k}$ é:

$$
\frac{\partial B^{2}}{\partial A_{k}}=2 B_{\rho} \frac{\partial B_{\rho}}{\partial A_{k}}+2 B_{z} \frac{\partial B_{z}}{\partial A_{z}} .
$$

O primeiro termo do lado direito da expressão acima é calculado utilizando 5.78, assim:

$$
B_{\rho} \frac{\partial B_{\rho}}{\partial A_{k}}=\left(-\frac{\partial A}{\partial z}\right) \frac{\partial}{\partial A_{k}}\left(-\frac{\partial A}{\partial z}\right) .
$$

A partir de $5.82 \partial A / \partial z$ é:

$$
\frac{\partial A}{\partial z}=\frac{1}{D} \sum_{l=1}^{3} q_{l} A_{l}
$$

que substituindo em 5.85 leva à: 


$$
B_{\rho} \frac{\partial B_{\rho}}{\partial A_{k}}=\left(-\frac{1}{D} \sum_{l=1}^{3} q_{l} A_{l}\right) \frac{\partial}{\partial A_{k}}\left(-\frac{1}{D} \sum_{l=1}^{3} q_{l} A_{l}\right)=\frac{1}{D^{2}} \sum_{l=1}^{3} q_{l} q_{k} A_{l}
$$

Determinando agora o segundo termo do lado direito da igualdade 5.84, utilizando 5.79, tem-se:

$$
B_{z} \frac{\partial B_{z}}{\partial A_{z}}=\left(\frac{A}{\rho}+\frac{\partial A}{\partial \rho}\right) \frac{\partial}{\partial A_{z}}\left(\frac{A}{\rho}+\frac{\partial A}{\partial \rho}\right) .
$$

A partir de $5.82 \partial A / \partial \rho$ é:

$$
\frac{\partial A}{\partial \rho}=\frac{1}{D} \sum_{l=1}^{3} s_{l} A_{l}
$$

Seja a seguinte aproximação para $A / \rho: A / \rho=A^{\prime} / r_{0}$, onde $A^{\prime}=\left(A_{1}+A_{2}+A_{3}\right) / 3$ é o potencial vetor magnético médio dos três nós do elemento, e $r_{0}$ é a distância do centróide do elemento ao eixo axial. Assim:

$$
A / \rho=\sum_{l=1}^{3} \frac{A_{l}}{3 r_{0}}
$$

$B_{z}$ pode então ser determinado:

$$
B_{z}=\frac{A}{\rho}+\frac{\partial A}{\partial \rho}=\sum_{l=1}^{3} \frac{A_{l}}{3 r_{0}}+\frac{1}{D} \sum_{l=1}^{3} s_{l} A_{l}=\sum_{l=1}^{3} A_{l}\left(\frac{1}{3 r_{0}}+\frac{s_{l}}{D}\right) .
$$

O termo $\partial B_{z} / \partial A_{k}$ pode ser calculado a partir de 5.79:

$$
\frac{\partial B_{z}}{\partial A_{z}}=\frac{1}{3 r_{0}}+\frac{s_{k}}{D}
$$

Substituindo as duas últimas expressões em 5.87 tem-se:

$$
B_{z} \frac{\partial B_{z}}{\partial A_{z}}=\left[\sum_{l=1}^{3} A_{l}\left(\frac{1}{3 r_{0}}+\frac{s_{l}}{D}\right)\right]\left(\frac{1}{3 r_{0}}+\frac{s_{k}}{D}\right)
$$

que pode ser reescrita como:

$$
B_{z} \frac{\partial B_{z}}{\partial A_{z}}=\frac{1}{D^{2}} \sum_{l=1}^{3} A_{l}\left(\frac{D}{3 r_{0}}+s_{l}\right)\left(\frac{D}{3 r_{0}}+s_{k}\right)=\frac{1}{D^{2}} \sum_{l=1}^{3} A_{l} f_{l} f_{k}
$$

onde, $f_{l}=\frac{D}{3 r_{0}}+s_{l}$.

Substituindo 5.86 e 5.89 em 5.84 tem-se:

$$
\frac{\partial B^{2}}{\partial A_{k}}=\frac{2}{D^{2}} \sum_{l=1}^{3} A_{l}\left(q_{l} q_{k}+f_{l} f_{k}\right)
$$

Aplicando esta última equação em 5.83, tem-se: 


$$
\frac{\partial F_{i 1}}{\partial A_{k}}=\frac{\pi r_{0} D \nu_{0}}{2} \frac{\partial B^{2}}{\partial A_{k}}=\frac{\pi r_{0} \nu_{0}}{D} \sum_{l=1}^{3} A_{l}\left(q_{l} q_{k}+f_{l} f_{k}\right) .
$$

A determinação do segundo termo do lado direito do funcional 5.77 é realizada por meio da multiplicação pelo fator de $2 \pi r_{0}$, sendo facilmente demonstrado que:

$$
\frac{\partial F_{i 2}}{\partial A_{k}}=\frac{\pi r_{0} J D}{3}
$$

Assim, utilizando 5.90 e 5.91:

$$
\frac{\partial F_{i}}{\partial A_{k}}=\pi r_{0} D\left[\frac{\nu_{0}}{D^{2}} \sum_{l=1}^{3} A_{l}\left(q_{l} q_{k}+f_{l} f_{k}\right)-\frac{J}{3}\right] .
$$

Utilizando MEF, serão realizadas diversas simulações de estruturas com PPM, as quais são compostas basicamente por ímãs permanentes. Neste caso, para ímãs permanentes, o funcional é [47]:

$$
F_{i}=2 \pi r_{0} \int_{\Omega_{i}} \frac{\nu_{0}}{2}\left(B-B_{r}\right)^{2} d \Omega=\pi r_{0} \int_{\Omega_{i}} \nu_{0} B_{i}^{2} d \Omega=\frac{\pi r_{0} \nu_{0} B_{i}^{2} D}{2},
$$

onde $B_{r}$ é a densidade de fluxo remanente do ímã. Neste caso, considera-se o campo magnético como sendo uniforme dentro do elemento. $\mathrm{O}$ passo seguinte consiste em determinar $\partial F_{i} / \partial A_{k}$, ou seja:

$$
\frac{\partial F_{i}}{\partial A_{k}}=\frac{\pi r_{0} \nu_{0} D}{2} \frac{\partial B_{i}^{2}}{\partial A_{k}}
$$

onde:

$$
B_{i}^{2}=\left(B_{\rho}-B_{r \rho}\right)^{2}+\left(B_{z}-B_{r z}\right)^{2}
$$

e $B_{r \rho}$ e $B_{r z}$ são as componentes do campo magnético remanente do ímã nas direções $\widehat{\rho}$ e $\widehat{z}$, respectivamente. Desta forma,

$$
\frac{\partial B_{i}^{2}}{\partial A_{k}}=2\left(B_{\rho}-B_{r \rho}\right) \frac{\partial}{\partial A_{k}}\left(B_{\rho}-B_{r \rho}\right)+2\left(B_{z}-B_{r z}\right) \frac{\partial}{\partial A_{k}}\left(B_{z}-B_{r z}\right)
$$

O primeiro termo do lado direito da expressão acima pode ser escrito como:

$$
\begin{gathered}
\left(B_{\rho}-B_{r \rho}\right) \frac{\partial}{\partial A_{k}}\left(B_{\rho}-B_{r \rho}\right)=\left(-\frac{\partial A}{\partial z}-B_{r \rho}\right) \frac{\partial}{\partial A_{k}}\left(-\frac{\partial A}{\partial z}-B_{r \rho}\right)= \\
=\left(-\frac{1}{D} \sum_{l=1}^{3} q_{l} A_{l}-B_{r \rho}\right)\left(-\frac{q_{k}}{D}\right) \\
\left(B_{\rho}-B_{r \rho}\right) \frac{\partial}{\partial A_{k}}\left(B_{\rho}-B_{r \rho}\right)=\frac{1}{D^{2}} \sum_{l=1}^{3} q_{k} q_{l} A_{l}+\frac{q_{k} B_{r \rho}}{D}
\end{gathered}
$$


O segundo termo do lado direito de 5.92, é calculado utilizando 5.88:

$$
\left(B_{z}-B_{r z}\right) \frac{\partial}{\partial A_{k}}\left(B_{z}-B_{r z}\right)=\left[\sum_{l=1}^{3} A_{l}\left(\frac{1}{3 r_{0}}+\frac{s_{l}}{D}\right)-B_{r z}\right]\left(\frac{1}{3 r_{0}}+\frac{s_{k}}{D}\right)
$$

Seja $f_{l}=s_{l}+D / 3 r_{0}$, a expressão acima pode ser simplificada:

$$
\left(B_{z}-B_{r z}\right) \frac{\partial}{\partial A_{k}}\left(B_{z}-B_{r z}\right)=\frac{1}{D^{2}} \sum_{l=1}^{3} f_{k} f_{l} A_{l}-\frac{f_{k} B_{r z}}{D} .
$$

Utilizando 5.93 e 5.94 em 5.92 tem-se:

$$
\frac{\partial B_{i}^{2}}{\partial A_{k}}=\frac{2}{D^{2}}\left[\sum_{l=1}^{3}\left(q_{k} q_{l}+f_{k} f_{l}\right) A_{l}+D\left(q_{k} B_{r \rho}-f_{k} B_{r z}\right)\right] .
$$

Assim, finalmente, o termo $\partial F_{i 1} / \partial A_{k}$ está totalmente determinado:

$$
\frac{\partial F_{i 1}}{\partial A_{k}}=\frac{\pi r_{0} \nu_{0}}{D}\left[\sum_{l=1}^{3}\left(q_{k} q_{l}+f_{k} f_{l}\right) A_{l}+D\left(q_{k} B_{r \rho}-f_{k} B_{r z}\right)\right] .
$$

\subsection{Método de Aproximação Sucessiva (MAS)}

As ferramentas computacionais utilizadas em simulações de dispositivos que operam na condição FSCL precisam ser capazes de determinar com boa precisão a solução do problema autoconsistente das cargas espaciais. O ponto fundamental, na condição FSCL, é como determinar as trajetórias das partículas que dependem dos campos sendo que estes, por sua vez, dependem do movimento das partículas. Este problema passa, portanto, por uma solução conjunta das equações dos campos e das trajetórias. O MAS é adotado em softwares como o EGUN2, o Trak e o MICHELLE, sendo descrito a seguir.

A primeira aproximação para os campos é aquela em que não se consideram as cargas espaciais ( solução da equação de Laplace). As trajetórias das partículas, nesta primeira aproximação, são então calculadas nestes campos. Estas trajetórias determinam uma distribuição de cargas no domínio do problema. Os novos campos aproximados, na segunda iteração, podem ser calculados devido aos campos gerados pelas cargas espaciais depositadas e, estes, por sua vez, são utilizados para se determinar a segunda aproximação das trajetórias das partículas. Tem-se uma nova aproximação de cargas espaciais depositadas e os novos campos são calculados.

Este procedimento é repetido até que algum critério de convergência seja atingido. A título de exemplo, um critério de convergência pode ser aquele em que, dado um plano afastado do catodo, as diferenças entre as inclinações das trajetórias das partículas, neste plano, em duas iterações consecutivas sejam inferiores a algum $\varepsilon$. Usualmente não mais que 20 iterações são necessárias para se obter a precisão necessária. 
A deposição de cargas, utilizando-se o MAS, é realizada como segue. Inicialmente, as partículas são discretizadas, neste caso, utilizando o modelo PIC. A superfície do catodo é subdivida em $n$ regiões, com uma macropartículas associada a cada uma delas. A $j$-ésima macropartícula , $1 \leq j \leq n$, transporta uma corrente $I_{j}$, que é calculada a partir da área do catodo e da distribuição da densidade de corrente de acordo com a Lei de Child-Langmuir. Seja a trajetória da $j$-ésima macropartícula que transporta a corrente $I_{j}$ e atravessa o $i$-ésimo elemento, tal como o modelo representado pela FIG. 5.5. A posição $x_{j}^{n}$ representa o vetor posição da $j$-ésima macropartículas no $n$-ésimo passo. Assim, $x_{j}^{n}=\mathbf{x}_{j}[n]$ e $x_{j}^{n+1}=\mathbf{x}_{j}[n+$ $1]$, onde $\mathbf{x}_{j}[n]$ e $\mathbf{x}_{j}[n+1]$ são os vetores posições em $2 \mathrm{D}$.

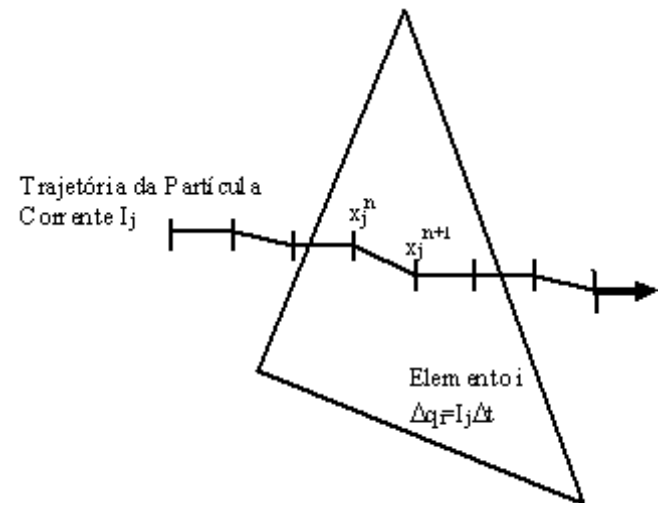

Figura 5.5: Trajetória da $j$-ésima macropartícula e, a respectiva, deposição de carga no $i$ ésimo elemento da malha.

Assim, a carga depositada $q_{j}^{n+1}$ entre os passos $n$ e $n+1$ é

$$
q_{j}^{n+1}=I_{j} \Delta \tau
$$

onde $\Delta \tau$ é o tempo gasto para percorrer a distância na célula no intervalo considerado. $\mathrm{O}$ intervalo de tempo $\Delta \tau$ é dado por:

$$
\Delta \tau=\left(\mathbf{x}_{j}[n+1]-\mathbf{x}_{j}[n]\right) / v_{j}^{n+1},
$$

onde $v_{j}^{n+1}$ é a velocidade média da partícula. A densidade de cargas do $i$-ésimo elemento $\rho_{i}$ será acrescida de um fator

$$
\Delta \rho_{i}=\frac{q_{j}^{n+1}}{\Delta V_{i}}=\frac{I_{j} \Delta \tau}{\Delta V_{i}}
$$

onde $\Delta V_{i}$ é o volume do $i$-ésimo elemento.

O MAS pode ser sintetizado de acordo com o fluxograma da FIG. 5.6.

A ponderação é realizada por meio do coeficiente de sobre-relaxação $u$, que utiliza a seguinte relação iterativa para a distribuição das densidades de cargas:

$$
\rho_{i}^{n+1}=(1-u) \rho_{i}^{n-1}+u \rho_{i}^{n}
$$




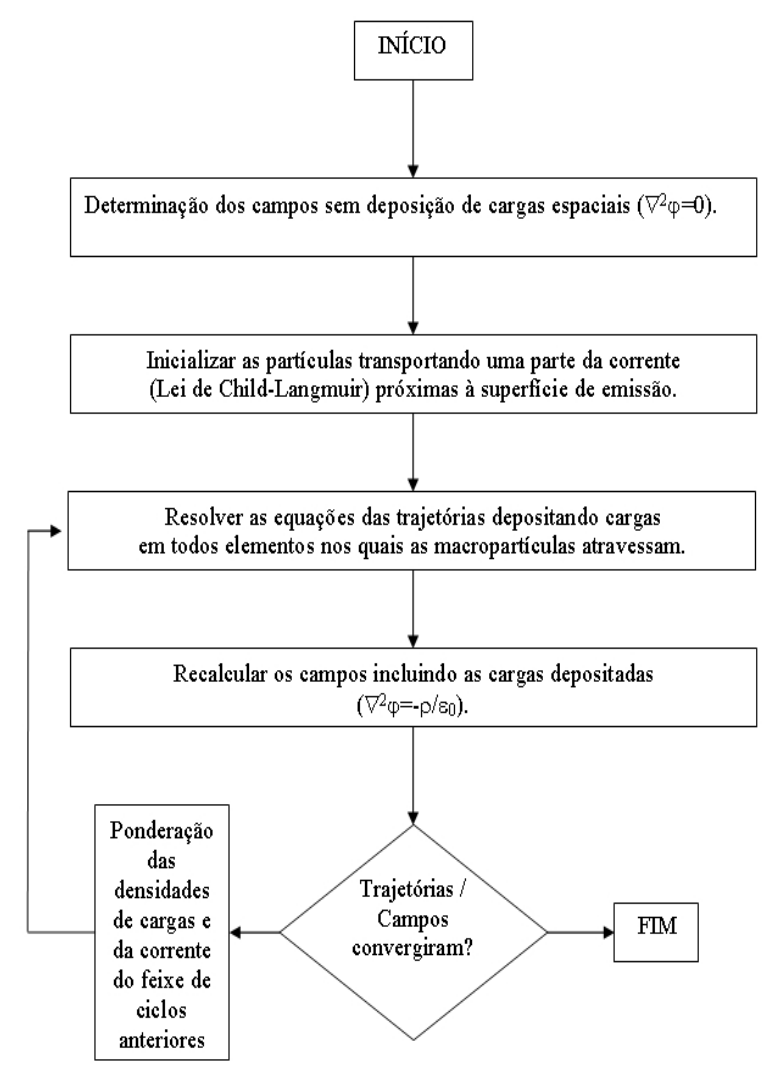

Figura 5.6: Fluxograma do MAS utilizado em ferramentas computacionais para a solução de problemas de canhões de elétrons operando na condição FSCL.

onde $n$ representa a iteração e $i$ o elemento finito. Para a primeira iteração, como não existe distribuição de cargas anterior, $u$ é igual a 1. É possível mostrar, seção 6.2.1, que convergências com um menor número de iterações podem ser obtidas para $0,3 \leq u \leq 0,4$.

\subsection{Sistemas Lineares Esparsos}

Diz-se que um sistema linear de equações é esparso quando apenas um número pequeno dos elementos $a_{i j}$ da matriz são não nulos,ou seja, a matriz é povoada primordialmente com elementos nulos [49]. O uso de métodos da álgebra linear em problemas que envolvam este tipo de matriz, tais como multiplicação e inversão requerem operações aritméticas $O\left(N^{3}\right)$ [50]. Seria extremamente ineficiente realizar operações de multiplicação e soma, percorrendo os laços (loops) sobre um elevado número de elementos nulos. Atualmente, existem diversas técnicas que são utilizadas para o armazenamento de matrizes esparsas.

A seguir são apresentados o método de armazenamento compacto por linha (Compressed Row Storage - CRS) e o método do gradiente conjugado para a solução do sistema de equações que foram utilizados pelos códigos XMGUN e XMAGUN. 


\subsubsection{Método de armazenamento compacto por linha}

Seja a matriz esparsa $A$ que se deseja armazenar de forma compacta de ordem $N$. O esquema de armazenamento CRS, também conhecido como formato de Harwell-Boeing, é baseado no uso de dois vetores:

- $s a$ : armazena os valores não nulos da matriz. Os $N$ primeiros correspondem aos elementos da diagonal. A posição $N+1$ não é utilizada sendo que, em seu conteúdo é armazenado um valor arbitrário. As posições $\geqslant N+2$ de $s a$ armazenam os elementos não-nulos que não pertençam a diagonal, ordenados linha a linha e, para cada linha, coluna a coluna; e

- ija : cada uma das $N$ primeiras posições de ija armazena o índice da matriz sa que contém o primeiro elemento não pertencente à diagonal e não-nulo de $A$. A primeira posição de ija é sempre igual a $N+2$, podendo ser utilizada para determinar $N$. O conteúdo da posição $N+1$ de $i j a$ é uma unidade maior que o índice de $s a$ do último elemento não pertencente à diagonal e não nulo da última linha, podendo ser utilizado para se determinar o número de elementos não-nulos. As posições $\geqslant N+2$ de $i j a$ armazenam o número da coluna correspondente do elemento no vetor sa da matriz $A$.

Assim, como exemplo, considere a matriz $A$ de ordem 5 abaixo:

$$
A=\left[\begin{array}{lllll}
1,0 & 0,0 & 0,0 & 0,0 & 5,0 \\
2,0 & 3,0 & 0,0 & 0,0 & 0,0 \\
0,0 & 0,0 & 6,0 & 0,0 & 0,0 \\
4,0 & 0,0 & 2,0 & 7,0 & 0,0 \\
0,0 & 8,0 & 0,0 & 0,0 & 9,0
\end{array}\right]
$$

A representação compacta de armazenamento baseada no esquema CRS da matriz $A$, considerando os vetores sa e ija é dada por:

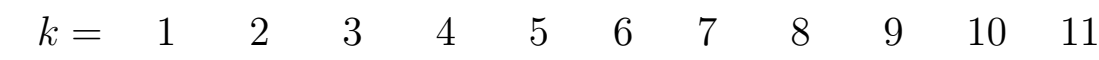

$$
\begin{aligned}
& i j a[k]=\begin{array}{lllllllllll}
7 & 8 & 8 & 9 & 11 & 12 & 5 & 1 & 1 & 3 & 2
\end{array} \\
& s a[k]=\quad 1,0 \quad 3,0 \quad 6,0 \quad 7,0 \quad 9,0 \quad x \quad 5,0 \quad 2,0 \quad 4,0 \quad 2,0 \quad 8,0
\end{aligned}
$$

\subsubsection{Método do Gradiente Biconjugado (MGB)}

Obtém-se utilizando o MGB um procedimento geral para a solução de sistemas lineares $N \times N$ da forma:

$$
A x=b .
$$

Sendo a matriz $A$ esparsa, a grande atratividade deste método reside no fato de se buscar uma solução realizando-se tão somente operações de multiplicação de $A$ ou sua transposta $A^{T}$ por um vetor. Os algoritmos de multiplicação de uma matriz esparsa e sua transposta armazenada, utilizando-se o esquema CRS são, tipicamente, eficientes [50]. 
Para o caso em que $A$ é simétrica e definida positiva ${ }^{2}$ o algoritmo mais simples é baseado na minimização da função $[50,51]$ :

$$
f(x)=\frac{1}{2} x A x-b x
$$

que é minimizada quando o seu gradiente é nulo, ou seja:

$$
\nabla f=A x-b=0
$$

A minimização é realizada pela geração sucessiva de direções de busca $p_{k}$ levando a soluções melhores $x_{k}$. A seguir é apresentado o algoritmo do MGB [50]:

$$
\begin{aligned}
\alpha_{k} & =\frac{\bar{r}_{k} r_{k}}{\bar{p}_{k} A p_{k}} \\
r_{k+1} & =r_{k}-\alpha_{k} A p_{k} \\
\bar{r}_{k+1} & =\bar{r}_{k}-\alpha_{k} A^{T} \bar{p}_{k} \\
\beta_{k} & =\frac{\bar{r}_{k+1} r_{k+1}}{\bar{r}_{k} r_{k}} \\
p_{k+1} & =r_{k}+\beta_{k} p_{k} \\
\bar{p}_{k+1} & =\bar{r}_{k}+\beta_{k} \bar{p}_{k}
\end{aligned}
$$

para $k=1,2, \ldots$. Inicialmente faz-se uma estimativa para o vetor solução $x_{1}$. Em seguida escolhe-se $r_{1}$ como sendo o resíduo

$$
r_{1}=b-A x_{1}
$$

e toma-se $\bar{r}_{1}=\bar{p}_{1}=p_{1}=r_{1}$. A sequência com soluções melhores estimadas tem a forma:

$$
x_{k+1}=x_{k}+\alpha_{k} p_{k} .
$$

Demonstra-se que a solução exata é conseguida com até $N$ iterações utilizando-se aritmética exata [50]. Tipicamente um número maior/menor de iterações pode ser utilizado por meio de algum critério de erro, avaliando-se por exemplo a norma do resíduo gerado por $x_{k+1}$, terminando o laço do algoritmo do MGB acima.

\subsection{Conclusões do Capítulo}

Foi apresentado neste Capítulo a fundamentação física para o problema acoplado envolvendo a determinação do potencial escalar elétrico e das trajetórias das partículas e a metodologia utilizada para resolvê-lo. O potencial escalar elétrico foi obtido a partir da solução da equação de Poisson e as trajetórias das partículas foram estabelecidas resolvendo-se a equação da trajetória que é diferencial de segunda ordem e não linear. A convergência, para

\footnotetext{
${ }^{2}$ Uma matriz $A$ é dita ser definida positiva se $x^{T} A x>0$, para todo $x \neq 0$.
} 
este problema acoplado, foi obtida utilizando-se o MAS. A abordagem baseada no PIC foi utilizada uma vez que, nos dias atuais, é impossível modelar todas as partículas do feixe de elétrons. Os potenciais elétricos foram determinados utilizando-se o MEF. Neste caso, o domínio do problema foi discretizado em um número finito de triângulos, denominados de elementos finitos e, em seguida, aplicado à equação que governa os elementos e, finalmente, faz-se reunião de todos os elementos do domínio. A união de todos os elementos leva a um sistema de equações, tipicamente esparso e simétrico. Para problemas, cuja discretização do domínio leva a um número grande de nós (geralmente $>10.000$ ), a matriz resultante apresenta um número elevado de zeros, sendo, nos dias atuais inviável armazenar todos os elementos (nulos e não nulos). A solução apresentada foi utilizar métodos (a) de armazenamento eficientes apenas para os valores não nulos e (b) para resolução do sistema assim armazenado. Assim, foram abordadas as técnicas para armazenamento do tipo CRS e o MGB para resolução de sistemas esparsos simétricos. 


\section{Capítulo 6}

\section{Resultados e Discussão}

Os resultados e discussões deste trabalho são apresentados em três seções. A seção 6.1 apresenta os resultados de simulações realizadas com o software EGUN, desenvolvido por Herrmannsfeldt e disponibilizado para computadores pessoais em 1988. A partir de componentes físicos de um canhão de elétrons existentes, foram determinadas as geometrias de catodos com grade e shadow-grid e de anodos. Em função da variação dos parâmetros encontrados nos componentes foram realizadas simulações com o EGUN considerando a variação de cinco parâmetros: (a) raio do catodo; (b) ângulo do eletrodo de focalização; (c) separação catodo-anodo; (d) separação grade catodo; e (e) tensão de grade. Resultados das simulações para corrente e perveância, relativos aos parâmetros (a)-(e) são apresentados e discutidos.

As ferramentas computacionais XMGUN e XMAGUN foram desenvolvidas utilizando a linguagem $C$ no ambiente Windows XP. Tanto o compilador quanto o uso de estruturas especiais de armazenamento eficiente de dados, interface gráfica e geração de malhas utilizadas, basearam-se nos sistemas opensource: DevC++ [52], STL [53, 54, 55], OpenGL [56] / GLUI [57] e EasyMesh [58] respectivamente (vide Apêndice A). A seção 6.2 apresenta, inicialmente, testes de benchmark. Os testes de benchmark foram realizados confrontando-se os resultados da simulação de um diodo plano de Pierce com os resultados analíticos. Resultados de simulações de canhões de elétrons com e sem grade, também, são apresentados e os resultados são comparados com o EGUN. Fez-se ainda, utilizando o XMGUN, a simulação de um coletor sem, entretanto, considerar a emissão de elétrons secundários.

Utilizando-se o XMAGUN, seção 6.3, são realizados dois testes de benchmark:

- PPM com ímãs permanentes separados pelo vácuo: são apresentados resultados de simulações com 1 (um), 2 (dois) e 20 (vinte) ímãs permanentes. Para 20 (vinte) ímãs permanentes são comparados a solução do campo magnético na direção axial utilizando-se FEM associado ao MGB com a solução analítica, 3.63, e, também, com a solução integral, 3.64, onde foi desenvolvido um programa específico para o cálculo da integral; e

- PPM com ímãs permanentes separados por pole pieces: embora a solução de Santra et al. é válida tão somente para uma estrutura PPM com pole pieces infinita, os resulta- 
dos, para o campo axial obtidos analiticamente, são confrontados com: (a) o campo no centro de uma estrutura PPM com cinco pole pieces, variando-se um dos parâmetros da estrutura do pole piece, obtidos em simulações com o XMGUN; (b) o programa ANSYS.

Resultados de simulações com o XMGUN de PPM com diferentes estruturas de pole pieces também são apresentados.

Finalmente, os resultados dos campos magnéticos na direção axial e radial, obtidos a partir do XMAGUN, para um PPM separado pelo vácuo com 20 (vinte) ímãs permanentes, são mapeados e utilizados pelo XMGUN para se determinar a dinâmica das partículas na região de deriva, para 5 (cinco) diferentes energias de aceleração do feixe de elétrons.

\subsection{Simulações com o EGUN}

Um dos elementos cruciais de uma TWT é o canhão de elétrons. É relevante, para o sucesso do projeto, durante a fase de concepção de um canhão de elétrons, a realização de simulações. O uso de ferramentas computacionais concebidas para simular os canhões de elétrons estão em pleno desenvolvimento. A utilização destas ferramentas computacionais são justificadas não só devido à redução dos custos de projeto durante o período de concepção mas, também, pela complexidade intrínseca dos modelos existentes atualmente.

EGUN, um trabalho seminal, apresenta resultados satisfatórios em simulações de canhões de elétrons. O EGUN permite:

- trabalhar na condição FSCL, que é caracterizado pelo fato de não mais elétrons poderem ser extraídos do catodo devido à repulsão mútua entre os elétrons do feixe;

- facilmente construir grades e, durante a simulação, mudar o potencial sobre elas; e

- resolver as equações das trajetórias dos elétrons modelados relativisticamente.

Utilizando EGUN, o erro devido à simulação do diodo plano padrão de Pierce é de aproximadamente $1 \%$ [59]. Resultados obtidos em simulações de canhões de elétrons utilizando EGUN, como uma ferramenta computacional, visando obter um melhor entendimento de um canhão de elétrons podem ser encontrados em [60] e [61]. O uso do EGUN voltado a um projeto físico de um canhão de elétrons [62] é aqui apresentado.

A geometria do canhão e as variáveis geométricas utilizadas em simulações com o EGUN podem ser observadas na FIG. 6.1 e são: raio do disco do catodo $r_{k}$; raio do catodo $r_{c}$; ângulo do eletrodo de focalização $\theta$; distância catodo-anodo $d$; e distância grade-catodo $g_{d}$.

\subsubsection{Procedimento do Projeto}

Uma faixa de operação para cada uma das variáveis foi estabelecida conforme TAB. 6.1. Em seguida foi investigado o comportamento do canhão de elétrons para cada uma 


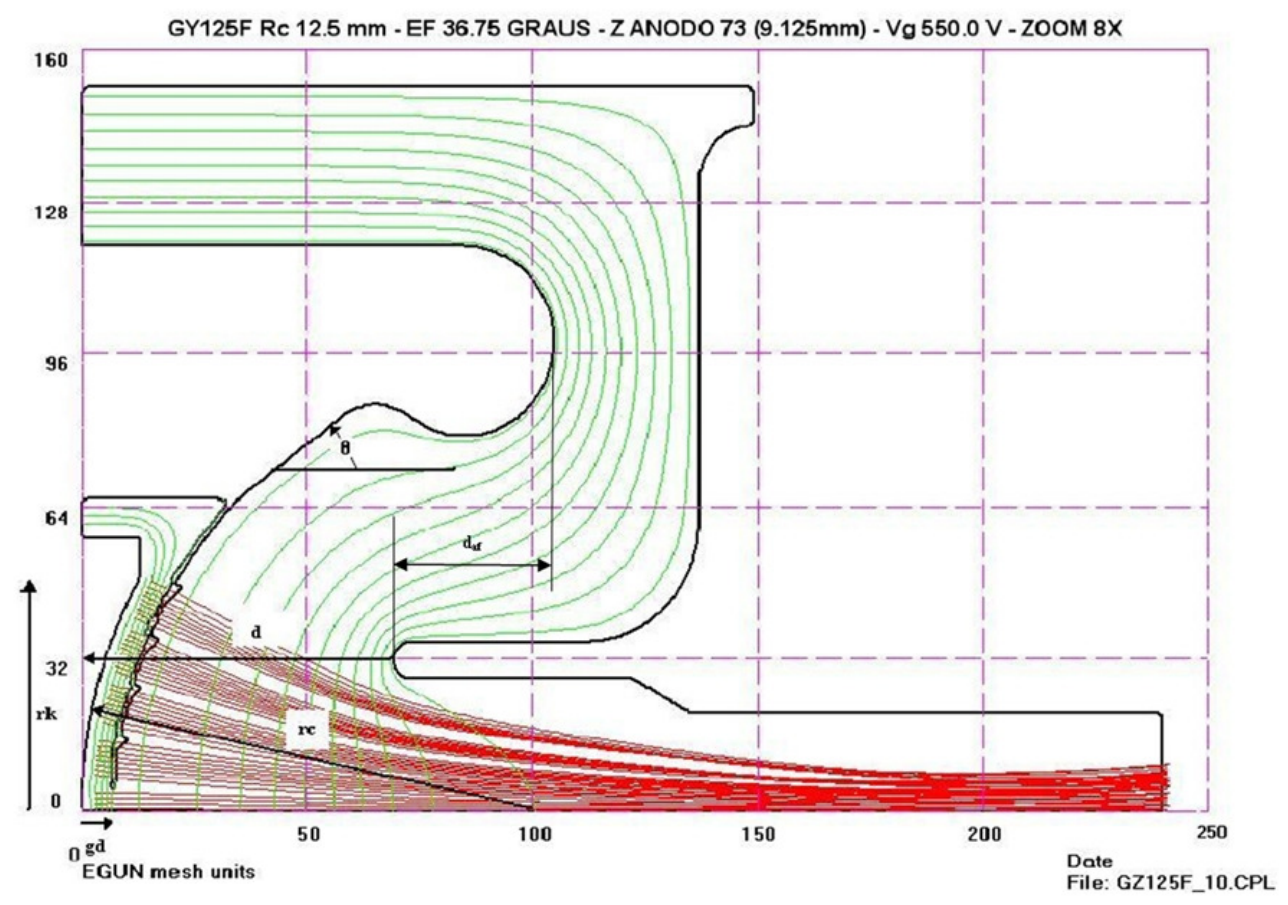

Figura 6.1: Geometria típica do canhão de elétrons e as variáveis geométricas utilizadas em simulações com o EGUN: raio do disco do catodo $r_{k}$; raio do catodo $r_{c}$; ângulo do eletrodo de focalização $\theta$; distância catodo-anodo $d$; e distância grade-catodo $g_{d}$.

das variáveis, operando dentro de sua respectiva faixa de operação, fixando-se as demais. Foram observados alguns parâmetros de resposta nas simulações com o EGUN tais como a perveância, a corrente, o alcance do feixe de elétrons e a cintura. A tensão do anodo foi fixada em $30 \mathrm{kV}$ em todas as simulações.

Os diversos elementos constitutivos do canhão de elétrons, tais como eletrodo de focalização, grade de interceptação, shadow-grid, anodo etc., devem ser modelados no EGUN com uma separação de uma unidade de malha e, para tanto, um fator de escala de 8 foi utilizado.

Embora o modelo físico das grades de interceptação utilizadas no canhão de elétrons sejam, geralmente, retangulares, FIG. 6.2(a), as simulações utilizando o EGUN só é possível se considerarmos o modelo aproximado em forma de anéis concêntricos, FIG. 6.2(b), que é uma limitação do modelo 2D com simetria axial.

Foram também realizadas simulações com o EGUN utilizando-se como parâmetros ge-

Tabela 6.1: Faixas de utilização das variáveis geométricas do canhão de elétrons em simulações com o EGUN.

\begin{tabular}{cccc}
\hline Variável & Valor Inicial & Valor Final & Incremento \\
\hline$r_{c}($ mm $)$ & 11,9 & 13,1 & 0,3 \\
$\theta($ graus $)$ & 6,2 & 39,2 & 3 \\
$d(m m)$ & 8,5 & 9,25 & 0,125 \\
$g_{d}(m m)$ & 0,9 & 1,1 & 0,1 \\
$V_{g d}(V)$ & 0 & 600 & 100 \\
\hline
\end{tabular}




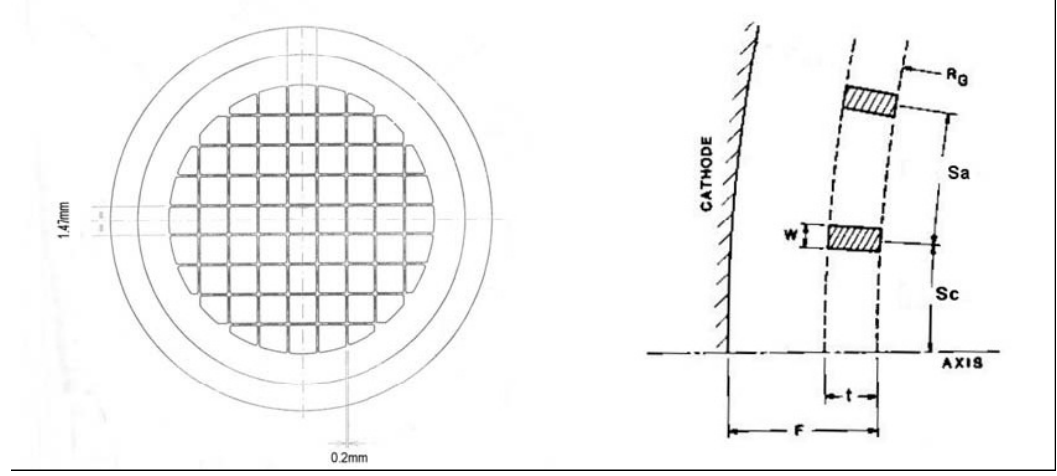

Figura 6.2: (a) Vista frontal da grade de controle e (b) aproximação da grade original, utilizada nas simulações com o EGUN, por meio de anéis concêntricos.

ométricos valores obtidos a partir de componentes físicos existentes no laboratório. A FIG. 6.3 apresenta um catodo com shadow-grid (a) e o eletrodo de focalização montado com a grade de controle. Nestas simulações os seguintes parâmetros foram mantidos fixos:

- Tensão do Anodo: $30 \mathrm{kV}$;

- Tensão da Grade de Controle: $500 \mathrm{~V}$;

- Distância Anodo-Eletrodo de Focalização $\left(d_{a f}\right): 3.2 \mathrm{~mm}$;

- Ângulo do Eletrodo de Focalização $\theta: 37^{\circ}$; e

- Raio do disco do Catodo $r_{k}: 6,2 \mathrm{~mm}$.

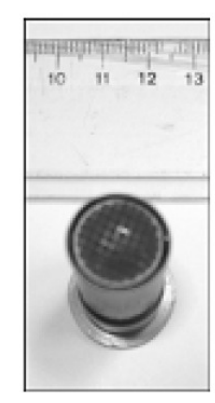

(a)

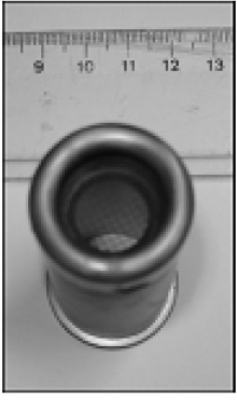

(b)

Figura 6.3: Componentes físicos de um canhão de elétrons: (a) catodo com shadow-grid e (b) eletrodo de focalização com a grade de controle.

A TAB. 6.2 apresenta, a partir das medidas físicas do raio do catodo dos componentes, a distância grade-catodo utilizadas nas simulações com o EGUN. 


\subsubsection{Resultados}

\section{Simulações dos Modelos Teóricos com o EGUN}

A seguir serão apresentados os resultados relevantes observados nas simulações com o EGUN para cada uma das cinco variáveis presentes na TAB. 6.1.

(a) Raio do disco do catodo

A FIG. 6.4 apresenta o comportamento da perveância em função da distância catodoanodo tomando-se o raio do catodo como um parâmetro. Pode-se observar que (i) para uma mesma distância catodo-anodo, a perveância sofre pequena queda com o aumento do raio do catodo; (ii) fixado um raio do catodo, a perveância aumenta com a aproximação catodoanodo. A corrente do feixe apresenta o mesmo comportamento.

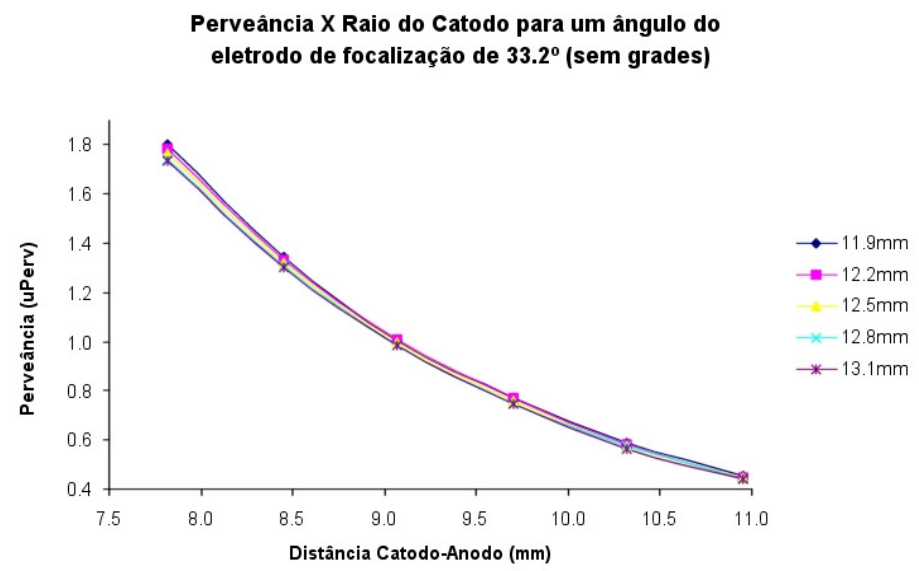

Figura 6.4: Perveância como uma função da distância catodo-anodo tendo o raio do catodo como parâmetro. O ângulo do eletrodo de focalização é de $33,2^{\circ}$.

(b) Ângulo do eletrodo de focalização

É observado na FIG. 6.5 o comportamento da perveância em função da distância catodoanodo tomando-se, como parâmetro, o ângulo do eletrodo de focalização. Pode-se observar

Tabela 6.2: Valores para os Raios do Catodo e distâncias Grade-Catodo utilizadas em simulações com o EGUN obtidas a partir de componentes físicos existentes no laboratório.

\begin{tabular}{ccc}
\hline Canhão & $\begin{array}{c}\text { Raio do Catodo } \\
r_{c}(\mathrm{~mm})\end{array}$ & $\begin{array}{c}\text { Distância Grade-Catodo } \\
g_{d}(\mathrm{~mm})\end{array}$ \\
\hline G1 & 13,5 & 1,7 \\
G1A & 13,5 & 1,0 \\
G1AX & 13,5 & 2,0 \\
G1AY & 13,5 & 1,5 \\
G2A & 14,5 & 1,0 \\
G2Y & 14,6 & 0,9 \\
GG2 & 14,5 & 2,8 \\
GG3 & 12,8 & 1,0 \\
\hline
\end{tabular}


que (i) para uma mesma distância catodo-anodo, a perveância cresce com o aumento do ângulo do eletrodo de focalização; (ii) uma mesma perveância pode ser obtida para diferentes ângulos do eletrodo de focalização pelo ajuste da distância catodo-anodo. A corrente do feixe apresenta o mesmo comportamento.

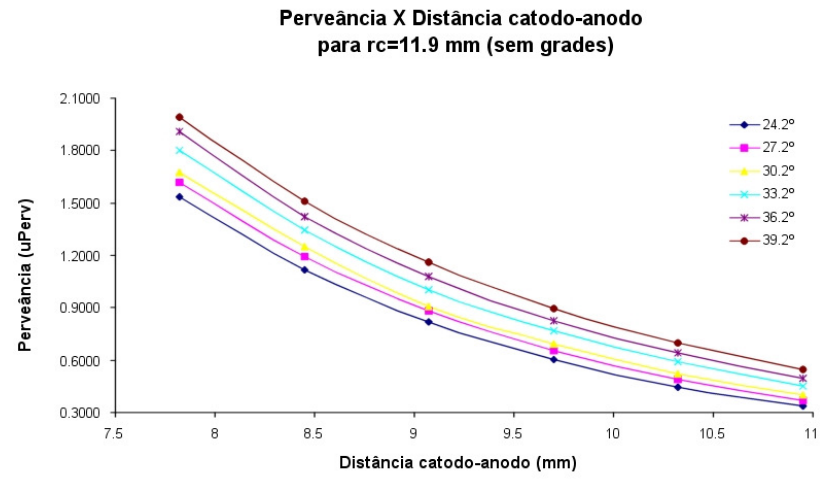

Figura 6.5: Perveância como uma função da distância catodo-anodo tendo o ângulo do eletrodo de focalização como parâmetro. $\mathrm{O}$ raio do catodo é de $11,9 \mathrm{~mm}$.

\section{(c) Distância catodo-anodo}

A FIG. 6.6 apresenta o comportamento da corrente em função da tensão aplicada na grade de controle tomando-se a separação catodo-anodo como parâmetro. Observa-se que $(i)$ para uma mesma tensão da grade de controle a corrente do feixe diminui com o aumento da separação catodo-anodo; (ii) para uma mesma separação catodo-anodo é possível aumentar a corrente aumentando-se a tensão da grade de controle; (iii) a mesma corrente pode ser obtida para diferentes distâncias de separação do catodo-anodo pelo ajuste da tensão da grade de controle. A perveância apresenta o mesmo comportamento.

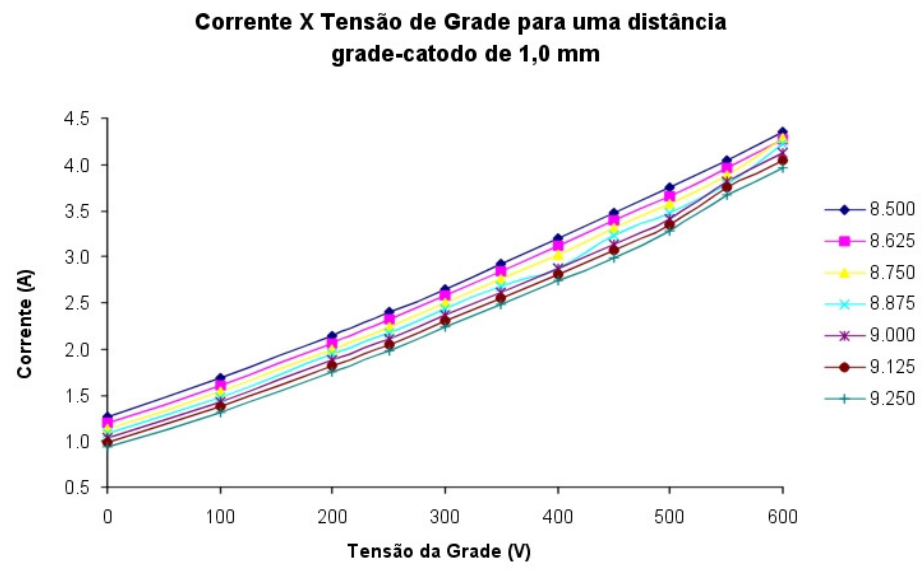

Figura 6.6: Corrente do feixe como uma função da tensão da grade de controle tendo a separação catodo-anodo como parâmetro. A distância grade-catodo é de 1,0 mm. 
A FIG. 6.7 apresenta o comportamento da corrente em função da tensão aplicada na grade de controle tomando-se como parâmetro a separação grade-catodo. Observa-se que $(i)$ para uma mesma tensão da grade de controle a corrente do feixe aumenta com a aproximação grade-catodo; (ii) para uma mesma separação grade-catodo é possível aumentar a corrente aumentando-se a tensão da grade de controle; (iii) a mesma corrente pode ser obtida para diferentes distâncias de separação grade-catodo pelo ajuste da tensão da grade de controle. A perveância apresenta o mesmo comportamento.

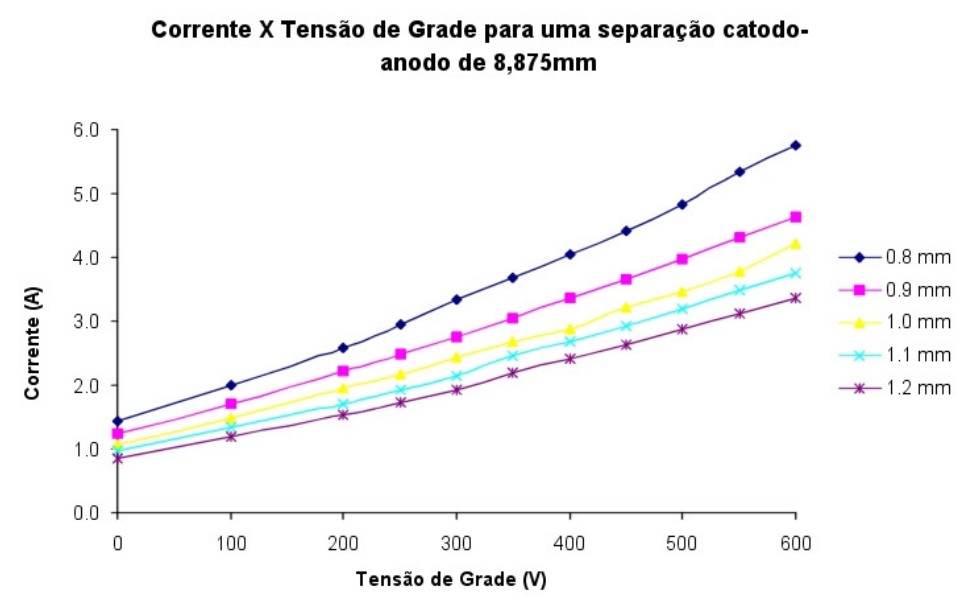

Figura 6.7: Corrente do feixe como uma função da tensão da grade de controle tomando-se como parâmetro a separação grade-catodo. A distância catodo é de $8,875 \mathrm{~mm}$.

(e) Tensão aplicada sobre a grade de controle

É observado na FIG. 6.8 o comportamento da corrente em função da separação catodoanodo tomando-se como parâmetro a tensão da grade de controle. Observa-se que (i) para uma mesma separação catodo-anodo a corrente do feixe cresce com o aumento da tensão da grade de controle; (ii) para uma mesma tensão da grade de controle é possível aumentar a corrente diminuindo-se a separação catodo-anodo. A perveância apresenta o mesmo comportamento.

\section{Simulações com o EGUN a partir de Modelos Físicos Existentes}

Foram realizadas simulações com o EGUN dos canhões constantes na TAB. 6.2. Valores de corrente, perveância e cintura do feixe obtidos nas simulações estão na TAB. 6.3. O canhão com melhor desempenho foi o G2Y com uma corrente de 5, $5 \mathrm{~A}$. Em função de uma possível variação da separação anodo-eletrodo de focalização durante fase de montagem, foi investigado o comportamento do canhão para uma variação, da separação de projeto, em $\pm 0,5 \mathrm{~mm}$. A FIG. 6.9 apresenta o comportamento dos canhões G2A, G2Y e GG2 para a variação acima. Para o canhão G2Y é observado uma variação em corrente de, aproximadamente, $\mp 0,5 \mathrm{~A}$.

O EGUN permite imprimir sobre a superfície do catodo regiões não emissoras de elétrons. Foi investigado também, para o canhão G2Y, o comportamento caso fosse modelado fisi- 


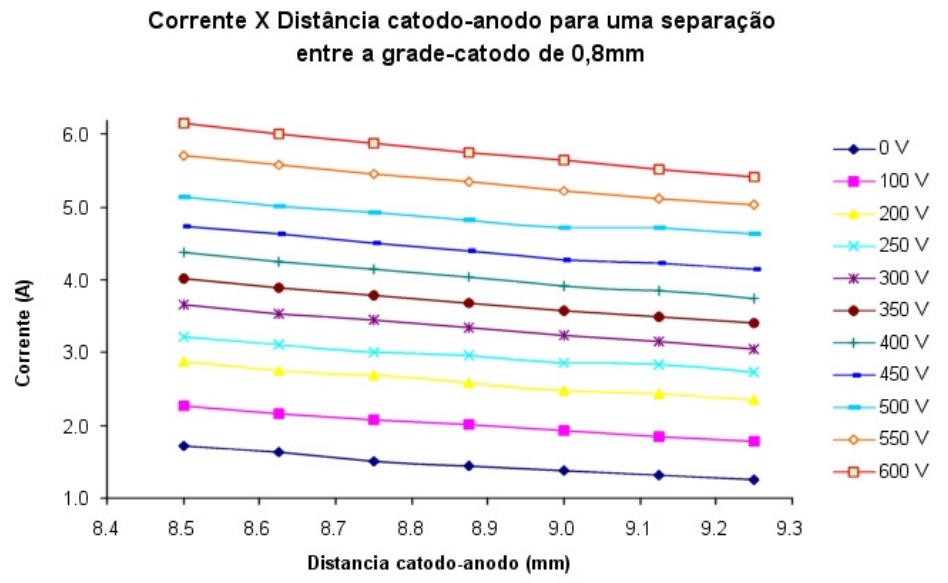

Figura 6.8: Corrente do feixe como uma função da separação catodo-anodo tomando-se a tensão da grade de controle como parâmetro. A distância entre a grade-catodo é de $0,8 \mathrm{~mm}$.

Corrente X Distância catodo-anodo para uma tensão de grade de 500V.

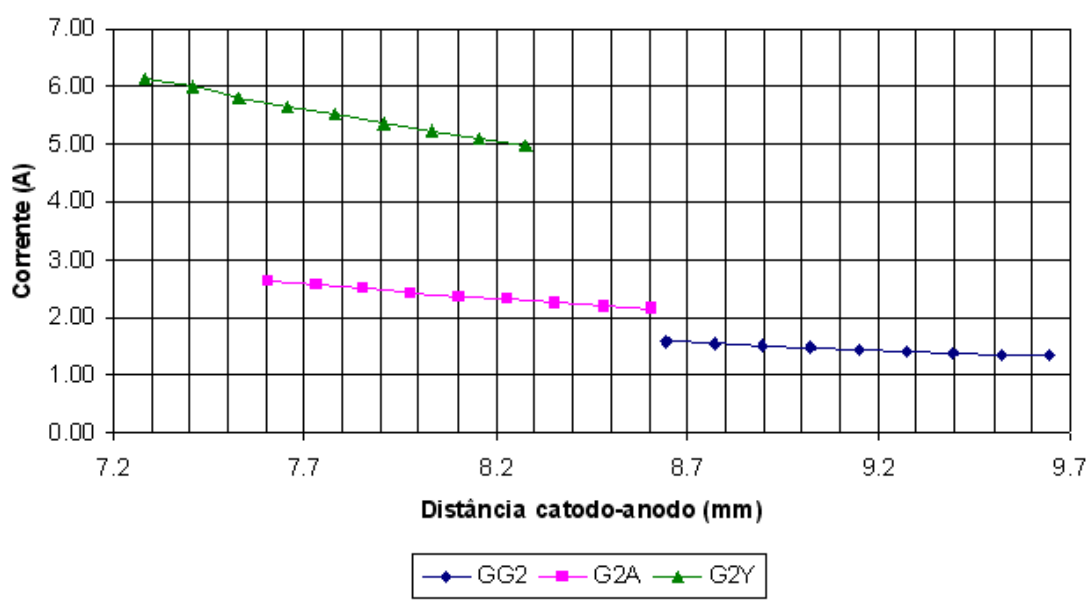

Figura 6.9: Corrente do feixe de elétrons em função da separação catodo-anodo para os canhões GG2, G2A e G2Y. 
camente a shadow-grid sobre a superfície do catodo, FIG. 6.10 (a) e (b) respectivamente. Constata-se uma redução de, aproximadamente, $10 \%$ para a corrente do feixe quando se modela fisicamente a shadow-grid sobre a superfície do catodo.

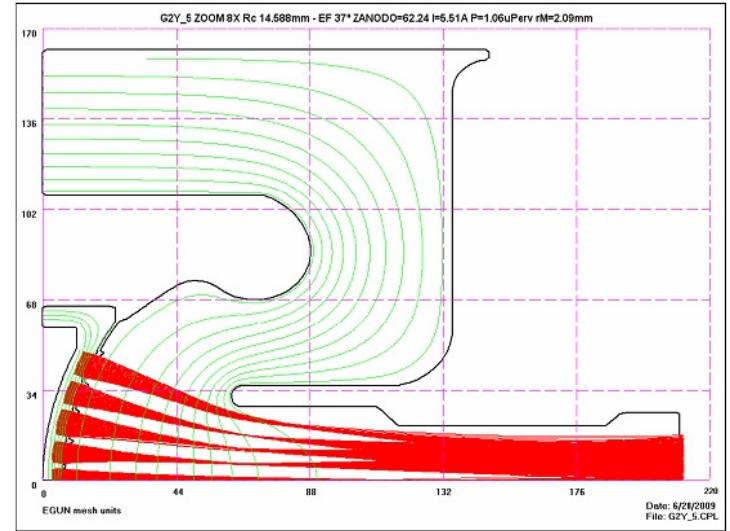

(a)

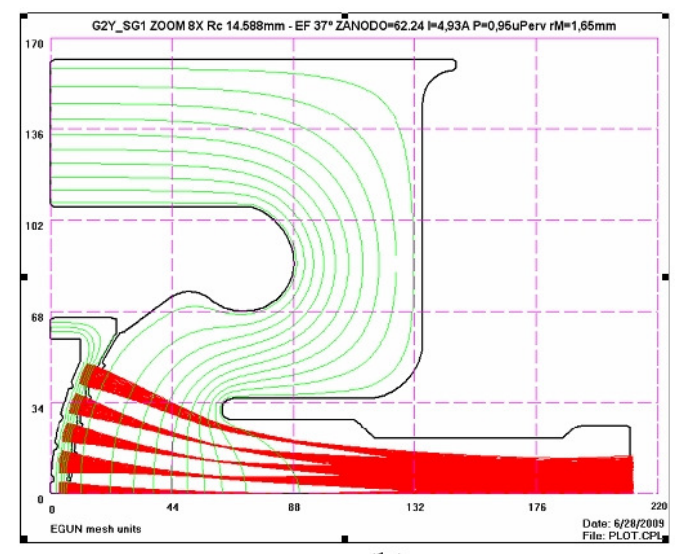

(b)

Figura 6.10: Canhão G2Y com shadow-grid modelado: (a) por meio de uma impressão sobre a superfície do catodo de uma região não emissora; (b) a partir da modelagem física da shadow-grid sobre a superfície do catodo.

Ao observar melhor a superfície do catodo nos dois casos, FIG. 6.11, constata-se que quando se modela a shadow-grid sobre a superfície do catodo a área de emissão é reduzida.

\subsection{XMGUN}

Foi desenvolvida uma ferramenta computacional em linguagem $C$ utilizando PIC (5.3), MEF (5.4) e o MAS (5.5) para análise e projeto de canhões de elétrons não relativísticos, na ausência de campos magnéticos externos e operando na condição FSCL denominado XMGUN [63]. Os elementos utilizados no MEF são triângulos de primeira ordem (5.4). A solução do sistema de equações obtido foi realizada utilizando-se o Método de Eliminação de Gauss ou o Método do Gradiente Conjugado. As trajetórias foram traçadas a partir da

Tabela 6.3: Medidas dos Raios do Catodo e distâncias Grade-Catodo utilizadas em simulações com o EGUN obtidas a partir de componentes físicos existentes.

\begin{tabular}{cccc}
\hline Canhão & $I(A)$ & Perveância $(\mu$ Perv $)$ & Cintura do Feixe $(\mathrm{mm})$ \\
\hline G1 & 1,6 & 0,30 & 2,0 \\
G1A & 3,5 & 0,68 & 1,7 \\
G1AX & 1,2 & 0,23 & 2,0 \\
G1AY & 2,0 & 0,39 & 1,9 \\
G2A & 2,4 & 0,45 & 2,1 \\
G2Y & 5,5 & 1,06 & 2,1 \\
GG2 & 1,7 & 0,33 & 2,2 \\
GG3 & 1,7 & 0,33 & 1,6 \\
\hline
\end{tabular}




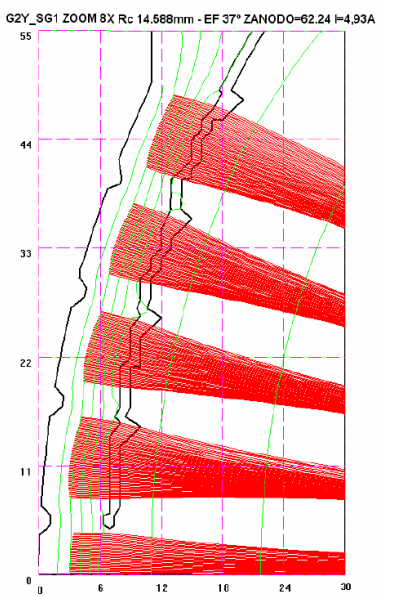

(a)

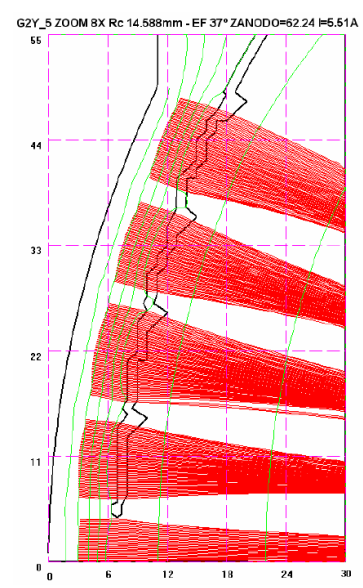

(b)

Figura 6.11: Amplificação visual da área de emissão do catodo do canhão G2Y. (a) A shadow-grid foi fisicamente modelada sobre a superfície do catodo enquanto que em (b) foram impressas áreas não emissoras.

integração numérica da equação (5.50). O método numérico utilizado para a integração do sistema de equações diferenciais foi o de Runge-Kutta de $4^{a}$ ordem. O sistema operacional utilizado em todas as simulações foi o Windows XP SP2, com um processador de quatro núcleos da Intel Q6600, operando com uma frequência de 2,4GHz e memória DDR2 RAM de $3,0 \mathrm{~Gb}$.

A interface com o usuário, FIG. 6.12, é bastante simples e as informações são apresentadas em cinco áreas distintas:

- VIEW: esta área é utilizada pelo usuário na escolha da visualização dos dados, que pode ser: (a) Malha, (b) Equipotenciais (c) Campo Elétrico e (d) Trajetórias. Uma combinação de visualização com mais de uma opção é possível de ser realizada.

- MESH DATA: é fornecido ao usuário o número de nós e de elementos da malha utilizada.

- VARIABLES: aqui o usuário tem liberdade de alterar diversos parâmetros do canhão plano de Pierce, a saber: (a) a Tensão do anodo, (b) a separação em volts entre as equipotenciais, (c) o número de partículas, (d) o coeficiente de sobre-relaxação, (e) largura da superfície de emissão e (f) o número de divisões utilizadas para a determinação da trajetória das partículas.

- SPACE CHARGE CURRENT DENSITY: aqui são apresentados:(a) o valor teórico e o valor obtido na simulação da densidade de corrente $J\left(A / m^{2}\right)$; (b) o erro relativo percentual; e (c) o número de iterações realizadas para convergir. A solução, utilizando o MAS, só é iniciada após o usuário pressionar o botão "Iterate".

- VIEW MESH ELEMENT: está disponível para o usuário a capacidade de navegar 
pelos elementos da malha. A cada elemento da malha são apresentados os índices associados a cada um dos 3 elementos vizinhos.

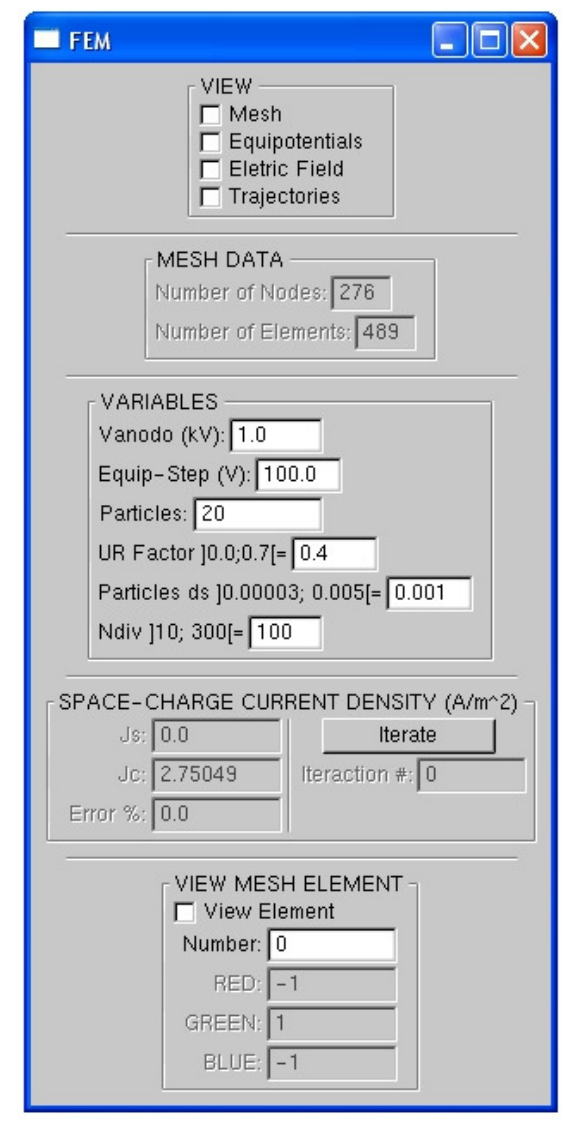

Figura 6.12: Interface com o usuário da ferramenta computacional desenvolvida. Está dividida em (a) Opções de visualização, (b) Dados da Malha, (c) Variáveis que podem ser alteradas pelo usuário, (d) Resultados Obtidos e (e) Visualização dos elementos da malha.

Na FIG. 6.13 são apresentadas as visualizações típicas do resultado de uma simulação de um canhão cujo catodo e anodo são planos. Em 6.13(a) e 6.13(b) estão representadas as trajetórias (cor azul) e as equipotenciais (cor vermelha) antes e depois de se utilizar o MAS. A FIG. 6.13(c) e 6.13(d) tem-se uma vista da malha nas proximidades do catodo e a representação do campo elétrico antes e depois de se utilizar o MAS.

\subsubsection{Benchmark}

Como forma de avaliar o desempenho da ferramenta computacional, vários testes foram conduzidos. As respostas da ferramenta computacional desenvolvida foram comparadas com a solução analítica do diodo plano de Pierce (2.2) cuja geometria é a apresentada na FIG. 2.9, onde o catodo tem altura de $1,5 \mathrm{~cm}$, a separação catodo-anodo é de $d=2,0 \mathrm{~cm}$, o eletrodo de focalização faz um ângulo de $67,7^{\circ}$ com o eixo de simetria e altura do diodo é de $4,0 \mathrm{~cm}$. A posição inicial de lançamento das macropartículas em relação ao catodo é denominada de $d_{s}$. 


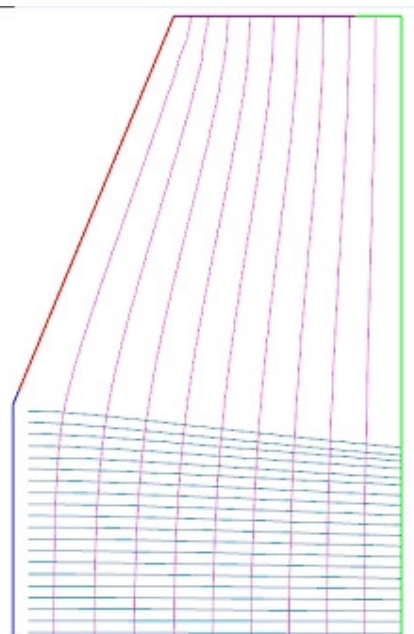

(a)

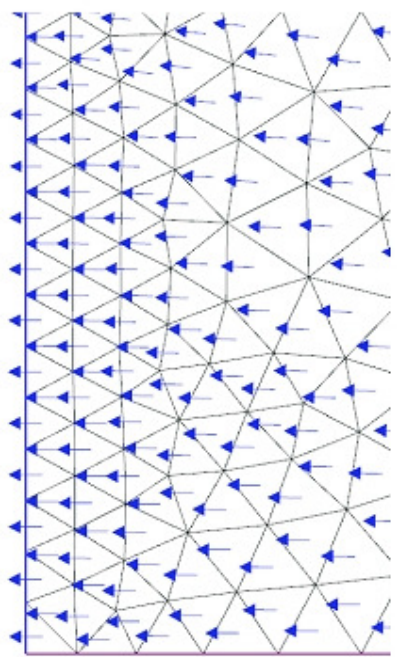

(c)

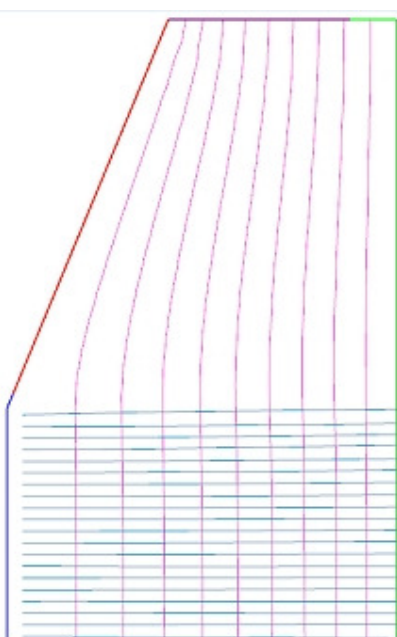

(b)

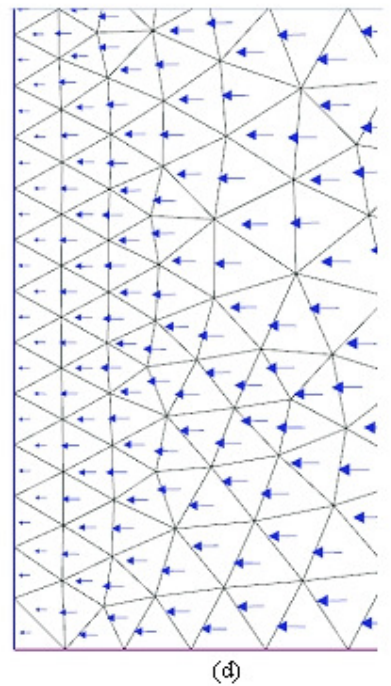

Figura 6.13: Visualização das trajetórias de 20 partículas em um diodo plano de Pierce: em (a), as trajetórias foram traçadas como uma primeira aproximação do problema, onde os campos foram obtidos a partir da solução da equação de Laplace; em (b) as trajetórias das partículas após terem atingido o critério de convergência utilizando o MAS. Em (c) e (d) são apresentados o campo elétrico e a malha na condição inicial, sem a deposição de cargas, e após a convergência. 
Para o problema clássico do diodo plano de Pierce é apresentada a seguir uma breve descrição de cada teste de performance realizado com a ferramenta computacional desenvolvida.

(a) Efeito da largura da região de emissão $\left(d_{s} / d\right)$ : este teste foi realizado fixando-se a tensão do anodo $V_{a}$ em $1 \mathrm{kV}$, o coeficiente de sobre-relaxação $u=0,345$ e o número de partículas $N_{P}=40$. Observa-se, FIG. 6.14, uma queda no erro percentual da densidade de corrente $J$ com o aumento da razão da largura de emissão. Erros inferiores a 3\% podem ser obtidos para uma razão da largura de emissão $d_{s} / d$ superior a 0,1 . Constata-se que o número de iterações necessárias para se obter convergência, para uma razão da largura de emissão superior a 0,1 , cresce inicialmente, atinge um máximo e, para uma grande faixa da razão da largura de emissão, permanece praticamente constante.

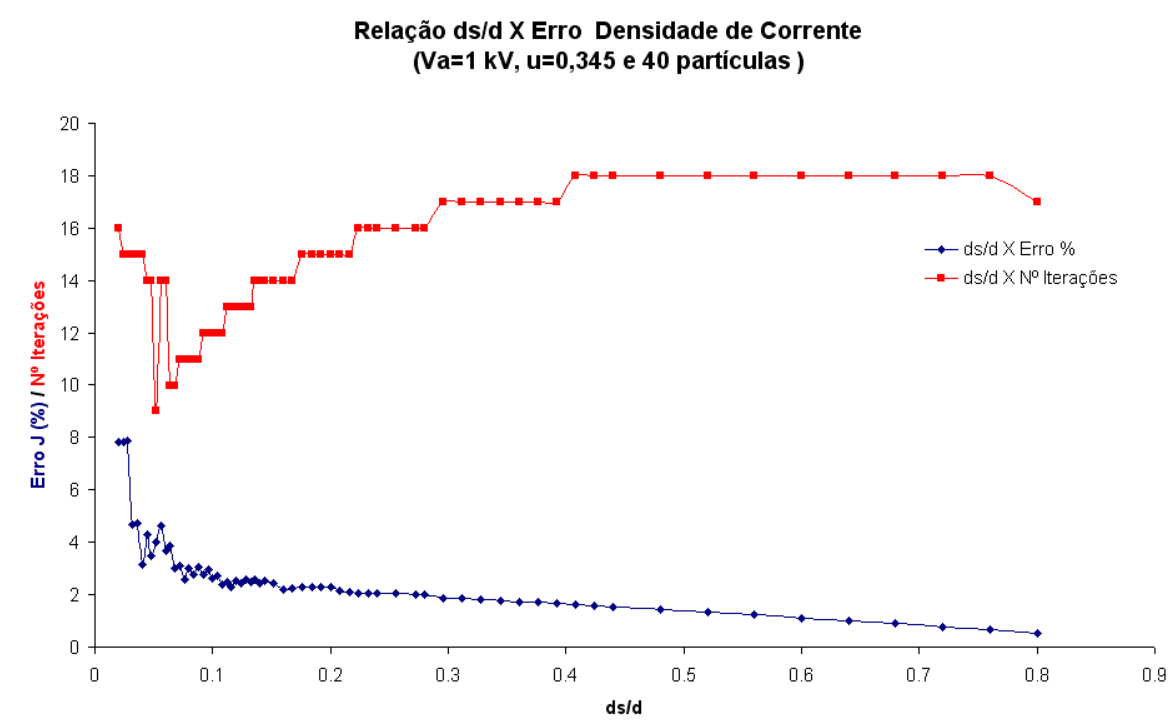

Figura 6.14: O gráfico em azul, que apresenta a razão da largura da área de emissão pelo erro percentual da densidade de corrente, indica que o erro diminui com o aumento da largura de emissão. O número de iterações para razão de largura de emissão superiores a 0,1, (gráfico em vermelho), cresce e permanece praticamente constante para $d_{s} / d>0,5$.

(b) Efeito do coeficiente de sobre-relaxação $u$ : o coeficiente de sobre-relaxação, utilizado como um fator que pondera a densidade de carga sobre vários ciclos, exerce um papel importante na taxa de convergência. A FIG. 6.15 apresenta a influência do coeficiente de sobre-relação sobre o número de iterações necessárias para que seja atingida a convergência.

Para uma melhor visualização, a FIG. 6.16 apresenta um zoom, permitindo observar o comportamento dos coeficientes de sobre-relaxação para até dez iterações. O coeficiente que apresentou o menor número de iterações para convergência foi para $u=0,4$ com 9 iterações. Experimentação com outros valores de tensão do anodo, do número de partículas e da razão da largura de emissão foram realizados e observou-se que um coeficiente de sobre-relaxação entre $[0,3 ; 0,5]$ proporciona uma convergência mais rápida do problema, FIG. 6.17.

(c) Efeito do número de partículas sobre o erro percentual da densidade de corrente: esta avaliação foi realizada tomando-se uma tensão de anodo de $V_{a}=1 \mathrm{kV}$ com um coeficiente 


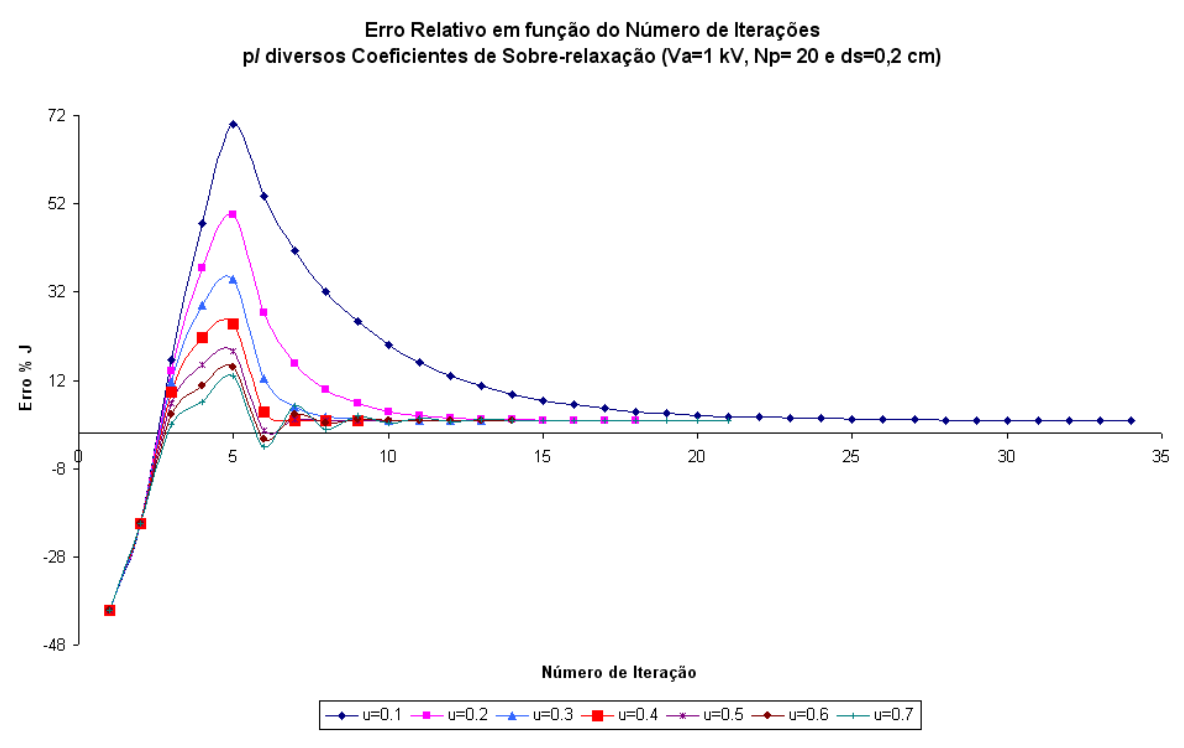

Figura 6.15: Efeito da variação do coeficiente de sobre-relaxação $u$ sobre o número de iterações para a convergência.

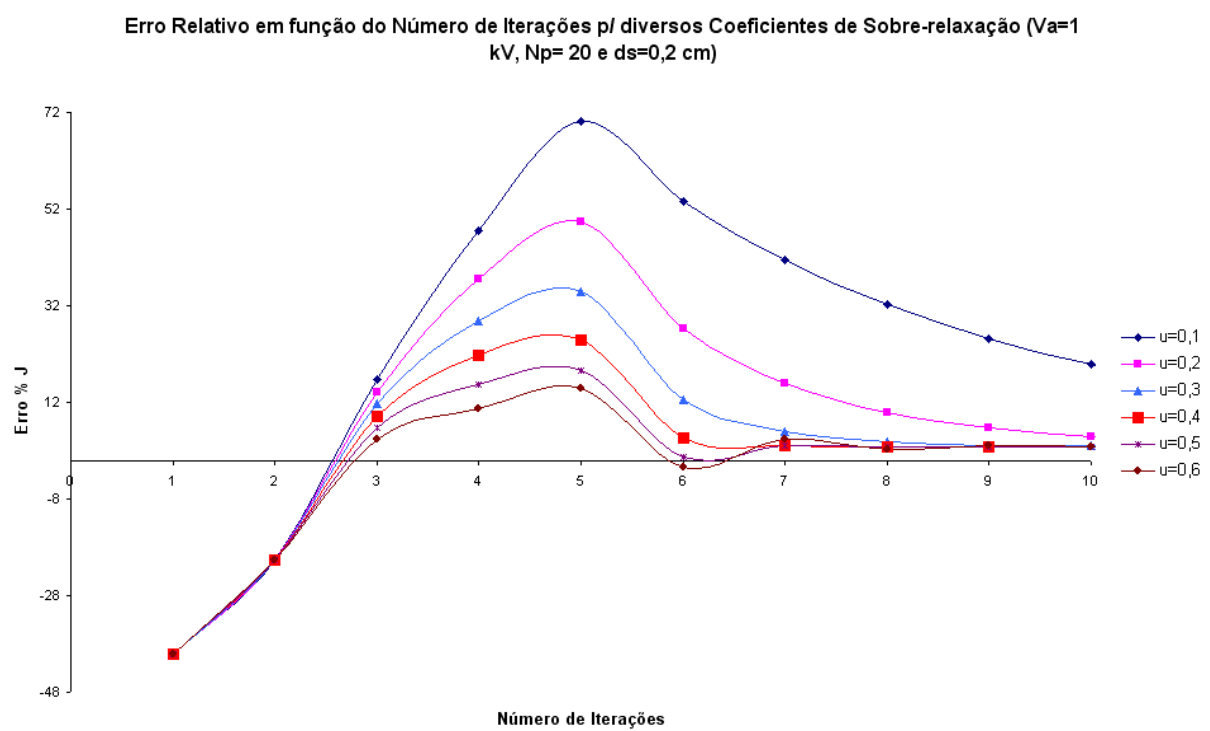

Figura 6.16: Visualização, para até dez iterações necessárias para convergência, do erro percentual da densidade de corrente tomando-se como parâmetro o coeficiente de sobrerelaxação. 


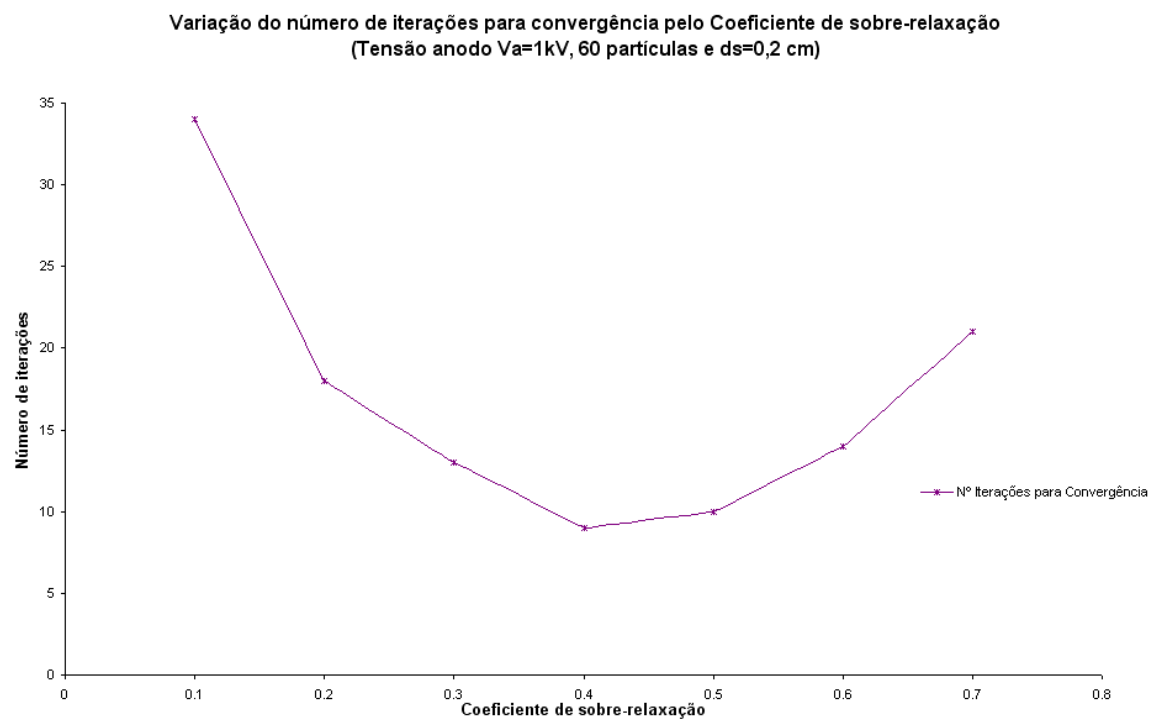

Figura 6.17: Variação do número de iterações necessárias para se obter a convergência para o problema do diodo plano de Pierce em função de diferentes coeficientes de sobre-relaxação.

de sobre-relaxação de $u=0,4$. Observa-se, FIG. 6.18, que o erro, aproximadamente de $3 \%$, se mantém praticamente constante para um número de partículas superior a 60 . Este comportamento foi observado, também, em outras simulações, desde que, a largura da região emissora $d_{s} / d \geq 0,1$.

(d) Efeito do número de partículas sobre o erro percentual na posição final da partícula: O gráfico da FIG. 6.19 apresenta o erro percentual encontrado na posição final das partículas, para um número diferente de partículas. Observa-se que os maiores erros na posição final das partículas são devidos às partículas que estão mais próximas ao eixo de simetria plana do diodo. Considerando o diodo de Pierce com a geometria do anodo corrigida observa-se que, FIG. 6.20, as posições finais, obtidas com este modelo, apresentam erros inferiores a $2 \%$ para posições do anodo no intervalo $[0,002 ; 0,0014] \mathrm{mm}$.

Foram realizadas simulações do diodo de Pierce considerando diversos graus de refinamento da malha os quais estão apresentados na TAB. 6.4.

Utilizando a Malha III em uma simulação do diodo de Pierce com 500 macropartículas, observou-se que as trajetórias das mesmas eram paralelas com um erro de $\pm 0,35^{\circ}$ na superfície do anodo. Em simulações realizadas até então, não foram observados erros superiores

Tabela 6.4: Dados das malhas, para o canhão de Pierce, utilizadas para validação da ferramenta computacional XMGUN.

\begin{tabular}{cccc}
\hline Malha & Nós & Elementos & Tempo Simulação(seg.) \\
\hline I & 284 & 499 & 2,8 \\
II & 486 & 875 & 3,3 \\
III & 958 & 1792 & 8,5 \\
IV & 1870 & 3560 & 22,7 \\
\hline
\end{tabular}




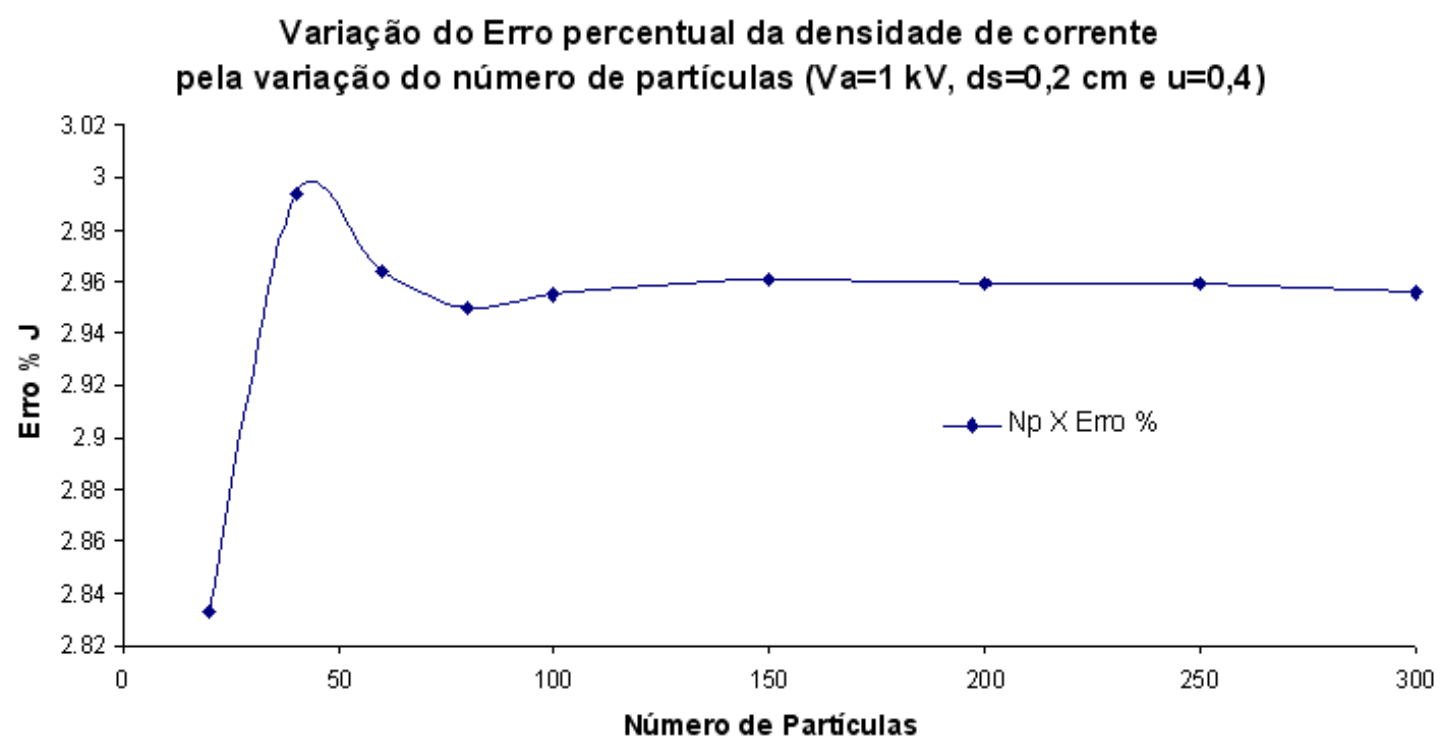

Figura 6.18: Variação percentual do erro da densidade de corrente pelo número de partículas utilizadas na simulação de um diodo plano de Pierce.

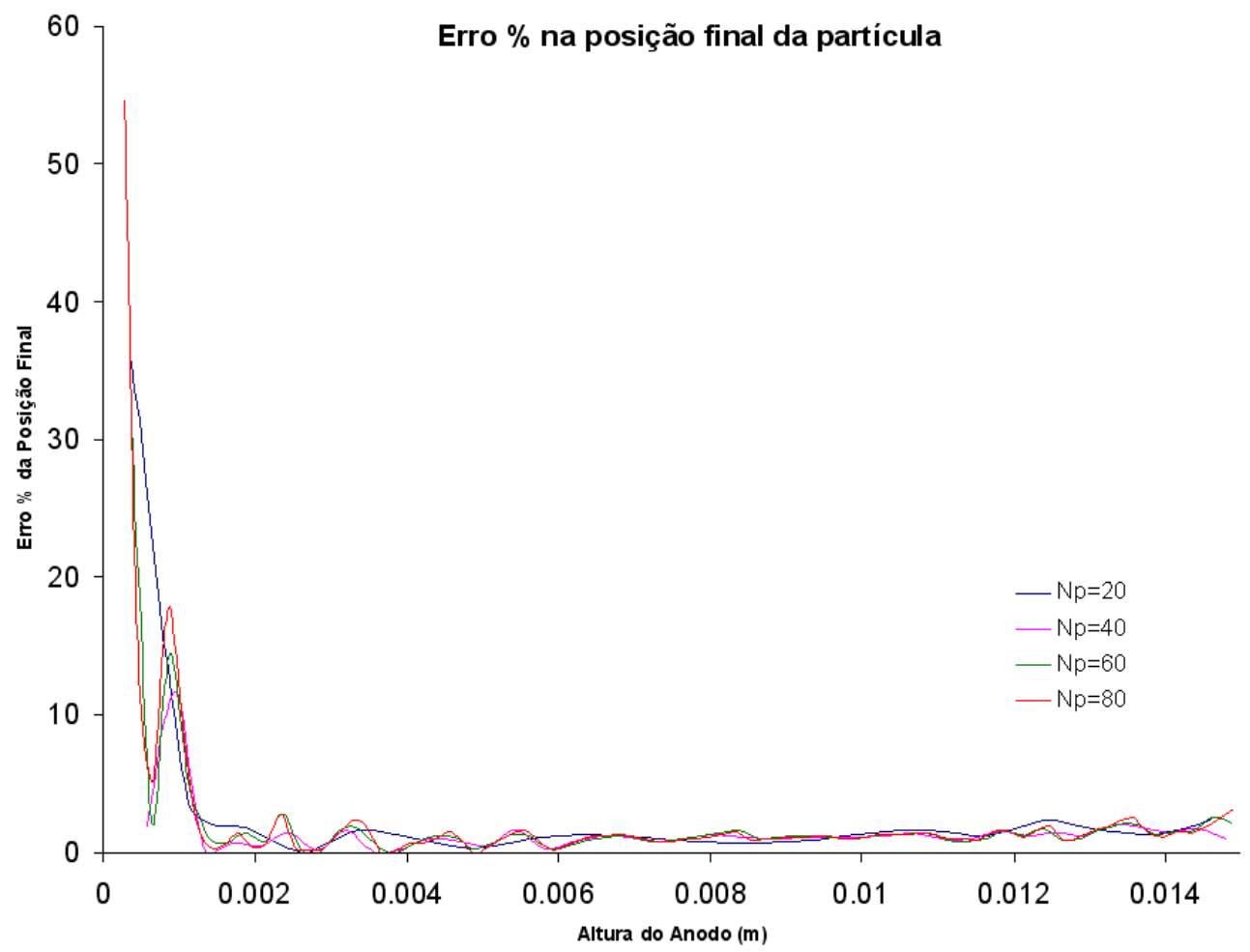

Figura 6.19: Erro percentual observado na posição final das partículas. Os maiores erros se referem às partículas que estão mais próximas do eixo de simetria. 


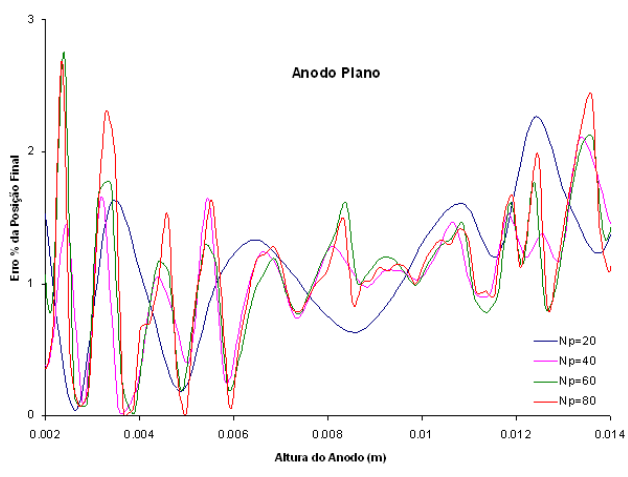

(a)

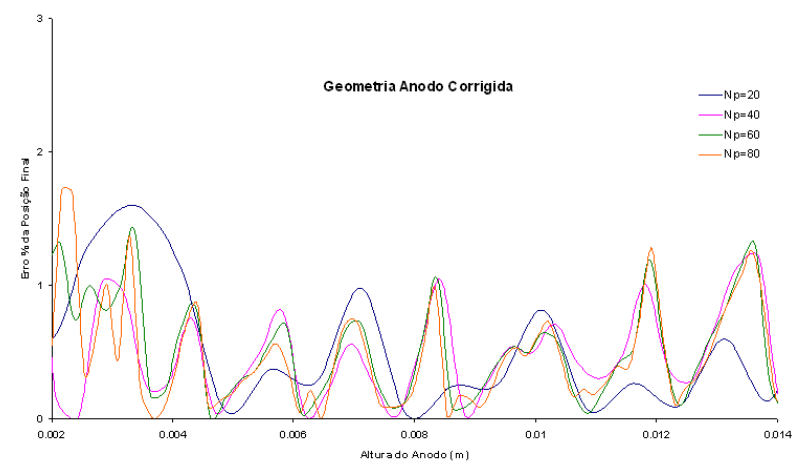

(b)

Figura 6.20: Erro comparativo para a posição final das partículas considerando a geometria do anodo plano e do anodo corrigido.

$\mathrm{a} \pm 0,8^{\circ}$ no anodo.

(e) Tempo de trânsito das pastículas do feixe $\tau$ : trata-se de outro parâmetro de relevância na indicação da qualidade do feixe e é definido como,

$$
\tau=\int_{d_{s}}^{d_{a}} \frac{d z}{v(z)}
$$

onde: $v(z)$ é a velocidade da macropartícula, $d_{a}$ é a separação catodo-anodo e $d_{s}$ é a posição de lançamento da macropartícula. Para o diodo plano de Pierce, o potencial escalar elétrico varia conforme 2.13. Utilizando a lei de conservação de energia, pode-se obter a velocidade da macropartícula:

$$
v(u)=\sqrt{2 \eta \varphi(z)}=\sqrt{2 \eta}\left[V_{a}\left(\frac{z}{d_{a}}\right)^{4 / 3}\right]^{1 / 2}=\sqrt{2 \eta V_{a}}\left(\frac{z}{d_{a}}\right)^{2 / 3} .
$$

Substituindo a expressão acima em 6.1:

$$
\tau=\frac{d_{a}^{2 / 3}}{\sqrt{2 \eta V_{a}}} \int_{d_{s}}^{d_{a}} \frac{d z}{z^{2 / 3}}
$$

Integrando obtém-se o tempo de trânsito da macropartícula dado por:

$$
\tau=\frac{3 d_{a}^{2 / 3}}{\sqrt{2 \eta V_{a}}}\left(d_{a}^{1 / 3}-d_{s}^{1 / 3}\right) .
$$

De modo geral, não foram observados erros superiores a 4\%. A FIG. 6.21 indica o comportamento do erro relativo observado para o tempo de trânsito utilizando-se a Malha III com 40 macropartículas.

(f) Energia das partículas do feixe: finalmente, como último parâmetro da qualidade do feixe para a validação do código, a energia das macropartículas foram observadas em quatro planos localizados a 10,9\%, 40,6\%, 80,2\% e 98,2\% da separação catodo-anodo. Observou- 


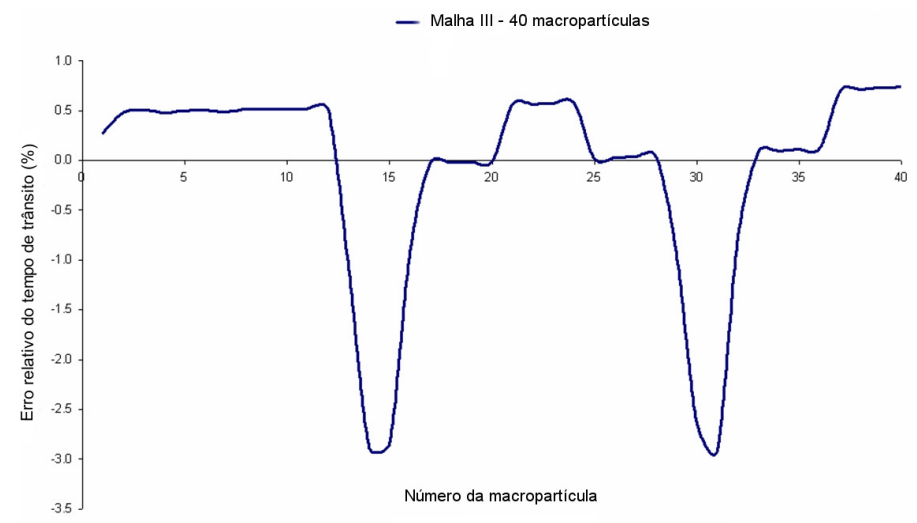

Figura 6.21: Comportamento típico observado para o tempo de trânsito das macropartículas.

se que os planos localizados mais próximos ao catodo apresentaram erros maiores. Para o plano localizado a $10,9 \%$ da separação catodo-anodo, utilizando a Malha I, o erro relativo da energia, em média, não foi superior a 3\%, enquanto que, ao utilizar a Malha IV, o erro reduziu para um valor inferior a $0,4 \%$. Como esperado, a utilização de malhas mais refinadas levam a uma melhor resposta para o parâmetro energia do feixe.

\subsubsection{Simulações com o XMGUN}

\section{Canhões de Elétrons}

O canhão de elétrons com a geometria da FIG. 6.22 foi simulado utilizando o XMGUN. Foi utilizado simetria axial e 90 macropartículas. O raio do catodo e raio do disco do catodo são $14,59 \mathrm{~mm}$ e $6,2 \mathrm{~mm}$ respectivamente. Sendo de $30 \mathrm{kV}$ a tensão do anodo, este canhão forneceu uma corrente de 7,10 A e apresentou uma perveância de 1,37 $\mu$ Perv. Realizando a simulação deste canhão utilizando o EGUN foram observados uma corrente de 7,54A e uma perveância de $1,45 \mu$ Perv.

A malha do canhão de elétrons simulado tem 2796 nós e 5057 elementos. Foram necessárias oito iterações para que fosse observado uma diferença na densidade de corrente abaixo de $0,1 \%$ entre dois ciclos consecutivos, utilizando como fator de sobre-relaxação $u=0,3$. É ainda possível observar na FIG. 6.22 as equipotenciais de $1,0 \mathrm{kV}$ e a posição radial do feixe que contém $95 \%$ da corrente total do feixe, $r_{95}$.

Uma figura de mérito que indica a qualidade do feixe de elétrons é a velocidade transversal normalizada $\sigma$ definida como [7]:

$$
\sigma=\left\{\left[\sum_{i=1}^{n} I_{i}\left(\alpha_{i}-\langle\alpha\rangle\right)^{2}\right] / I_{0}\right\}^{1 / 2}
$$

onde: $\alpha_{i}$ é a inclinação da trajetória de $i$-ésima macropartícula ao cruzar um plano perpendicular ao eixo de simetria; $I_{i}$ é a corrente transportada pela $i$-ésima macropartícula; e $\langle\alpha\rangle$ é o valor médio da inclinação da trajetória das $n$ macropartículas ao cruzarem o plano 


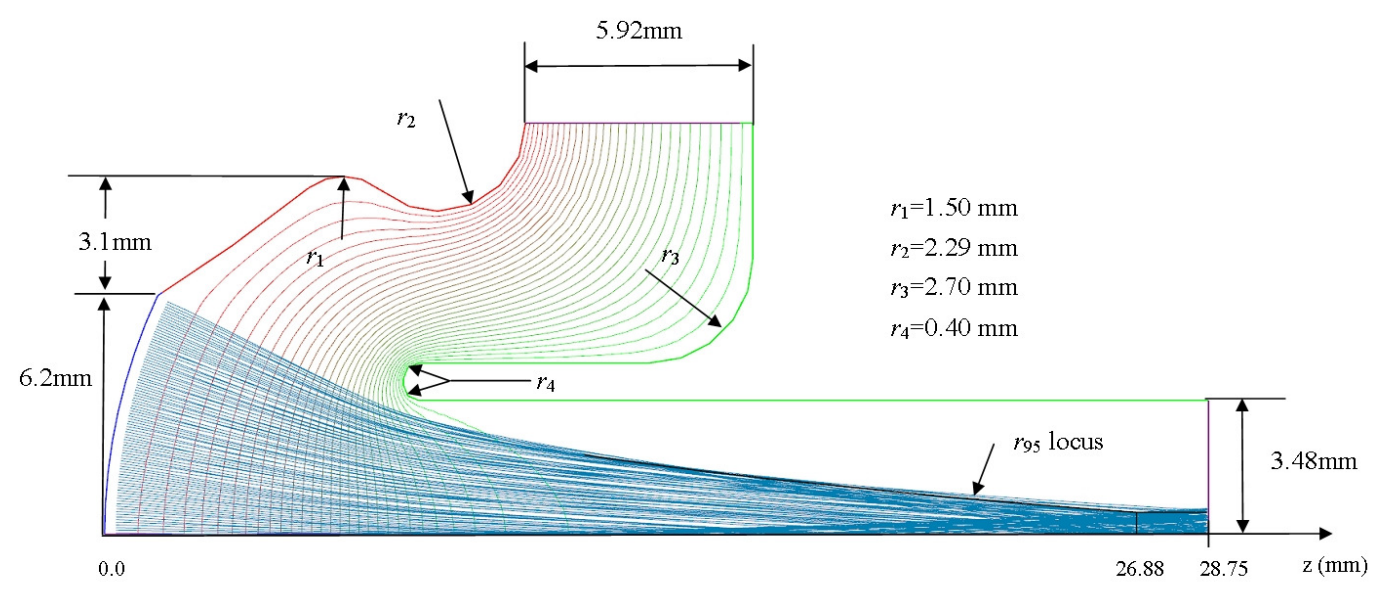

Figura 6.22: Simulação de um canhão de elétrons, onde as trajetórias das partículas foram estabelecidas pela integração da equação diferencial de $2^{a}$ Ordem da Trajetória, considerando inexistir campo magnético na região simulada.

perpendicular ao eixo $z$ dado por:

$$
\langle\alpha\rangle=\left(\sum_{i=1}^{n} I_{i} \alpha_{i}\right) / I_{0} .
$$

Quanto menor o valor de $\sigma$, melhor é a laminaridade do feixe sob análise. O raio mínimo que contém $95 \%$ da corrente, $r_{95}$, foi observado na posição $z=26,88 \mathrm{~mm}$. Nesta posição foram observados que $\langle\alpha\rangle=-2,7 \pi \operatorname{mrad}$ e $\sigma=0,068$.

Também foi estudado o efeito da grade sobre a trajetória do feixe de elétrons [65]. A simulação foi realizada considerando ainda a existência da shadow-grid, FIG. 6.23. A separação grade-catodo é de $0,78 \mathrm{~mm}$ e está polarizada com uma tensão de $550 \mathrm{~V}$. Foram utilizadas 74 macropartículas e o potencial do anodo é de $30 \mathrm{kV}$. Este canhão foi modelado com 2996 nós e 5230 elementos e a corrente elétrica fornecida foi de 4,58 A. A redução da corrente elétrica fornecida, quando comparada ao canhão sem grade, é justificada pela redução da área de emissão do catodo.

Os comportamentos do alcance do feixe $\left(z_{95}\right)$, da cintura do feixe $\left(r_{95}\right)$ e da velocidade transversal normalizada $(\sigma)$ para uma variação de tensão de grade na faixa de 420 a $600 \mathrm{~V}$, FIG. 6.24, foram observados e estão assim sintetizados:

- $z_{95}:$ o alcance do feixe cresce com o aumento de tensão de grade até, aproximadamente, $610 \mathrm{~V}$;

- $r_{95}$ : a cintura média do feixe, $\overline{r_{95}}$, é de $\overline{r_{95}}=0,41 \mathrm{~mm}$ com um desvio padrão de 0,06 $m m$, ou seja, a cintura sofre uma variação inferior a $15 \%$;

- $\sigma$ : a qualidade do feixe melhora com o aumento da tensão de grade, cujo melhor valor observado se dá com uma tensão de grade de aproximadamente $550 \mathrm{~V}$ e, em seguida, observa-se redução da laminaridade do feixe com o aumento da tensão de grade. 


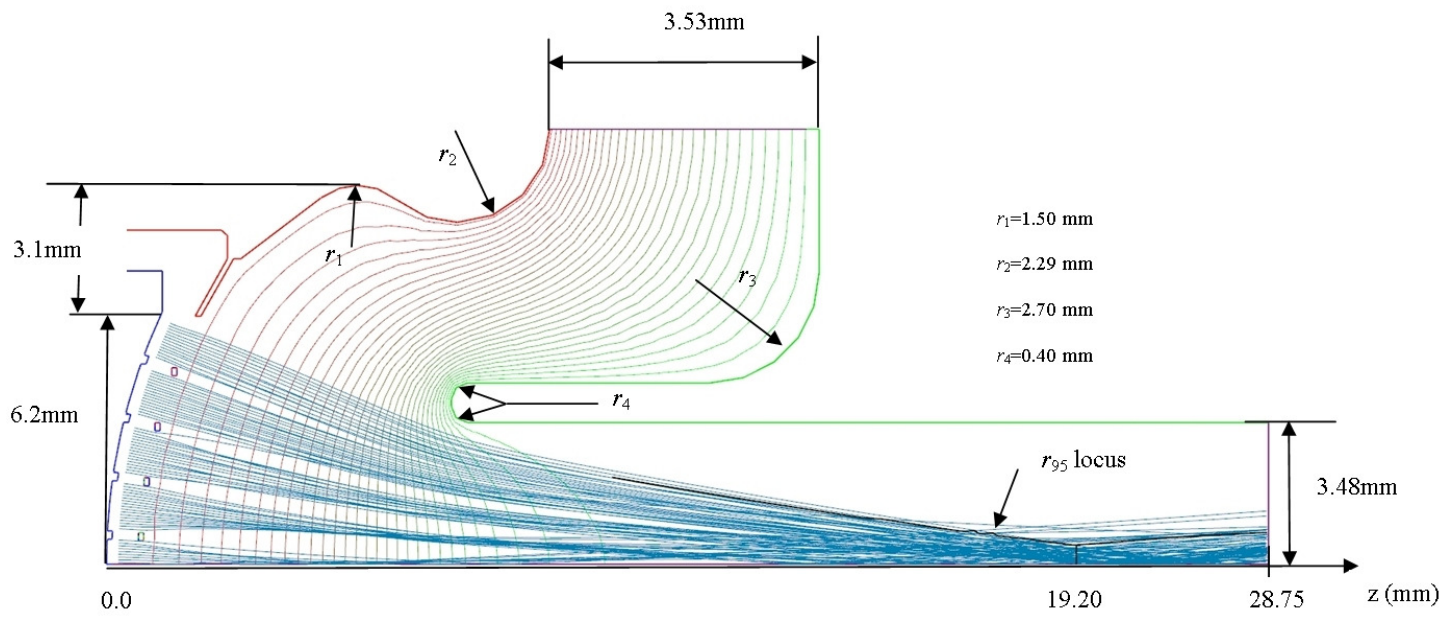

Figura 6.23: Geometria do canhão de elétrons com simetria axial, com grade e shadow-grid operando na condição limitado pela carga espacial. Equipotenciais de $1 \mathrm{kV}$ e $r_{95}$ também são apresentados. Utilizando a equação da trajetória, este canhão fornece uma corrente de 4,58A.

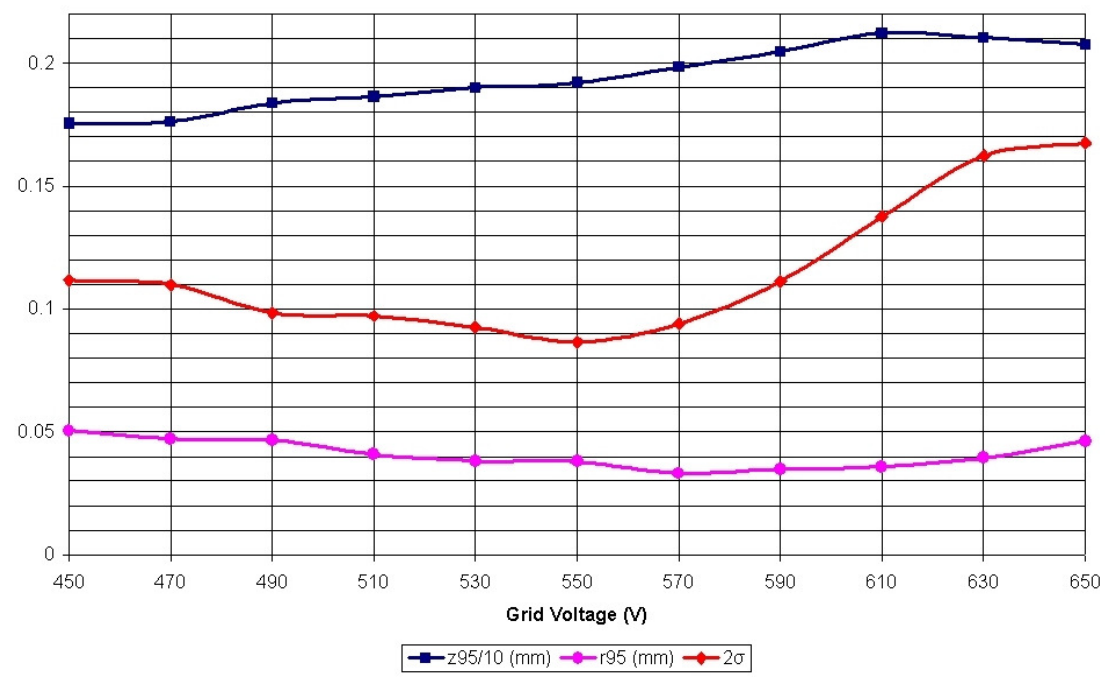

Figura 6.24: Comportamento da posição $\left(z_{95}\right)$ e cintura $\left(r_{95}\right)$ do feixe e da velocidade transversal normalizada $(\sigma)$ para uma variação da tensão de grade de 420 a $600 \mathrm{~V}$. 


\section{Coletores}

$\mathrm{Na}$ ausência do campo magnético na região do coletor de elétrons, é apresentado na FIG. 6.25(a), o resultado de uma simulação das trajetórias de 52 elétrons primários (cor azul) transportando uma corrente de $0,132 \mathrm{~A}$ e elétrons secundários espalhados (cor laranja) em um coletor de simples estágio. O coletor foi modelado com 1652 nós e 3033 elementos, FIG. 6.25(b).

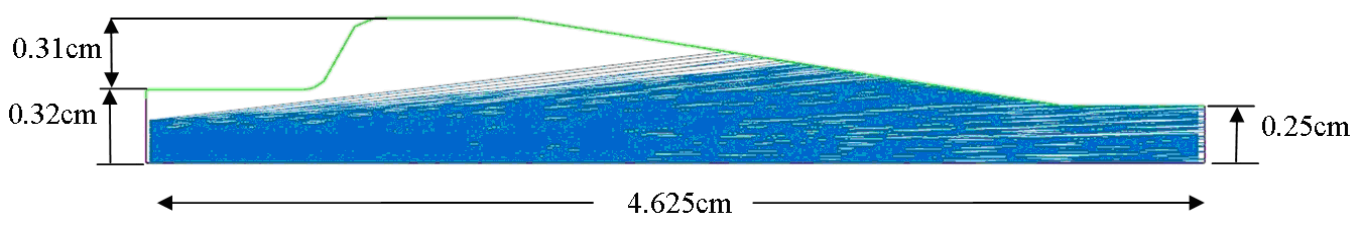

(a)

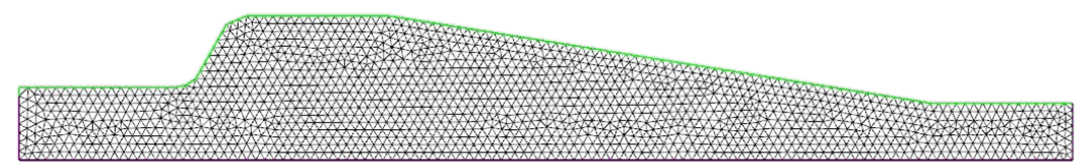

(b)

Figura 6.25: Simulação das trajetórias de 51 elétrons primários (cor azul) e espalhados (cor laranja) em um coletor simples utilizando o XMGUN (a) e a malha de elementos triangulares utilizada na simulação com 3033 elementos triangulares e 1652 nós, (b).

Ao entrar no coletor, os elétrons primários possuíam, tipicamente, uma energia de 30 $k e V$ e inclinação de trajetória inferior a $6,3^{\circ}$ com a direção longitudinal. A tensão do coletor, na simulação, foi de 3, $0 \mathrm{kV}$. Foi observado que 3,9\% da corrente transportada pelos elétrons secundários primários, retornaram à região de deriva. Esta corrente deve-se à corrente transportada pelos elétrons secundários espalhados emitidos a partir da colisão dos elétrons primários com a superfície vertical do coletor. Este resultado sugere alteração da geometria desta superfície. É representado ainda na FIG. 6.25(a) equipotenciais de 1, $0 \mathrm{kV}$.

\subsection{XMAGUN}

\subsubsection{Benchmark \#1: PPM separados pelo vácuo}

Testes de benchmark utilizando o XMAGUN foram realizados para uma estrutura de PPM com ímãs toroidais separados pelo vácuo com um, dois e vinte ímãs. A estrutura do PPM é baseada nos valores geométricos apresentados na TAB. 6.5. Em todos os testes de benchmark foi considerado para o(s) ímã(s) uma remanência de $B_{r}=1,3 \mathrm{~T}$.

Utilizando um ímã, a FIG. 6.26 ilustra a concordância entre a intensidade do campo magnético ao longo do eixo de simetria calculado pela equação 3.61 (solução analítica) e a simulação via XMAGUN (solução numérica). 


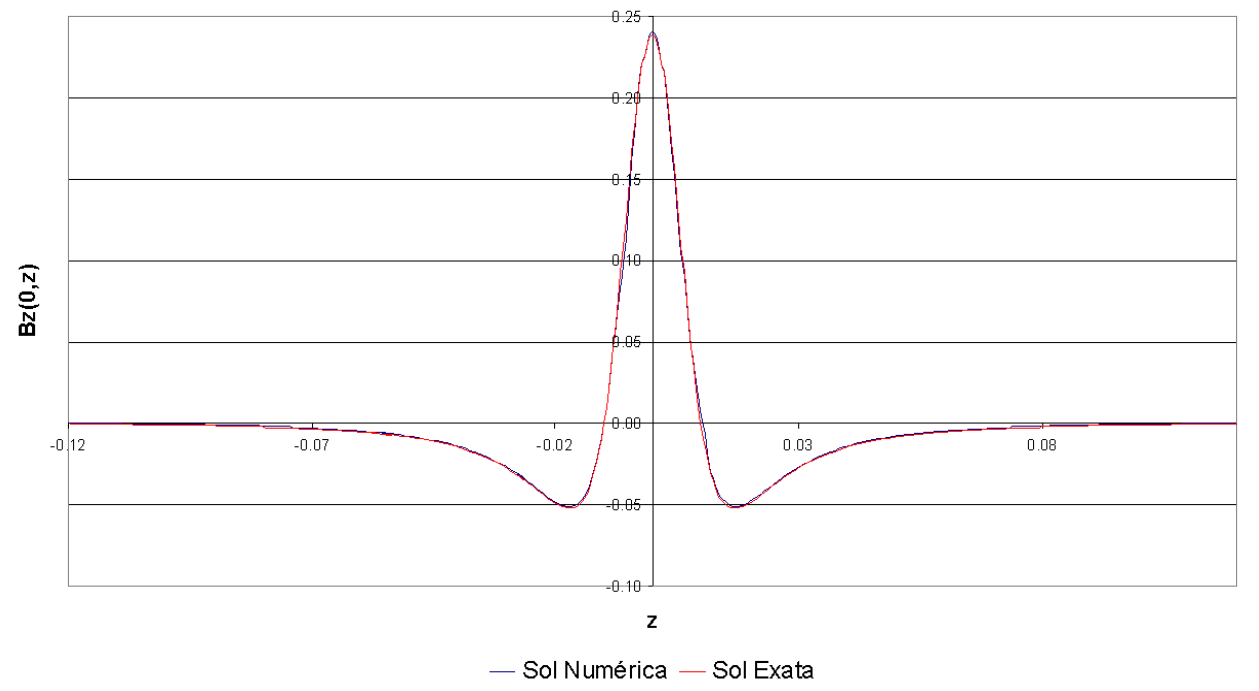

Figura 6.26: É observado boa concordância entre as curvas do campo magnético no eixo de simetria, entre a solução numérica, por meio do MEF, e a exata.

Para uma estrutura de PPM com 2 ímãs separados pelo vácuo, a FIG. 6.27 apresenta os campos magnéticos ao longo do eixo de simetria obtidos por meio: (a) da simulação com o XMAGUN em que para solução do sistema linear foram utilizados os métodos de eliminação de Gauss (FEM_GAUSS) e Gradiente Conjugado (FEM_CGM); (b) da solução integral, equação 3.64 (Integral) e; (c) da solução analítica, equação 3.63 (Exata). Observa-se boa concordância das curvas para comportamento do campo magnético no eixo de simetria.

Finalmente, é apresentado o resultado da intensidade do campo magnético no eixo de simetria obtido em uma simulação de um PPM composto de 20 ímãs separados pelo vácuo, FIG. 6.28, que foi modelado com uma malha de 27851 nós e 54998 elementos. Uma vez mais é possível observar boa concordância entre a solução por meio do método do gradiente conjugado e as soluções exata e integral. A diferença entre o resultado numérico e o das soluções analítica e integral para a intensidade do campo magnético no eixo de simetria observada nas bordas, deve-se ao fato de se ter imposto um campo magnético nulo na fronteira do domínio do problema. O método de eliminação de Gauss não foi utilizado uma vez que seria necessário alocar uma memória RAM de $3102 \mathrm{~Gb}$ para armazenar a matriz $S$ de 5.70.

O erro observado ao longo do eixo de simetria pode ser observado na FIG. 6.29.

Tem-se na FIG. 6.30 a representação do campo magnético gerado por esta estrutura nas

Tabela 6.5: Parâmetros geométricos do feixe e da estrutura do PPM.

\begin{tabular}{ccc}
\hline Parâmetro & Valor & Unidade \\
\hline Raio do Feixe & 9,5 & $\mathrm{~mm}$ \\
$R_{1}$ & 9,5 & $\mathrm{~mm}$ \\
$R_{2}$ & 17,0 & $\mathrm{~mm}$ \\
$2 L$ & 10,0 & $\mathrm{~mm}$ \\
$b$ & 2,0 & $\mathrm{~mm}$ \\
\hline
\end{tabular}




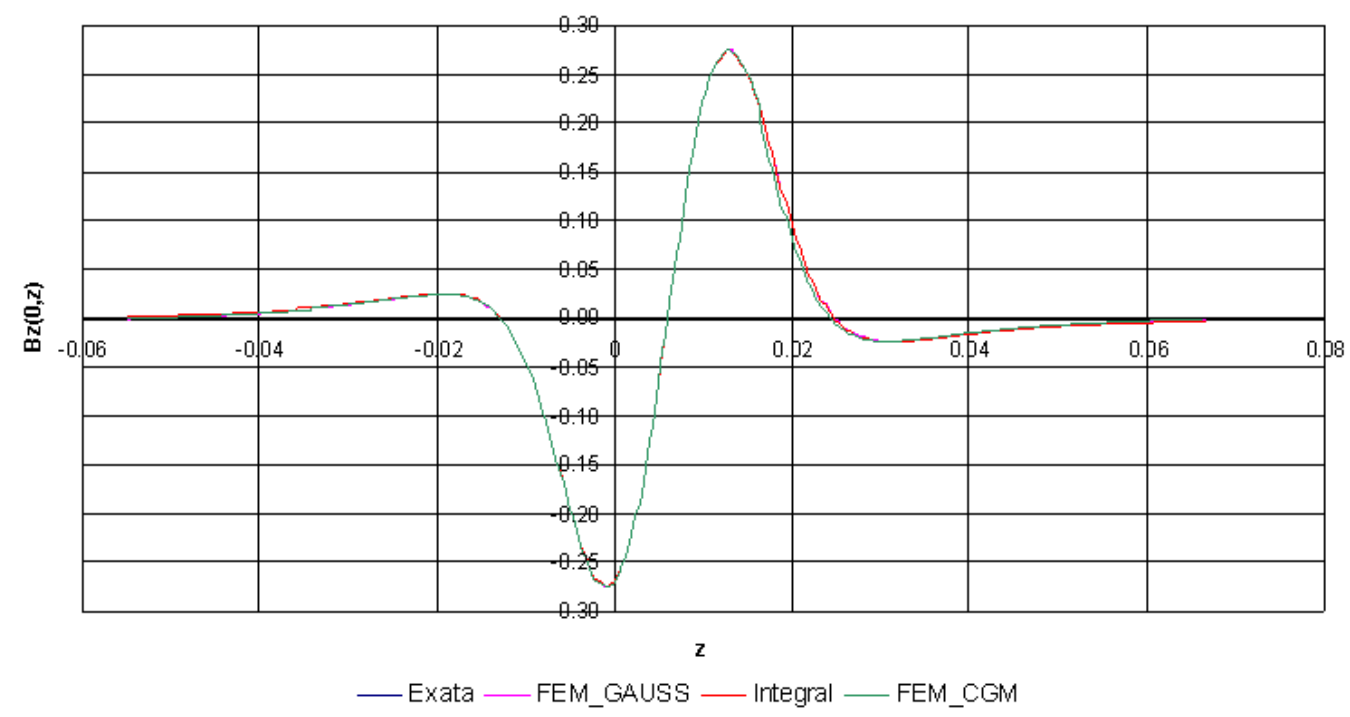

Figura 6.27: Campo magnético, devido a dois ímãs, no eixo de simetria. É observado boa concordância entre as curvas que representam as soluções numéricas, MEF-Gauss e MEFMGC, e a exata e a obtida pela expressão integral.

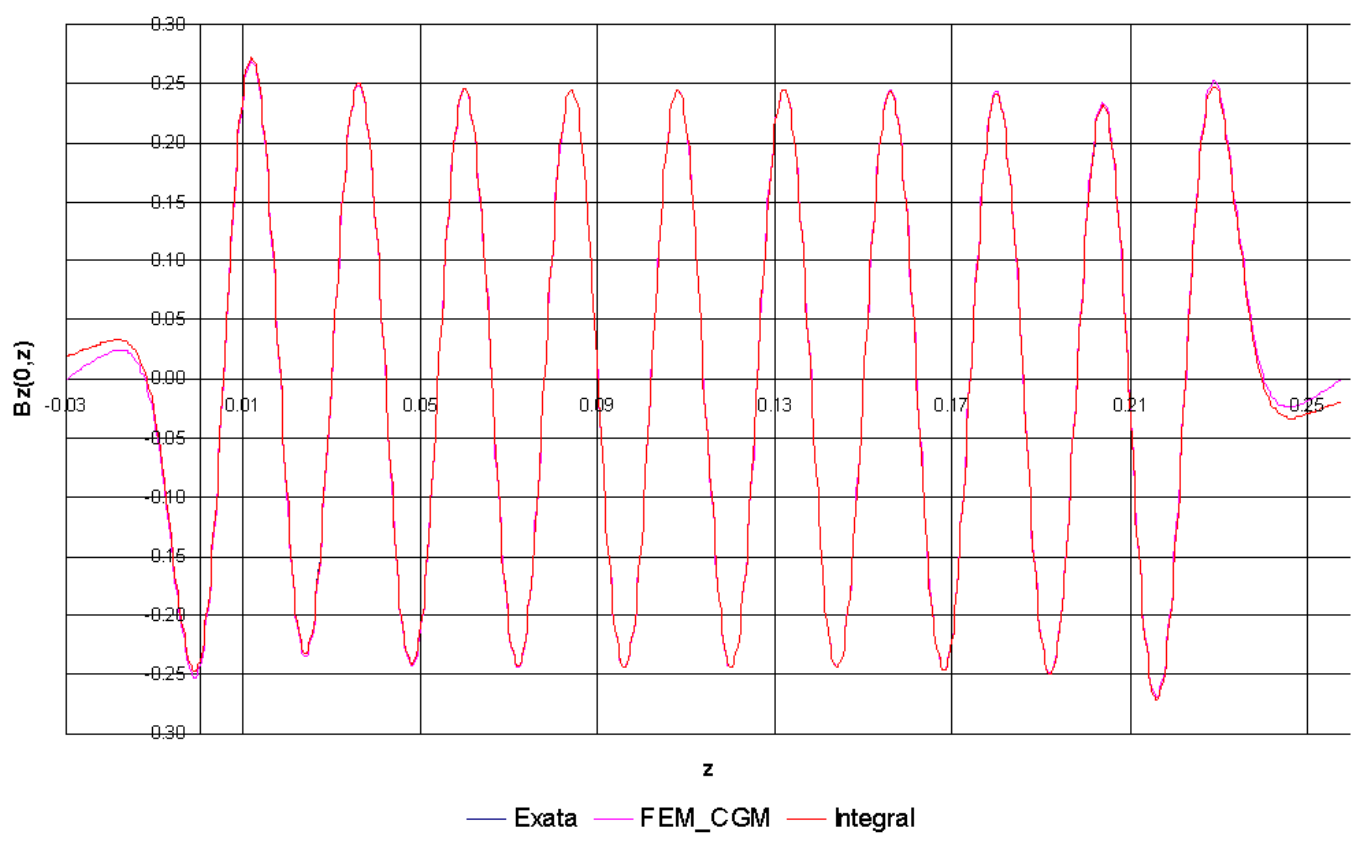

Figura 6.28: Campo magnético, devido a vinte ímãs, no eixo de simetria. É observado boa concordância entre as curvas que representam a solução numérica, MEF-MGC, a exata e a integral. 


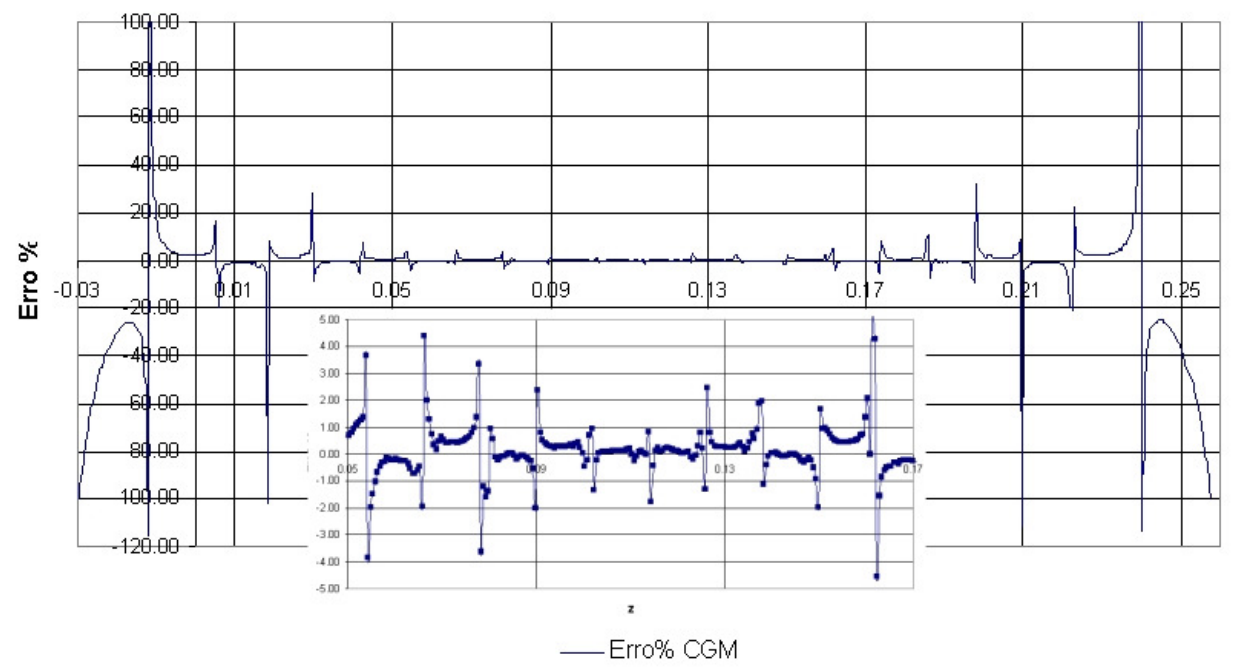

Figura 6.29: Erro relativo observado para o campo magnético no eixo axial para um PPM composto de 20 ímãs. Os maiores erros acontecem quando o campo magnético axial se aproxima absolutamente de zero.

proximidades do eixo de simetria.

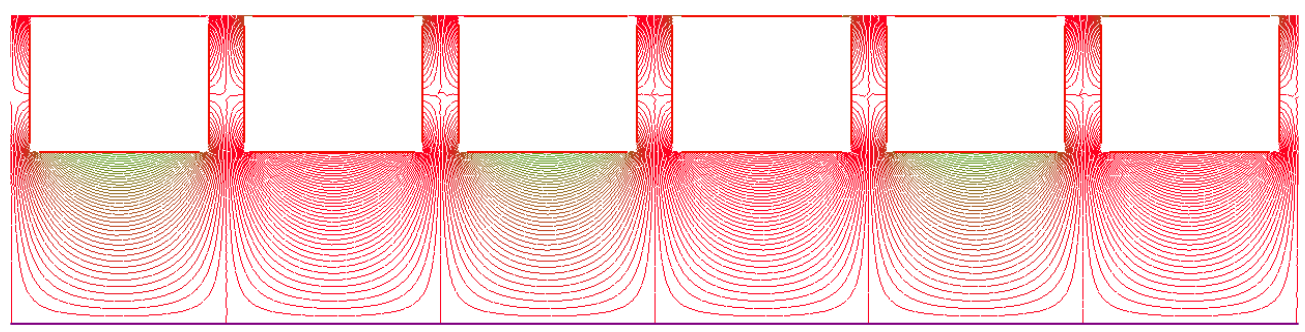

Figura 6.30: Vista ampliada e parcial do campo magnético gerado por um conjunto de 20 ímãs permanentes.

\subsubsection{Benchmark \#2: PPM separados por pole pieces}

Testes de benchmark foram realizados com estrutura do PPM com pole piece baseado nos resultados obtidos por Santra et al que apresentou as soluções analíticas para os campos e os resultados de simulações com o ANSYS [66]. O modelo do PPM com pole piece é o da FIG.3.12 com parâmetros de geometria apresentados na TAB. 6.6.

A solução analítica obtida por Santra et al. para a intensidade do campo magnético, 5.79, por meio das equações 3.111 ou 3.114 e, em seguida utilizando-se, 3.95, 3.96 e 3.89, é

Tabela 6.6: Parâmetros geométricos da estrutura do PPM com pole piece.

\begin{tabular}{cccccccccc}
\hline Parâmetro & $r_{m 1}$ & $r_{m 2}$ & $T$ & $r_{f 1}$ & $r_{f 2}$ & $r_{3}$ & $t_{p}$ & $g$ & $L / 2$ \\
\hline Valor $(m m)$ & 3,5 & 7,5 & 2,95 & 1,6 & 3,05 & {$[6,3-8,7]$} & 1,3 & 2,25 & 4,25 \\
\hline
\end{tabular}


válido para a estrutura de um PPM com pole piece infinita. Entretanto, foi investigado, por meio de simulações de uma estrutura de um PPM com 5 (cinco) ímãs permanentes com pole piece, o comportamento da intensidade do campo magnético no ímã permanente central para diferentes raios externos do pole piece $\left(r_{3}\right)$ [64].

O material do pole piece foi modelado assumindo uma permeabilidade relativa de 5000 . Foi utilizada uma remanência de 0,85 T para modelar os ímãs permanentes. Para modelar a fronteira do modelo, os limites axiais e radiais utilizados foram, tipicamente, cinco vezes o valor do raio externo do pole piece que apresentava um campo nulo. Na maioria das simulações um número superior a 20.000 nós e 40.000 elementos foram utilizados para modelar o PPM e a estrutura do pole piece.

A FIG.6.31(a) apresenta uma vista ampliada dos ímãs permanentes, de cor mais escura, as peças do pole piece, em cor cinza claro, e as malhas utilizadas, enquanto que a FIG.6.31(b) apresenta a solução do perfil do campo magnético obtida pelo XMAGUN quando $r_{3}=$ $7,8 \mathrm{~mm}$.

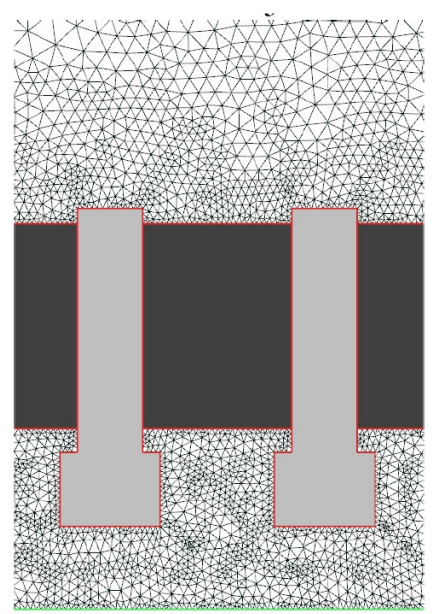

(a)

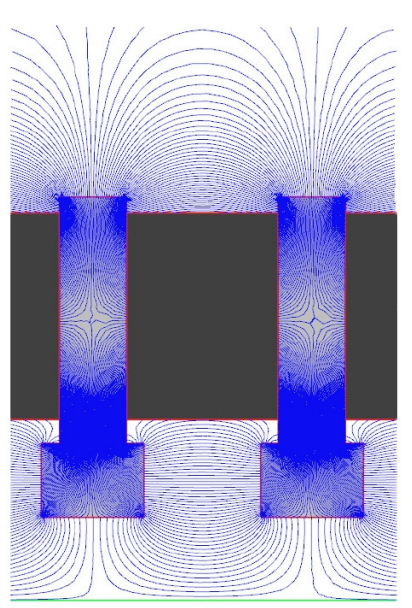

(b)

Figura 6.31: Vistas ampliadas da estrutura da malha gerada de um PPM com pole piece (a) e do perfil do campo magnético obtido (b).

As simulações foram realizadas considerando uma variação radial entre o raio externo do pole piece e o raio externo do ímã permanente de $\pm 1,2 m m$. Seja $r_{e x t}=r_{3}-r_{m 2}$. A FIG.6.32 apresenta o resultado obtido em simulações com o XMAGUN, o ANSYS e a solução ANALÍTICA para uma variação do $r_{e x t}= \pm 1,2 \mathrm{~mm}$. É possível constatar uma boa concordância entre os resultados obtidos por meio de simulações com o XMAGUN, o software ANSYS e a solução analítica.

Pode-se constatar, em simulações com o XMAGUN, para o intervalo $r_{e x t}=[-1,2$ : $+1,2]$ que, quanto menor $r_{e x t}$, maior é a intensidade do valor de pico do campo magnético axial, resultado que está de acordo com o previsto experimentalmente [34]. A FIG. 6.33 apresenta a intensidade do campo magnético axial ao longo do eixo de simetria para a estrutura do PPM com 5 (cinco) ímãs permanentes e pole pieces para 5 (cinco) valores para $r_{\text {ext }}$. 


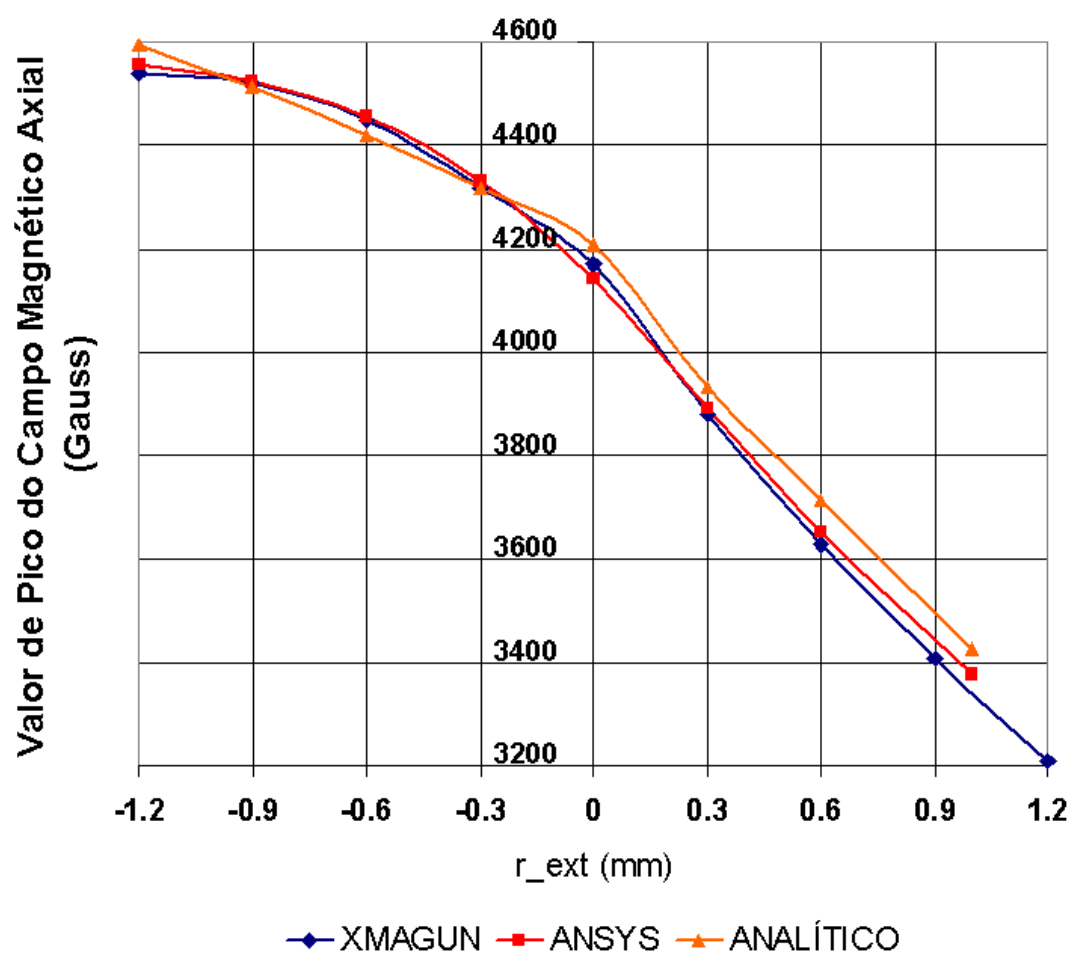

Figura 6.32: Variação do valor de pico do campo magnético axial utilizando-se o XMGUN, o código ANSYS e a solução ANALÍTICA para distintos valores de $r_{\text {ext }}$.

\subsubsection{Simulações com o XMAGUN}

\section{Estruturas diferenciadas de pole piece}

O programa XMAGUN foi utilizado para estudar o comportamento do campo magnético para dois modelos de pole pieces em um conjunto de dois ímãs, FIGS. 6.34 e 6.35 .

Observa-se que, o campo magnético gerado pelo segundo modelo de pole piece forneceu um valor de pico do campo magnético no eixo de simetria superior em mais de $40 \%$ para o primeiro modelo com pole piece e, para a configuração sem pole piece, superior a $60 \%$, FIG. 6.36 .

\section{Campo Magnético e Trajetória de Partículas em um PPM separados pelo vácuo}

Foi realizado um estudo visando verificar a capacidade de se obter um feixe de elétrons confinado por meio de um PPM composto de ímãs toroidais separados pelo vácuo [65], com a geometria da TAB. 6.5. Neste caso, foram utilizados 20 ímãs toroidais. Nas FIGS. 6.37-6.40 é possível observar o resultado das simulações considerando diversos potenciais de aceleração do feixe, a saber: $15 \mathrm{kV}, 20 \mathrm{kV}, 40 \mathrm{kV}, 60 \mathrm{kV}$ e $80 \mathrm{kV}$. Em todos os modelos considerou que o feixe transportava uma corrente de 4,6 A, entrava na estrutura paralelamente ao eixo de simetria e tinha um diâmetro de $1,0 \mathrm{~mm}$. Os resultados das simulações indicaram que:

- não há colisão do feixe de elétrons com a estrutura do PPM em toda a região de deriva; 
Intensidade do Campo Magnético Axial para um PPM com 5 Ímãs

Permanentes e 6 Pole Pieces para distintos valores de $r_{\text {ext }}$

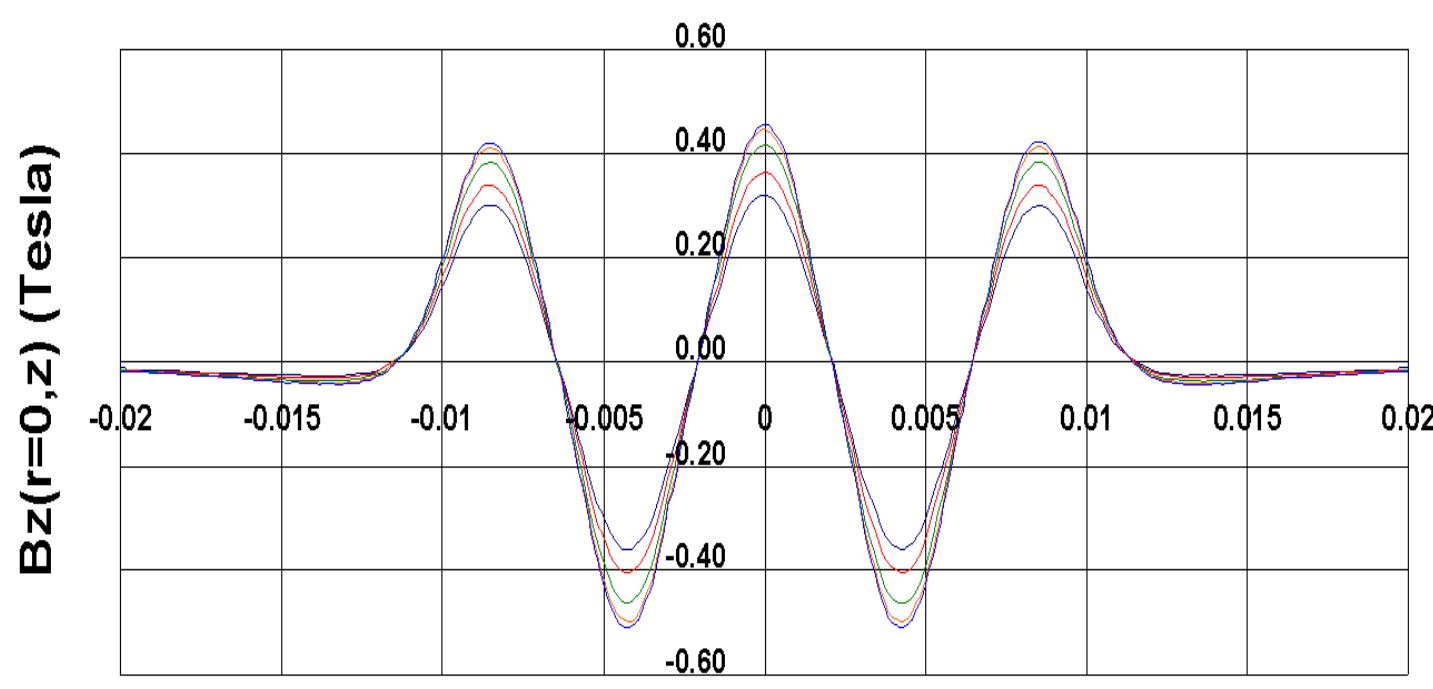

$$
\begin{gathered}
z(\mathrm{~mm}) \\
-1,2 \mathrm{~mm}-0,6 \mathrm{~mm}-0,0 \mathrm{~mm}--0,6 \mathrm{~mm}--1,2 \mathrm{~mm}
\end{gathered}
$$

Figura 6.33: Perfil da intensidade do campo magnético axial ao longo do eixo para 5 (cinco) valores distintos de $r_{e x t}=r_{3}-r_{m 2}$.

Figura 6.34: Um modelo típico de pole piece empregado entre dois ímãs permanentes e as linhas do campo magnético gerado. 


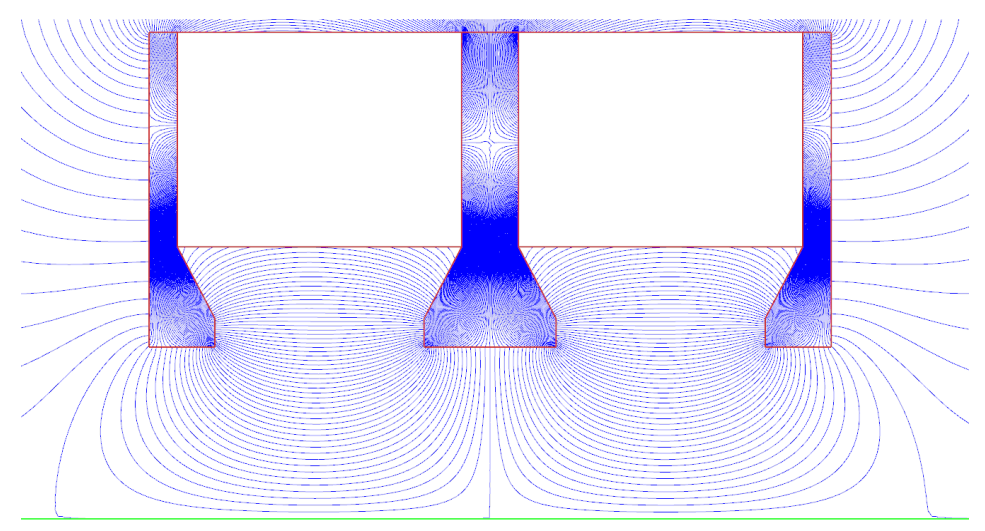

Figura 6.35: Um modelo diferenciado de pole piece empregado entre dois ímãs permanentes e as linhas do campo magnético gerado.

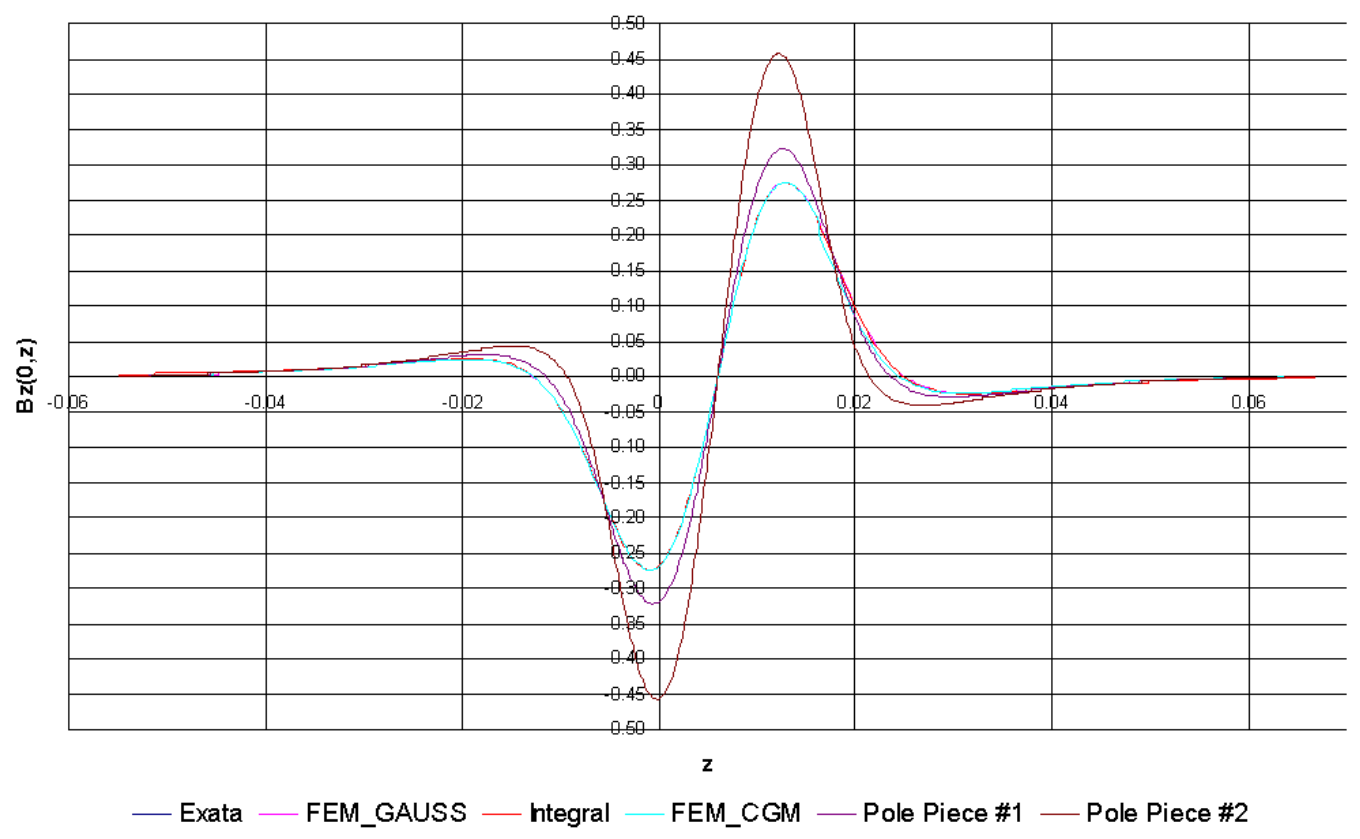

Figura 6.36: Comparação entre as intensidades do campo magnético gerado no eixo de simetria para três configurações de pole piece: (a) inexiste o pole piece; (b) modelo FIG. 6.34; (c) modelo FIG. 6.35 . 
- a ondulação (ripple) observada em todas as simulações foram inferiores a 15\%;

- embora não facilmente observável, a inclinação das trajetórias das macropartículas do feixe, poucos passos após entrarem na região de deriva, diminuia com o aumento da energia cinética do feixe, sendo que para o feixe com $60 \mathrm{keV}$, FIG. 6.40, apresenta inclinação superior a 34\%, na média, quando comparada com a inclinação das trajetórias do feixe com $80 \mathrm{keV}$, FIG.6.41; e

- sendo o parâmetro devido à carga espacial $\beta$, maior que o parâmetro devido ao campo magnético $\alpha$ em todas as simulações é possível observar, em particular na FIG.6.37, que mesmo no valor absoluto do pico da intensidade do campo magnético (primeiro ciclo negativo) o feixe continua a divergir mas, logo no semi-ciclo seguinte, a ação do campo magnético já é forte o suficiente para impor uma condição de convergência sobre o feixe.

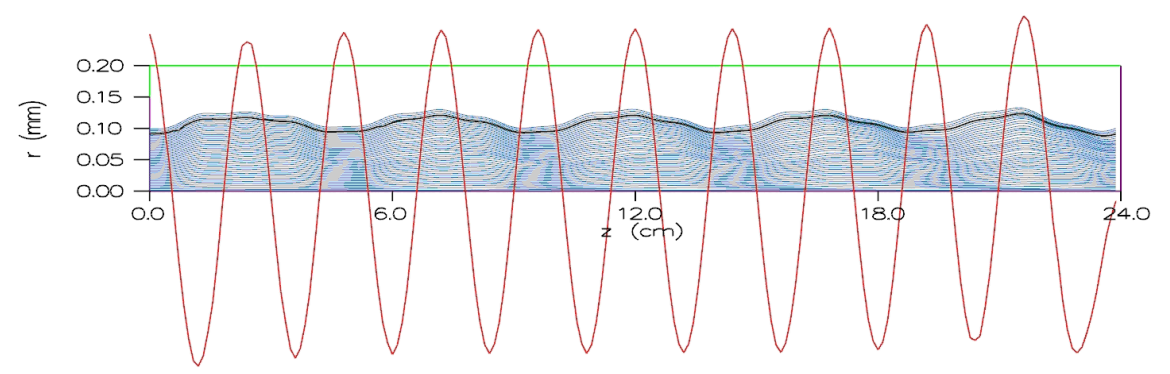

Figura 6.37: Trajetória das macropartículas considerando um potencial de aceleração, corrente do feixe e campo magnético de $15 \mathrm{kV}, 4.6 \mathrm{~A} B_{p}=85 \mathrm{mT}$ respectivamente. Também é possível observar o $r_{95}$ e a intensidade do fluxo magnético axial, $B_{z}(\rho=0)$, devido à estrutura de um PPM. Neste caso $\alpha=0,08$ e $\beta=0,55$.

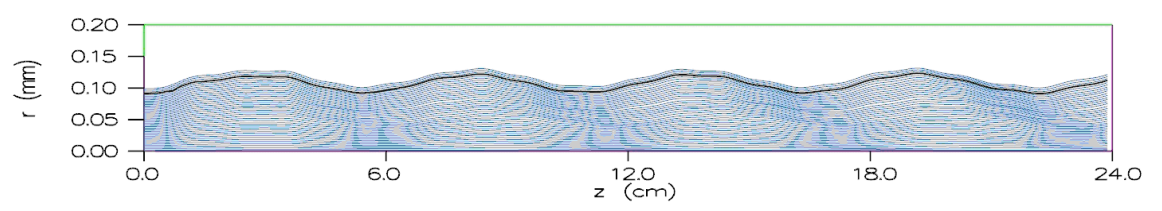

Figura 6.38: Trajetória das macropartículas considerando um potencial de aceleração, corrente do feixe e campo magnético de $20 \mathrm{kV}, 4.6 \mathrm{~A} B_{p}=85 \mathrm{mT}$ respectivamente. Também é possível observar o $r_{95}$. Neste caso $\alpha=0,06$ e $\beta=0,36$. 


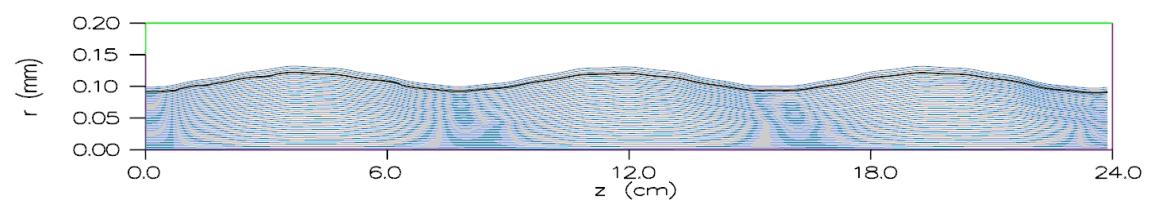

Figura 6.39: Trajetória das macropartículas considerando um potencial de aceleração, corrente do feixe e campo magnético de $40 \mathrm{kV}, 4.6 \mathrm{~A} B_{p}=85 \mathrm{mT}$ respectivamente. Também é possível observar o $r_{95}$. Neste caso $\alpha=0,03$ e $\beta=0,13$.

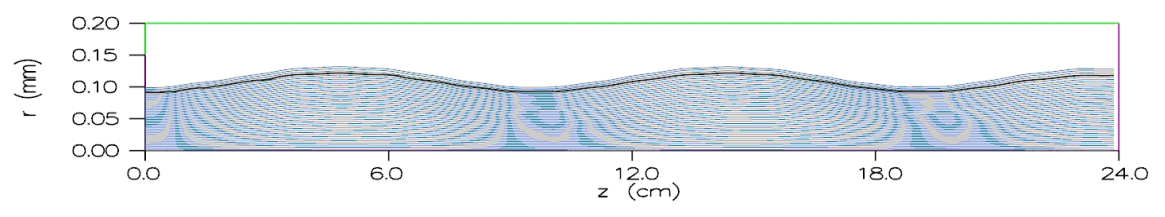

Figura 6.40: Trajetória das macropartículas considerando um potencial de aceleração, corrente do feixe e campo magnético de $60 \mathrm{kV}, 4.6 \mathrm{~A} B_{p}=85 \mathrm{mT}$ respectivamente. Também é possível observar o $r_{95}$. Neste caso $\alpha=0,02$ e $\beta=0,07$.

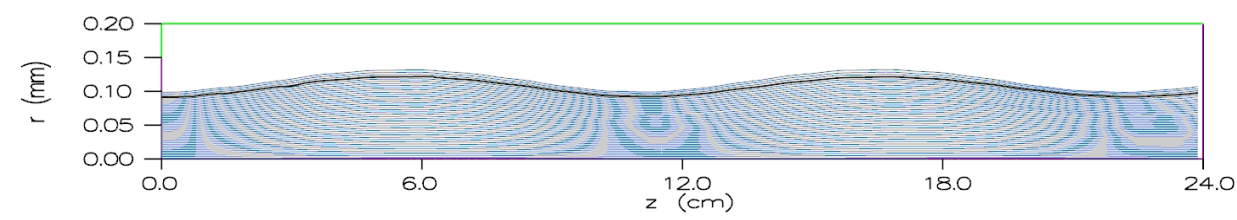

Figura 6.41: Trajetória das macropartículas considerando um potencial de aceleração, corrente do feixe e campo magnético de $80 \mathrm{kV}, 4.6 \mathrm{~A} B_{p}=85 \mathrm{mT}$ respectivamente. Também é possível observar o $r_{95}$. Neste caso $\alpha=0,01$ e $\beta=0,04$. 


\subsection{Conclusões do Capítulo}

Partindo de modelos físicos de componentes de canhões de elétrons de válvulas do tipo TWT existentes no laboratório, foram realizadas simulações com o software EGUN. Estes componentes foram dimensionalmente caracterizados nas instalações do CTMSP. Dentre os diversos canhões simulados, o que apresentou o melhor desempenho foi o G2Y. Fez-se, em seguida, uma análise do efeito de uma variação na separação catodo-anodo de $\pm 0,5 \mathrm{~mm}$, em simulações com o EGUN, sendo observado uma variação em corrente de $\mp 0,5 \mathrm{~A}$. Foram observadas, também, variações no comportamento da trajetória do feixe de elétrons e respectiva intensidade de corrente em simulações com o EGUN considerando o modo como é modelado a shadow-grid. Simulações com o EGUN em que a shadow-grid é fisicamente modelada sobre a superfície do catodo resultou, geralmente, em correntes inferiores quando comparado com as simulações em que a shadow-grid era modelada como regiões não emissoras sobre a superfície do catodo.

Importantes relações, para uma melhor compreensão de como corrente e perveância se comportam, considerando a variação de 5 (cinco) parâmetros da geometria de um modelo típico de canhões de elétrons, foram estudadas.

O XMGUN foi utilizado em simulações de um canhão plano de Pierce e os seguintes resultados para a densidade de corrente foram observados:

- erros inferiores a 3\% podem ser obtidos para largura de emissão superior a 0,1 ;

- o número de iterações necessárias para se obter convergência cresce com o crescimento de $d_{s} / d$ para $0,1 \leq d_{s} / d \leq 0,4$ permanecendo praticamente constante para $d_{s} / d>$ 0,4

- o coeficiente de sobre-relaxação $u$ leva a um menor número de iterações para $0,3 \leq$ $u \leq 0,5 ; \mathrm{e}$

- o erro, para um número de partículas $N_{p}$ lançadas a partir do catodo no intervalo $50 \leq N_{p} \leq 300$, é praticamente constante.

De modo geral, para a posição final das partículas, erros inferiores a $1 \%$ foram observados para $80 \%$ das partículas emitidas a partir do catodo, considerando o diode plano de Pierce em que a geometria do anodo é corrigida. Não foram observados desvios superiores a $\pm 0,8^{\circ}$ para as trajetórias das partículas do feixe em simulações realizadas até então.

O erro observado para o tempo de trânsito de, tipicamente, $85 \%$ das partículas são inferiores a $\pm 0,5 \%$. Em relação aos erros da energia das partículas do feixe, observa-se que malhas mais refinadas apresentam erros menores, sendo estes inferiores a $0,4 \%$ quando se utilizou a Malha IV. Estes erros foram avaliados em quatro planos colocados entre o catodo e o anodo.

Simulações de canhões de elétrons com e sem grade de controle foram realizadas. A posição radial do feixe de elétrons, ao longo do eixo de simetria, que contém $95 \%$ da corrente, $r_{95}$ e a velocidade transversal normalizada $\sigma$ foram apresentados e introduzidos à 
ferramenta computacional para (a) se determinar a cintura do feixe e (b) ter um parâmetro que indica a qualidade do feixe de elétrons. Finalmente, para o XMGUN, foi simulado um coletor de simples estágio considerando o modelo de emissão simplificado de elétrons secundários.

Não foram observadas, para os campos magnéticos longitudinais gerados por uma estrutura do tipo PPM separados pelo vácuo com um, dois e vinte ímãs, grandes discrepâncias entre os resultados obtidos em simulações com a ferramenta computacional XMAGUN e as soluções analíticas, sendo que, para vinte ímãs, os erros, tipicamente, foram inferiores a 1\%. Soluções analíticas dos campos magnéticos axial e radial no interior de estruturas de focalização do tipo PPM com pole pieces só existem para dimensão infinita. Foi apresentado, entretanto, uma comparação, para o campo axial no centro de uma estrutura PPM com pole pieces em que um dos parâmetros da geometria era variável, entre (a) o XMAGUN, em que foi avaliado o campo no centro de uma estrutura com cinco ímãs permanentes, (b) a solução analítica proposta por Santra et al. e (c) a ferramenta computacional ANSYS. É observado uma boa concordância entre os resultados apresentados pelos XMAGUN ( mesmo não utilizando uma estrutura infinita ) e ANSYS com a solução analítica. Utilizando o XMAGUN, foram ainda realizadas simulações com estruturas do pole piece diferenciadas e os resultados para as linhas de campo e intensidade do campo axial foram apresentados.

Finalmente, o resultado dos campos axial e radial obtidos pelo XMAGUN, considerando um PPM com 20 (vinte) ímãs permanentes separados pelo vácuo, foram mapeados na estrutura da malha e, utilizando o XMGUN, feixes de elétrons foram lançados com diversos potenciais de aceleração e suas trajetórias foram traçadas e os resultados foram apresentados. 


\section{Capítulo 7}

\section{Conclusão}

Este trabalho apresentou os principais resultados obtidos durante o desenvolvimento de uma ferramenta computacional capaz de simular, a partir da equação da trajetória, a dinâmica de partículas: em canhões de elétrons com grades e shadow-grids operando na condição FSCL; na região de deriva sob a ação de campos magnéticos externos gerados, tipicamente, por estruturas de focalização do tipo PPM; e, em coletores de simples e múltiplos estágios.

A linguagem de programação utilizada no desenvolvimento da ferramenta computacional foi o $C$. Ferramentas de suporte opensource, associadas às atividades subsidiárias, foram utilizadas, tais como: (a) OpenGl e GLUI - interface gráfica; (b) STL - biblioteca com diversos tipos de coleções de dados e algoritmos eficientes; e (c) EasyMesh - gerador de malha 2D não estruturada.

Foram estudados os canhões de elétrons plano de Pierce de feixe paralelo e de fluxo convergente. Nos dois estudos, foi adotada uma emissão de partículas pelo catodo operando na condição limitada pela carga espacial. Os principais conceitos envolvidos na determinação da dinâmica do feixe, para os casos estudados, tais como perveância, alcance e cintura do feixe foram apresentados. Demonstrou-se que, para o canhão plano de Pierce, podem ser obtidas trajetórias retilíneas para as partículas (a) tomando-se um ângulo de $67,5^{\circ}$ entre o eletrodo de focalização e a direção longitudinal, e (b) por meio da construção de uma geometria do anodo adequada. Foi demonstrado, ainda, que a máxima densidade de corrente $J_{c \max }$ que pode ser extraída deste canhão é diretamente proporcional a $V_{a}^{3 / 2}$ e inversamente a $d_{a c}^{2}$, onde $V_{a}$ e $d_{a c}$ são o potencial do anodo e a separação catodo-anodo respectivamente. Para o canhão de Pierce de fluxo convergente demonstrou-se que é possível determinar toda a geometria do canhão a partir de quatro parâmetros de projeto: tensão do anodo $\left(V_{a}\right)$; corrente do feixe $\left(I_{0}\right)$; cintura do feixe $\left(r_{M}\right)$; e densidade de corrente de operação $\left(J_{o p}\right)$.

Para que o feixe de elétrons seja colimado na região de deriva, uma vez que devido às cargas espaciais o feixe tende a divergir, provou-se que é possível utilizar tanto uma estrutura solenoidal quanto uma do tipo PPM. A vantagem da estrutura do tipo PPM sobre a solenoidal está no peso, que chega a ser de uma a duas ordens de grandeza menor, e ausência de consumo de energia. A desvantagem da estrutura PPM, entretanto, reside no fato de que, uma vez projetada, as intensidades dos campos no interior da estrutura são fixos. Utilizando a estrutura solenoidal para confinar um feixe de elétrons, que se comporta como um fluxo de 
Brillouin, e transporta uma corrente $I$, com cintura $a$ e velocidade axial $v_{z}$, foi demonstrado que a intensidade do campo magnético $B_{z}$ é proporcional a $B_{z} \propto(1 / a)\left(I / v_{z}\right)^{1 / 2}$. Utilizandose, entretanto, uma estrutura do tipo PPM para confinar o feixe foi provado que, a intensidade do campo magnético $B_{p}$ deve ser, no mínimo, $B p=\sqrt{B z}$ e, o período magnético $L$, deve obedecer à condição: $L<14,44\left(v_{z} / \eta B_{p}\right)$.

Foram ainda estudadas estruturas do tipo PPM separados pelo vácuo e com pole piece. Considerando um PPM com $N$ ímãs permanentes separados pelo vácuo, foi apresentada a solução analítica para os campos magnéticos axial e radial em todo o domínio do problema. Entretanto, só se dispõe de solução analítica para os campos magnéticos axial e radial no interior de uma estrutura do tipo PPM com pole piece, caso seja considerado um arranjo infinito.

No estudo de coletores, foi demonstrado que se tratam de componentes fundamentais por contribuírem, de forma significativa, para o aumento da eficiência das válvulas onde são empregados, por meio da desaceleração do feixe de elétrons. Devido a colisão das partículas do feixe com a superfície do coletor, elétrons secundários são emitidos. Foram apresentados dois modelos para a emissão de elétrons secundários, um adotado pela NASA em 1986 e, outro, mais recente, utilizado pelos programas MICHELLE e EOS.

Toda a fundamentação física do problema acoplado para os campos eletromagnéticos e para as trajetórias das partículas foi apresentada. O MEF foi utilizado, no domínio do problema, para se obter os potenciais (a) escaleres elétricos a partir da equação de Poisson, e (b) os potenciais vetores magnéticos a partir do funcional magnético. Desta forma, as trajetórias das partículas podem ser estabelecidas, por meio da integração da equação da trajetória que é diferencial de segunda ordem e não linear, utilizando-se, por exemplo, o método de RungeKutta de $4^{a}$ ordem. Ao longo da trajetória de todas as macropartículas, as cargas elétricas são depositadas e armazenadas em uma estrutura do elemento finito. O método MAS foi descrito, e aqui, é utilizado como solução iterativa para o problema acoplado. Uma vez que, geralmente, o sistema linear a ser resolvido, ao se utilizar o MEF, é esparso, os esquemas adotados para armazenamento, CRS, e solução do sistema, MGB, foram desenvolvidos.

Foram realizadas simulações de canhões de elétrons utilizando o software EGUN2 para se obter uma melhor compreensão do comportamento dos canhões de elétrons, a partir da geometria obtida de componentes físicos existentes no CTMSP. Foram observados a corrente e a perveância dos canhões simulados pela variação de cinco parâmetros, sendo quatro da geometria de um canhão de referência, a saber: raio do disco do catodo; ângulo do eletrodo de focalização; distância catodo-anodo; separação grade-catodo; e, o quinto, não geométrico, foi a tensão aplicada sobre a grade de controle. Foram estabelecidos um intervalo para cada um dos parâmetros acima e, os resultados das simulações, em corrente e perveância observados são assim sintetizadas para cada parâmetro:

- Raio do disco do catodo: a perveância/corrente diminui com o aumento do raio do catodo e, fixado um raio do catodo, a perveância/corrente aumenta com a aproximação catodo-anodo; 
- Ângulo do eletrodo de focalização: fixada uma separação catodo-anodo, a perveância/corrente cresce com o aumento do ângulo do eletrodo de focalização e, uma mesma perveância pode ser obtida, para diferentes ângulos do eletrodo de focalização, pelo ajuste da distância catodo-anodo;

- Distância catodo-anodo: para uma mesma tensão da grade de controle, a perveância/corrente do feixe diminui com o aumento da separação catodo-anodo e, para uma mesma separação catodo-anodo, é possível aumentar a perveância/corrente aumentandose a tensão da grade de controle;

- Separação grade-catodo: para uma mesma tensão da grade de controle, a perveância/corrente do feixe aumenta com a aproximação grade-catodo e, para uma mesma separação grade-catodo, é possível aumentar a perveância/corrente aumentando-se a tensão da grade de controle; $\mathrm{e}$

- Tensão aplicada sobre a grade de controle: fixada uma separação catodo-anodo, a perveância/corrente do feixe cresce com o aumento da tensão da grade de controle e, para uma mesma tensão da grade de controle, é possível aumentar a perveância/corrente diminuindo-se a separação catodo-anodo.

A simulação do canhão de elétrons G2Y, projetado a partir de componentes físicos existentes do CTMSP, com grade e shadow-grid, utilizando o EGUN2 indica ser possível obter uma corrente de 4A com uma cintura do feixe de aproximadamente 2,0mm.

As ferramentas computacionais MICHELLE, Trak e o EGUN, resolvem a equação horária da partícula, integrando-a no tempo, enquanto que, o XMGUN resolve o problema das trajetórias das partículas, integrando a equação da trajetória. Foi avaliado o desempenho da ferramenta computacional desenvolvida, XMGUN, confrontando as respostas obtidas em simulações com a solução analítica de um diodo plano de Pierce operando na condição FSCL. O erro observado para a densidade de corrente $J$ do feixe de elétrons foi inferior a 3\% para uma razão da largura da área de emissão não inferior a 0,1 . Para o diodo plano de Pierce, em que a geometria do anodo foi corrigida, os resultados indicam que os erros são inferiores quando comparados com os do diodo plano de Pierce cujo anodo é plano. Simulações, utilizando o XMGUN, de canhões de elétrons com grades e shadow-grids foram realizadas e parâmetros do feixe, cintura, alcance, corrente e perveância foram apresentadas.

Foram realizados, ainda, testes de benchmark entre o XMAGUN, o ANSYS e a solução analítica para uma estrutura de um PPM com pole piece. Foi observada uma boa concordância em todas as simulações realizadas. O XMAGUN foi ainda utilizado para modelar estruturas tipo PPM com pole pieces modificadas, que serão objetos de estudo e posterior validação experimental uma vez que, a configuração simulada apresentou aumento significativo na intensidade do campo magnético axial no eixo de simetria.

Os trabalhos futuros, voltados para o aprimoramento das ferramentas computacionais XMGUN e XMAGUN, podem ser assim sintetizados:

- integração entre os módulos (a) gerador de malhas, (b) XMGUN e (c) XMAGUN; 
- estudo e obtenção da equação da trajetória na forma relativística;

- utilização de técnicas de processamento paralelo, tanto para a montagem do sistema esparso quanto para a sua solução utilizando-se o MGC;

- estudo e aprimoramento do modelo de cálculo de trajetórias para elétrons secundários em coletores do tipo MDC; e

- evolução do projeto para uma versão totalmente 3D. 


\section{Apêndice A}

\section{Ferramentas Open Source}

Utilizando a ferramenta de busca do Google com o termo "software livre"é disponibilizado ao usuário mais de 3,6 milhões de sítios, indicando existir uma grande comunidade de usuários e desenvolvedores de ferramentas open source. É possível, atualmente, encontrar desde pequenos utilitários até sistemas operacionais open source disponíveis na web. $\mathrm{O}$ software livre tem um papel importante no desenvolvimento de novos códigos, uma vez que exigem dos desenvolvedores de códigos não-livres que apresentem um diferencial de seus produtos, seja em desempenho ou na disponibilização de novos recursos ao usuário final. É premissa do software livre o acesso ao código fonte. Desta forma, se pode estudar como o programa funciona, modificá-lo e aperfeiçoá-lo. As melhorias implementadas podem, então, ser disponibilizados para que toda a comunidade de desenvolvedores se beneficie.

Neste Apêndice, são apresentados os pacotes livres utilizados no desenvolvimento das ferramentas computacionais XMGUN e XMAGUN. Na seção A.1 é apresentado o ambiente de desenvolvimento integrado para as linguagens $\mathrm{C}$ e $\mathrm{C}++$. As principais características e funcionalidades da STL no gerenciamento de diferentes estruturas de dados são brevemente descritos na seção A.2. A visualização dos resultados obtidos em simulações de canhões de elétrons, na região de deriva com estruturas do tipo PPM e coletores foi possível por meio do OpenGL. Trata-se de uma biblioteca gráfica leve (menos de $500 \mathrm{~Kb}$ ), fácil de utilizar e bem documentada, e é detalhada na seção A.3. Integrada a visualização de resultados, foi utilizada a biblioteca GLUI, seção A.4. Esta biblioteca permite elaborar janelas para a interface com o usuário. Finalmente, na seção A.5, os conceitos relativos à geração de malhas e a descrição do programa EasyMesh são detalhados.

\section{A.1 DevC++}

Desenvolvido pela empresa Bloodshed, o programa DevC++, FIG. A.1, é um ambiente de desenvolvimento integrado para a linguagem $\mathrm{C}$ e $\mathrm{C}++$ [52]. Faz uso do MingW como compilador, o qual foi desenvolvido pelo projeto GNU [68].

As principais características deste ambiente de desenvolvimento são:

- Depurador integrado; 


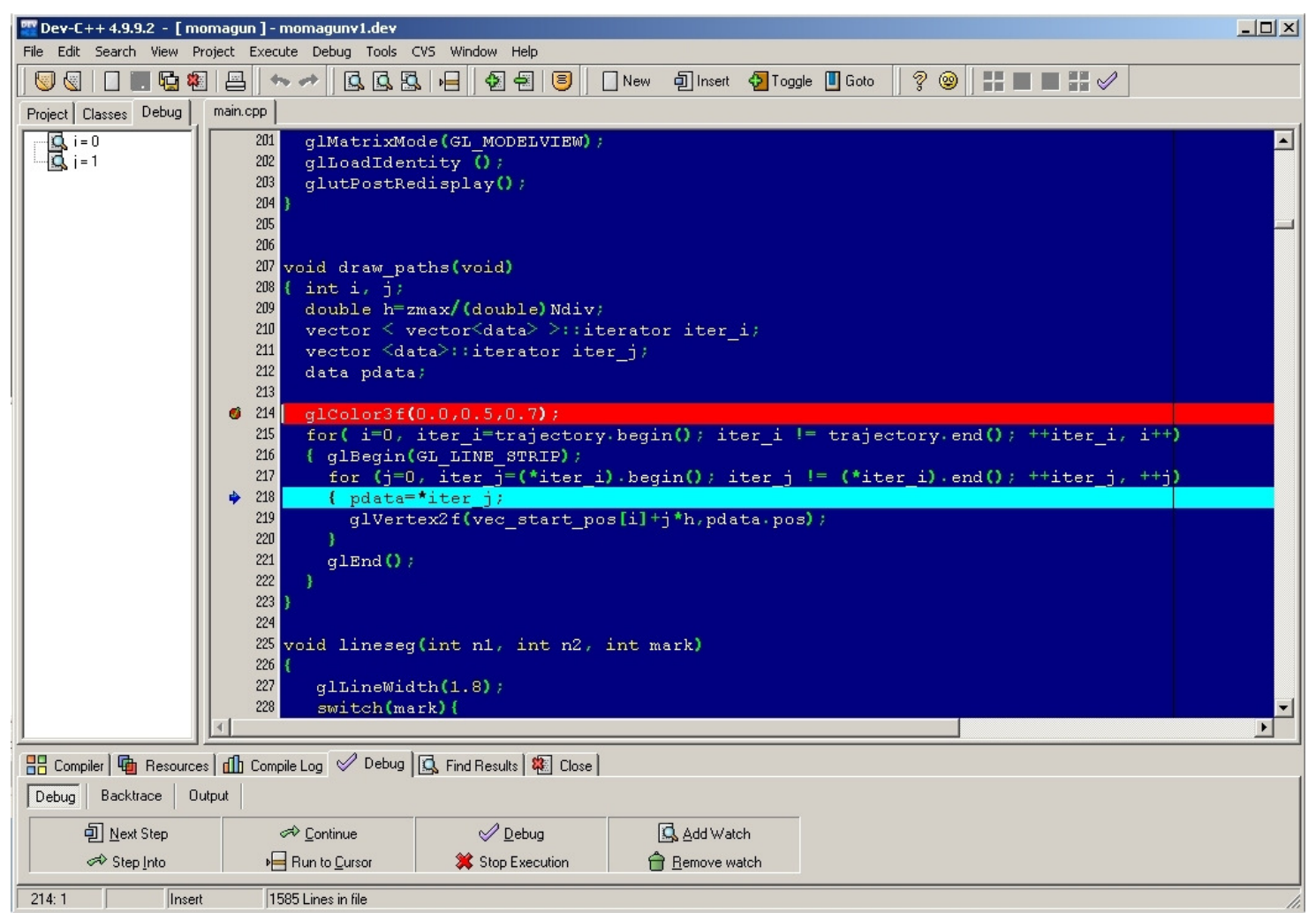

Figura A.1: Vista do ambiente gráfico integrado do DevC++.

- Navegador de Classes e de variáveis depuradas;

- Gerenciador de Compilação do Projeto;

- Editor customizado de sintaxe;

- Criação de programas em janelas, de consoles, de bibliotecas estáticas e de DLL ( $D y$ namic Link Library);

- Gerenciador de Pacotes, que facilita a instalação de novas bibliotecas; e

- Janela com o código em assembler da CPU.

O DevC ++ tem como requisito mínimo para instalação o sistema operacional Windows 95 com 32 Mb de RAM. A versão atualmente disponível para download é a 4.9.9.2.

\section{A.2 STL}

A biblioteca STL [53]-[55], parte integrante da biblioteca padrão do $C++$, disponibiliza ao desenvolvedor de aplicativos, soluções para o gerenciamento de coleções de dados por meio do uso de algoritmos modernos e eficientes. STL permite utilizar tipos arbitrários de dados. Utilizando a biblioteca STL, o programador não mais necessita desenvolver arranjos dinâmicos, listas encadeadas e árvores binárias, assim como diferentes algoritmos de busca. 
O uso da STL permite, tão simplesmente que o desenvolvedor especifique o tipo de contêiner mais adequado (vetor, lista, deque, conjunto ou mapa) para os dados do seu problema e, em seguida, utilize as funções membros e os algoritmos disponíveis para processar os dados. São três os componentes da STL:

- Contêineres: são utilizados para manipular coleções de objetos de um determinado tipo. Cada tipo de contêiner possui vantagens e desvantagens, podendo, portanto, refletir no desempenho de um programa. Os contêineres, por sua vez, são classificados em sequênciais ou associativos ${ }^{1}$. Um contêiner é dito ser sequencial quando cada elemento ocupa uma determinada posição. A ordem com que os elementos são inseridos é importante. São exemplos de contêiner sequencial: vector, deque e list. Quando a posição de um elemento depende de seu valor devido a algum critério de ordenação, diz-se que este contêiner é associativo. Neste caso a ordem de inserção dos elementos não é importante. São quatro os tipos de contêineres associativos: set, multiset, map e multimap.

- Iteradores: são uma generalização de ponteiros, uma vez que são objetos que apontam para outros objetos. São utilizados para percorrer os elementos de uma coleção de objetos, os quais podem ser contêineres. Assim como um ponteiro, se um iterador de uma coleção aponta para um elemento, é possível acessar o elemento que se segue utilizando-se o operador ++ ou, caso necessário, decrementá-lo para acessar o elemento da coleção que o antecede e, neste caso, utiliza-se o operador - - .

- Algoritmos: são utilizados para manipular os elementos de contêineres. Uma vez que os algoritmos devem trabalhar com diferentes tipos de contêineres, os mesmos não utilizam os contêineres como argumentos, mas sim, iteradores. Os algoritmos incluem operações de ordenação ( $\operatorname{sort}(), \operatorname{merge}(), \min (), \max (), \ldots)$ de busca (find(), $\operatorname{count}()$, equal ()$, \ldots)$, de mudança ( $\operatorname{transform}()$, replace () , fill () , rotate ()$, \operatorname{shuffle}(), \ldots)$ e operações numéricas generalizadas (accumulate $($ ), adjacent_find () , set_difference ()$, .$.$) .$

\section{A.3 OpenGL}

OpenGL [56] é um conjunto de rotinas, aproximadamente 150, utilizadas em computação gráfica, as quais fazem a interface com todos os recursos do hardware de vídeo, para o desenvolvimento de aplicativos gráficos $2 \mathrm{D}$ ou 3D. Atualmente o OpenGL está na versão 4.1, no entanto, todos os recursos utilizados para o desenvolvimento dos códigos XMGUN e XMAGUN estão disponíveis desde a versão 1.1. Uma excelente fonte disponível online que serve como introdução em programação gráfica utilizando-se o OpenGL é encontrado em [69].

\footnotetext{
${ }^{1}$ Alguns autores sugerem um terceiro tipo de contêineres denominados adaptativos. Estes porém, são construídos a partir dos contêineres sequenciais e são: stack (funciona como uma pilha LIFO - last in first out), queue (funciona como uma fila FIFO - first in first out) e priority-queue (funciona como uma fila ordenada, onde quem sai é sempre o elemento de maior valor).
} 
Todos os modelos ou objetos são renderizados a partir do um conjunto de vértices e de três primitivas geométricas: pontos, linhas e polígonos. $\mathrm{O}$ comando utilizado para especificar um vértice é glVertex*(), onde * indica se o parâmetro passado é: $2 \mathrm{D}$ ou $3 \mathrm{D}$; inteiro ou ponto flutuante. Toda chamada a glVertex*() deve ser executada entre os comandos glBegin() e glEnd(). $\mathrm{O}$ argumento passado por glBegin() indica qual o tipo de primitiva é construída a partir dos vértices conforme pode ser visto na FIG. A.2.
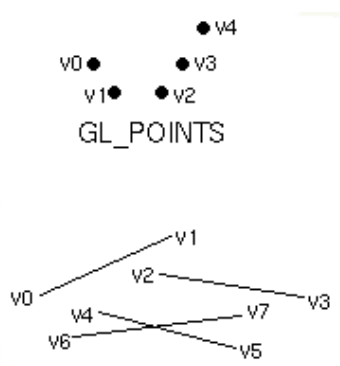

GL_LINES

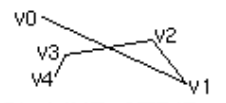

GL_LINE_STRIP

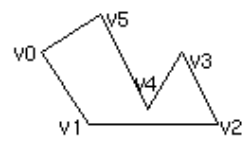

GL_LINE_LOOP
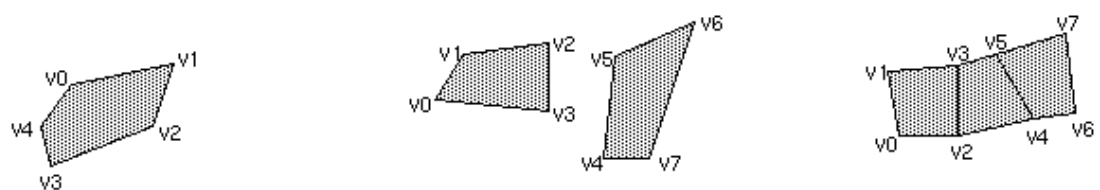

GL_POLYGON

GL_QUADS
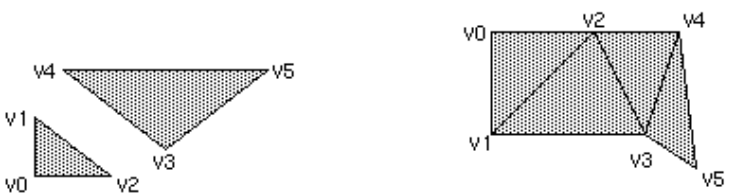

GL_QUAD_STRIP

GL_TRIANGLES

GL_TRIANGLE_STRIP

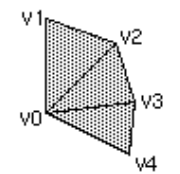

GL_TRIANGLE_FAN

Figura A.2: Primitivas utilizadas pelo OpenGL para renderizar objetos.

A seguir é apresentado uma descrição sintetizada para cada primitiva, onde considera-se que os $n$ vértices $\left(v_{0}, v_{1}, v_{2}, \ldots, v_{n-1}\right)$ estão descritos entre os comandos glBegin() e glEnd().

- GL_POINTS: desenha cada um dos $n$ vértices;

- GL_LINES: desenha uma série de segmentos de linha não conectados. Os segmentos são desenhados entre os vértices $\mathrm{v}_{0}$ e $\mathrm{v}_{1}$, entre $\mathrm{v}_{2}$ e $\mathrm{v}_{3}$ e assim sucessivamente. Caso $n$ seja ímpar, o último segmento desenhado será entre os vértices $\mathrm{v}_{n-3} \mathrm{e}_{n-2}$, e o vértice $\mathrm{v}_{n-1}$ é ignorado;

- GL_POLYGON: desenha um polígono utilizando os pontos $\mathrm{v}_{0}, \ldots, \mathrm{v}_{n-1}$ como vértices. $n$ deve ser pelo menos 3 pois, caso contrário, nada será desenhado. Outra condição para que o polígono seja desenhado é que ele seja convexo;

- GL_TRIANGLES: desenha uma série de triângulos utilizando-se os vértices $\mathrm{v}_{0}, \mathrm{v}_{1} \mathrm{e}$ $\mathrm{v}_{2}$, em seguida $\mathrm{v}_{3}, \mathrm{v}_{4}$ e $\mathrm{v}_{5}$ e assim sucessivamente. Caso $n$ não seja múltiplo de $3, \mathrm{o}$ vértice final ou os dois últimos são ignorados; 
- GL_LINE_STRIP: desenha um segmento de linha entre $v_{0}$ e $v_{1}$, entre $v_{1}$ e $v_{2}$ e assim sucessivamente, até o último segmento entre $\mathrm{v}_{n-2}$ e $\mathrm{v}_{n-1}$. Um total de $n-1$ segmentos são desenhados ou nenhum segmento é desenhado caso $n$ não seja maior que 1 . Neste caso os segmentos podem arbitrariamente interceptarem-se;

- GL_LINE_LOOP: tem a mesma característica de GL_LINE_STRIP à exceção de que um último segmento é desenhado entre os vértices $\mathrm{v}_{n-1}$ e $\mathrm{v}_{0}$, fechando o ciclo;

- GL_QUADS: desenha um conjunto de quadriláteros utilizando-se os vértices $\mathrm{v}_{0}, \mathrm{v}_{1}$, $\mathrm{v}_{2}, \mathrm{v}_{3}$ em seguida $\mathrm{v}_{4}, \mathrm{v}_{5}, \mathrm{v}_{6}, \mathrm{v}_{7}$ e assim sucessivamente. Caso $n$ não seja um múltiplo de 4, um, dois ou os três últimos vértices são ignorados;

- GL_QUAD_STRIP: desenha uma série de quadriláteros, inicializando com $\mathrm{v}_{0}, \mathrm{v}_{1}, \mathrm{v}_{3}$, $\mathrm{v}_{2}$, e em seguida $\mathrm{v}_{2}, \mathrm{v}_{3}, \mathrm{v}_{5}, \mathrm{v}_{4}$, em seguida $\mathrm{v}_{4}, \mathrm{v}_{5}, \mathrm{v}_{7}, \mathrm{v}_{6}$ e assim sucessivamente. $n$ deve ser no mínimo 4 ou nada será desenhado e, caso $n$ seja ímpar, o vértice final é ignorado;

- GL_TRIANGLE_STRIP: desenha uma série de triângulos, utilizando os vértices $\mathrm{v}_{0}$, $\mathrm{v}_{1}, \mathrm{v}_{2}$, e em seguida $\mathrm{v}_{2}, \mathrm{v}_{1}, \mathrm{v}_{3}$ em seguida $\mathrm{v}_{2}, \mathrm{v}_{3}, \mathrm{v}_{4}$ e assim sucessivamente. Esta ordenação é utilizada para garantir que todos os triângulos sejam desenhados com a mesma orientação de forma que possam corretamente formar uma parte de uma superfície. $n$ deve ser no mínimo 3 ou nada será desenhado;

- GL_TRIANGLE_FAN: desenha tal como GL_TRIANGLE_STRIP, à exceção que os vértices são $\mathrm{v}_{0}, \mathrm{v}_{1}, \mathrm{v}_{2}$, em seguida $\mathrm{v}_{0}, \mathrm{v}_{2}, \mathrm{v}_{3}$, em seguida $\mathrm{v}_{0}, \mathrm{v}_{3}, \mathrm{v}_{4}$ e assim sucessivamente.

Pode-se controlar o tamanho da primitiva tipo ponto ou a espessura da primitiva tipo linha. Para o controle da primitiva tipo ponto utiliza-se a função glPointSize() e para a primitiva linha, glLineWidth(). Às duas funções deve-se passar como parâmetro o tamanho e/ou a espessura (em pixels) desejado(a) para o(a) ponto e/ou linha, que deve ser maior que zero.

O uso de cores é extensivamente utilizado na visualização de objetos. A função do OpenGL que atribui cores na renderização dos objetos é glColor3f(red, green, blue) onde, red, green e blue são parâmetros do tipo float representando a intensidade de cor vermelha, verde e azul respectivamente. Os valores permitidos para estes parâmetros são: $0.0 \leq$ red, green, blue $\leq 1.0$. Assim, o preto é representada pelo comando glColor3f(0.0, 0.0, 0.0) enquanto que o branco, glColor3f(1.0, 1.0, 1.0).

OpenGL permite, para visualização dos objetos, a utilização de projeções do tipo ortográfica (glOrtho()) ou em perspectiva (glFrustum()). Pode-se ainda facilmente gerar animações utilizando-se funções de translação (glTranslate()), rotação (glRotate()) e de deformação (glScale()) dos objetos.

Basicamente, as funções do OpenGL acima descritas, correspondem a mais de $95 \%$ dos comandos do OpenGL utilizados no desenvolvimento dos códigos XMGUN e XMAGUN. 
O exemplo abaixo escrito em $C$, utilizando-se OpenGL, desenha um círculo de raio radius centrado em $x c$ e $y c$ :

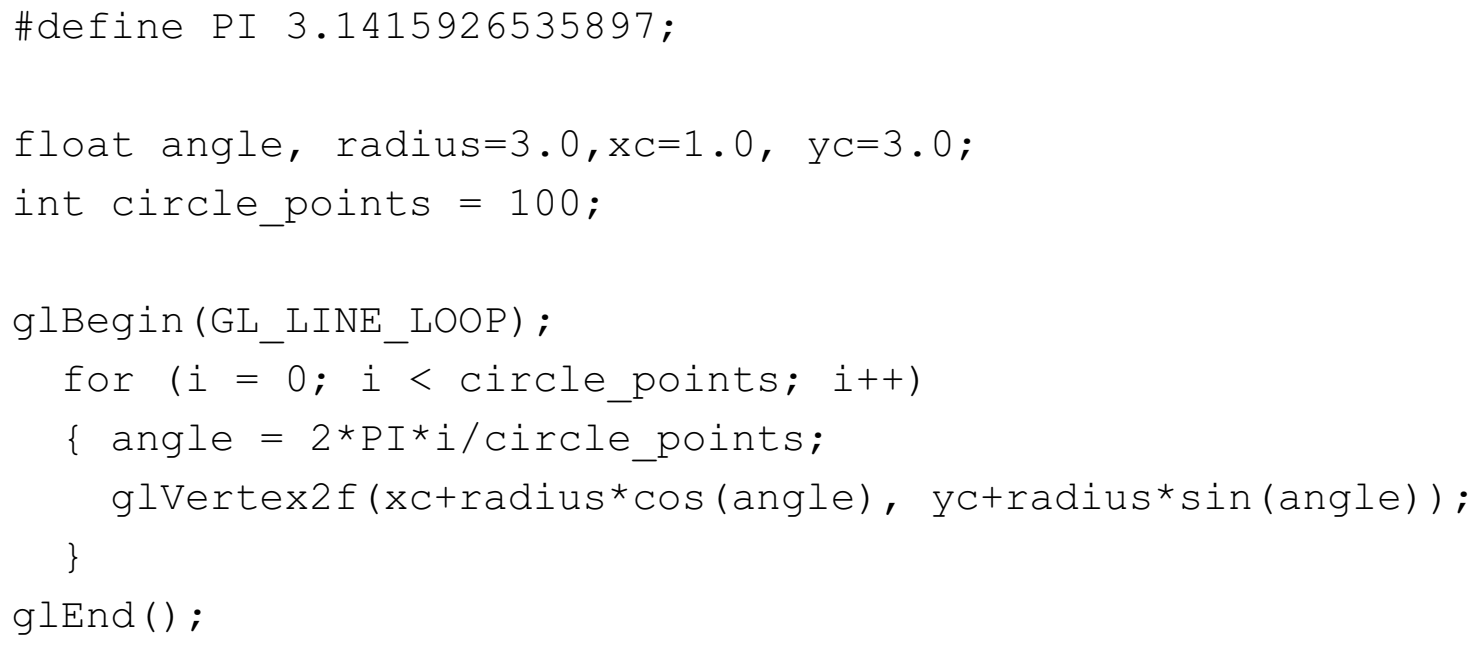

Um exemplo final ilustrando como o XMGUN, para um canhão de elétrons, renderiza as trajetórias das partículas é apresentado no código a seguir. Todas as partículas são lançadas a partir da posição axial inicial armazenada no vetor vec_start_pos (L1). Se o catodo é plano, as posições axiais iniciais de lançamento, para cada uma das partículas são as mesmas, o que não acontece no caso em que o catodo é esférico. A estrutura de dados data, L2-4, armazena para uma partícula, uma posição radial pos e o coeficiente angular de sua trajetória, dpos. A variável trajectory (L5) armazena, para cada partícula do problema do canhão de elétrons, um vetor com a estrutura data. Assim, a trajetória de todas as partículas está unicamente determinada a partir da posição inicial de cada uma delas, e as posições radiais ocupadas ao serem aceleradas pelo potencial do anodo. O incremento axial $h$ (L8) é dado pela razão entre o tamanho do modelo de canhão simulado, armazenado na variável zmax, e o número de divisões Ndiv estabelecido pelo projetista. A variável iter_i, L9, é um iterador de vetores, que representa um apontador para cada uma das trajetórias das partículas. A variável iter $j$, L10, é um iterador para um vetor de estruturas do tipo data. Utiliza-se a variável pdata para acessar a posição radial da trajetória armazenada na estrutura data. A L12 estabelece a cor da linha da trajetória a ser desenhada por meio da chamada da função do OpenGL glColor3f(). A variável $i$, do laço externo, L13-21, é utilizada para acessar a posição inicial de cada partícula armazenada no vetor vec_start_pos. Neste laço, o iter_i é inicializado com a primeira trajetória, iter_ $i=$ trajectory.begin(), e será incrementado, iter $i_{-}++$, até não mais existir trajetória a ser renderizada, iter_i $!=$ trajectory.end(). Na L14, a chamada à função do OpenGL gIBegin(GL_LINE_STRIP) indica o início da renderização de uma linha. O laço interno, L15-18, é utilizado para renderizar toda a trajetória da partícula por meio de consecutivas chamadas à função do OpenL glVertex2f().

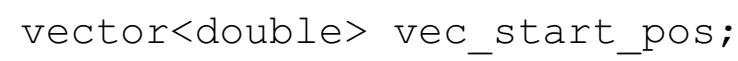




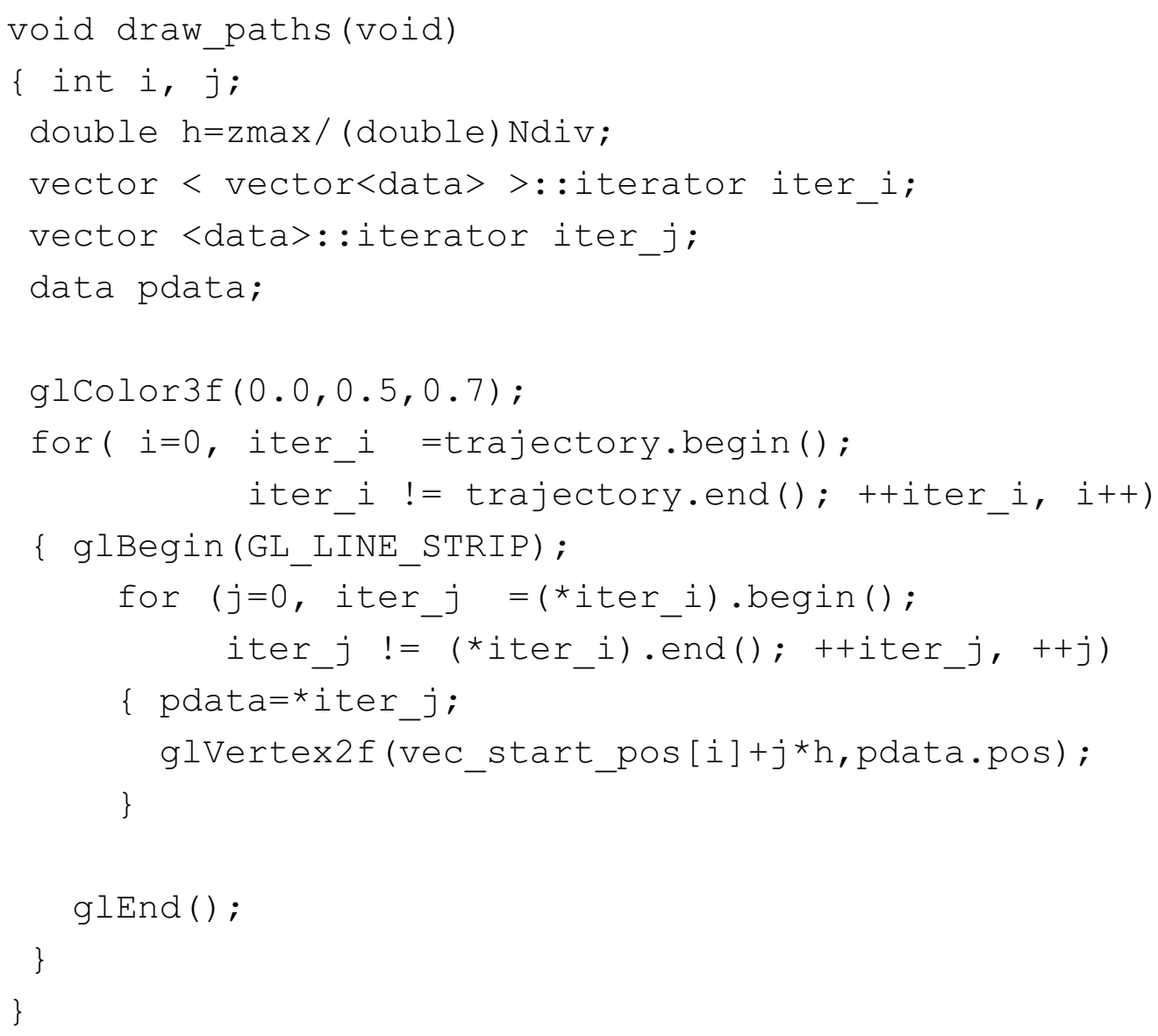

\section{A.4 GLUI}

A biblioteca GLUI (OpenGL Utility Interface) [57] desenvolvida em C++ por Paul Rademacher, disponibiliza ao desenvolvedor a possibilidade de criar janelas, caixas de seleção, botões de seleção e botões de rolagem para a interface com o usuário. As FIGS A.3-A.5 apresentam os diversos recursos de interface com o usuário que a biblioteca GLUI disponibiliza ao desenvolvedor. O manual da biblioteca exemplificando o uso de todas as funcionalidades da interface está disponível em [57].

O exemplo a seguir descreve brevemente o código utilizado no XMGUN para gerar a interface com o usuário, por meio da biblioteca GLUI, que permite ao usuário visualizar um elemento triangular da malha e seus elementos vizinhos por aresta, identificados pelas cores RED, GREEN e BLUE de acordo com a FIG. A.6.

A estrutura element para cada elemento da malha, L1-5, contém os seguintes campos: 


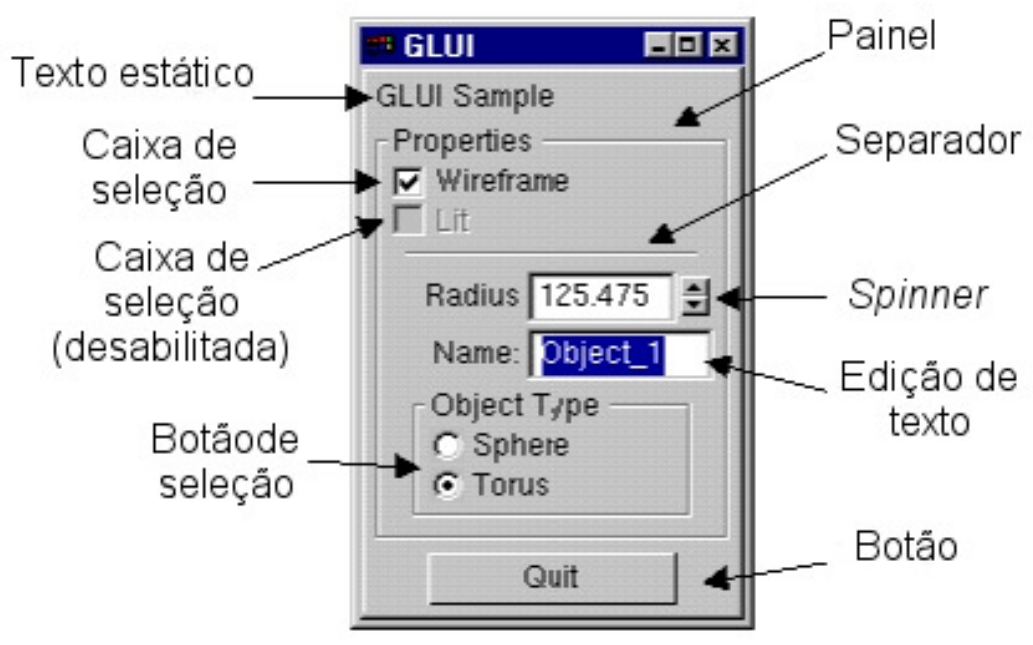

Figura A.3: Diversos tipos de recursos disponibilizados pela biblioteca GLUI.

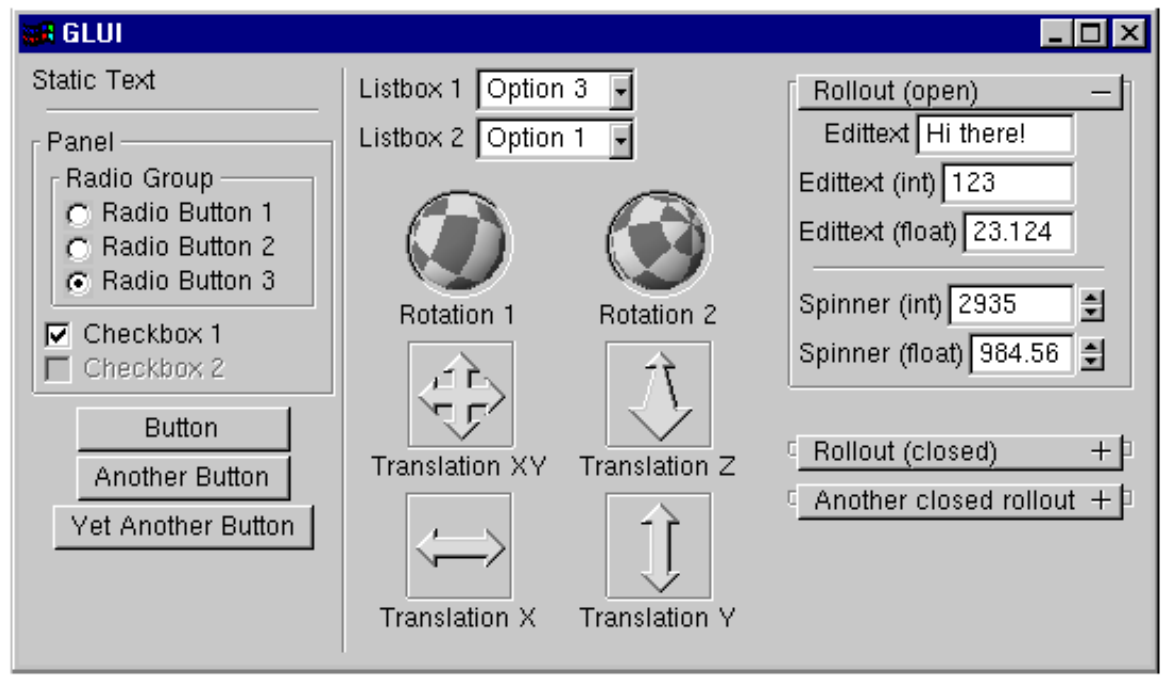

Figura A.4: Modelo de uma típica janela para visualização de objetos em 3D utilizando a biblioteca GLUI. 


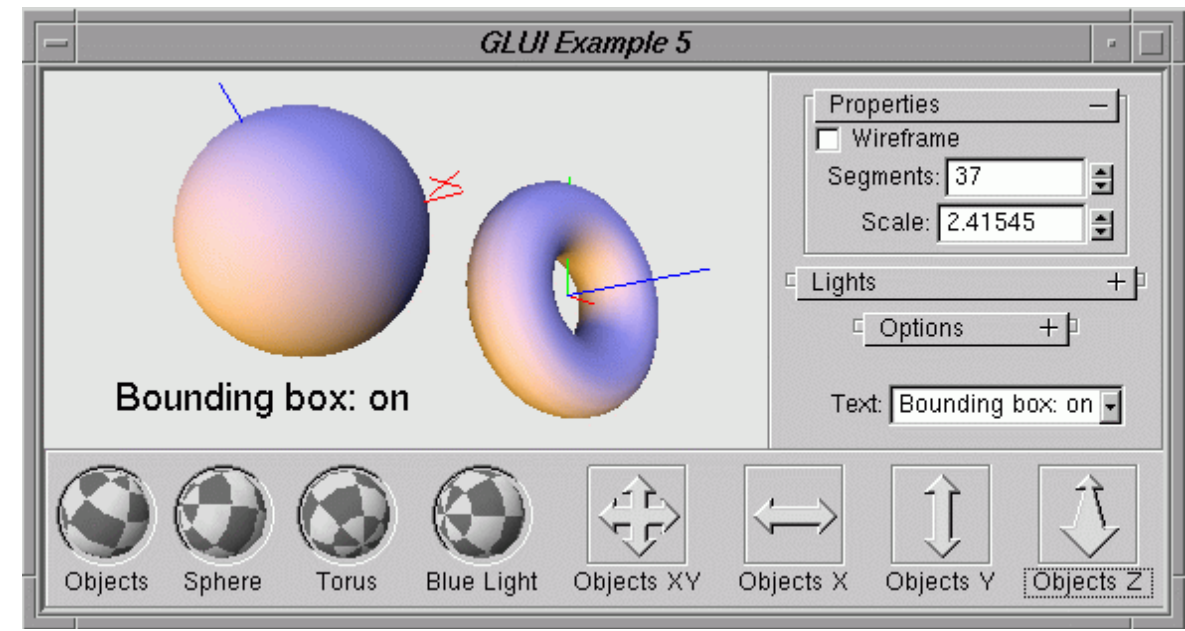

Figura A.5: Utilizando-se GLUI é possível construir janelas com diversos recursos de interface integrados para a visualização de modelos 3D.

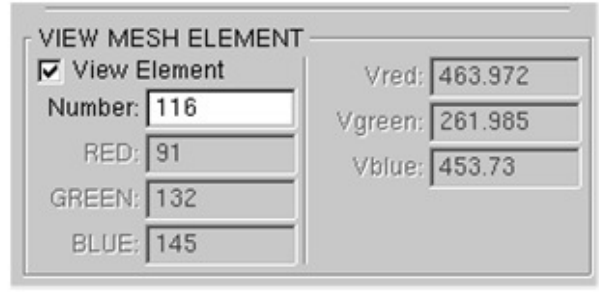

(a)

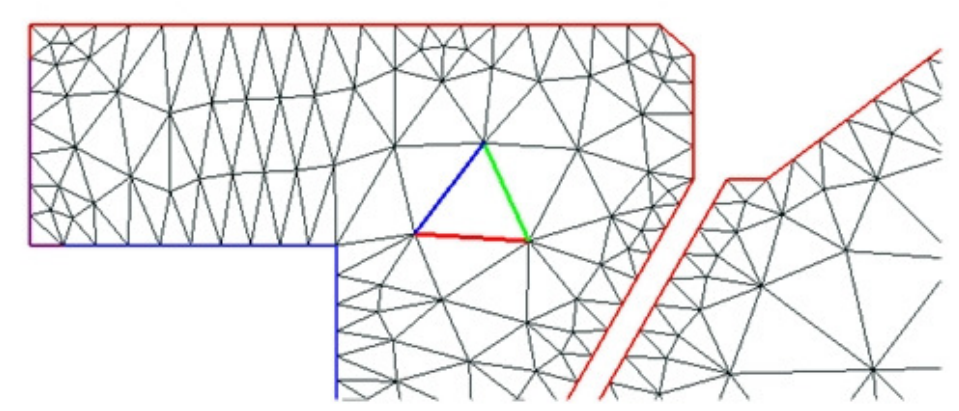

(b)

Figura A.6: (a) Interface com o usuário que permite ao usuário visualizar qualquer elemento da malha. Estabelecido o elemento, a interface indica os seus vizinhos e o potencial escalar elétrico associado a cada nó do elemento; (b) em destaque a visualização do elemento número 116 da malha. 
- $i, j, k$ : indicam os índices do nós, que apontam para as ordenadas e abscissas dos nós;

- ei, ej, ek: representam índices que apontam para os elementos vizinhos à aresta que não contém cada um dos nós;

- ro: armazena a carga depositada no elemento; e

- ex, ey: direção do campo elétrico nas direções $\vec{i}$ e $\vec{j}$ (coordenadas cartesianas) ou $\vec{z}$ e $\vec{\rho}$ (coordenadas cilíndricas) respectivamente.

Cada elemento da malha tem armazenado todas as informações da estrutura element acima na memória RAM, sendo o acesso a elas por meio do uso do apontador a estrutura *elemPtr construído em L6. A visualização de um elemento só será possível caso o usuário selecione a caixa de seleção "View Element", FIG. A.6-(a), cuja informação de seleção é armazenada na variável triCheck. Quando esta é selecionada, habilita-se a caixa de texto Number para que o usuário possa entrar com o número do elemento da malha, armazenado na variável trinum L8, que se deseja visualizar as informações referentes ao mesmo. A variável *vvPtr, L9, é um ponteiro que armazena o potencial escalar elétrico associado a cada nó do elemento. A função functri(), declarada em L10, é responsável por inserir corretamente as informações RED, GREEN, BLUE, Vred, Vgreen e Vblue referentes ao elemento inserido na caixa de texto Number (não apresentada aqui). O argumento passado à função functri() é o número do elemento trinum. Todas as informações referentes à visualização de um elemento da malha do problema em estudo, estão concentrados em um único painel, que em GLUI é declarado em L11. São declaradas em L12-18 as variáveis do tipo texto do GLUI referente ao elemento de número trinum. A função do GLUI glui->add_separator(), L19, insere uma linha horizontal que pode ser vista na FIG. A.6-(a) acima do texto "VIEW MESH ELEMENT", o qual é o nome do painel, L20. A função glui->add_checkbox_to_panel(), L21, adiciona ao painel panel_tri, uma caixa de seleção com o texto inserido à esquerda da caixa de seleção "View Element"e quem cujo estado, marcado ou não, é armazenado na variável triCheck. L22 chama a função glui->add_edittext_to_panel() onde será inserido um campo do tipo texto. Esta função é chamada com os seguintes parâmetros:

- o painel onde será inserido uma caixa de texto, neste caso panel_tri ;

- texto a ser inserido à esquerda da caixa de texto, neste caso é "Number:";

- o tipo de texto a ser inserido. O GLUI permite a inserção dos dados considerando os tipos (a) GLUI_EDITTEXT_TEXT: o parâmetro a ser editado é do tipo texto; (b) GLUI_EDITTEXT_INT: o parâmetro a ser editado é do tipo inteiro; e (c) GLUI_EDITTEXT_FLOAT: o parâmetro a ser editado é do tipo ponto flutuante. Neste caso, o parâmetro passado é do tipo GLUI_EDITTEXT_INT, pois o usuário informará o número de elemento da malha que se deseja obter informações;

- o quarto parâmetro, caso especificado, deve ser um ponteiro para ou um arranjo de caracteres ou, uma variável do tipo inteiro ou do tipo ponto flutuante dependendo do 
tipo da variável, ou seja, tipo GLUI_EDITTEXT_TEXT, GLUI_EDITTEXT_INT ou GLUI_EDITTEXT_FLOAT respectivamente. A variável do tipo arranjo de caracteres, inteiro ou ponto flutuante será modificada quando o usuário alterar o conteúdo da caixa de texto;

- caso uma função de chamada for definida, o valor do inteiro aqui especificado será passado toda vez que o texto for alterado; e

- ponteiro para uma função a ser chamada quando o texto é modificado. Neste caso o argumento do tipo inteiro definido no parâmetro anterior é passado para esta função.

As linhas do programa L23-25 funcionam de modo similar à L22. L26-29 atribuem a cada caixa de texto os valores numéricos dos elementos vizinhos por aresta do elemento trinum. Uma vez que estes dados são fornecidos ao usuário, não é permitido ao mesmo alterar seus conteúdos e, desta forma, as caixas de textos referentes a estes elementos devem ser desabilitadas para alteração pelo usuário, que é realizado em L30-32. A L33 insere uma coluna dividindo o painel em duas colunas. As L34-36 inserem três caixas de texto do tipo ponto flutuante associados aos potenciais escalares elétricos dos três nós do elemento trinum. Os potenciais escalares elétricos associados aos três nós do elemento trinum são preenchidos em L37-39 e, as L40-42, impedem que o usuário altere o conteúdo das caixas de textos referentes aos mesmos.

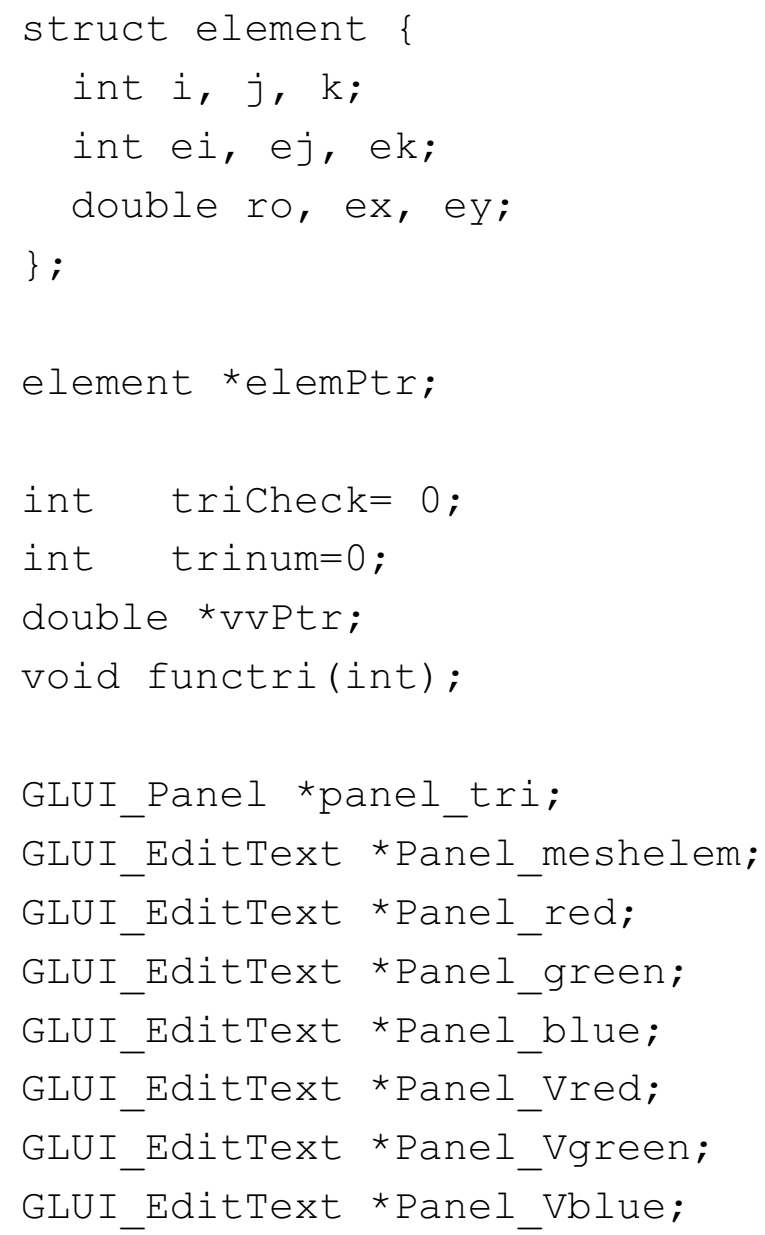


(20) panel_tri=glui->add_panel ( "VIEW MESH ELEMENT" );

(21) glui->add_checkbox_to_panel (panel_tri, "View Element", \&triCheck);

(22) Panel_meshelem=glui->add_edittext_to_panel (panel_tri, "Number:",GLUI_EDITTEXT_INT, NULL,1,functri);

(23) Panel_red=glui->add_edittext_to_panel (panel_tri, "RED:",GLUI_EDITTEXT_INT, NULL, 1,NULL) ;

$$
\text { glui->add_column_to_panel(panel_tri, true) ; }
$$

$$
\begin{aligned}
& \text { Panel_Vred=glui->add_edittext_to_panel (panel_tri, } \\
& \text { "Vred:",GLUI_EDITTEXT_FLOAT, NULL, 1,NULL); } \\
& \text { Panel_Vgreen=glui->add_edittext_to_panel (panel_tri, }
\end{aligned}
$$$$
\text { "Vgreen:",GLUI_EDITTEXT_FLOAT, NULL, 1, NULL) ; }
$$$$
\text { Panel_Vblue=glui->add_edittext_to_panel (panel_tri, }
$$

$$
\begin{aligned}
& \text { "Vblue:",GLUI_EDITTEXT_FLOAT, NULL, 1,NULL) ; } \\
& \text { Panel_Vred->set_float_val(vvPtr[elemPtr[trinum].i]); }
\end{aligned}
$$$$
\text { Panel_Vgreen->set_float_val(vvPtr[elemPtr[trinum].j]); }
$$$$
\text { Panel_Vblue->set_float_val (vvPtr[elemPtr[trinum].k]); }
$$$$
\text { Panel_Vred->disable (); }
$$$$
\text { Panel_Vgreen->disable (); }
$$$$
\text { Panel_Vblue->disable(); }
$$

\section{A.5 EasyMesh}

Antes de apresentar o EasyMesh, faz-se necessário definir alguns conceitos chaves, comumente utilizados em Geometria Computacional e Computação Gráfica, relacionados à 
geração de malhas não estruturadas que tem larga aplicação em problemas que utilizam o MEF.

O MEF é uma técnica largamente utilizada para modelar problemas de engenharia uma vez que é possível obter uma solução aproximada para problemas, tipicamente governados por equações diferenciais parciais, cujos domínios são geralmente complexos. A primeira etapa, no uso do MEF, consiste em dividir o domínio do problema em pequenas regiões, aqui denominadas de elementos. Estes elementos são, usualmente, triângulos ou quadriláteros. A precisão do MEF depende diretamente da malha produzida: quanto maior o refinamento da malha, melhor é a solução [70]. Entretanto, a utilização de malhas refinadas implicam em um esforço computacional elevado. Observa-se também que a forma dos elementos tem uma importância fundamental na solução do problema em estudo. Triângulos irregulares, por exemplo, com um ângulo interno pequeno, tipicamente menor que $20^{\circ}$, leva a uma solução do problema na qual a convergência numérica é lenta [71].

Uma malha é dita ser conforme quando dado um triângulo da malha não é permitido que outro triângulo tenha um vértice no interior de uma de suas arestas. Diz-se que uma malha tem uma boa forma quando os triângulos que compõem a malha tem ângulos entre $45^{\circ}$ e $90^{\circ}$. A conectividade de uma malha diz respeito à conexão dos vértices que formam os elementos da malha, enquanto que, a conectividade de um elemento da malha refere-se às conexões entre um elemento e seus vizinhos por arestas. Uma malha é dita ser estruturada ou regular quando a sua conectividade é do tipo diferença finita. Neste caso, a malha pode ser denominada de grade, e a conectividade entre os nós é do tipo $(i, j, k)$, de forma que, o vizinho à esquerda tem índice $(i-1, j, k)$ e o vizinho à direita $(i+1, j, k)$. Uma malha, por sua vez, é não estruturada ou não regular quando a sua conectividade é de outro tipo. A FIG.

A.7 apresenta estes dois tipos de malha.

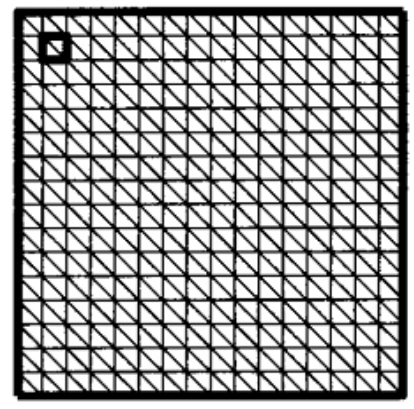

(a)

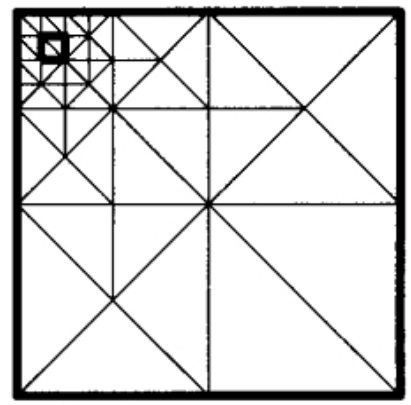

(b)

Figura A.7: Exemplo de uma malha (a) regular e (b) não-regular.

Uma triangulação é dita ser de Delaunay somente se dado em um plano um conjunto de pontos $P$ de uma triangulação $T(P)$ a circunferência formada pelos vértices de um triângulo não contém nenhum outro ponto da $T(P)$ em seu interior. A FIG. A.8 apresenta um exemplo de uma triangulação de Delaunay.

Apresentados os conceitos acima, a seguir é ilustrado as principais características do 


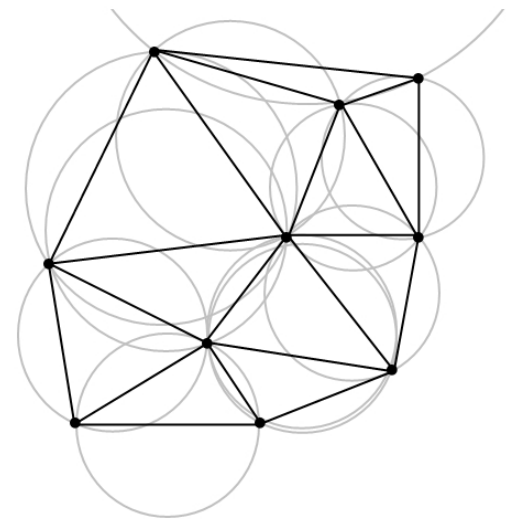

Figura A.8: Uma triangulação de Delaunay no plano e a representação das circunferências de cada triângulo da malha indicando que atender o critério exigido.

software EasyMesh [58], desenvolvido por Bojan Niceno, o qual é um código aberto escrito em linguagem $C$ e largamente utilizado pelos programas XMGUN e XMAGUN que são:

- geração de malhas 2D não estruturadas utilizando a triangulação de Delaunay sob domínios genéricos;

- permite geometrias que apresentam buracos;

- trabalha com domínios com mais de um tipo de material;

- faz renumeração automaticamente dos nós, elementos e arestas com a finalidade de reduzir a largura de banda da discretização do conjunto de equações;

- tem internamente uma função que não permite a criação de nós com mais de sete e menos de cinco elementos, resultando na geração de malhas suaves;

- utiliza arquivos simples no formato ASCII como arquivo de entrada;

- gera três tipos de arquivos de saída ASCII com todas as informações de conectividade da malha; e

- gera, se especificado, imagens nos formatos DXF ou FIG da triangulação de Delaunay e do diagrama de Voronoy da malha gerada.

$\mathrm{O}$ arquivo de entrada, também denominado arquivo do domínio, do tipo ASCII tem o seguinte formato:

- primeira linha: numero_de_nos

- linhas seguintes: numero_do_no $x$ y tamanho_aresta_triangulo rotulo_fronteira

- próxima linha: numero_segmentos 
- linhas seguintes: numero_segmento no_inicial no_final rotulo_segmento

As variáveis $x, y$ e tamanho_aresta_triangulo são geralmente valores em ponto flutuante enquanto que, todas as demais, são necessariamente valores inteiros. A variável tamanho_aresta_triangulo indica o tamanho das arestas do triângulo que contém este nó. Quanto menor este valor, maior será o grau de refinamento da malha nas proximidades deste nó. Um valor não nulo deverá ser atribuído a esta variável pois, de outra forma, EasyMesh provavelmente entrará em um ciclo infinito. O uso de rótulos permite ao desenvolvedor identificar pontos e segmentos associados à fronteira do problema. Comentários podem ser inseridos em qualquer linha do arquivo, sendo o caractere "\#"o indicador de início e fim dos mesmos. O arquivo de entrada deve ter a extensão ".d".

A seguir, FIG. A.9 (a), é apresentado um exemplo do formato de um arquivo de entrada, para a simulação de um canhão de elétrons do tipo plano de Pierce para operação na condição FSCL, utilizado pelo programa EasyMesh e em FIG. A.9 (b) a visualização da malha de saída criada.

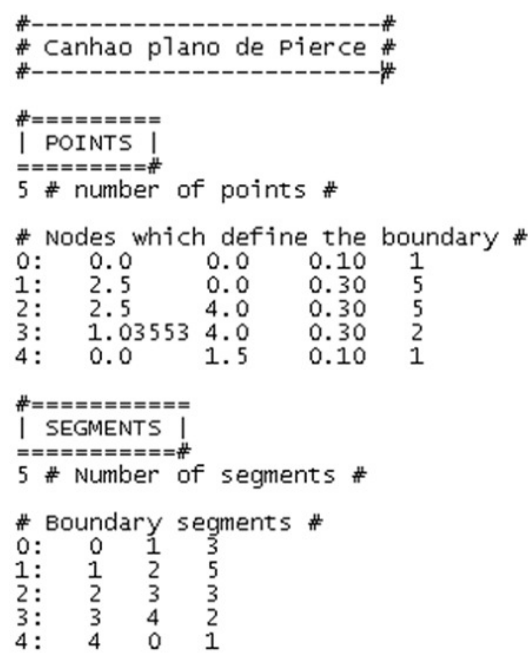

(a)

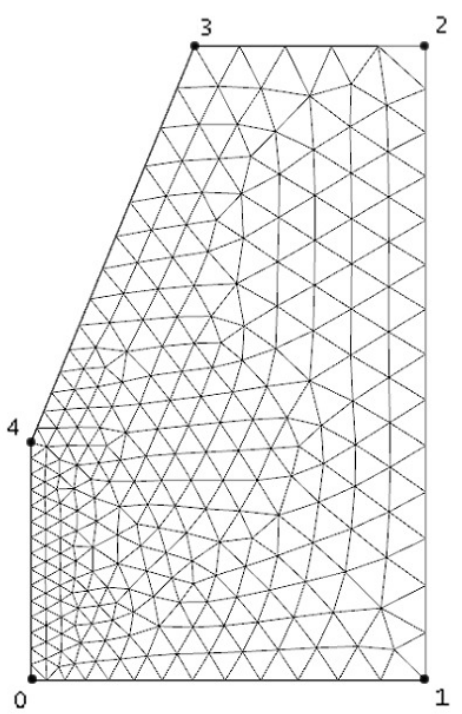

(b)

Figura A.9: (a) Arquivo de entrada utilizado pelo EasyMesh de um diodo plano de Pierce de largura 2,5 mm, altura de 4,0 mm e área de emissão do catodo com uma altura de 1,04 mm e (b) a malha gerada apresentando 276 nós e 489 elementos.

Para o exemplo anterior, os rótulos dos segmentos têm o seguinte significado:

- 1: catodo;

- 2: eletrodo de focalização;

- 3: segmento onde a condição de Newman é imposta. Neste caso, para simetria axial, $\frac{\partial \varphi}{\partial \rho}=0 ; \mathbf{e}$ 
- 5: anodo. 


\section{Apêndice B}

\section{Simuladores de Canhões de Elétrons}

Este Apêndice descreve, sucintamente, as principais características de 3 (três) ferramentas computacionais dedicadas a simulação de válvulas de micro-ondas: Michele (seção B.1); Trak (seção B.2); e EGUN2 (seção B.3).

\section{B.1 MICHELLE}

MICHELLE [9] é uma ferramenta computacional desenvolvida por 18 especialistas nos Laboratórios de Pesquisa da Marinha Americana (NRL) para projeto 3D de dispositivos que operam com feixe de partículas carregadas. O software MICHELLE foi apresentado à comunidade científica em 2002, sendo ganhador do prêmio $R \& D 100$ Award Winner em 2006. Entre as principais aplicações em simulações com MICHELLE destacam-se:

- canhões de elétrons com aplicação em válvulas de micro-ondas de alta potência com grade, multifeixe, feixe plano ou com simetria axial;

- coletores de múltiplos estágios para válvulas de micro-ondas de alta potência;

- válvulas de micro-ondas de alta potência completas, desde o catodo até o coletor; e

- transporte do feixe em aceleradores de partículas.

Dentre os grandes benefícios reportados no uso do software MICHELLE destacamse: a economia de anos em tentativa e erro de laboratório dado o insight físico obtido a partir das simulações; as válvulas de micro-ondas projetadas resultaram em sistemas de radares de defesa com maior durabilidade; foram obtidos dispositivos com menor custo e maior eficiência em sistemas de comunicação de radares; capacidade de projetar válvulas de micro-ondas com potência mais elevada para aplicações em aceleradores de partículas e comunicação espacial.

Um exemplo da capacidade do MICHELLE em simular canhões de elétrons com geometrias 3D complexas é apresentado na FIG. B.1. Nesta figura tem-se o resultado 3D da simulação de um canhão de elétrons com oito feixes. É possível observar a malha sob os diversos componentes que compõem o canhão de elétrons, os quais estão representados por 
cores diferentes. Os feixes de elétrons, que foram gerados por oito catodos separados, não são visíveis na figura e estão localizados atrás do eletrodo de focalização, que recebe a cor verde. $\mathrm{O}$ anodo, que acelera os feixes conduzindo-os à estrutura de deriva, está representado pela cor vermelha. As energias associadas aos feixes de elétrons são representadas por cores diferentes. Elétrons do feixe com baixa energia possuem a cor vermelha e, os de alta energia, a cor azul. MICHELLE numericamente obtém a solução para os campos eletromagnéticos por meio do MEF, MAS e PIC.

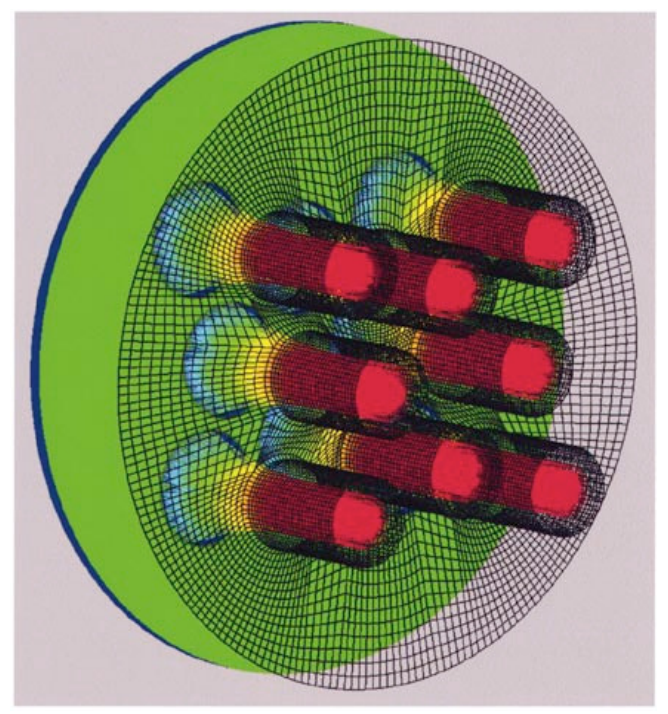

Figura B.1: Visualização final decorrente por meio de uma simulação com o MICHELLE de um canhão de elétrons de oito feixes. Os componentes do canhão multifeixe estão assim identificados: cor AZUL ESCURO: catodo - não totalmente visível; cor VERDE: eletrodo de focalização; MALHA: anodo; VERMELHO-AZUL CLARO: feixe de elétrons (o de menor energia tem a cor azul claro e, o de maior energia, vermelho).

Todo dispositivo simulado com o MICHELLE pode ser discretizado utilizando malhas estruturadas, compostas por hexaedros, ou não-estruturadas, compostas por tetraedros.

Três modelos de emissão das partículas são empregados no software MICHELLE: FSCL; limitado pela temperatura; e distribuição termiônica, os quais são plenamente suficientes para modelar canhões de elétrons com simetria axial, planar e dispositivos multifeixe. O software MICHELLE tem, ainda, a habilidade de simular um número arbitrário de feixes, múltiplas espécies de partículas em múltiplas posições em um único modelo.

Modelos de emissão secundária também foram implementados no software MICHELLE, sendo imprescindível em projetos de coletores de elétrons. Coletores de elétrons multiestágios promovem a recuperação de parte da energia do feixe de elétrons, proporcionando uma melhor eficiência em termos de potência. Entretanto, coletar os elétrons do feixe nos vários eletrodos do coletor resulta, invariavelmente, na geração de emissão secundária de elétrons, os quais podem ser acelerados ou ainda deixar o coletor reduzindo a eficiência, produzindo ruído, distorção do sinal e aquecimento do circuito. A FIG. B.2 apresenta um exemplo modelado de um coletor de cinco estágios da Boeing. A potência do feixe de elétrons é de $440 \mathrm{~W}$ e 


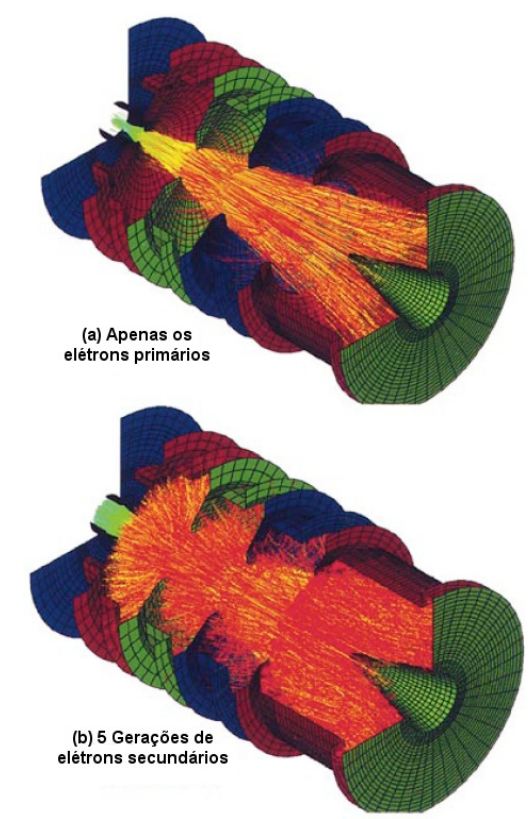

Figura B.2: Coletor de cinco estágios de uma válvula tipo TWT da Boeing. Tensões do corpo e dos cinco estágios do coletor são $6,335 \mathrm{kV}, 3,44 \mathrm{kV}, 2,141 \mathrm{kV}, 1,223 \mathrm{kV}, 0,589 \mathrm{kV}$ e 0,133 $\mathrm{kV}$ respectivamente. As duas figuras apresentam a geometria do coletor. (a) Coletor com apenas 77,2 mA de corrente devido aos elétrons primários do feixe. (b) Elétrons primários e cinco gerações de elétrons secundários emitidos.

uma corrente de 77,2 mA foi observada. As tensões do corpo e dos cinco estágios do coletor estão na TAB. B.1.

Nesta simulação um total de 116.612 elétrons secundários foram produzidos em cinco gerações. Cada elétron primário originou um elétron secundário verdadeiro (baixa energia) e um difuso (alta energia).

\section{B.2 Trak}

Desenvolvido por Stanley Humphries Jr. [3], Trak foi apresentado à comunidade científica em 1994. É um software comercial que está atualmente na versão 7.2. Entre as diversas

Tabela B.1: Tensões do corpo e dos cinco estágios do coletor de uma válvula TWT da Boeing.

\begin{tabular}{cc}
\hline $\begin{array}{c}\text { Componente } \\
\text { do coletor }\end{array}$ & $\begin{array}{c}\text { Tensão } \\
(k V)\end{array}$ \\
\hline Corpo & 6,335 \\
$1^{\circ}$ Estágio & 3,440 \\
$2^{\circ}$ Estágio & 2,141 \\
$3^{\circ}$ Estágio & 1,223 \\
$4^{\circ}$ Estágio & 0,589 \\
$5^{\circ}$ Estágio & 0,133 \\
\hline
\end{tabular}


aplicações em que o Trak pode ser utilizado destacam-se:

- canhões de elétrons e íons;

- aceleradores de partículas;

- fontes de íons;

- lentes eletrostática e magnetostática; e

- dispositivos eletro-ópticos.

O software Trak funciona em conjunto com outros dois módulos: Mesh (gerador de malha) e EStat/PerMag (programas que geram os arquivos de campos para uso do Trak). A FIG. B.3 apresenta o resultado de uma simulação de um canhão de elétrons utilizando o Trak.

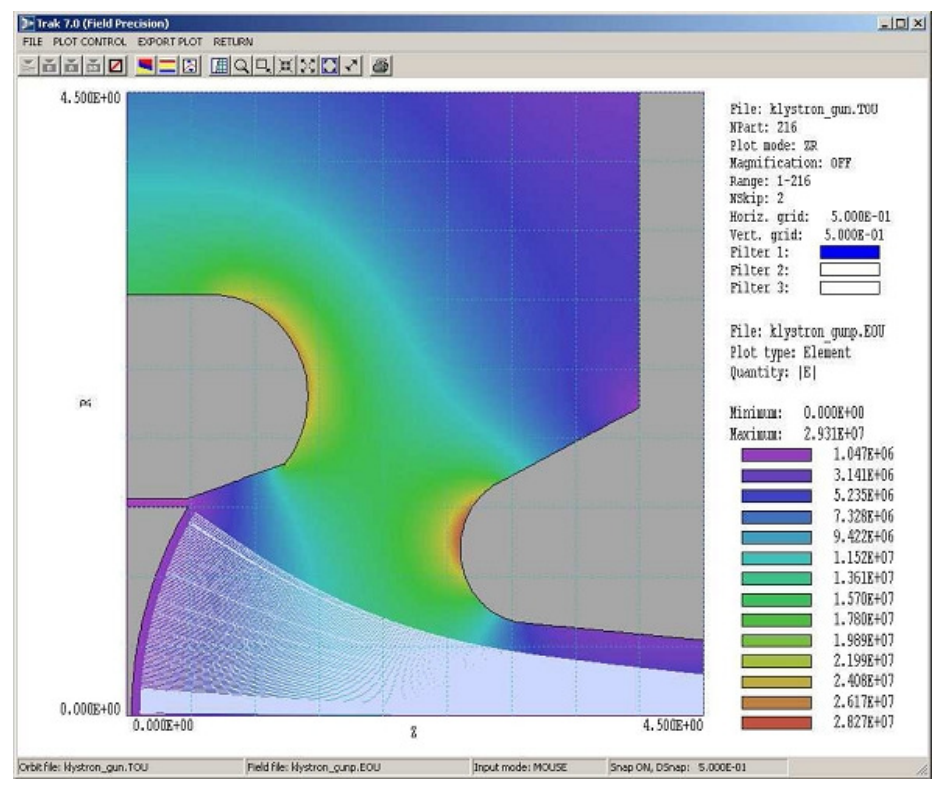

Figura B.3: Simulação de um canhão de elétrons utilizando o Trak.

Assim como o MICHELLE, Trak também faz uso do MEF e PIC. Para a solução do problema autoconsistente dos campos e determinação das trajetórias das partículas, em canhões de elétrons, o Trak faz uso do método iterativo de aproximação sucessiva. O Trak, entretanto, diferentemente do MICHELLE, trabalha com modelos 2D, os quais podem ter simetria axial (variação em $r$ e em $z$, uniforme em $\theta$ ) ou ainda serem planos (variação em $x$ e em $y$, comprimento infinito ao longo do eixo $z$ ). Embora os modelos sejam 2D, Trak resolve computacionalmente as trajetórias das partículas em 3D. Portanto, é comum, neste caso dizer, que Trak é na verdade um código 2-1/2D.

Trak disponibiliza ao usuário a capacidade de avaliar o comportamento das partículas na terceira dimensão por meio do diagrama de espaço de fase dado uma posição $z$. Um exemplo típico é apresentado na FIG. B.4. 


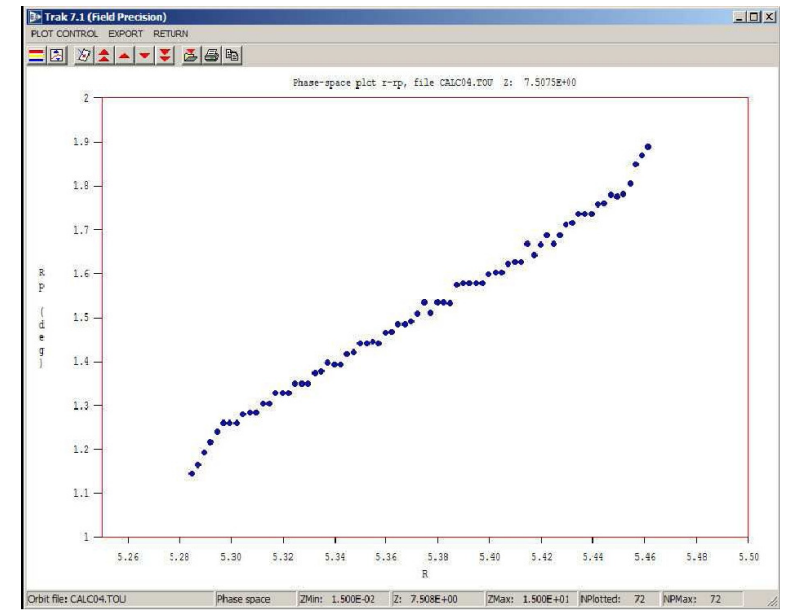

Figura B.4: Distribuição no espaço de fase de um feixe anular.

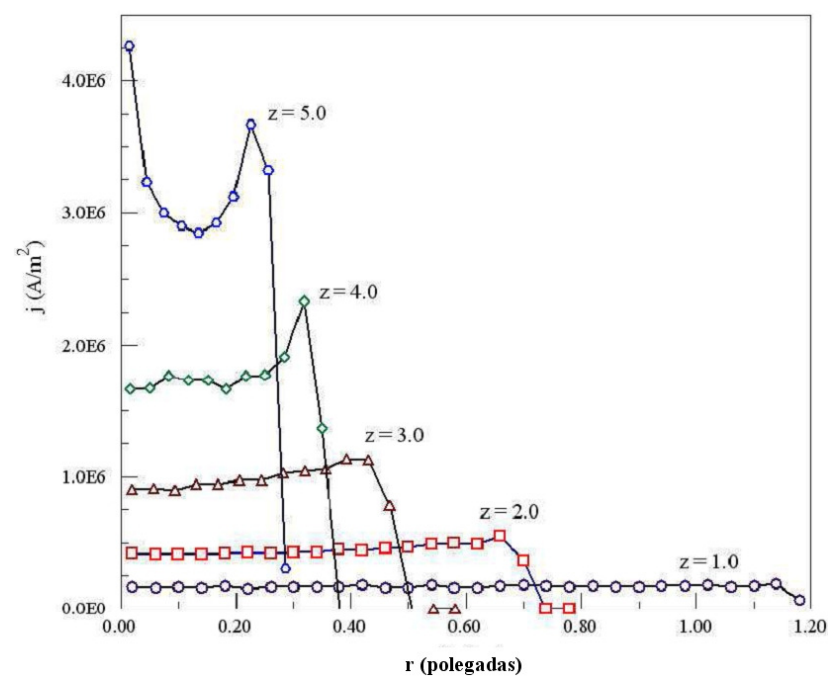

Figura B.5: Distribuição radial da densidade de corrente avaliada em cinco diferentes posições.

Outra funcionalidade visual importante do Trak é a capacidade do usuário avaliar a distribuição da densidade de corrente em diferentes posições em um mesmo gráfico. Uma possível visualização é apresentado na FIG. B.5.

Uma informação relevante que pode ser extraída da FIG. B.5 que caracteriza, também, um canhão de elétrons é a razão de compressão do feixe, definida como sendo a razão do raio do disco do catodo pela cintura do feixe de elétrons.

O software Trak, assim como o MICHELLE, permite: modelar um ou mais campos magnéticos no problema; resolver as equações das trajetórias das partículas do feixe relativisticamente; e modelar a emissão de elétrons secundários. 


\section{B.3 EGUN2}

O programa EGUN foi desenvolvido por Willian B. Herrmannsfeldt em 1988 e, desde então, passou por diversos aprimoramentos. Canhões de elétrons com aplicações em TWT, Gyrotrons, aceleradores etc. foram, com sucesso, aprimorados e projetados com o EGUN [67]. O EGUN2 foi desenvolvido em linguagem de programação $C$ e, diferentemente dos programas MICHELLE e Trak, numericamente implementa o método de diferenças finitas para resolver a equação de Poisson. Assim como o Trak, o EGUN2 também é um programa 2-1/2D que é capaz de modelar um ou mais campos magnéticos no mesmo problema. Entretanto, diferentemente do Trak, EGUN2 sempre resolve as equações das trajetórias das partículas do feixe de elétrons relativisticamente. Um exemplo típico de uma simulação de um canhão de elétrons utilizando o EGUN é mostrado na FIG. B.6. As trajetórias das partículas estão representadas na cor coral, as equipotenciais nas cor azul claro e o campo magnético externo na cor verde.

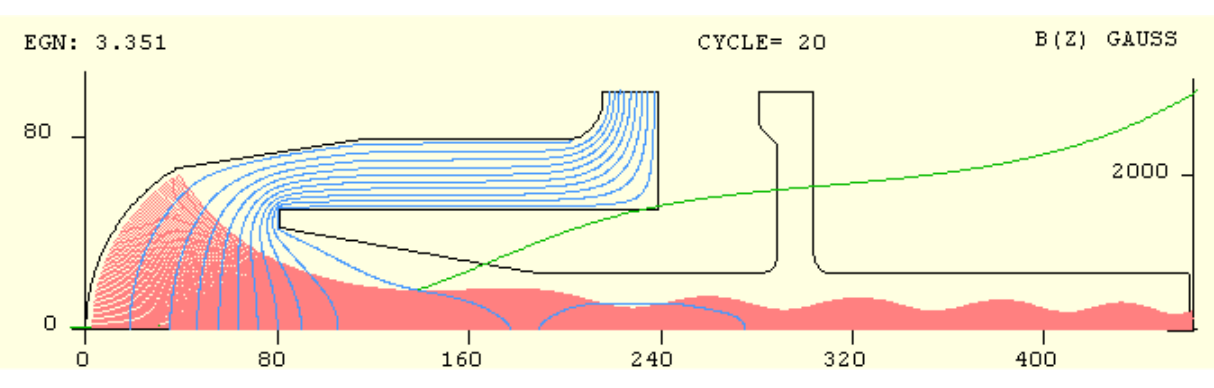

Figura B.6: Exemplo de resposta do EGUN de uma simulação de um canhão de elétrons submetido a um campo magnético externo.

É possível estabelecer quatro modelos para lançamento dos elétrons utilizando o EGUN: FSCL, emissão limitada pela temperatura, emissão de campo ou simplesmente pela atribuição das posições e velocidades das partículas.

Assim como o Trak, o EGUN disponibiliza para visualização, dado uma posição fixa axial, tanto a densidade de corrente quanto o diagrama de espaço de fase das partículas. A seção seguinte descreve a utilização do EGUN como uma ferramenta importante na determinação de parâmetros relevantes no projeto de um canhão de elétrons tais como a cintura do feixe, perveância e alcance. 


\section{Apêndice C}

\section{Bancada Experimental}

Este Apêndice descreve o arranjo experimental de testes de canhões de elétrons (seção C.1), em fase final de montagem, e os principais resultados obtidos nos testes de validação do vácuo e do filamento (seção C.2).

\section{C.1 Arranjo Experimental}

O arranjo experimental de testes de canhões de elétrons, FIG. C.1, é composto, basicamente, dos seguintes itens:

- câmera de ultra-alto vácuo;

- bomba iônica;

- solenóide para ser utilizado no sistema de focalização magnética;

- janela óptica para medir a temperatura do catodo;

- medidores de voltagem e corrente; e

- fontes de alimentação para o filamento, catodo, grade e anodo.

\section{C.2 Testes de Aceitação}

\section{C.2.1 Vácuo}

Montado o filamento do catodo, o mesmo foi submetido a uma corrente de $12 \mathrm{~A}$, e ao longo de três dias foram realizadas diversas corridas, onde se observou o comportamento do vácuo ao longo do tempo, FIG. C.2.

O melhor vácuo obtido na bancada experimental foi de $1,2 \times 10^{-8}$ Torr . 


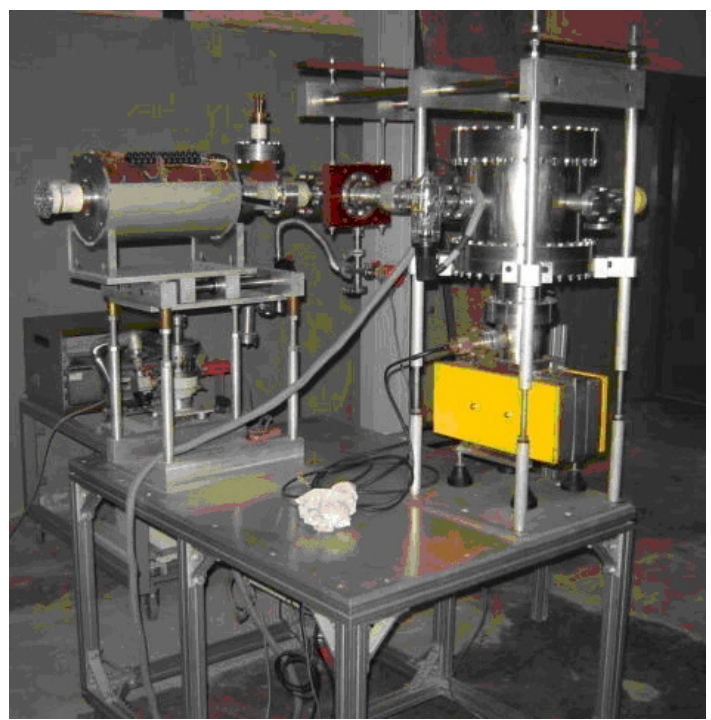

Figura C.1: Arranjo experimental para testes de canhões de elétrons em fase final de montagem.

Dia $28 / 07 / 2010$

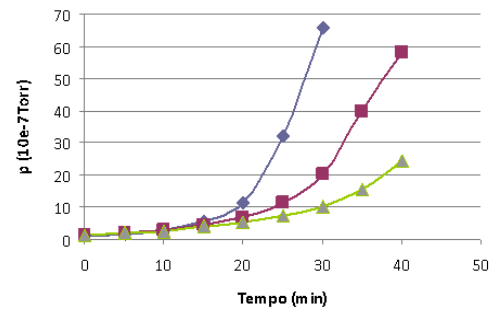

(a)

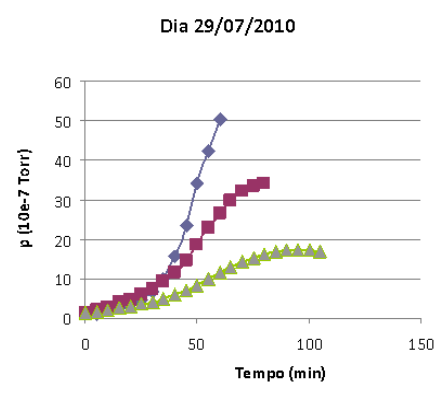

$\rightarrow$ Corrida\#1 $0850 \rightarrow$ Corrida\#2 $1125 \rightarrow$ Corridat\#

(b)

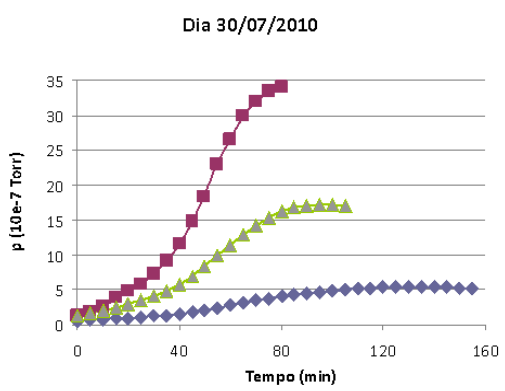

$\rightarrow$ Corrida\#1 $0820 \rightarrow$ Corrida\#2 $1125 \longrightarrow$ Corrida\#3 1505

Figura C.2: Comportamento do vácuo ao longo de três dias. O aquecimento produzido pelo filamento melhorou significativamente a qualidade do vácuo. 


\section{C.2.2 Filamento}

Ao longo de três semanas foi observado o comportamento da potência sobre o filamento pela sua temperatura. Por meio de uma fonte de corrente, foram realizadas medições para correntes de 9,0 A com incrementos de 0,5 A até a corrente de 12,5 A. Um multímetro foi utilizado para medir a tensão sob o filamento, e a partir desta medida obter a potência. As medições eram realizadas duas vezes ao dia. A FIG. C.3 mostra o comportamento típico obtido da potência pela temperatura nas últimas doze medições realizadas entre os dias 03/08/2010 e 25/08/2010.

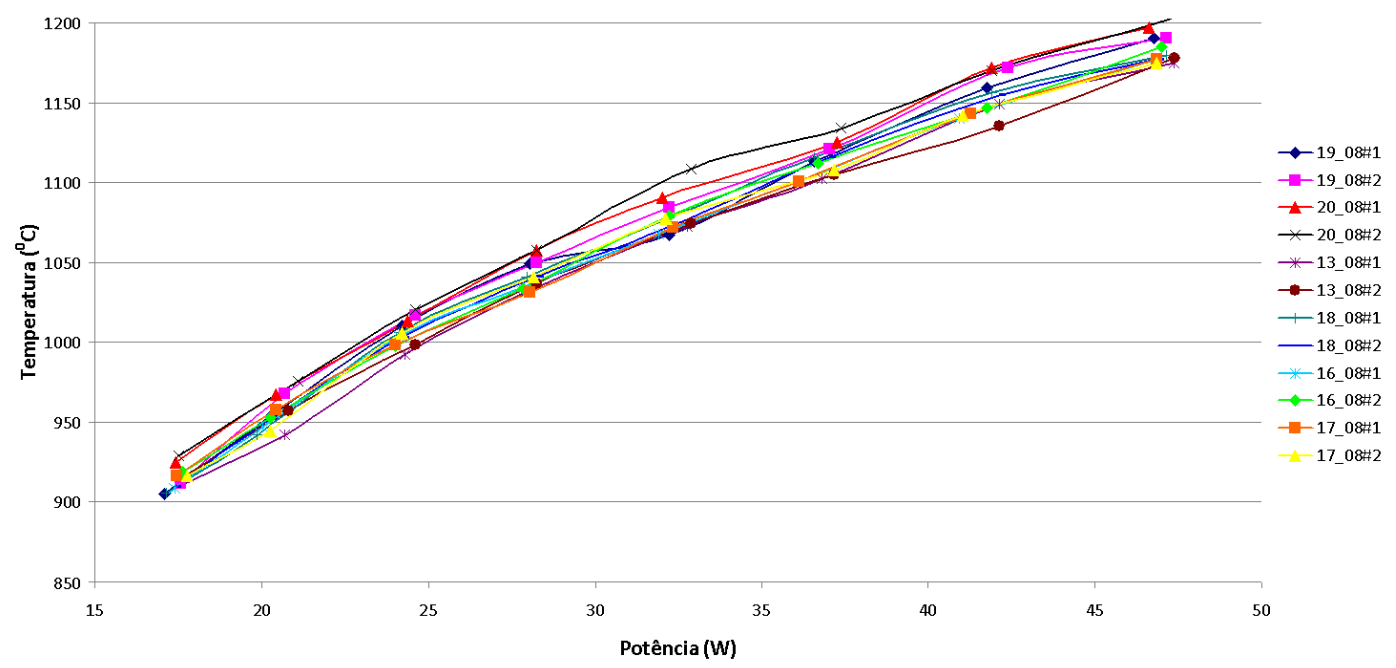

Figura C.3: Comportamento da potência do filamento pela variação de temperatura. 


\title{
Apêndice D
}

\section{Publicações}

\section{D.1 MOMAG - 2008}

\author{
Design and Characterization of a Gridded Electron \\ Gun for Traveling-Wave Tubes \\ César C. Xavier ${ }^{1}$ e Cláudio C. Motta
Instituto de Pesquisas Energéticase Nucleares
Av. Lineu Prestes 2242 - Cidade Universitária - CEP: 05508-000 - Sío Paulo - SP BRASIL
2 \\ César C. Xavier ${ }^{1}$ e Cláudio C. Motta
IInstituto de Pesquisas Energéticase Nucleares
Av. Lineu Prestes 2242 - Cidade Universitária - CEP: 05508-000 - Sio Paulo - SP BRASIL \\ Centro Tecnológico da Marinha em São Paulo \\ Av. Lineu Prestes 2468 - Cidade Univervit ́riria - CEP. 05508-000 - Sto Paulo - SP BRASIL
}

Abstract -A design procedure of a $30 \mathrm{kV}-3.5 \mathrm{~A}$ electron gun
with grid and shadow grid under space-charge llmited flow to be
used on Travellng-Wawe Tube (TWT), Is presented. The
numerical code used to determine the self-constent electric
flelds for the relativistlc electron beam was EGUN. It is also
presented the experimental methodology that will be used to
valdate the gun designed on the laboratory. Key-words - TWT, EGUN, electron gun, space-charge limited

\section{INTRODUCTIN}

The search for the technology domain of design of power vacuum microwave devices, such as TWT it is of high vacuum microwave devices, such as TWT it is or high commercial value. The use of grids is an indispensable requirement on important applications such as defense and telecommunications, once it guarantes a control over the beam flow, which could be pulsed when needed. A overview of others electron guns applications see [1].

One of the critical components of a TWT is the electron gun. It is relevant, for the success of design, during the electron gun conception phase, the use of numerical simulations. The use of numerical tools designed to simulate electron guns, more recently three-dimensional (3D) simulators, is growing. Their use are not only justified because of the costs reduction during the development, bu also, the intrinsic complexity of the models nowadays. In chronological order, over twenty years, many codes were developed, such as [2]-[4]. EGUN [2], a seminal work, presents satisfactory result during simulations. EGUN allows: work under space-charge limited flow condition: it is characterized by the fact that no more electrons could be extracted from the cathode because of the mutual repulsion between the electrons themselves; easily build grids and, during simulation, change the potential on them; and

solve the electrons trajectory equations fully relativistic.

Using EGUN, the error noticed on the simulation of the standard Pierce diode for a sheet electron beam is about $1 \%$ [5].

C. C. Motta, motta Quspher Tel+ 55-11-3817-7256, F
The first part of this work presents some results obtained on the design of an electron gun working on $30 \mathrm{kV}-3.5 \mathrm{~A}$. The second part presents the experimental set-up projected to measure the electron gridded gun performance.

A. EGUN Design Procedure

Presented on Fig.1, it is a computer simulation of an intercepting gridded gun $(30 \mathrm{kV} ; 3.5 \mathrm{~A} ; 12.3 \mathrm{~mm}$ cathode radii of curvature; and $6 \mathrm{~mm}$ cathode-disc radii) with EGUN. The electric equipotentials and the electrons trajectory reveal a fully satisfactory laminar beam.

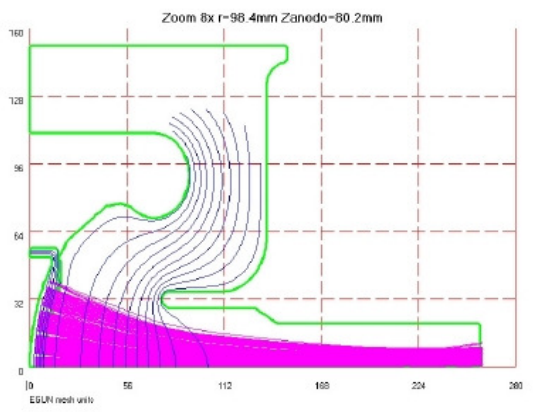

Fig. 1. Trajectories and voltage equipotentials of an electron gun designed
and simulated with EGUN.

This gun uses a rectangular grid as shown by Fig. 2. All the guns design values were scaled by a factor of eight. This is justified by the EGUN limitation under mesh generation, since there must have, at least, one mesh unit of separation between different elements. Since EGUN is aration dimensional (2-D) code, to make possible to simulate the dimensiona (2-D) code, to make possibe to simulate the original grid model, the grids are approximated as concentric rings as shown in Fig. 3. 


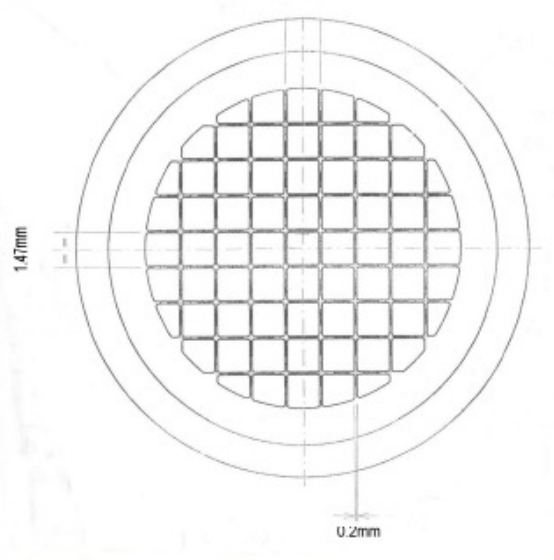

Fig. 2. Cathode's grid frontal view and dimensions used on EGUN simulation.

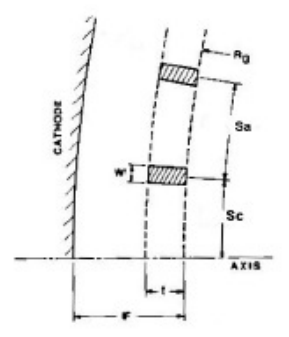

Fig. 3. A proximation used on EGUN simulations Note that the cathode gridded-gun is simulated as concentric rings.

There are important implications regarding to grid design. First, the grid and the cathode spherical radii must be equal, and in this case the best laminar beam is produced. Secondly, the grid must coincide precisely with an equipotential contour, if not, the grid will be totally or partially overvoltage/undervoltage [6].

A zoom close to the cathode, Fig. 4, indicates a satisfactory laminar beam, with some aberration, due to the grids. The shadow-grid is taken into account by the control of electron emission area over the cathode surface, also shown in Fig. 4.

The EGUN output, after seven iterations, gives as results a $0.7 \mu$ Perv and $3.5 \mathrm{~A}$ electron gridded gun.

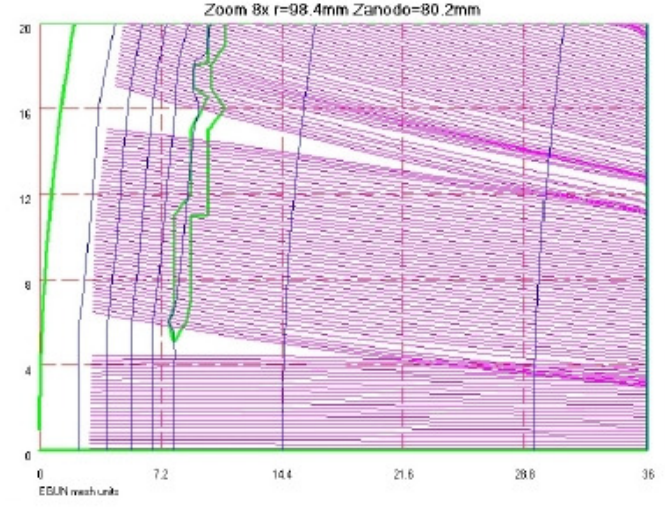

Fig 4. Zoom on elections trajectories closer to the grids. It is possible to notice the absence of the electron beam due to the shadow-grid at the cathode surface.

It is also important to show how the paths change as the distance to anode increase or decrease. As example, Fig. 5 shows the aberrations produced when the anode is closer to cathode by $16.2 \mathrm{~mm}$ (only $2.03 \mathrm{~mm}$ real world due to scale factor).

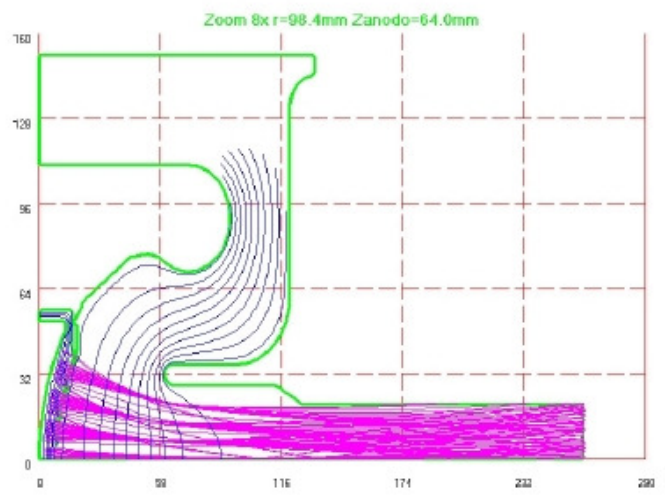

Fig. 5 presents negative potential variation over the grid $\left(v_{g}\right)$ from $-50 \mathrm{~V}$ up to $-230 \mathrm{~V}$. It is evident the drop of electron flow.

At Figs. 6a-d is possible to evidence how the electron gun flow vanishes due to the application of negative potential on the grid control under $650 \mathrm{~V}$ of bias grid voltage. The grid potential decreases from: $-50 \mathrm{~V}$ (Fig 6.a), $-110 \mathrm{~V}$ (Fig. 6.b), $170 \mathrm{~V}$ (Fig. 6c) and $-230 \mathrm{~V}$ (Fig.6.d), where there is no electrons flow at all. 


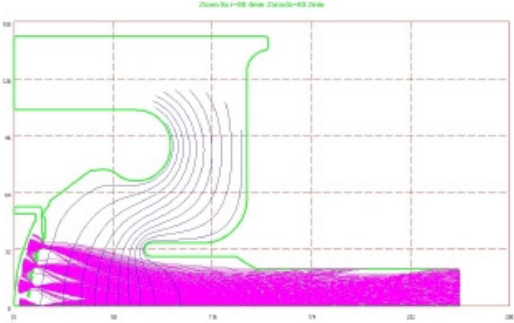

$6 . \mathrm{a}$

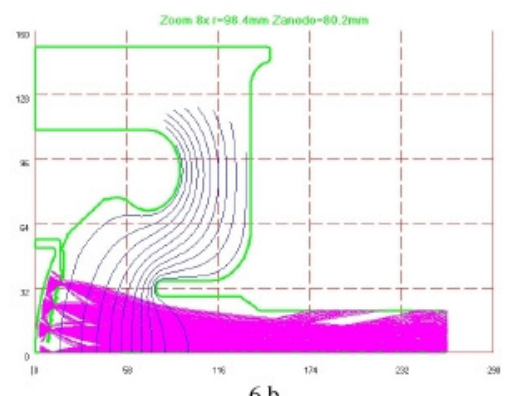

6.b
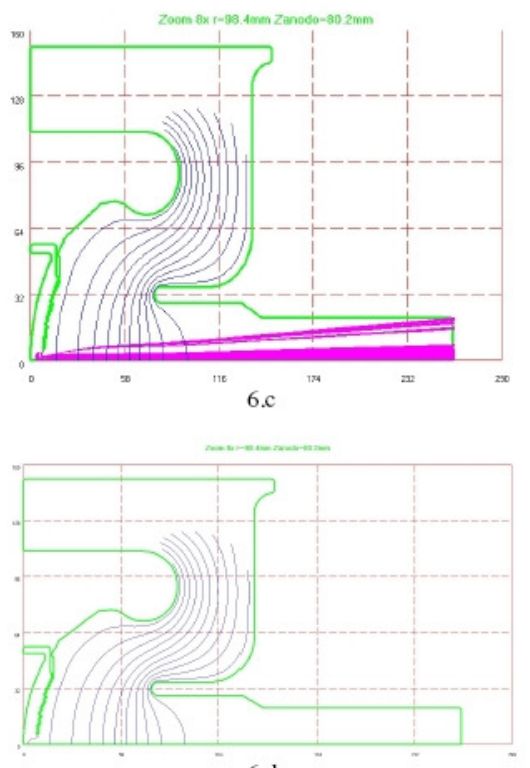

$6 . \mathrm{d}$

Fig. 6a-d Reduction electron flow due to bias potential applied on the control grid. The potentials on control grid (a), (b), (c) and (d) are $-50 \mathrm{~V}$,

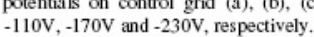

It is also possible to notice the drop on electron flow, due to consecutive reduction on control grid's potential, by the averaged current density $J_{\text {avg, }}$ as shown in Fig. 7 .

Current Density Varation over Control Grid Potential

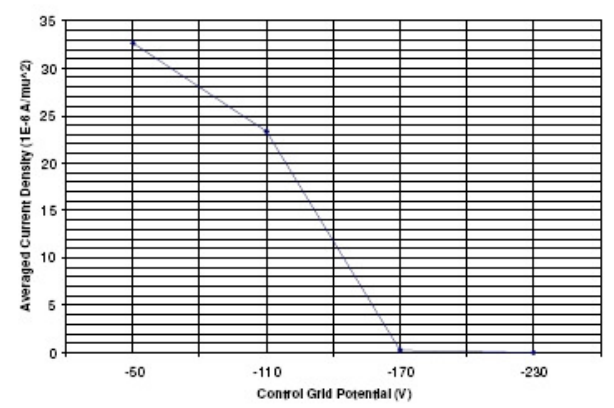

Fig. 7. Diop of averaged current density due to decreasing poentials grid control potentials.

Finally, for the gun design, Fig. 8 shows the current behavior under potential variation under space-charge limited condition, where is possible to notice a constant perveance.

Current $x$ Potencial (squared three-halves) curve under space-charge limited emission

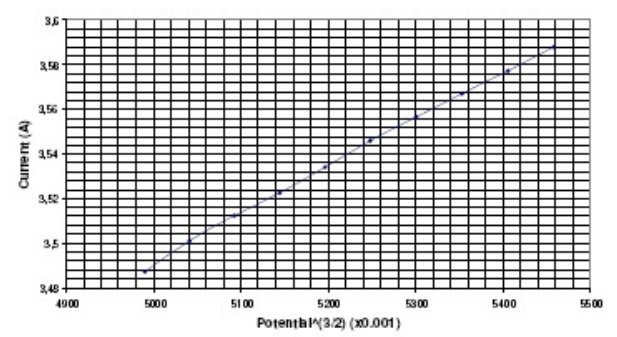

Fig. 8. Current versus potential variation under space-charge flow condition.

B. Experimental Set-up

The test work bench, Fig. 9, it is on final assembling stage. Basically it is composed by the following items:

ionic vacuum pump;

solenoid to be used as magnetic focusing system;

optical windows to measure the cathode temperature

ultra-high vacuum chamber;

current and voltage monitors;

heater, cathode, grid and anode power suppliers. 


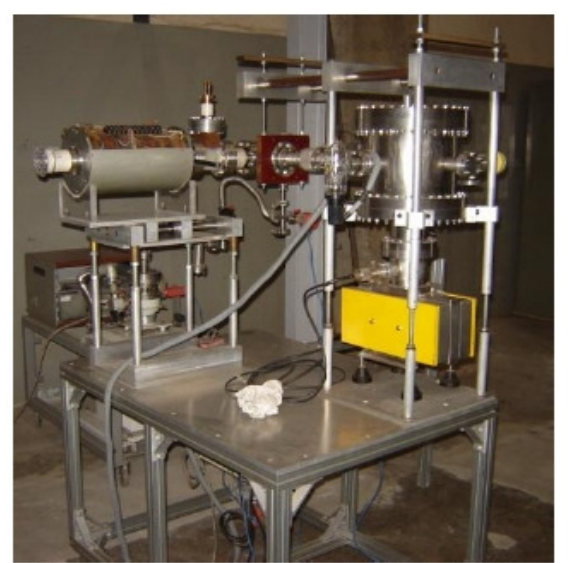

Fig. 9. Electron gun test wak bench under final mounting.

The experimental setup details will be presented in the final version of this paper.

\section{CONCLUSION}

This paper presents some results regarding a gun design, 30 $\mathrm{kV}-3.5 \mathrm{~A}$ and $0.7 \mu \mathrm{Perv}$, for TWT application using EGUN It was shown the grid's importance, it's model and electron guns flow under different control grid potential. Some limitations on using EGUN was also presented. To validate the design, a test bench is in final assembling stage and a final version of this paper it will be presented.

\section{REFERENCES}

[1] Barker, Robert Jr., "Modern Microwave and millimeter-wave power e lectronics", IEEE Press - Wiley Inter science, NJ, ch. 2 and 4, 2005 [2] Hermannsfeldt, W. B., Stanford Linear Acc. Center, SLAC-331 1988 (unpublished).

[3] Humphries Jr., S., "TRACK", Computational Accelerator Physics, edited by R. Ryne (Am. Inst. of Phys., New York 1994), p.597; "Integrated Software System for High-Power Beam Design", in Beams 94: Proc, $10^{\text {th }}$ Conf. High Power Particle Beams, p. 568.

[4] Petillo, J. Eppley, K. Panagos, D. Blanchard, P. Krueger, W. Mondelli, A. Saic, T.M Lanl, EN. Raytheon, N.D. Precision, S.H.J.F Deford, J. Star, B.H. Nrl, B.L., "The MICHELLE electron gun and collector modeling tool: Theory and design", IEEE Trans Plasma Sci, vol. 30, pp. 1238-1264, Jun. 2002.

[5] Humphries Jr., S., "Numerical Modeling of Space-Charged-Limited Charged-Particle Emission on a Conformal Traiancular Mesh", Journ of Comp. Phis, vol. 125, pp. 488-497, 1996.

[6] True, R., "The Desim of Gridded Pierce Guns for Accelerators", IEEE Trans Nucl. Sci, vol. 32, Issue 5, Oct. 1985, page(s):2611 - 2613S. 


\title{
D.2 IVEC - 2009
}

\author{
Design of a Gridded Electron Gun for Traveling-Wave Tubes: an EGUN case \\ study \\ César Candido Xavier ${ }^{1}$ and Cláudio C. Motta ${ }^{2}$ \\ ${ }^{1}$ Instituto de Pesquisas Energéticas e Nucleares/CNEN-SP \\ University of Sao Paulo \\ 1'cesarcx@usp.br, ${ }^{2}$ ccmotta@usp.br, Av. Lineu Prestes 2242 - Cid. Universitária - Sao Paulo - Brazil - 05508-000
}

\begin{abstract}
A design procedure of a $0.7 \mu$ Perv electron gun, with grid and shadow grid, under space charge-limited flow to be used in traveling-wave-tube (TWT) is presented. The EGUN was used to determine the self-consistent electric fields for the electron beam and, as a result, it was obtained a current/perveance growth as the grid voltage increased and the cathode-to-anode spacing decreased. This behavior was observed when grid voltages and cathode-to-anode spacing were varied from $0-600 \mathrm{~V}$ and $0.8-1.2 \mathrm{~mm}$, respectively.
\end{abstract}

Keywords: TWT; EGUN; electron gun; space-chargelimited flow.

\section{Introduction}

The proprietary design of TWTs is of high commercial value since it represents over $50 \%$ of all sales of microwave vacuum electronic devices [1] such as in satellite transmitters and in high-power radar systems. These applications require the use of grids, which ensure the beam flow control that can be pulsed whenever it is needed.

The electron gun is one of the critical components of a TWT, and computer simulations of the gun model are crucial for the success of the design, ensuring not only lower cost and reduced time but also the ability to develop highly complex geometries. Many codes have been developed in the last two decades, such as [2]-[4].

The EGUN, a seminal software program, was used to simulate the guns. The three major characteristics of EGUN are: user friendly; ability to work under space-chargelimited flow conditions; and solve electron trajectory equations using guns modeled even with grids and shadow grids. Deviation from EGUN results and the theoretical one of the standard Pierce diode for a sheet electron beam is about $1 \%$.

In this work, in order to obtain a $0.7 \mu$ Perv electron gun, with grid and shadow grid, under space-charge-limited flow, the gun's behavior was evaluated by changing the following parameters (Figure 1): cathode radius disc $\mathbf{r}_{\mathbf{k}}$; electrode focus angle $\boldsymbol{\theta}$; cathode-to-anode distance d gridto-cathode distance $\mathrm{g}_{\mathrm{d}}$; and grid voltages $\mathbf{V}_{\mathrm{gd}}$.

The first part of this work presents the main characteristics of the gun model used in simulations. The second part describes the most relevant results obtained in the design of an electron gun working at $30 \mathrm{kV}-3.5 \mathrm{~A}$.

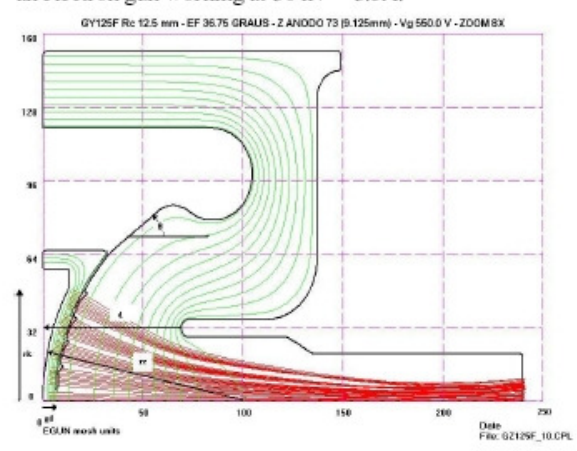

Figure 1-Gun parameters changed within EGUN to evaluate its response behavior: cathode radius disc $\mathbf{r}_{\mathbf{k}}$; electrode focus angle $\theta$; cathode-to-anode distance $\mathbf{d}$; grid-to-cathode distance $\mathbf{g}_{\mathrm{d}}$; and grid voltages.

\section{The gun model}

The simulations were conducted, and the gun's parameters vanied as indicated in Table 1.

Table 1 - Range of values used in EGUN simulations

\begin{tabular}{|c|c|c|c|}
\hline Variable & Initial Value & Final Value & Step \\
\hline $\mathbf{r}_{\mathbf{k}}(\mathrm{mm})$ & 11.9 & 13.1 & 0.3 \\
\hline $\boldsymbol{\theta}$ (degrees) & 6.2 & 39.2 & 3 \\
\hline $\mathbf{d}(\mathrm{mm})$ & 8.5 & 9.25 & 0.125 \\
\hline $\mathbf{g}_{\mathrm{d}}(\mathrm{mm})$ & 0.9 & 1.1 & 0.1 \\
\hline $\mathbf{V}_{\mathrm{ed}}$ (Volts) & 0 & 600 & 100 \\
\hline
\end{tabular}

The anode voltage was set to $30 \mathrm{kV}$ in all simulations. In view of the EGUN's limitations, a scale factor of 8 was used since, when the mesh is created, there must be at least one mesh unit of separation between the different elements. As the EGUN is a two-dimensional (2D) code that supports either rectangular or cylindrical symmetry, the original grids were approximated as five concentric rings due to the axisymmetric model 


\section{Results}

Figure 2 presents the perveance behavior as a function of the grid voltage using the cathode-to-anode spacing as a parameter. Note that (i) perveance grows as the grid voltage increases; (ii) for the same grid voltage, the perveance grows as the cathode-to-anode distance decreases. It wa also observed that for the same cathode-to-anode spacing and voltage, the grids closer to the anode provide higher gun perveance.

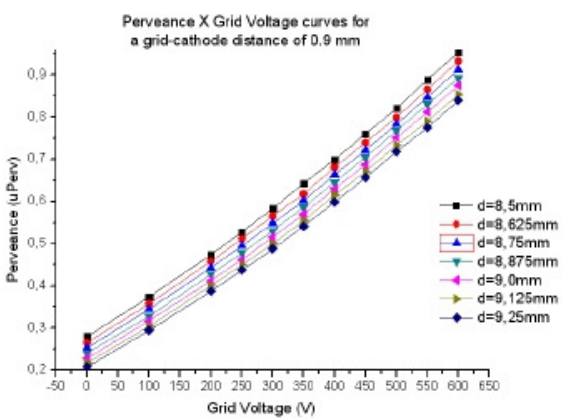

Figure 2 - Behavior of perveance curves under different shadow-grid voltages and distance-tocathode $0.9 \mathrm{~mm}$, with varying cathode-to-anode gap.

Without any grids, Figure 3 shows perveance decaying as a function of the cathode-to-anode spacing. It can be seen that perveance is increased for the same cathode to anode spacing by increasing the beam focus angle $\theta$. On the other hand, it was observed that there is no significant variation in perveance, fixed a cathode-to-anode distance, when the cathode radius varies from $11.9 \mathrm{~mm}$ to $13.1 \mathrm{~mm}$.

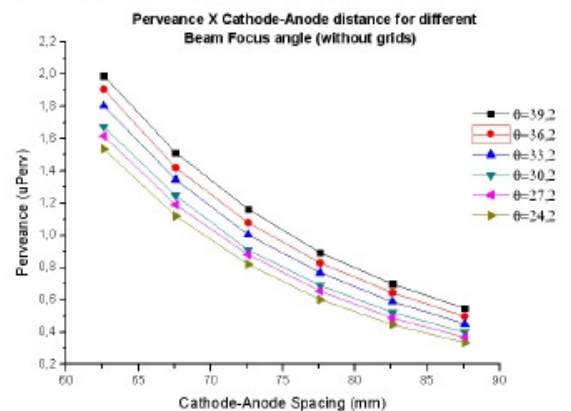

Figure 3 - Perveance versus Cathode-Anode distance curves obtained without the grid.

A relevant quantity in an electron gun design is its beamwaist. Since EGUN output gives only current density as a function of the radial coordinate using the axial coordinate as a parameter, and in order to determine the beam-waist, a three-dimensional (3D) viewer was developed. Figure 4 presents a typical output, highlighting the $\mathrm{z}$ beam-waist coordinate where the current density is at its maximum, with its value shown in a window

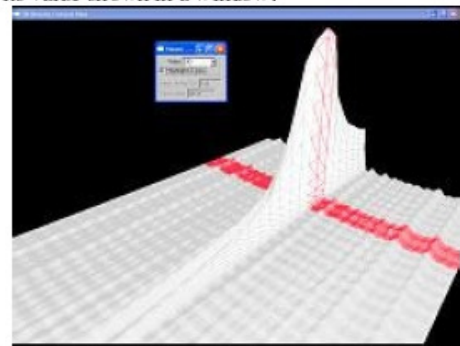

Figure 4-Typical view of the 3D current density plot along the symmetry axis, highlighting the position where its value is highest

The gun design will be validated in a test workbench which is in its final stage of assembling. Basically, this workbench comprises the following items: an ultra-high vacuum chamber, an ionic vacuum pump; a solenoid to be used as a magnetic focusing system; optical windows to measure the cathode temperature; current and voltage monitors; a heater, cathode, grid and anode power suppliers.

\section{Conclusions}

In order to determine a $0.7 \mu$ Perv electron gun working at $30 \mathrm{kV}-3.5 \mathrm{~A}$, with grid and shadow grid, under spacecharge-limited flow, five physical geometric parameters of the gun was studied. Since it was possible to determine the current and perveance behavior as a function of each of the five geometric parameters, and the beam-waist with the $3 \mathrm{D}$ current-den sity viewer, a gun geometry model is provided.

\section{References}

1. Barker, Robert Jr., John H. Booske, Neville C. Luhmann Jr., Gregory S. Nusinovich, "Modern Microwave and millimeter-wave power electronics", IEEE Press-Wiley Interscience, NJ, ch. 2 and 4, 2005

2. Herrmannsfeldt, W. B., Stanford Linear Acc. Center, SLAC-331 1988 (unpublished).

3. Humphries Jr., S., "TRACK", Computational Accelerator Physics, edited by R. Ryne (Am. Inst. of Phys., New York 1994), p.597; "Integrated Software System for High-Power Beam Design", in Beams 94: Proc., $10^{\text {th }}$ Conf. High Power Particle Beams, p. 568.

4. Petillo, J. Eppley, et al., "The MICHELLE electron gun and collector modeling tool: Theory and design", IEEE TPS, vol. 30, pp. 1238-1264, Jun. 2002. 


\title{
D.3 COMPUMAG - 2009
}

\section{A Particle Trajectory Code using the FEM approach: preliminary results}

\author{
${ }^{1}$ César C. Xavier and ${ }^{2}$ Cláudio Costa Motta \\ ${ }^{1}$ Instituto de Pesquisas Energéticas e Nucleares/CNEN-SP \\ ${ }^{2}$ Universidade de Sao Paulo \\ Av. Lineu Prestes 2242 - Cid. Universitária - Sao Paulo - 05508-000 - Brazil \\ ${ }^{1}$ cesarcx@usp.br, ${ }^{2}$ ccmotta@usp.br
}

\begin{abstract}
We describe the numerical code based on Finite Element Method (FEM) developed to study the focusing properties of eletros tatic lenses for non-relativistic electrons trajectories on a two-dimensional electron gun with cylindrical symetry. In order to apply the FEM, the Galerkin Weak Formulation was used. A Delaunay triangulation of the domain was built, and using FEM, the sparse system was solved for the scalar potential associated to the nodes. In order to solve the non-linear second order electron path differential equation, a fourth-order RungeKutta integrator is used.We show that absolute paths errors are below $1.5 \times 10^{-4} \%$, even with a modest discretization of the total space domain.
\end{abstract}

Index Terms-Finite Element Method, electron path, electron gun.

\section{INTRODUCTION}

The focusing properties might be investigated analysing the charged-particle path equation. The particles paths in electron gun it is important because they stablish the beam edge and the beam waist. In order to correctly solve this kind of problem many gun codes, such as [1]-[3], were developed.

Starting with the Lorentz force and energy conservation equations, the charged-particle path is obtained by elimination of the time variable. In order to obtain the scalar potential, a code using FEM with first order triangles elements was developed.

The present paper presents the finite element formulation and the derivation of the path second order differential equation for non-relativistic charged-particle and axially symmetric problems. The code has been beenchmarked and the most relevant results are also presented.

\section{The Physical Problem Description}

The axially symmetric electron path steady-state flow is described by the following governing set of equations:

$\nabla^{2} V=\frac{1}{r} \frac{\partial}{\partial r}\left(r \frac{\partial V}{\partial r}\right)+\frac{\partial^{2} V}{\partial z^{2}}=-\frac{q}{\varepsilon_{0}} \sum_{i} \frac{\delta\left(r-r_{i}\right) \delta\left(z-z_{i}\right)}{2 \pi r_{i}}$

$$
\vec{E}=-\nabla V=-\left(\frac{\partial V}{\partial z} \widehat{z}+\frac{\partial V}{\partial r} \widehat{r}\right)=-E_{z} \widehat{z}-E_{r} \widehat{r}
$$

$$
\frac{d^{2} r}{d z^{2}}=\left[\frac{1+\left(\frac{d r}{d z}\right)^{2}}{2 V}\right]\left(E_{r}-E_{z} \frac{d r}{d z}\right)
$$

where the escalar potential, the electrical field and macro particle charge are denoted by $V, \vec{E}$ and $q$.

In order to solve 1-2, a FEM code with first-order triangle elements was developed to obtain the nodal escalar potentials. The electric field might be found using 2 . To solve the path second-order differential equation a fourth-order Runge-Kutta integrator was used.

\section{A. Finite Element Formulation}

Due to accuracy and versatility associated with residual methods, such as Garlekin method, the finite-element method (FEM) [4]-[5], has been adopted as a standard on solving electromanetic problems. For first order elements, the finite element scalar potential $V_{f e}$ is written as $V_{f e}(z, r)=a_{1}+$ $a_{2} z+a_{3} r$. Let $V_{1}, V_{2}$ and $V_{3}$ be the unknown potential at nodes 1,2 and 3 respectively so,

$$
V_{f e}(z, r)=\sum_{i=1}^{3} \frac{1}{2 A}\left(p_{i}+q_{i} z+r_{i} r\right) V_{i}=\sum_{i=1}^{3} \phi_{i} V_{i}
$$

where

$$
p_{1}=z_{2} r_{3}-z_{3} r_{2} \quad q_{1}=r_{2}-r_{3} \quad r_{1}=z_{3}-z_{2}
$$

$p_{2}, q_{2}, r_{2}, p_{3}, q_{3}$ and $r_{3}$ might be obtained by cyclical permutation of the indices, $A$ equals the triangle area and the $\phi_{i}$ functions are called shape functions. Since the solution using FEM is an approximation, using (4) on (1) a residual $R$ is generated. Is desired a minimum $R$, so it must be imposed that,

$$
\int_{\Omega} W R d \Omega=0
$$

where $W$ is a weighting function and $\Omega$ is the domain. For the discretized domain $\Omega$ the above equation is written as

$$
\sum_{i=1, N} \int_{\Omega_{i}} W_{i} R_{i} d \Omega=0
$$


where $W_{i}$ is the weighting function for node $i, N$ is the total number of unknow nodes, and $\Omega_{i}$ is the domain where node $i$ belongs. This system can be solved for the $N$ unknown equations and coefficients. To use the Garlekin method the weighting functions must be set as the same as shape functions. A Gaussian Elimination solver was developed to solve the global system matrix.

\section{B. Path Equation Derivation}

The electron motion equation must obey the Lorentz force:

$$
\frac{d(m \vec{v})}{d t}=-e(\vec{E}+\vec{v} \times \vec{B}),
$$

Considering $v / c \ll 1$, where $c$ is the light velocity, then $\vec{B}$, the total magnetic flux due to the electron motion current, is such that $|\vec{B}| \approx 0$. Matching component to component at equation (8) and using the energy conservation law, the path equation (3) is obtained

\section{RESULTS}

In order to validate the code, five axial-symetric rectangular regions, with length equals five times height, were evaluated. The number of nodes and finite elements vary from 12 up to 3000 and 14 up to 4790 respectivelly. It was used 20 paths and was observed an absolute error radial position at the final point of integration lower than $1.5 \cdot 10^{-4 \%}$.

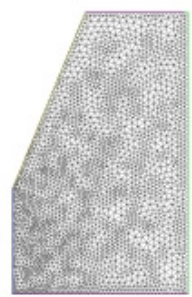

Fig. 1. A Pierce structure domaind subdivided into 5731 finite elements.

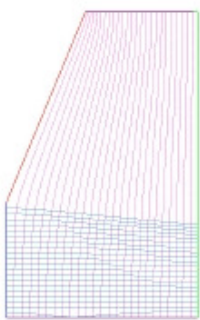

Fig. 2. Output solution shown for the ideal Pierce diode structure. Equipotentials are represented by the red lines and the trajectories by the light-blue.

It was also evaluated the charged-particle trajectory for the ideal Pierce diode structure. This model, Fig. 1, has 2996 nodes and 5731 finite elements. As expected, due to the focusing electrode, the paths curved down to the axis of symmetry according to Fig. 2. Under space-charge limited condition, the paths have to be parallel [6]

The next objective is solve the paths taking into account the space-charge limited condition as well as implement the conjugate gradient method to solve the global matrix system. All electron gun codes, used to design intense beam motion, are said to be self-consistently if their solvers take into account the particle contribution to the static fields and the static fields forces contribution that act on the particles.

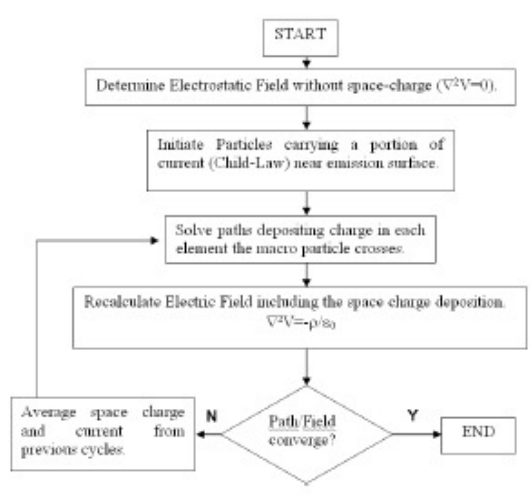

Fig. 3. Flowchart of the method of successive approximation

The flowchart at Fig. 3 presents the successive appoximattion method to be implemented.

\section{CONCLUSION}

It was described the FEM formulation to solve Laplace equation for the scalar potential and the non-linear second order path differential equation for non-relativistic electrons, which was integrated using the fourth-order Runge-Kutta integrator method to obtain the electrons paths. Paths absolut errors were below $1.5 \times 10^{-4} \%$ on a rectangular model, and on a Pierce diode structure, without space-charge deposition, paths presented a consistent behavior which indicates that the code is ready to evolve in order to work under space-charge limited condition.

\section{REFERENCES}

[1] Hermannsfeldt, W. B., Stanford Linear Acc. Center, SLAC-331 1988 (unpublished).

[2] Humphries Jr., S., "TRACK", Computational Accelerator Physics, edited by R. Ryne (Am. Inst. of Phys., New York 1994), p.597; 'Integrated Software System for High-Power Beam Design", in Beams 94: Proc., loth Conf. High Power Particle Beams, p. 568.

[3] Petillo J. Eppley et al. "The MICHELLE electron gun and collector modeling tool: Theory and design", IEEE TPS, vol. 30, pp. 1238-1264, modeling tool: Theory and design", IEEE TPS, vol. 30, pp. 1238-1264
Jun. 2002 . Jun. 200

J. P. A. Bastos and N. Sadowski, Electromagnetic Modeling by Finite Element Methods, New York: Routledge, 2003

5] P. P. Silvester and R L. Ferrari, Finite Ele ments for Electrical engineers 3rd ed. Cambridge:Cambridge University Press, 1996

[6] J.R.Pierce, Theory and Design of Electron Beams (Van Nostrand, Princeton, NJ, 1949) 


\section{D.4 PPC - 2009}

\section{MODELING OF A GRIDDED ELECTRON GUN FOR TRAVELING-WAVE TUBES}

C. C. Xavier and C. C. Motta

Nuclear \& Energetic Research Institute, São Paulo, SP, Brazil University of São Paulo, São Paulo, SP, Brazil

\section{Abstract}

The EGUN code was used to model a $0,7 \mu$ Perv electron gun with control and shadow gids under space-charge limited flow to be used in a pulsed traveling-wave tube (TWT). The simulation main goal is to obtain an electron gun to yield a $2.0 \mathrm{~mm}$ beam-waist with a 6.5 compression ratio. This work presents the sensitivity analysis for the following input geometric quantities: the cathode radius disc; the electrode focus angle; the cathode-to-anode distance; the grid-to-cathode distance. The grid voltage was also varied to investigate its control under beam. Current and perveance plots as function of the five quantities are presented. It was observed a decreasing of the gun perveance and the current when the grid voltage was tumed on if it compared to the gun design without grids. The results also show that a shadow-grid physically modeled led a gun with lower current/perveance Moreover, in order to make easier to establish the beam-waist position from the anode, a 3-Dimensional (3D) viewer of the EGUN output current density data was implemented. An experimental setup of the electron gun is in final assembling stage and, it will be also presented

\section{INTRODUCTION}

TWTs and klystron amplifiers are the two major categories of high-power vacuum microwave devices, also known as linear-beam or O-type tubes, but TWTs represent over half of all world sales [1]. TWTs are used in applications such as broadcasting, satellite communications and high-power radar systems. Therefore, the property design is of high commercial value. TWTs can operate in pulsed as well continuous wave modes. Pulsed mode requires the usage of grids once they guarantee a control over the electron beam flow.

The main components of a TWT are: the electron gun, the RF input/output circuits, the sever circuits, the single or multistage collector, the helix slow-wave or coupled cavity circuits and a magnetic focusing system. Among these elements, the electron gun is one crucial component. Nowadays, TWT computing simulations are decisive for the success design, because guarantee not only cost and time reductions, but also the ability to develop gun with high complex geometry [2]-[4].
The code used in this work to simulate the electron guns is EGUN, a seminal work. The most important EGUN properties are: user friendly, ability to work under spacecharge limited flow condition and solving of fully relativistic electron trajectory equations for guns with control and shadow grids. The error noticed using EGUN simulations for the standard Pierce diode is about $1 \%[5]$ Fig. 1 shows the geometric quantities: the cathode radius disc $r_{k}$; the electrode focus angle $\theta$; the cathode-to-anode distance $d$, and the grid-to-cathode distance $g_{d}$.

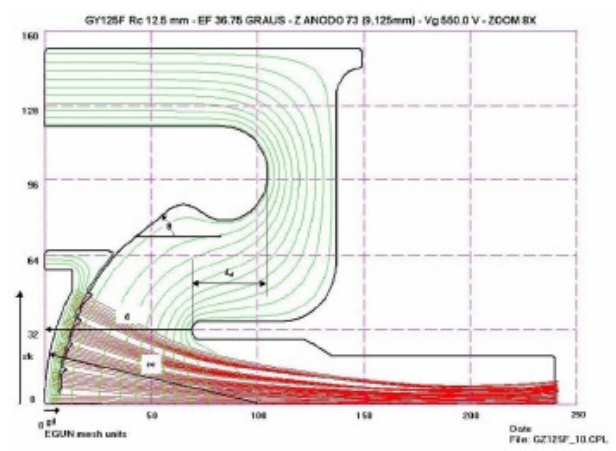

Figure 1. Electron gun geometric quantities used as input variables in EGUN: the cathode radius disc $r_{k}$, the electrode focus angle $\theta$; the cathode-to-anode distance $d$, and the grid-to-cathode distance $g_{d}$.

To summarize, this work presents in Section II the main characteristics of the electron gun used on simulations. The Section III presents the significant simulation results obtained on the design of a pulsed electron gun working on $30 \mathrm{kV}-4.0 \mathrm{~A}$ using EGUN, the next, a 3D current density output EGUN viewer and the last the experimental setup that is in final assembling stage.

\section{THE GUN DESIGN PROCEDURE}

This section presents the sensitivity analysis results using EGUN for the five input quantities presented in Table 1. The output quantities such as the beam current, the perveance and the laminarity of the electron beam flow 
were observed. The anode voltage was set to $30 \mathrm{kV}$ for all simulations. Due to EGUN limitations a scale factor of 8 was used to guarantee, at least, one mesh unit of separation between elements. Since EGUN is a two-dimensional (2D) code, and to make possible a simulation of the rectangular grids, the grids were approximated as concentric rings, as shown in Fig. 2. A total of five shadow-grids were modeled on EGUN

Table 1. Range of the input parameters values used on EGUN simulations.

\begin{tabular}{|c|c|c|c|}
\hline Quantity & Initial Value & Final Value & Step \\
\hline$n_{(\mathrm{mm})}$ & 11.9 & 13.1 & 0.3 \\
\hline$\theta($ degrees $)$ & 6.2 & 39.2 & 3 \\
\hline$d(\mathrm{~mm})$ & 8.5 & 9.25 & 0.13 \\
\hline$g_{d}(\mathrm{~mm})$ & 0.9 & 1.1 & 0.1 \\
\hline$V_{g \mathrm{~d}}(\mathrm{~V})$ & 0 & 600 & 100 \\
\hline
\end{tabular}

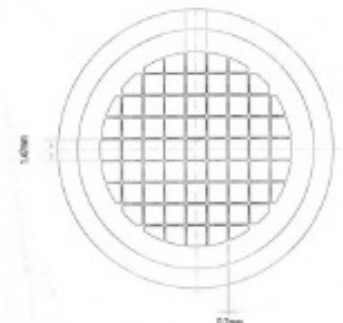

(a)

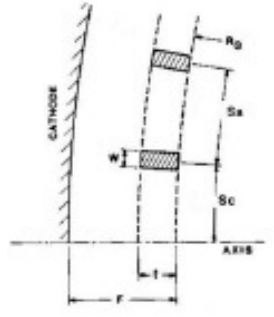

(b)
Figure 2. (a) Cathode's grid frontal view and dimensions used on EGUN simulation, and (b) approximation model used on EGUN simulations. Note that the cathode griddedgun is simulated as concentric rings.

Another set of data was also simulated, based on an existing electron gun, such as that shown in Fig. 3.

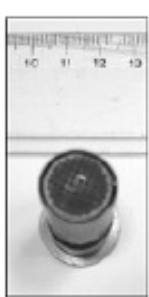

(a)

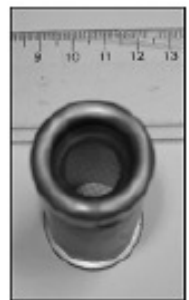

(b)
Figure 3. (a) Cathode with shadow-grid, and (b) focusing electrode with control grid.

Regarding to this set of simulations some input parameters was kept as:

- Anode voltage: $30 \mathrm{kV}$;

- Grid voltage: $500 \mathrm{~V}$;

- Anode-to-focusing electrode distance $d_{a f} .3 .2 \mathrm{~mm}$;

- Electrode focus angle $\theta: 37^{\circ}$; and
- Cathode-disc radii $r_{k}: 6.2 \mathrm{~mm}$.

Table 2 shows the cathode radius and the grid-to-cathode distances used on those set of simulations with EGUN.

Table 2. Cathode radius and grid-to-cathode distance used on EGUN simulations, based on an existing electron gun.

\begin{tabular}{|c|c|c|}
\hline GUN & $\begin{array}{c}\text { Cathode Radius } \\
r_{c}(\mathrm{~mm})\end{array}$ & $\begin{array}{c}\text { Grid-to-cathode } \\
\text { distance } g_{d}(\mathrm{~mm})\end{array}$ \\
\hline G1 & 13.5 & 1.7 \\
\hline G1A & 13.5 & 1.0 \\
\hline G1AX & 13.5 & 2.0 \\
\hline G1AY & 13.5 & 1.5 \\
\hline G2A & 14.5 & 1.0 \\
\hline G2Y & 14.6 & 0.9 \\
\hline GG2 & 14.5 & 2.8 \\
\hline GG3 & 12.8 & 1.0 \\
\hline
\end{tabular}

\section{RESULTS}

\section{A. Theoretical Model Simulations}

Main results obtained for each of the five input quantities in Table 1 are shown below:

\section{1) Cathode radius disc}

Figure 4 presents the perveance as a function of cathodeto-anode separation taking the cathode radius as a parameter. One can observe that: (i) perveance slightly decreases with the increase on the cathode radius; (ii) for the same cathode radius, perveance grows with the decrease of the cathode-to-anode distance. The beam current has the same behavior.

\section{Perveance $X$ Cathode radius for an electrode focus angle of} $33.2^{\circ}$ without grids

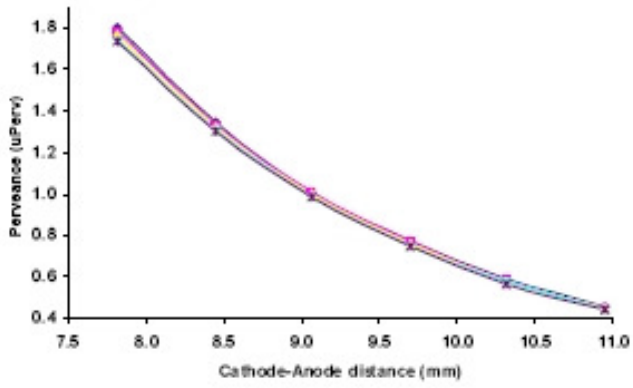

Figure 4. Perveance as a function of cathode-to-anode distance taking the cathode radius as a parameter. The electrode focus angle is $33.2^{\circ}$.

\section{2) Electrode focus angle}

It is shown in Fig. 5 the perveance as a function of the cathode-to-anode separation taking the electrode focus angle as a parameter. In this situation, it is observed that: (i) perveance grows with the increasing of the electrode focus angle; and (ii) for the same electrode focus angle, the 
perveance grows with the decreasing of the cathode-toanode separation. The beam current has the same behavior.

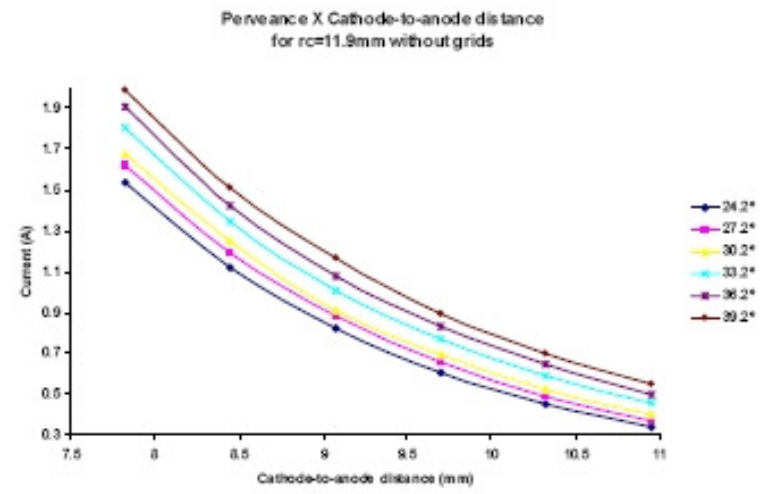

Figure 5. Perveance as a function of cathode-to-anode separation taking the electrode focus angle as a parameter. The cathode radius is taken as $11.9 \mathrm{~mm}$.

\section{3) Cathode- to-anode separation}

Figure 6 presents the beam current as a function of the control grid bias voltage taking the cathode-anode separation as a parameter. The grid-to-cathode distance is taken as $1.0 \mathrm{~mm}$. It can be seen that: (i) for the same grid voltage a current decreases with the increase cathode-toanode distance; (ii) for the same cathode-to-anode distance it is possible to increase perveance by increasing the grid voltage; and (iii) the same current behavior might be found under different cathode-to-anode distance by varying the grid voltage. The perveance has the same behavior.

Current $X$ Grid Voltage for a grid-b-cathode distance of $1.0 \mathrm{~mm}$

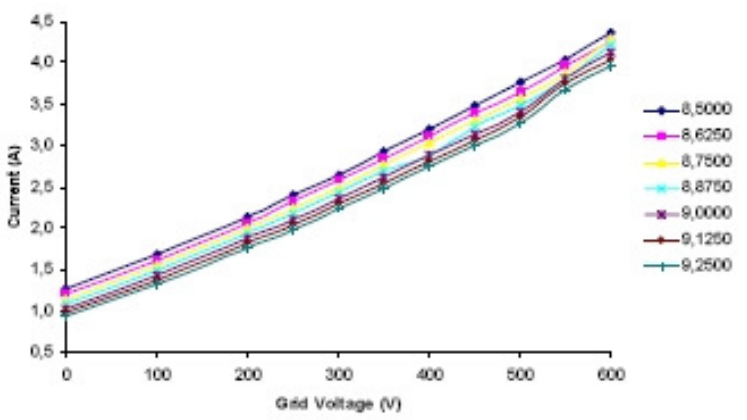

Figure 6. Beam current as a function of control grid bias voltage taking the cathode-to-anode separation as a parameter. The grid distance is taken as $1.0 \mathrm{~mm}$

\section{4) Grid-to-cathode separation}

Figure 7 depicts the current as a function of the control grid bias voltage taking the grid-to-cathode distance as a parameter. The grid-to-anode distance is taken as $8.9 \mathrm{~mm}$. In this case it is observed that: (i) the beam current grows with the increasing of the control grid bias voltage; (ii) for the same control grid bias voltage, the beam current grows with the decreasing of the grid-to-cathode distance; and (iii) the same beam current value might be found under different grid-to-cathode separation by increasing the control grid bias voltage. The perveance has the same behavior.

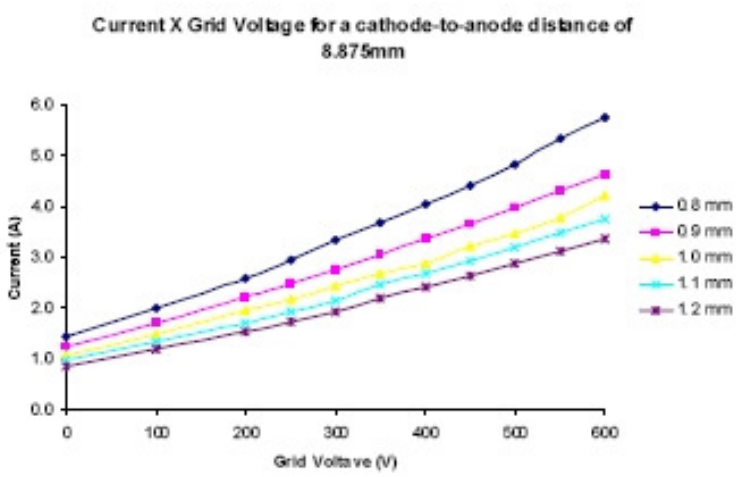

Figure 7. Beam current as a function of the control grid bias voltage taking the grid-to-cathode separation as a parameter. The cathode-to-anode distance is taken as 8.9 $\mathrm{mm}$.

\section{5) Control grid bias voltage}

It is shown in Fig. 8 the beam current as a function of the cathode-to-anode separation taking the control grid bias voltage as a parameter. The grid-to-cathode distance is taken as $0.8 \mathrm{~mm}$. One can observe that: (i) for the same control grid bias voltage, the current decreases with the increasing of the cathode-to-anode separation; and (ii) for the same cathode-to-anode separation it is possible to increase the beam current by increasing the control grid bias voltage. The perveance has the same behavior.

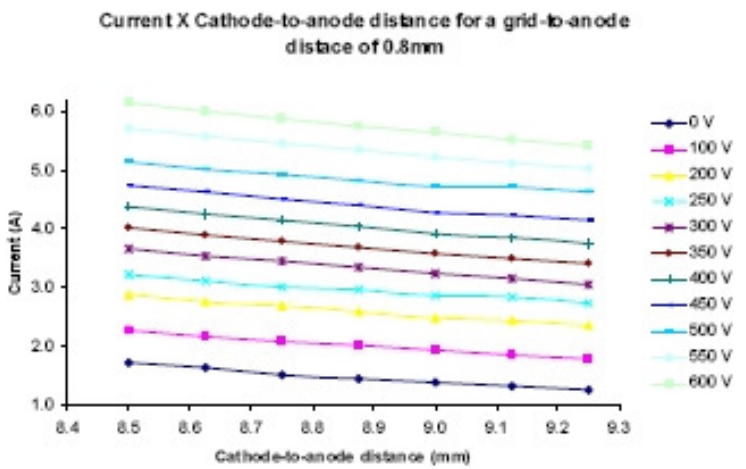

Figure 8. Beam current as a function of the cathode-toanode separation taking the control grid bias voltage as a parameter. The grid-to-cathode separation is taken as 0.8 $\mathrm{mm}$.

\section{B. Physical Model Simulations}

Simulations were made with all electron guns shown in Table 2. The current and the perveance yields are presented in Table 3. The gun G2Y presented the best performance. It 
presents a current of $5.5 \mathrm{~A}$. In order to estimate the gun behavior under a variation of the anode-to-focusing electrode separation of $\pm 0.5 \mathrm{~mm}$, which could occur during the gun assembly, simulations were taken and are depicted in Fig. 9.

Table 3. Output values of current, perveance and beamwaist obtained with EGUN.

\begin{tabular}{|c|c|c|c|}
\hline GUN & $I(A)$ & Perv $(\mu$ Perv $)$ & Beam waist $(\mathrm{mm})$ \\
\hline G1 & 1.6 & 0.30 & 2.0 \\
\hline G1A & 3.5 & 0.68 & 1.7 \\
\hline G1AX & 1.2 & 0.23 & 2.0 \\
\hline G1AY & 2.0 & 0.39 & 1.9 \\
\hline G2A & 2.4 & 0.45 & 2.1 \\
\hline G2Y & 5.5 & 1.06 & 2.1 \\
\hline GG2 & 1.7 & 0.33 & 2.2 \\
\hline GG3 & 1.7 & 0.33 & 1.6 \\
\hline
\end{tabular}

Current $X$ Cathode-to-anode distance for a grid voltage of $500 \mathrm{~V}$.

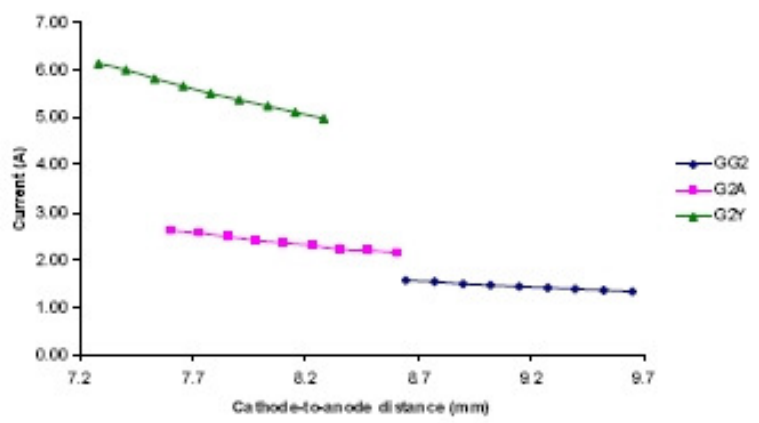

Figure 9. Beam current as a function of the cathode-anode separation taking a focusing electrode separation as a parameter for the guns GG2, G2A and G2Y.

An attempt to investigate the G2Y gun behavior was also performed when the shadow-grid was physically built over the gun cathode surface instead of just introducing a nonemitting surface at the cathode.

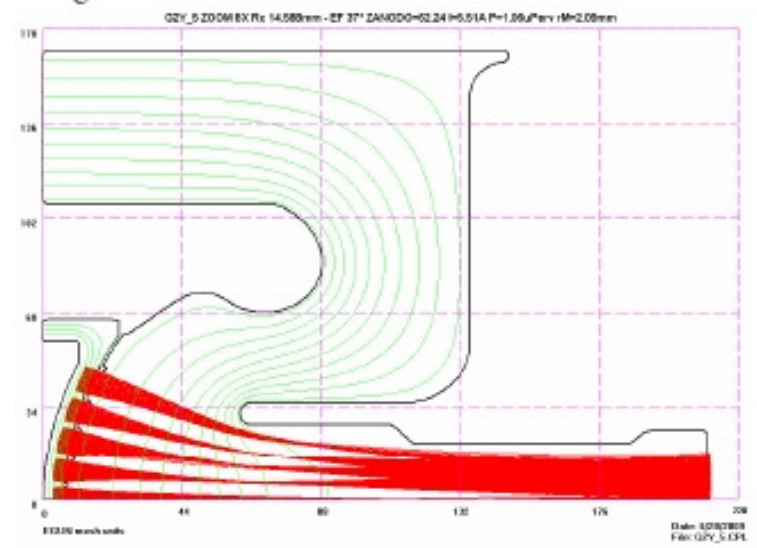

(a)

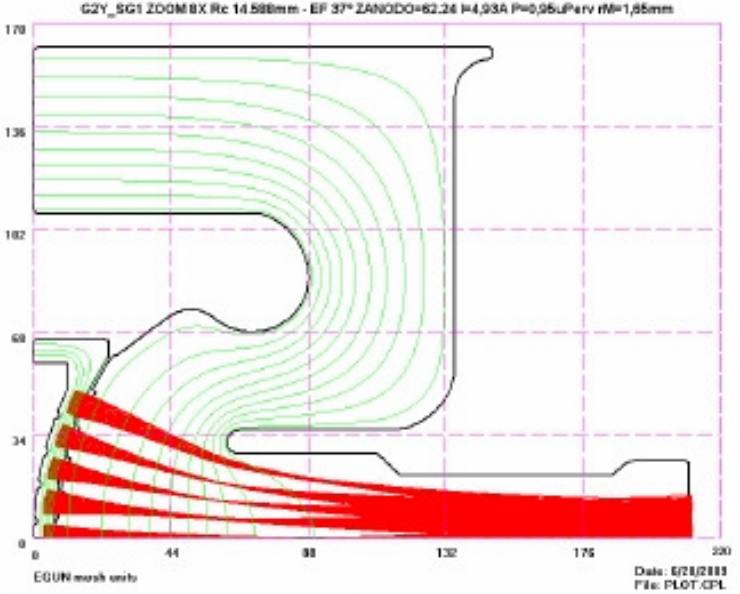

(b)

Figure 10. Gun G2Y shadow-grid modeled as: (a) nonemissive regions introduced manually; (b) real physical component, with $0.13 \mathrm{~mm}$ height.

It is possible to notice differences at the electron flow, according to Fig. 10 (a) and (b). When the shadow-grid is considered in modeling is observed a reducing of $10 \%$ in the beam current as well as in the perveance. Actually, it can be seen a scaling in the cathode emission surface, Fig. 11 , that decreases the emission area.

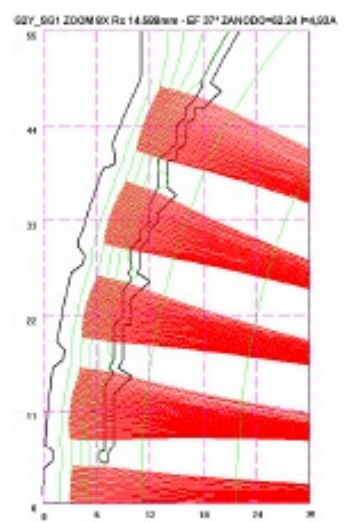

(a)

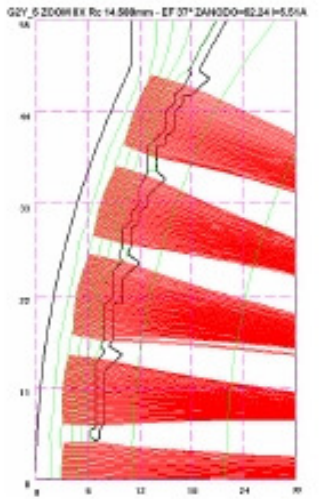

(b)
Figure 11. G2Y cathode emission area zoomed. (a) The shadow-grid was physically modeled over the cathode while (b) the shadow-grid was simulated by constrains of non-emissive cathode area.

\section{3D Current Density Viewer}

Since EGUN allows 2D view, only step-by-step along the symmetry axis, a 3D current density viewer was developed. The main purpose is to determine the beamwaist. To achieve this task, a search on the beam profile current density is made. Fig. 12 presents a typical output, highlighting the $z$-coordinate where the current density is a maximum and its value is presented on the window. 


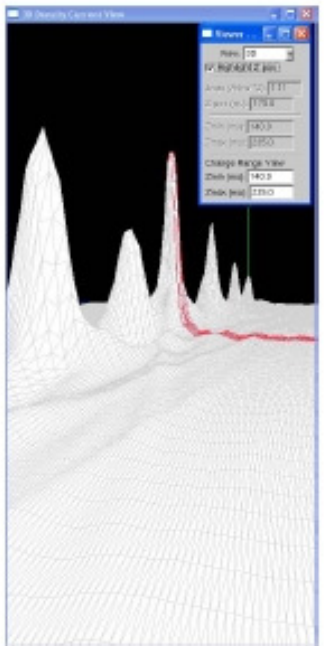

Figure 12. A typical view of the 3D current density plot viewer along the symmetry axis. The position where it has the highest value is highlighted.

\section{Experimental Set-up}

It is on final assembling stage a test work bench which will validate this work. The experimental set-up is basically composed by the following items: an ultra high vacuum chamber with an ionic pump; a magnetic focusing system; an optical window to measure the cathode temperature; current and voltage monitors; heater, cathode, grid and anode power suppliers. Fig. 13 shows the set-up.

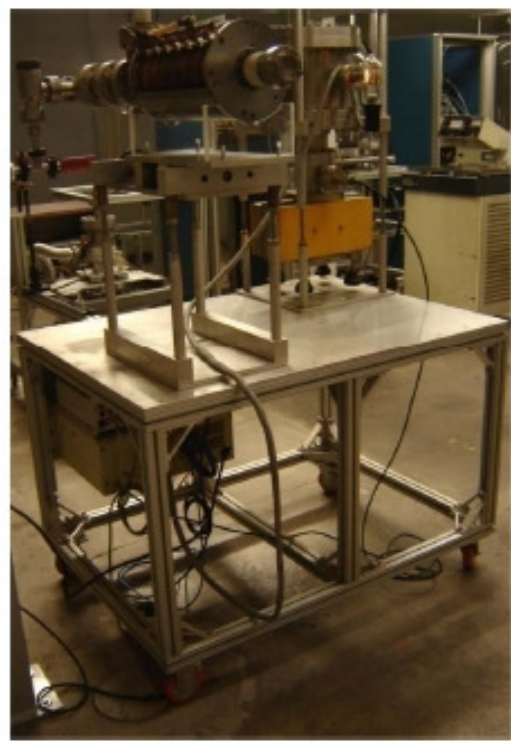

Figure 13. An overview of the experimental set-up.

\section{CONCLUSION}

The use of EGUN for modeling and simulating a $30 \mathrm{kV}$ $4.0 \mathrm{~A}$ and $0.7 \mu$ Perv pulsed electron gun provides a research tool for simulation of a TWT and facilitate its further use as viewer. The main observations from this work can be summarized as follows: 1) without grids, perveance slightly decreases with the increase on the cathode radius; 2) the same current/perveance might be found for different cathode-to-anode separation by adjusting the grid voltage; and 3) different current/perveance results when the shadow-grid is modeled by different ways. Modeling the shadow-grid physically in the cathode led to a gun with lower current and perveance.

\section{REFERENCES}

[1] Barker, R. Jr., at al., "Modern Microwave and millimeter-wave power electronics," IEEE Press - Wiley Interscience, NJ, ch. 2 and 4, 2005.

[2] Herrmannsfeldt , W. B., Stanford Linear Acc. Center, SLAC-331 1988 (unpublished).

[3] Humphries Jr., S., "TRACK", Computational Accelerator Physics, edited by R. Ryne (Am. Inst. of Phys., New York 1994), p.597; "Integrated Software System for High-Power Beam Design," in Beams 94: Proc., 10 ${ }^{\text {th }}$ Conf. High Power Particle Beams, p. 568.

[4] Petillo, J., at al., "The MICHELLE electron gun and collector modeling tool: Theory and design," IEEE Trans. Plasma Sci, vol. 30, pp.1238-1264, Jun. 2002.

[5] Humphries Jr., S., "Numerical modeling of spacecharge-limited charged-particle emission on a conformal triangular mesh," Joumal of Comp. Phys, vol. 125, pp. 488$497,1996$. 


\title{
D.5 IEEE - 2010
}

\section{The XMGUN Particle Path FEM Code}

\author{
César C. Xavier ${ }^{1}$ and Cláudio C. Motta
}

${ }^{1}$ Instituto de Pesquisas Energéticas e Nucleares/CNEN-SP, São Paulo 05508, Brazil ${ }^{2}$ Universidade de São Paulo, São Paulo 05508-000, Brazil

This work reports some initial results of a 2-D electron gun design code (XMGUN) based on the finite-element method (FEM). Using the Galerkin weak formulation, the nodal analysis, and the first-order elements, the Poisson equation was solved for the electron gun electrostatic potential. The nonrelativistic particle paths were numerically calculated by a fourth-order Runge-Kutta method. An iterative scheme was repeated until the electron paths convergence was achieved under full space-charge limited condition. In order to validate the algorithm, the focusing properties of a 2-D Pierce electron gun with planar symmetry were studied. The quality of the beam was evaluated based on the particle's final position, the transit time, and the particle energy evaluations. Using these three parameters, a good agreement was found between the theoretical and calculated results. Absolute current density errors of less than $1 \%$ were found, even with a coarse discretization of the domain. The XMGUN tool was used to design a 30-kV, 7.1-A, and 1.37- $\mu$ Perv axis-symmetric high-power electron gun for use in vacuum microwave devices. The figure of merit used as reference to measure the quality of the electron beam was the normalized transverse velocity.

Index Terms-Electron gun, electron path, finite-element method (FEM).

\section{INTRODUCTION}

$\mathrm{T}$

HE focusing properties of the electron guns, used in power microwave tubes design, can be investigated by analyzing the charged particle path. Knowledge about the particle paths in an electron gun is relevant, since these paths establish the beam edge, the beam waist, and the beam waist distance from the cathode. However, to the authors' knowledge, the existing gun codes, such as [1]-[5], use motion equation instead of the path equation. This work proposes a new methodology to solve the self-consistent space-charge limited condition from the particle path. Based on this approach, the newly developed tool was used to design a $30-\mathrm{kV}, 7.1-\mathrm{A}$, and $1.37-\mu$ Perv, axis-symmetric high-power electron gun for use in vacuum microwave devices. The normalized transverse velocity was used as a figure of merit in measuring the quality of the electron beam.

The work is organized as follows. Section II presents the physical formulation of the problem, the finite element method (FEM), the derivation of the second-order differential equation for the nonrelativistic charged-particle path, and the self-consistent algorithm. Section III shows the code's benchmark consisting in a Pierce planar diode, and the most relevant results are discussed. Finally, the conclusions follow in Section IV.

II. THEORETICAL DESCRIPTION OF THE PROBLEM

\section{A. Physical Formulation}

In order to obtain the scalar potential, a code using FEM with first-order triangle elements was developed. The planar symmetric electron steady-state flow can be described by the

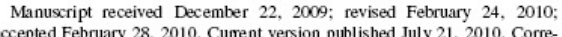
accepted February 28, 2010. Current version published July 21, 2010. Corresponding author: C. C. Xavier (e-mail: œesarcx@usp.br).

Color versions of one or more of the figures in this paper are available online
Poisson equation for the scalar potential in orthogonal curvilinear coordinates $\psi(u, v)$ as

$$
\begin{aligned}
\nabla^{2} \psi & =\frac{1}{h_{u} h_{v}}\left[\frac{\partial}{\partial u}\left(\frac{h_{v}}{h_{u}} \frac{\partial \psi}{\partial u}\right)+\frac{\partial}{\partial v}\left(\frac{h_{u}}{h v} \frac{\partial \psi}{\partial v}\right)\right] \\
& =-\frac{1}{\varepsilon_{0}} \sum_{i} q_{i} \delta\left(u-u_{i}\right) \delta\left(v-v_{i}\right)
\end{aligned}
$$

where the right-hand side refers to the space charge. $q_{i}$ represents the $i$ th charge of the macroparticle that is transported by the beam current of the electron gun located at the position $\left(u_{i}, v_{i}\right) . \delta\left(u-u_{i}\right)$ and $\delta\left(v-v_{i}\right)$ denote the Dirac delta functions. The scale factors $h_{\iota_{u}}$ and $l_{l_{v}}$, in rectangular coordinates, are equal to 1 . In cylindrical coordinates, due to the transformation $x=\rho \cos \phi, y=\rho \sin \phi$ and $z=z, h_{u}=h_{\rho}=1$ and $h_{v}=h_{\phi}=1$ hold.

The charged-particle path is determined using the Lorentz force under the condition $(v / c)^{2} \ll 1$ and the energy conservation law

$$
\frac{d^{2} u_{i}}{d v_{i}^{2}}=\frac{1}{2 \psi_{i}}\left[1+\left(\frac{d u_{i}}{d v_{i}}\right)^{2}\right]\left(-E_{u_{i}}+E_{v_{i}} \frac{d u_{i}}{d v_{i}}\right)
$$

where the subscript $i$ represents the $i$ th particle path of the problem and $\vec{E}=-\nabla \psi$ is the electric field. Equation (2) shows that the particle path does not depend on the particle charge and mass ratio.

To solve the coupled problem (1)-(2), an in-house FEM code was used to determine the scalar potential and therefore the electric field. Then, to find the solution of (2), the second-order differential equation is transformed into a two first-order differential equation system, and then an in-house fourth-order Runge-Kutta integrator, with constant step size, is used. It is worth noting that the particle path slope can be directly extracted from the Runge-Kutta integration output. This leads to, for each particle path, a fast evaluation of the minimum of the path, which would be used to establish the beam waist and hence the beam waist distance from the cathode.

Since it is necessary to satisfy the charge conservation law, the total current $I$ inside the device is constant. 


\section{B. Finite Element Formulation}

Due to accuracy and versatility of weighted residual methods, such as the Galerkin method, the FEM [6], [7] has been adopted as a standard for solving electromagnetic problems. The triangular finite element scalar potential $V_{E}$ is written as $V_{e}(u, v)=\sum \Phi_{i} V_{i}$, where $V_{1}, V_{2}$, and $V_{3}$, respectively, are the unknown potential at nodes 1,2 , and 3 , respectively, and $\Phi_{i}=\Phi_{i}(u, v)$ represents the basis functions. This leads to the following system of equations:

$$
[S][U]+[g]=0
$$

where

$$
\begin{aligned}
S_{i j} & =\int_{\Omega} \nabla \Phi_{i} \cdot \nabla \Phi_{j} u \Omega \\
U_{i} & =V_{i}
\end{aligned}
$$

and

$$
g_{i}=\frac{1}{\varepsilon_{0}} \int_{\Omega} \Phi_{i} \rho_{i} d \Omega
$$

where $\rho_{i}$ is the right-hand side of (1), $\Omega$ is the element area, and $V_{i}$ is the unknown potential. To use the Galerkin method, the weighting functions are set the same as the base functions, and since the matrix coefficients $S_{i j}$ are determined from the basis functions $\Phi_{i}$, system (3) can be solved for the unknown node variables $V_{i}$. It should be noted that the basis function $\Phi_{i}$ refers to the $i$ th node. An in-house Gaussian elimination solver was developed to solve the global system matrix.

\section{The Self-Consistent Algorithm}

All electron gun codes, used for designing intense beam guns, are said to be self-consistent if their solvers take into account the space-charge contribution to evaluate the static fields and the static fields forces contribution that act on the particles. The flowchart in Fig. 1 presents the successive approximation method. This procedure is repeated until the convergence criterion of the $n$th iteration is closer to the previous one, the $(n-1)$ th. The convergence criteria may be the slopes of the particle paths or the electric field intensity in some chosen plane. However, the scheme adopted in this work takes into account the variation of the current density between two consecutive approximations. In this work, an absolute relative error of current density, between two consecutive approximations, of $0.01 \%$ was adopted. Usually, 7-16 iterations are required to reach the desired accuracy.

The calculation of the charge deposition increment $\Delta \rho_{j}$, at the $j$ th triangular element of the mesh, is straightforward and is given by

$$
\Delta \rho_{j}=\frac{q_{i}}{\Delta V_{j}}=\frac{I_{i} \Delta \tau}{\Delta V_{j}}
$$

where $I_{i}$ is the $i$ th macroparticle current, $\Delta \tau$ is the transit time inside the $j$ th element, and $\Delta V_{j}$ is the volume of the $j$ th element. For the planar diode, using the Child-Langmuir law [8], the $i$ th macroparticle current at the $(n+1)$ th iteration $I_{i}^{(n+1)}$ is approximated by

$$
I_{i}^{(n+1)}=\left(\frac{4 \sqrt{2}}{9}\right) A_{i} \varepsilon_{0} \sqrt{\eta}\left[\frac{\left(V_{j i}^{(n)}\right)^{3 / 2}}{d_{s}^{2}}\right]
$$

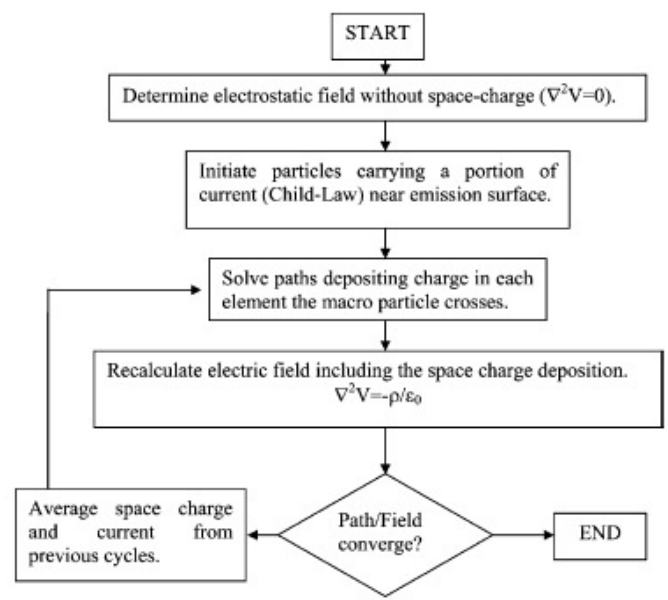

Fig. 1. Flowchart of the successive approximation method.

where $A_{i}$ is the area of the cathode that contributes to the $i$ th macroparticle, $\varepsilon_{0}$ is the vacuum permittivity, $\eta$ is the particle charge-mass ratio, $V_{i}^{(n)}$ is the $j$ th finite element, $i$ th particle potential evaluated at the center of the $i$ th path located at the distance $d_{s,}$, where $d_{s}$ is the macroparticle distance normal to the cathode. The macroparticles start at a distance $d_{s}$ from the cathode since, under the space-charge limited condition, the fields and the particle velocities at the cathode are null and they would never advance.

To avoid current density divergences, the $j$ th element charge at the $(n+1)$ th iteration $\rho_{j}^{n+1}$ is averaged as

$$
\rho_{j}^{n+1}=(1-w) \rho_{j}^{n-1}+w \rho_{j}^{n}
$$

where $w$ represents the under-relaxation factor $(0.0 \leq w \leq$ 1.0). At the first iteration, $w$ is set to 1.0. A low value of $\bar{w}$ corresponds to the average charge density over several cycles.

Charge deposition between the cathode and the emission region follows the procedure adopted by [9]. The macroparticles move backward from the emission surface to the cathode at a constant velocity $v_{b}$ of

$$
v_{b}=-\left(\frac{2}{3}\right) \sqrt{2 \eta V_{j s}}
$$

where $V_{j a}$ is the $j$ th particle potential at the distance $d_{k}$.

Because the initial current is too high, a suppression factor is used in the first iteration cycles. Therefore, the initial current in the first, second, and third cycles is multiplied by $0.25,0.50$, and 0.75 , respectively.

\section{RESULTS}

In order to validate the code, a benchmark consisting in a Pierce diode with a cathode-anode separation is of $2 \mathrm{~cm}$, a cathode emission height is of $1.5 \mathrm{~cm}$, and a focusing electrode height of $2.5 \mathrm{~cm}$ was considered. Otherwise specified, the anode (8) voltage was set to $1 \mathrm{kV}$, the under-relaxation factor $w=0.4$, and the number of macroparticles was set to 40 . 
TABLE I

MESH DATA USED TO VAUDATE THE XMGUN CODE

\begin{tabular}{cccc}
\hline Mesh & Nodes & Elements & $\begin{array}{c}\text { Simulation Time } \\
\text { (sec) }\end{array}$ \\
\hline I & 284 & 499 & 2.8 \\
II & 486 & 875 & 3.3 \\
III & 958 & 1792 & 8.5 \\
IV & 1870 & 3560 & 22.7 \\
\hline
\end{tabular}

Systam: XP with SP2, Intel Q66002.4 GHz with 3.0Gb RAM

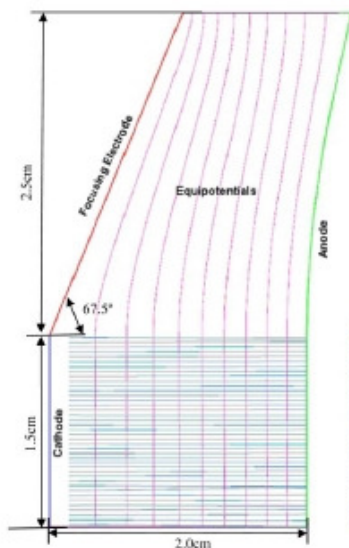

(a)

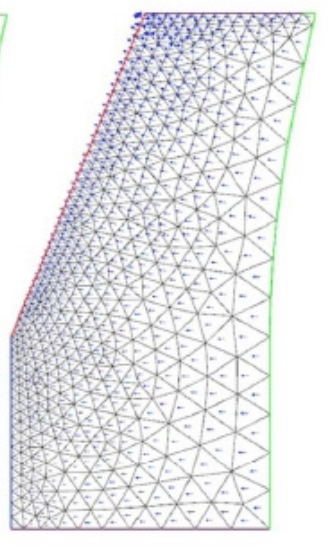

(b)
Fig. 2. For the self-consistent field solution, a detailed view of (a) 40 particle paths and the equipotentials, and (b) the mesh and the electric field

Under space-charge limited condition, the paths must be parallel [8]. Four mesh models were analyzed according to Table I In all the models, a refined mesh was used closer to the cathode, while a coarse one closer to the anode.

Fig. 2(a) indicates that each particle trajectory is nearly parallel. Although it is not easy to observe [Fig. 2(b)], the electric field vanishes closer to the cathode. These behaviors show good agreement with the analytical solution [8].

The current density error decreases as the mesh model is refined. Mesh I presented an error of less than $1 \%$ while that of Mesh IV was less than $0.6 \%$. No significant improvement by increasing the number of particles was observed.

The process of convergence to the correct self-consistent fields depends on the under-relaxation coefficient $w$, which plays an important role since the convergence depends on it. A faster convergence rate was obtained for $0.2 \leq w \leq 0.6$.

Fig. 3 indicates that an initially higher under-relaxation factor provides minor errors. To improve the convergence rate, the use of a variable $w$ may be adopted.

There are three quantities available to validate the quality of the beam calculation: the particle final position, the transit time, and the particle energy. With regard to the final position, it is known that the particle trajectories, in the Pierce planar diode, are parallels. Using Mesh III with 500 particles, it was found that the particles were parallel to within $\pm 0.35^{\circ}$ at the anode

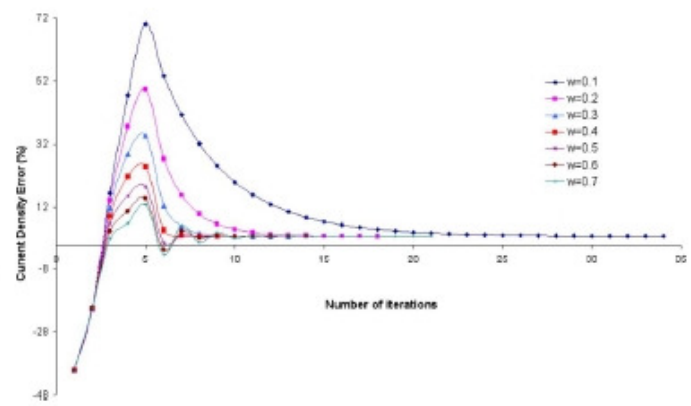

Fig. 3. Relative error of the current density $J$ versus iteration, using various under-relaxation coefficients.

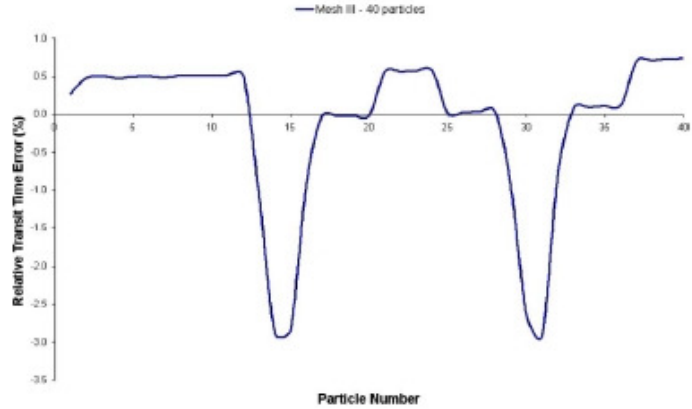

Fig. 4. Typical behavior of the relative transit time error observed during simulations.

During the simulations, no deviation errors exceeding $\pm 0.8^{\circ}$ at the anode were observed.

The quality of the beam, due to the transit time $\tau$, is done knowing that, since the paths are parallel

$$
\tau=\int_{d_{s}}^{d_{a}} \frac{d u}{v(u)}
$$

where $v(u)$ is the macroparticle velocity, $d_{a}$ is the cathode-anode separation, and $d_{s s}$ is the macroparticle's starting position. Due to the energy conservation law and the scalar potential for the Pierce planar diode, the transit time is written as

$$
\tau=\frac{3 d_{a}^{2 / 3}}{\sqrt{2 \eta V_{a}}}\left(d_{a}^{1 / 3}-d_{s}^{1 / 3}\right) .
$$

Typically, transit time errors below $4 \%$ were observed. Fig. 4 depicts a usual output obtained during simulations.

To validate the particle energy, it was observed whether the particles conserve their energy as they travel from the cathode to the anode. Four planes were used to measure the particle energies. The planes were located at $10.9 \%, 40.6 \%, 80.2 \%$, and $98.2 \%$, along the space separating the cathode and the anode. Planes closer to the emission area had higher errors. Regarding the plane located at $10.9 \%$, which presented the worst result, it 


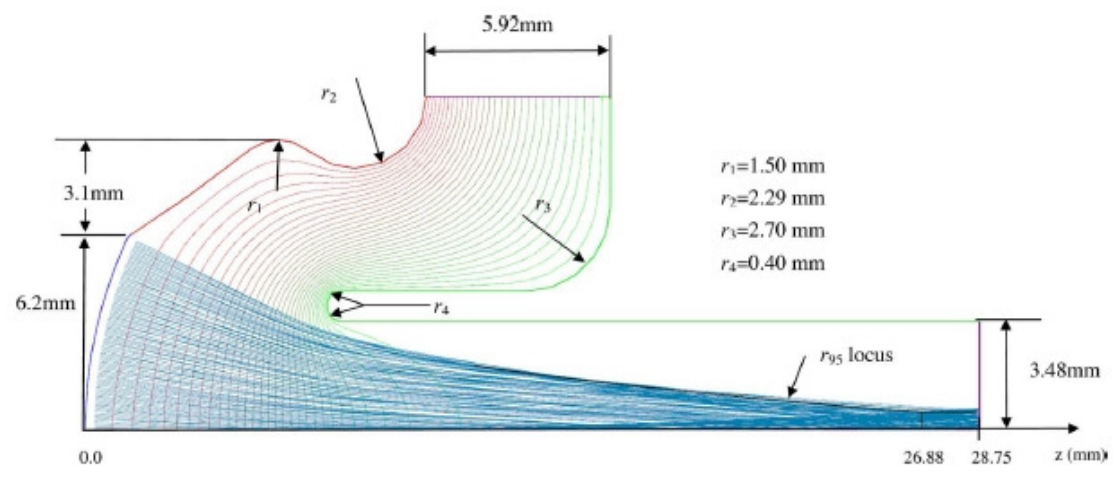

Fig. 5. Electron gun simulation using the particles path equations approach.

was observed that the use of Mesh I produced relative energy errors not greater than $3 \%$, while using Mesh IV produced relative energy errors below $0.4 \%$. Therefore, refined meshes led to a better particle energy response.

A gun model for use in a typical power microwave tube (Fig. 5) was also simulated.

The gun was modeled using cylindrical symmetry, 90 macroparticles, with cathode curvature and cathode-disc radii of 14.59 and $6.2 \mathrm{~mm}$, respectively, and $30 \mathrm{kV}$ at the anode. The gun's mesh contained 2796 nodes and 5057 elements. Eight iterations were needed to reach a current density difference below $0.1 \%$ between two consecutive cycles using $w=0.3$. This gun yields a current of $7.10 \mathrm{~A}$ and a perveance of 1.37 $\mu$ Perv. A current of $7.54 \mathrm{~A}$ and a perveance of $1.45 \mu$ Pery were observed running an EGUN simulation for the same gun model. The 1-kV equipotentials are also shown in Fig. 5.

A figure of merit used as reference in measuring the quality of the electron beam is [10] the normalized transverse velocity

$$
\sigma=\left\{\left[\sum_{i=1}^{n} I_{i}\left(\alpha_{i}-\langle\alpha\rangle\right)^{2}\right] / I_{0}\right\}^{1 / 2}
$$

where $\alpha_{i}$ is the slope of the $i$ th macroparticle path as it crosses a given plane, $I_{i}$ is the current transported by the $i$ th macroparticle path, $I_{0}$ is the total current crossing the plane, and $\langle\alpha\rangle$ is the weighted mean macroparticle path slope of the $n$ macroparticles that cross a given plane perpendicular to the $z$-axis, given by

$$
\langle\alpha\rangle=\left(\sum_{i=1}^{n} I_{i} \alpha_{i}\right) / I_{0} .
$$

The lower the value of $\sigma$ is, the better is the laminarity of the beam under analysis. The minimum beam radius containing $95 \%$ of the current, $F_{95}$, was found in position $z=26.88 \mathrm{~mm}$. In this position, it was observed that $\langle\alpha\rangle=-2.7 \pi \mathrm{mrad}$ and $\sigma=0,068$.

\section{CONCLUSION}

A FEM formulation to solve the coupled Poisson equation for the scalar potential and the nonlinear second-order differential equation for the nonrelativistic electrons path were described. A Pierce planar diode benchmark indicated current density errors below $1 \%$. The under-relaxation factor $w$ plays an important role in the number of iterations, since it may establish faster convergence solutions. To validate the quality of the beam, such as the macroparticle deviation, transit time, and energy, benchmarks were performed and good agreement with the theoretical results was demonstrated. The use of the particle path approach led directly to the macroparticles minimum of the path that would be used to estimate the beam waist and beam waist distance from the cathode.

\section{ACKNOWLEDGMENT}

The authors would like to thank Dr. A. Laudani for his invaluable suggestions that improved the results, Prof. W. B. Herrmannsfeldt for his assistance with the EGUN, and Prof. S. Humphries for his willingness to clarify some doubts regarding the charge deposition scheme adopted by TRACK. This work was supported by FINEP (Research and Projects Financing) under Contract 01.09.0049.00

\section{REFERENCES}

[1] W. B. Herrmannsfeldt, Stanford Linear Acc. Center SLAC-331, 1988, unpublished.

2] Sumphries, Jr., "TRACK." in Computational Accelerator Physics, R. Ryne, Ed. New York: AIP, 1994, p. 597.

[3] J. E. Petillo et al., "The MICHELLE electron gun and collector mod3] J. E. Petillo et al., "The MICHELLE electron gun and collector mod-
eling tool: Theory and design," IEEE Trans. Plasma Sci., vol. 30, pp. eling tool: Theory and

[4] S. Coco et al," "3-D finite-element analysis of TWT grid electron guns," IEEE Trans. Magn., vol. 43, no. 4, pp. 1233-1236, Apr. 2007.

[5] P. Girdinio, M. Repetto, and J. Simkin, "Finite element modelling of charged beams," IEEE Trans. Magn, vol. 30, no. 5, pp. 2932-2935, Sep 2004.

6] J. P. A. Bastos and N. Sadowski, Electromagnetic Modeling by Finite Element Methods. New York: Routledge, 2003.

7] P. P. Silvester and R. L. Ferrari, Finite Elements for Electrical Engineers, 3rd ed. Cambridge, U.K.: Cambridge Univ. Press, 1996.

8] J. R. Pierœ, Theory and Design of Electron Beams. Prinœton, NJ: Van Nostrand, 1949.

[9] S. Humphries, Jr., Field Solutions on Computers. Boca Raton, FL: CRC Press, 1997, Section 10.7.

[10] R. True, "A theory for coupling gridded gun design with PPM foR. True, "A theory for coupling gridded gun design with PPM fo-
cusing,"IEEE Trans. Electron Devices, vol. ED-31, no. 3, pp. 353-362, Mar. 1984. 


\title{
D.6 IVEC - 2010
}

\section{Design of a Gridded Electron Gun using the Particle Path and the FEM approach}

\author{
César C. Xavier ${ }^{1}$ and Cláudio C. Motta ${ }^{2}$ \\ ${ }^{1}$ Instituto de Pesquisas Energéticas e Nucleares/CNEN-SP \\ ${ }^{2}$ University of Sao Paulo
}

1'cesarcx@usp.br. ${ }^{2}$ ccmotta@usp.br, Av. Lineu Prestes 2242 - Cid. Universitária - Sao Paulo - Brazil - 05508-000

\begin{abstract}
Using the particle path instead of the motion equation and the FEM approach a two-dimensional (2-D) tool used to design electron guns was developed $(X M G U N)$. The XMGUN was used to design a $30 \mathrm{kV}, 4.6 \mathrm{~A}$ and $0.88 \mu$ Perv axis-symmetric high power electron gun, with grid and shadow grid, working under the space charge-limited flow to be used in a power traveling-wavetube (TWT). It was observed a current increase and a decrease of the normalized transverse velocity when the control grid voltage was varied from $400 \mathrm{~V}$ to $600 \mathrm{~V}$.
\end{abstract}

Keywords: TWT; electron gun; space-charge-limited flow.

\section{Introduction}

The sales volume for TWTs, of all microwave vacuum electronic devices, represents over $50 \%$ [1]. The TWTs major applications are in satellite transmitters, in highpower radar systems, and in electronic countermeasure systems. At these systems, it is required that the electron beam flow must be controlled. The use of control grids ensures that the beam flow can be pulsed whenever it is needed. In order to reduce the cathode current intercepted by the control grid, which might be as $15 \%$ or more of the total cathode current that produces an excessive heating of the grid, structures built at or near the cathode, denominated shadow-grids, can be used [2].

Nowadays, in order to guarantee lower cost, reduced time and the ability to develop electron guns with highly complex geometries, the use of sophisticated computational models is essential to the design success. As example, many codes have been developed in the last two decades [3-6].

This work presents an axis-symmetric and planar 2-D software program, called XMGUN, developed to design non-relativistic electron guns working under the spacecharge limited condition. To the authors' knowledge, codes [3-6] made use of the motion equation of the particles while XMGUN code makes use of the path equation instead. The XMGUN is a 2-D code that supports either rectangular or cylindrical symmetry. In order to establish self-consistent electric field solutions an iterative scheme is used until the full space-charge limited condition is achieved. It was shown [7] that the deviation from XMGUN results and the theoretical one of the standard Pierce diode for a sheet electron beam was below $1 \%$.

In this work, in order to design a $30 \mathrm{kV}, 4.6 \mathrm{~A}$ and $0.88 \mu$ Perv axis-symmetric high power electron gun, with control and shadow grids, under space-charge-limited flow, its behavior was evaluated by changing the control grid voltage $V_{\text {gd. }}$ It was also investigated the beam-waist behavior against the control grid voltage variation.

The work is organized as follows: first it is presented the main physical characteristics of the gun model used in all simulations, next the path equation and the normalized transverse velocity are presented, finally it is described the most relevant results obtained.

\section{The gun physical characteristics}

All the simulations were conducted with a standard geometry gun, Fig.1, that was: cathode radius $r_{\mathrm{c}}$ $=14.588 \mathrm{~mm}$; cathode radius disc $r_{\mathrm{h}}=6.2 \mathrm{~mm}$; electrode focus angle $\theta=37^{\circ}$; grid-to-cathode distance $\boldsymbol{d}_{\mathrm{cg}}=0.8275 \mathrm{~mm}$. The grid voltages $V_{\text {gd }}$ varied from $400-600 \mathrm{~V}$ on $20 \mathrm{~V}$ steps. The anode voltage was set to $30 \mathrm{kV}$ in all simulations. The original grids were approximated as five concentric nings due to the axis-symmetric model.

\section{The path equation}

The XMGUN code uses the particle path equation in order to establish the trajectory of a macroparticle. To obtain the particle path equation one must integrate the Lorentz force under the condition $v / c \ll 1$ (non-relativistic condition) and the energy conservation law leading to:

$$
\frac{d^{2} r_{i}}{d z_{i}^{2}}=\frac{1}{2 \psi_{i}}\left[1+\left(\frac{d r_{i}}{d z_{i}}\right)^{2}\right]\left(-E_{r_{i}}+E_{z_{i}} \frac{d r_{i}}{d z_{i}}\right)
$$

where the subscript $i$ represents the $i$ th macroparticle path, $r_{i}$ and $z_{i}$ are its radial and axial positions, respectively. $E_{r_{i}}$ and $E_{z}$ are the electric field components applied over the $i$ th macroparticle which are obtained from $\vec{E}=-\nabla \psi$, where $\psi$ is the scalar potential.

\section{The normalized transverse velocity}

To measure the quality of the beam, it is used the normalized transverse velocity [8] $\sigma$.

$$
\sigma=\left\{\left[\left.\sum_{i=1}^{n} I_{i}\left(\alpha_{i}-\langle\alpha\rangle\right)^{2}\right|_{\rfloor}\right]_{0} I_{0}^{1 / 2}\right\}^{1 / 2},
$$

where $\alpha_{i}$ is the slope of the $i$ th macroparticle path as it crosses a given plane, $I_{i}$ is the current transported by the $i$ th macroparticle path, $I_{0}$ is the total current crossing the plane and $\langle\alpha\rangle$ is the weighted mean macroparticle path 


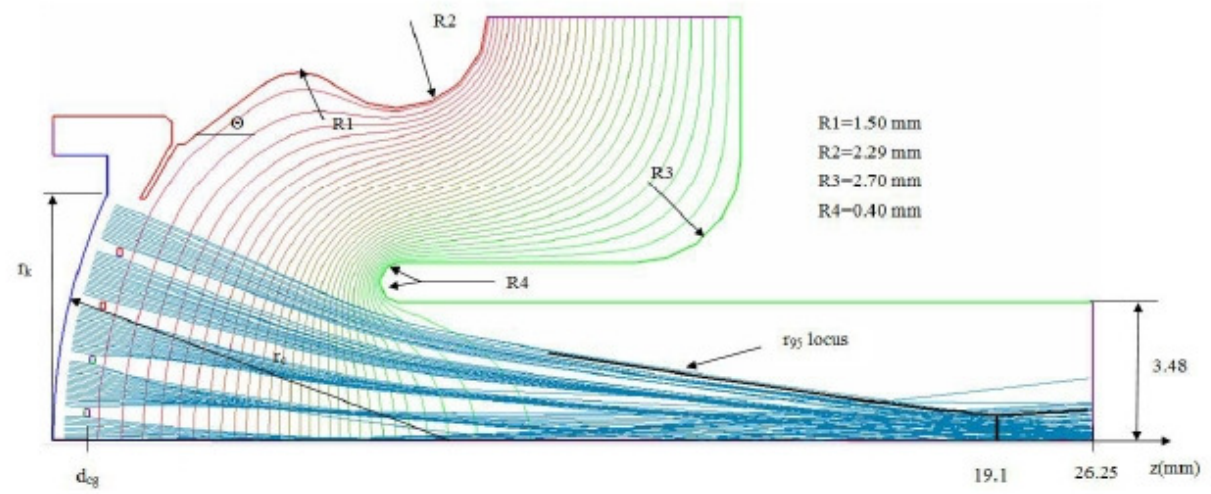

Figure 1. The electron gun geometry with the control grid and the shadow grid.

slope of the $n$ macroparticles which cross a given plane perpendicular to the $z$-axis, given by

$$
\langle\alpha\rangle=\left(\sum_{i=1}^{n} I_{i} \alpha_{i}\right) / I_{0}
$$

The better the beam quality the lower is the value of $\sigma . r_{95}$ is the minimum beam radius containing $95 \%$ of the current, called beam waist, and $z_{w}$ is its axial position.

\section{Results}

Fig. 1 shows the gun geometry and the result of a simulation using the XMGUN code. The gun was modeled with 4996 nodes and 9349 elements. A total of 74 macroparticles were used. The grid voltage was biased to $500 \mathrm{~V}$. It is also possible to see the $r_{95}$ locus and the aberrations in the macroparticle flow due to the control grid. The $1 \mathrm{kV}$ equipotentials are also shown. The transverse velocity was $\sigma=0.091$. The mesh was refined closer to the cathode and the control grid as shown in Fig. 2(b).
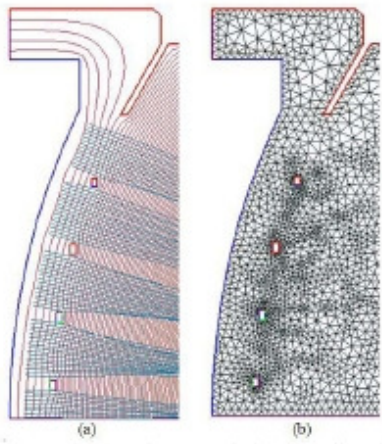

Figure 2. (a) $100 \mathrm{~V}$ equipotentials distribution closer to the cathode and (b) the mesh refining

The beam-waist was found at the axial position $z_{\mathrm{w}}$ $=19.1 \mathrm{~mm}$. It was observed, duning simulations, a growth of the current from $3.83 \mathrm{~A}$ to $5.41 \mathrm{~A}$ when the control grid voltage was biased from $400 \mathrm{~V}$ to $600 \mathrm{~V}$. For the same voltage variation, the normalized transverse velocity decreased from 0.1 to 0.0785 with a minimum at $V_{\mathrm{gd}}=$ $560 \mathrm{~V}$.

\section{References}

1. Barker, Robert Jr., John H. Booske, Neville C Luhmann Jr., Gregory S. Nusinovich, "Modern Microwave and millimeter-wave power electronics", IEEE Press - Wiley Interscience, $N J$, ch. 2 and 4, 2005

2. A. S. Gilmour, Jr., Principles of Traveling wave Tubes, Arthech House, 1994, Section 6.2.4

3. Hermannsfeldt, W. B., Stanford Linear Acc. Center, SLAC-331 1988 (unpublished).

4. Humphries Jr., S., "TRACK", Computational Accelerator Physics, edited by R. Ryne (Am. Inst. of Phys., New York 1994), p.597; "Integrated Software System for High-Power Beam Design", in Beams 94: Proc., 10 $0^{\text {th }}$ Conf. High Power Particle Beams, p. 568.

5. Petillo, J. Eppley, et al., "The MICHELLE electron gun and collector modeling tool: Theory and design", IEEE Trans. Plasm Sci., vol. 30, pp. 1238-1264, Jun. 2002.

6. S. Coco et al., "3-D Finite-Element Analysis of TWT Grid Electron Guns," IEEE Trans. Mag,, vol. 43 Issue 4, pp. 1233-1236, Apr. 2007.

7. C. C. Xavier, C. C. Motta, "The XMGUN Particle Path FEM Code". Submitted to IEEE Trans Magn, 2009

8. True, R., "A theory for coupling gridded gun design with PPM focusing," IEEE Trans. Electron Devices, vol. ED-31, No. 3, pp. 353-362, Mar. 1984 


\section{D.7 MOMAG - 2010}

\section{A Particle-Path FEM Approach Used on Electron Gun, Magnetic Focusing and Collector TWT Design}

\author{
César C. Xavier \\ Instituto de Pesquisas Energéticas e Nucleares/CNEN-SP \\ University of Sao Paulo \\ Sao Paulo, Brazil \\ cesarcx@usp.br
}

\author{
Cláudio C. Motta \\ University of Sao Paulo \\ Sao Paulo, Brazi \\ ccmotta@usp.br
}

\begin{abstract}
By using a particle-path approach code, instead of the motion equation, this paper reports on the electron-beam propagation behavior in: an electron gun; a drift tube; and a collector to be used on traveling-w ave tubes (TWT) design. In the electron gun with cont rol grid and shadow-grid, it is investigated the influence of the grid voltage on the beam-waist size, the distance to the cathode, and the transverse velocity. In the drift tube, using a periodic permanent magnet (PPM) focusing structure, considering a Brillouin flow, the beam behavior is analyzed keeping constant the electric current. Finally, using one single electron collector, the beam behavior is also reported.
\end{abstract}

Keywords - electron gun; periodic permanent magnet; electron collector; path equation; traveling-wave tubes.

\section{INTRODUCTION}

In the design of microwave tubes, such as TWT, it is important to know the particle trajectories of the electron beam from the cathode to the collector. Many codes have been developed in the last two decades [1-4] in order to guarantee lower cost, highly complex geometries analysis and reduced design time. Such codes make use of the motion equation, instead of the of the path equation, in order to perform the ray tracing of the macroparticles.

The XMGUN code [5], developed to design non-relativistic electron beam, with 2-D axis-symmetric or planar electron guns working under the space charge limited condition, was benchmarked against the Pierce diode and presented errors below $1 \%$ even with a coarse mesh. It was also shown [5] that the numerical simulations errors regarding the current density were reduced to $0.6 \%$ when the number of nodes was increased by a factor of 7 . In order to ray trace the macroparticles, the XMGUN code makes use of the particle path equation approach. In this paper, to evaluate the beam behavior on a drift tube, in the presence of the magnetic field, the path equation was enhanced and is presented below.

In this work, the particle trajectories, using XMGUN, are investigated in an electron gun, in a drift tube with a PPM focusing structure and in a collector. In the electron gun with control grids and shadow-grid, whereas the grid voltages range from 450 to $650 \mathrm{~V}$, the beam-waist size and location and the transverse velocity are analyzed. The use of PPM focusing structures minimize both weight and size of a TWT, and the weight reduction of focusing system, compared to a solenoid, becomes one to two orders of magnitude [6]. This paper also

This work is being sponsored by FINEP (Research and Projects Financing) under contract 01.09 .0049 .00$. examines the beam behavior in the drift tube with a PPM focusing structure with a constant electric current of $I_{0}=4.6 \mathrm{~A}$ but under different beam voltage. Finally, is presented a simple electron collector used to collect the beam flow.

This work is organized as follows. Section II presents the physical formulation of the problem to be solved, including the path second order differential equation and a brief description of the simulations Section III discusses the simulations results, and Section IV provides a summary and describes future improvements to be developed.

\section{Particle Path EQUation AND Simulations}

\section{A. Physical Formulation}

The scalar potential was obtained using the Finite Element Method (FEM) with first order triangles elements approach. The beam flow must obey the coupled problem of the Poisson equation for the scalar potential $\psi$, to self-consistently take into account the space charge effect on the fields, and the Lorentz equation, which is used to integrate the macroparticles trajectories through the fields.

$$
\begin{gathered}
\nabla^{2} \psi=-\frac{\rho}{\varepsilon_{0}}, \\
\frac{d(m \overrightarrow{\mathrm{v}})}{d t}=-e(\vec{E}+\overrightarrow{\mathrm{v}} \times \vec{B}),
\end{gathered}
$$

where: $\rho$ is the charge density, $\varepsilon_{0}$ is the permittivity of vacuum, $\vec{E}$ and $\vec{B}$ are the electric and magnetic field, respectively, $m$ is the relativistic mass and $e$ and $\overrightarrow{\mathrm{v}}$ are the electron charge and velocity, respectively.

Using the Lorentz force, under the condition $(\mathrm{v} / c)^{2} \ll 1$, the energy conservation law and Busch's Theorem the macroparticles path is given by:

$$
\frac{d^{2} r}{d z^{2}}=\left[\left.\frac{1+\left(\frac{d r}{d z}\right)^{2}}{2 Q}\right|_{\rfloor}\left(\frac{\partial Q}{\partial r}-\frac{\partial Q d r}{\partial z d z}\right),\right.
$$

where $Q$ is the generalized potential: 


$$
Q=\psi-\frac{\eta}{8 \pi^{2}}\left(\frac{\Phi_{M}-\Phi_{k}}{r}\right)^{2},
$$

where $\eta$ is the electron charge mass ratio, $\Phi_{M}$ and $\Phi_{k}$ are magnetic fluxes evaluated at the surfaces bounded by the circles with radius $r$ and $r_{k}$ respectively, where the subscript $k$ denotes a position where the magnetic flux is known.

\section{B. Simulations}

The XMGUN was designed using the open source libraries Standard Template Library (STL) [7], Open Graphics Library (OpenGL) [8] and EasyMesh [9]. The STL a C++ library of container classes, algorithms, and iterators, was widely used to manipulate the XMGUN data structures The models, mesh, electric and magnetic fields, equipotentials and particles trajectory were presented to the uservia OpenGL. In order to easily obtain gun models with different degrees of mesh refinement, EasyMesh presents a good solution. EasyMesh generates two dimensional, unstructured, Delaunay and constrained Delaunay triangulations in general domains. It uses very simple ASCII file as input and creates three different ASCII output files with the nodes data and the triangular elements connectivity. Although the C++ STL is used, the code is eminently written using the structured $\mathrm{C}$ language.

Axial symmetry is used to model the electron gun, the drift tube and the collector. The electron gun is modeled with grid and shadow-grid. The number of nodes and elements are 2996 and 5232 , respectively. A total of 74 macroparticles are used to model the electron beam. The anode was biased to $30 \mathrm{kV}$. The methodology adopted by XMGUN [5] to establish the particles convergence is based on the Successive Approximation Method (SAM), Fig. 1, and is summarized as follow. The first particle trajectory is obtained by considering no previous charge deposition in the domain and by the scalar potential obtained from the solution of the Laplace equation. As a particle moves, according to the solution of (3), charge is deposited along the triangular elements of the mesh. Next, considering the charge deposited by all particles, the Poisson equation for the scalar potential is solved and new trajectories are found. In order to avoid divergences, the triangular elements charge is averaged between two consecutive cycles. The criterion adopted to admit convergence is a relative current difference lower than $1 \%$. In all simulations no more than 7 iterations were needed to reach the convergence criterion. The beam-waist is the minimum radius of the electron beam that contains $95 \%$ of the total current, $r_{95}$; the normalized transverse velocity $\sigma$, a figure of merit used in measurements of the quality of the beam, is defined as [10]:

$$
\sigma=\left\{\left[\left.\sum_{i=1}^{n} I_{i}\left(\theta_{i}-\langle\theta\rangle\right)^{2}\right|_{\rfloor} /\left.I_{0}\right|_{j} ^{1 / 2}\right\}^{1 / 2}\right.
$$

where $\theta_{i}$ is the slope of the $i$-th macroparticle path as it crosses a given plane perpendicular to the z-axis, $I_{i}$ is the current transported by the $i$-th macroparticle path, $I_{0}$ is the total current crossing the plane, and $\langle\theta\rangle$ is the weighted mean macroparticle path slope of the $n$ macroparticles that cross a given plane perpendicular to the $\mathrm{z}$-axis, given by

$$
\langle\theta\rangle=\left(\sum_{i=1}^{n} I_{i} \theta_{i}\right) / I_{0} .
$$

The better laminarity of the beam under analysis is found for lower values of $\sigma$.

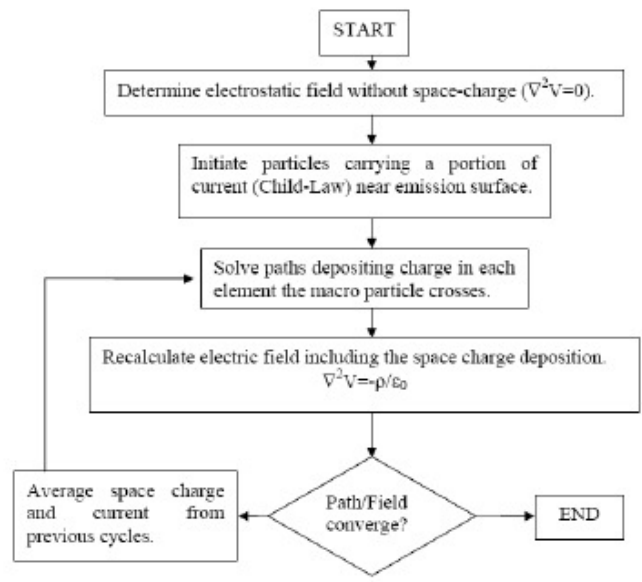

Figure 1- Flowchart of the successive approximation method used by the XMGUN code toestablish convergence.

The electron gun under analysis is considered to be magnetically shielded, then the path equation (3) is reduced to:

$$
\frac{d^{2} r}{d z^{2}}=\left[\left.\frac{1+\left(\frac{d r}{d z}\right)^{2}}{2 \psi}\right|_{\rfloor} ^{7}\left(-E_{r}+E_{z} \frac{d r}{d z}\right)\right.
$$

where $E_{r}$ and $E_{z}$ are the radial and longitudinal components of the electric field respectively.

Fixed the electron gun geometry, the grid voltage has ranged from 450 to $650 \mathrm{~V}$ while the beam-waist size and position, and the transverse velocity were observed.

It is also examined the beam behavior in the drift tube with a PPM stack with 20 permanent magnets. At all drift tube simulations, a total of 40 macroparticles was used. No more than three iterations were needed to guarantee $1 \%$ final position error between two consecutive iterations. The computational tool. so far. does not determine. from the physical structure of the PPM, and characteristics of magnets, the magnetic field in the drift region. The software tool uses the solution [11] to determine the magnetic field around the problem domain. The axial component of magnetic field, for $r<R_{1}$ and a structure of the PPM as the arrangement of Fig. 2, is given by (8) where $I_{0}$ and $K_{l}$ are modified Bessel functions of first and second order respectively, $N$ is the number of permanent magnets, and $M$ is the magnetization. The computational tool implemented numerically the integral (8) and mapped de $B$, into the nodes of the mesh. A comparison between the integral evaluations along 
$B_{z}(0)$ with the existing analytical solution [11] was made, and it was observed that the absolute errors were lower than $0.01 \%$.

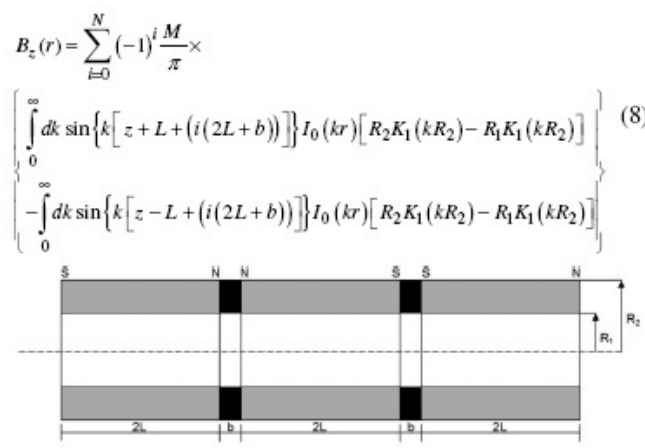

Figure 2 - Schematic drawing of a PPM with toroidal permanent magnets having inner radius $R_{1}, R_{\text {s }}$ and external thickness $2 \mathrm{~L}$ with spacing between adjacent magnets $b$. The polarity is also presented.

The beam behavior in the drift tube with a PPM structure was investigated under a constant electric current of $I_{0}=4.6 \mathrm{~A}$ In all these study cases, the beam enters the magnetic field on ax is with no radial motion. The beam and the PPM focusing structure parameters are presented in Table I. The simulations results will be discussed based on the magnetic-field parameter $\alpha$ and the space-charge parameter $\beta[12]$ defined as:

$$
\alpha=\frac{1}{2}\left(\frac{\eta B_{0} L}{4 \pi v_{z}}\right)^{2},
$$

and

$$
\beta=\frac{\eta I_{0} L^{2}}{8 \pi^{3} \varepsilon_{0} \mathrm{v}_{\mathrm{z}}{ }^{3} a^{2}} .
$$
simulated and is also presented.

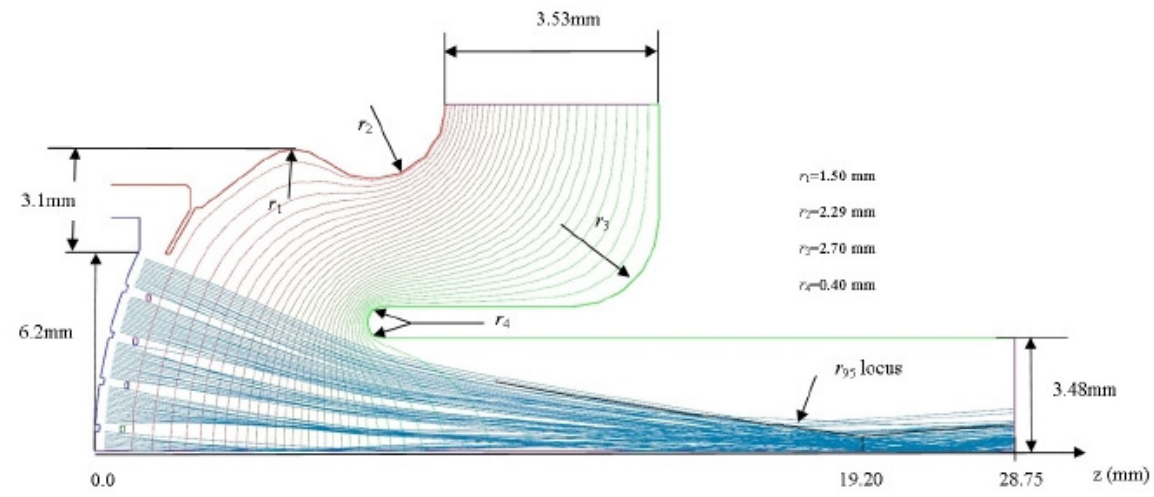

Figure 3 - Geometric drawing of an axis symmetric electron-mun, with grids and shadow-grids, working under the space-charge limitedcondition. $1 \mathrm{kV}$ equipotentials and the $r_{95} l o c u s$ are also presented. Using the particles path equations approach this gun furnished an electric current of $4.58 \mathrm{~A}$.
A. Electron Gun

Fig. 3 shows: an axis symmetric electron gun with control grid and shadow-grid; the behavior of the 74 macroparticles path when the grid voltage is biased to $550 \mathrm{~V}$ and the anode to $30 \mathrm{kV}$; the $\mathrm{r}_{95}$ locus; and $1 \mathrm{kV}$ equipotentials. When the grid voltage ranged from 420 to $600 \mathrm{~V}$ the current varied from 4.26 to 5.76 A respectively. One can observe as the grid voltage increases, Fig. 4, that (a) the beam-waist decreases; (b) the beam-waist distance from the cathode ranges from 19.4 \pm 1.9 $\mathrm{mm}$; and (c) the normalized transverse velocity ranges from $0.086 \pm 0.009$. The gun was modeled with 2996 nodes and 5232 elements.

\section{B. Drift Tube}

The beam behavior subjected to different beam voltages, but with the same electric current $I_{0}=4.6 \mathrm{~A}$ is presented in Figs. $5-9$. The drift region was modeled with 2796 nodes and 4622 elements. When $V_{0}=15 \mathrm{kV}$ or $V_{0}=20 \mathrm{kV}$, Figs. $5-6$, it is noticed that there is no satisfactory electron beam transmission along the drift tube. This can be explained taking into account that the accelerating potential promoted a reduced speed in the beam of electrons. When $V_{0}=40 \mathrm{kV}$ or $V_{0}=60 \mathrm{kV}$, Figs. 7-8, is unsatisfactory because an initial beam spreading might be observed. When $V_{0}=80 \mathrm{kV}$, Fig. 9, the space charge flux is more homogeneous than the other cases analyzed. In this case, the $\alpha$ parameter is closer to the $\beta$ parameter. The closer the $\alpha$ and $\beta$ parameters, the better focusing occurs.

It was not simulated accelerating potentials with voltages higher than $80 \mathrm{kV}$ since relativist effects are not taken into account in the path equation (3). The ripple observed in all simulations was below $15 \%$. Although not easily seen, Figs 8 9 , the macroparticle paths at $60 \mathrm{kV}$ had trajectory inclination, at very few steps after the entrance of the PPM, $34 \%$ higher on ave rage, than those at $80 \mathrm{kV}$. 
TABLE I

BEAM AND PPM FOCUSING STRUCTURE PARAMETERS

\begin{tabular}{ccc}
\hline Parameter & Value & Unit \\
\hline Beam radius & 1.0 & $\mathrm{~mm}$ \\
$R_{l}$ & 9.5 & $\mathrm{~mm}$ \\
$R_{2}$ & 17.0 & $\mathrm{~mm}$ \\
$2 L$ & 10 & $\mathrm{~mm}$ \\
$b$ & 2 & $\mathrm{~mm}$ \\
$B_{p}$ & 85 & $\mathrm{mT}$ \\
\hline
\end{tabular}

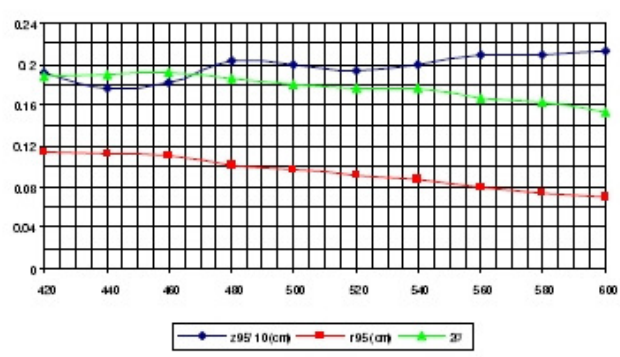

Figure 4 -.Behavior of the beam-waist size, separation to the cathode and the normalized transverse velocity when the grid voltage is varied in the range 420 to $600 \mathrm{~V}$.

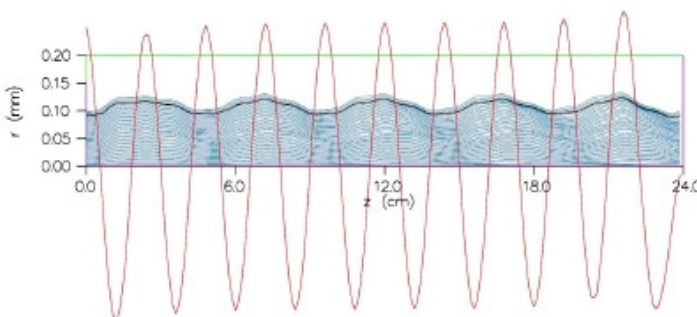

Figure 5 - The particles path for $V_{0}=15 \mathrm{kV}, I_{0}=4.6 \mathrm{~A}$ and $B_{\mathrm{p}}=85 \mathrm{mT}$. It's also shown the $r_{05}$ and the magnetic flux on axis due to the PPM structure $B_{z}(0)$. In this case: $\alpha=0.08$ and $\beta=0.55$.

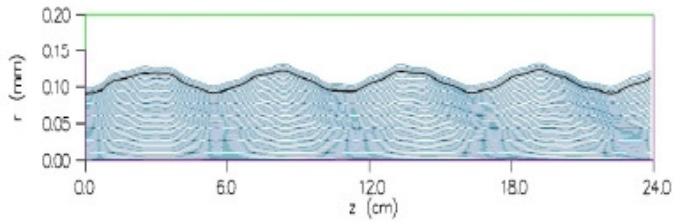

Figure 6 - The particles path for $V_{0}=20 \mathrm{kV}, I_{0}=4.6 \mathrm{~A}$ and $B_{\mathrm{p}}=85 \mathrm{mT}$. It's also shown the $r_{55}$. In this case: $\alpha=0.06$ and $\beta=0.36$.

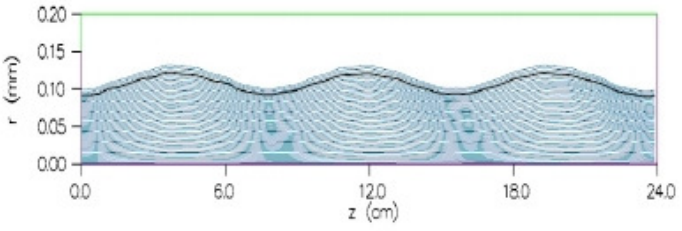

Figure 7 - The particles path for $V_{0}=40 \mathrm{kV}, h=4.6 \mathrm{~A}$ and $B_{\mathrm{p}}=85 \mathrm{mT}$. It's al so shown the $r_{8}$. In this case: $\alpha=0.03$ and $\beta=0.13$.

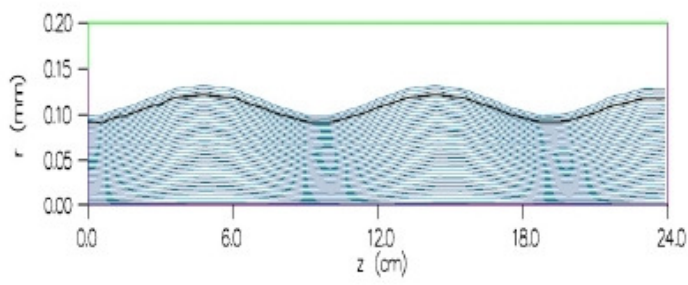

Figure 8 - The particles path for $V_{0}=60 \mathrm{kV}, h_{0}=4.6 \mathrm{~A}$ and $B_{\mathrm{p}}=85 \mathrm{mT}$. It's also shown the $r_{95}$. In this case: $\alpha=0.02$ and $\beta=0.07$.

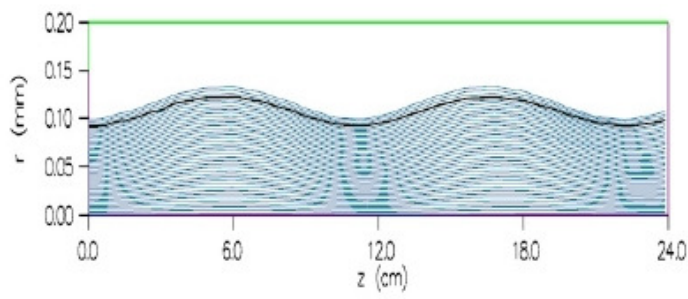

Figure 9 - The particles path for $V_{0}=80 \mathrm{kV}, h_{0}=4.6 \mathrm{~A}$ and $B_{\mathrm{p}}=85 \mathrm{mT}$. It's also shown the ros. In this case: $\alpha=0.01$ and $\beta=0.04$.

C. Collector

In the absence of a magnetic field in the region of the electron collector, the same equation for the trajectory of the particles used in the design of electron gun (7) was used. Next, Fig. 10, a simulation of a single collector, with 1612 nodes and 2969 elements is presented. Simulations with more complex models of collectors, typically Multistage Depressed Collectors - (MDC), will also be simulated in the future. The use of MDCs promote a significant improvement in the efficiency of TWTs [13]. 


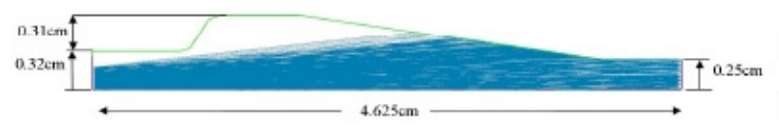

(a)

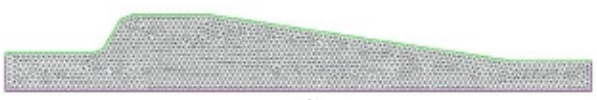

Figure 10 - XMGUN response for (a) a collector simulation using 264 partic les with (b) a mesh with 1612 nodes and 2969 e lements

\section{SUMMARY}

The XMGUN code has been implemented and used to model relevant components of a TWT. Instead of using the motion equation to derive the macroparticles trajectory, XMGUN makes use of the path equation. It is possible to model using XMGUN the electron gun, the drift region and the collector of a TWT.

More simulations will be added in the future. The code will evolve to make use of relativistic particles motion and implement a magnetic solver.

The XMGUN has been under testing and validation for six months. The XMGUN FEM solver needs to improve its computational time since it makes use of the Gaussian Elimination Method. The use of sparse matrix storage and the conjugate gradient method solver is under development.

With the enhancements above, it is intended to evolve the computational tool to a $3 \mathrm{D}$ version.

\section{REFERENCES}

[1] Herrmannsfeldt, W. B., Stanford Linear Acc. Center, SLAC-331 1988 (unpublished).

[2] Humphries Jr., S., "TRACK", Computational Accelerator Physics, edited by R. Ryne (Am. Inst. of Phys, New York 1994), p.597; "Integrated Software System for High-Power Beam Design", in Beams 94: Proc., 10 $10^{\text {th }}$ Conf. High Power Particle Beams, p. 568.

[3] Petillo, J. Eppley, et al., "The MICHELLE electron gun and collector modeling tool: Theory and design", IEEE Trans. Plasm Sci., vol. 30, pp. 1238-1264, Jun. 2002 .

[4] S. Coco et al., "3-D Finite-Element Analysis of TWT Grid Electron Gun s," IEEE Trans. Mag., vol. 43 Issue 4, pp. 1233-1236, Apr. 2007.

[5] C. C. Xavier and C. C. Motta, "The XMGUN Particle Path FEM Code", IEEE Trans. Mag. vol. 46, No. 8, pp.3281-3284, Aug. 2010.

[6] J. T. Mendel, C. F. Quate, W. H. Yocom, "Electron Beam Focusing with Periodic Permanent Magnet Fields," Proceedings of the IRE, May 1954 pp. $800-810$.

[7] Hewlett-Packard Company, "Standard Template Library Programmer's Guide", [Online]. Available: http://www.sgi.com/tech/stl/index.html [Accessed: Jul. 25, 2010]

[8] SGI, "OpenGL - The Industry's Foundation for High Performance Graphics", [Online]. Available: http://www.opengl.org/ [Accessed: Jul. $25,2010]$.

[9] Bojan Nicena "EasyMesh - A Two-Dimensional Quality Mesh Generator." [Online]. A Available: htt://wwwdinma.univ.trieste.it'nirftc/rese arch/easymesh/ [A ccessed: Jul. 25, 2010].

[10] R. True, "A theory for coupling gridded gun design with PPM focusing." IEEE Trans. Electron Devices, vol. ED-31, No. 3, pp. 353 362, Mar. 1984.

[11] E. A. Périgo, R. N. Faria, C.C. Motta. "General Expressions for the Magnetic Flux Density Produced by Axiaaly Magnetized Toroidal Permanent Magnets," Trans. Mag., IEEE, vol. 43 (10), p.3826-3832, Oct. 2007.

[12] B. N. Basu, Electromagnetic Theory and Applications in Beam-Wave Electronics, Singapore: World Scierrific, 1996.

[13] A. S. Jr Gilmour, Principles of Traveling Wave Tubes, Artech House, Istedition, 1994. 


\title{
D.8 IVEC - 2011
}

\section{XMAGUN: An Iron Pole Piece PPM Design and Analysis FEM Code}

\author{
César C. Xavier ${ }^{1}$ and Cláudio C. Motta ${ }^{2}$ \\ ${ }^{1}$ Instituto de Pesquisas Energéticas e Nucleares/CNEN-SP \\ ${ }^{2}$ University of Sao Paulo
}

'cesarcx@usp.br, ${ }^{2}$ cemotta@usp.br, Av. Lineu Prestes 2242 - Cid. Universitária - Sao Paulo - Brazil - 05508-000

\begin{abstract}
An analysis of an iron pole piece PPM code based on the Finite Element Method (FEM) to be used in traveling-wave-tube (TWT) design is presented. The $X M A G U N$ was developed to determine the axial and radial magnetic fields inside such devices. During simulations, the outer pole piece radius varied and, as a result, it was obtained a growth of the axial peak magnetic field value when the outer pole piece radius was reduced. This behavior was observed when the outer pole piece radius ranged $8.7 \mathrm{~mm}-6.3 \mathrm{~mm}$. The axial magnetic field peaks obtained by the XMAGUN were compared with the analytically calculated and the FEM commercial code ANSYS and good agreement was observed.
\end{abstract}

Keywords: FEM, focusing, pole piece; PPM; TWT.

\section{Introduction}

To predict the electron beam trajectories in linear microwave devices, a computational code is under development by the authors. The first suite developed was XMGUN, an electron gun code [1]. To transport beams, PPM structures are widely used due to theirs reduced weight and electric power consumption when compared to a solenoid structure [2].

The seminal work of Chang et al. [3] presented a design guide based on an infinitely long PPM structure, but neglecting a flux path that was later incorporated in the work of Sterzer [4]. Although that method is accurate, it is not valid for some practical PPM structures Recently, practical PPM models were successfully studied by Santra et al. [5], presented in Fig. 1, where the magnetic field was analytically established but for an infinite PPM structure. At all cases studied, the determination of the magnetic field peak is achieved by the computation of the magnetic circuit permeances of the PPM structure with pole piece.

To analyze the beam transport, a second suite, called XMAGUN has been developed, tested and integrated to the main code. In the XMAGUN, the magnetic field is obtained using the FEM approach associated to the variational method for the magnetic vector potential. Additionally, an indexed sparse matrix storage associated to the conjugate gradient method solver scheme was developed.

In this work, using XMAGUN, the axial and radial magnetic fields are completely determined in a PPM structure, with five permanent magnets and six iron pole pieces. Some results are presented, and the axial magnetic field peak in the axis at the center of the PPM structure modeled is compared to those presented by Santra et al., using ANSYS [6] and the analytical one [5].

The first part of this work presents the main characteristics of the PPM structure model used in simulations. The second part describes the most relevant results obtained and finally, the conclusion.

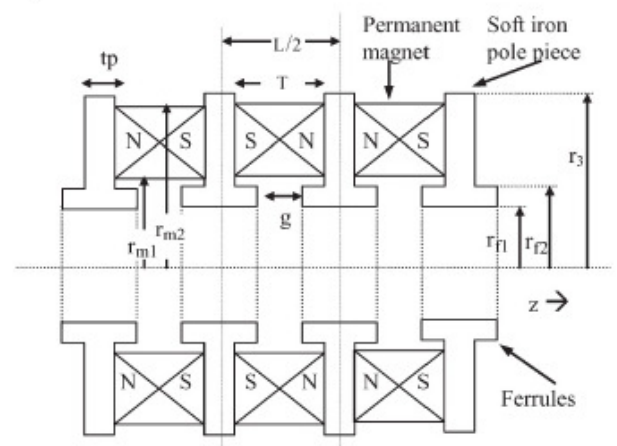

Figure 1 - PPM parameters used on the XMAGUN simulations: magnet inner radius $\mathbf{r}_{\mathrm{ml}}$; magnet outer radius $\mathbf{r}_{\mathrm{m} 2}$; magnet thickness $\mathbf{T}$; pole piece inner radius $\mathbf{r}_{\mathrm{fi}}$; ferrule outer radius $\mathbf{r}_{\mathrm{f}} ;$ pole piece outer radius $\mathbf{r}_{3}$; pole piece thickness $\mathbf{t}_{\mathbf{p}}$; gap length $\mathbf{g}$; half magnet period $\mathbf{L} \mathbf{2}$.

\section{The PPM model}

The PPM simulations were conducted, using the parameters as indicated in Table 1. The soft-iron was modeled assuming a relative permeability of 5000 . A remnant of $0.85 \mathrm{~T}$ was used to model the permanent magnets. The axial and radial boundaries were typically five times the pole piece outer radius to emulate a far field boundary. On most simulations over $20 \mathrm{k}$ nodes and $40 \mathrm{k}$ elements were used to model the PPM and the pole piece structure.

Table 1 - Values used in XMAGUN simulations

\begin{tabular}{|c|c|}
\hline Variable & Value \\
\hline $\mathbf{r}_{\mathrm{m} 1}(\mathrm{~mm})$ & 3.5 \\
\hline $\mathbf{r}_{\mathbf{m} 2}(\mathrm{~mm})$ & 7.5 \\
\hline $\mathbf{T}(\mathrm{mm})$ & 2.95 \\
\hline $\mathbf{r}_{\mathbf{f 1}}(\mathrm{mm})$ & 1.6 \\
\hline $\mathbf{r}_{\mathbf{2} 2}(\mathrm{~mm})$ & 3.05 \\
\hline
\end{tabular} \begin{tabular}{|c|c|c|}
\hline Variable & Value \\
\hline $\mathbf{r}_{3}(\mathrm{~mm})$ & $8.7-6.3$ \\
\hline $\mathbf{T} \mathbf{p}(\mathrm{mm})$ & 1.3 \\
\hline $\mathbf{G}(\mathbf{m m})$ & 2.25 \\
\hline
\end{tabular}




\section{Results}

Fig. 2(a) presents a view of the permanent magnets, darker color, the pole pieces, light gray, and the mesh used, while Fig. 2(b) the magnetic field profile solution obtained using XMAGUN when $\mathbf{r}_{3}=7.8 \mathrm{~mm}$.

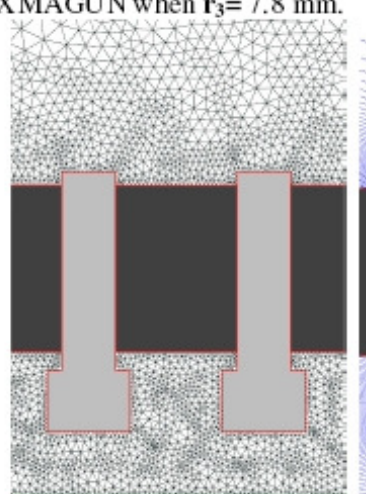

(a)

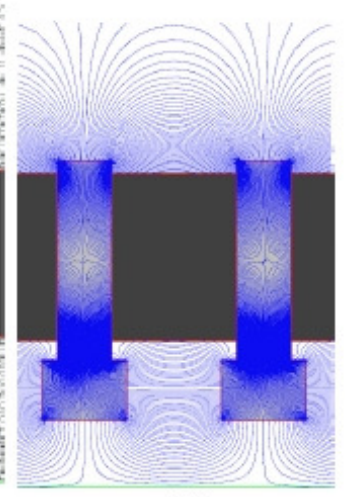

(b)
Figure 2-Zoom at the PPM mesh structure (a) and the magnetic field profile (b).

Fig. 3 presents the magnetic field peak measured: (a) in the center of the PPM structure using XMAGUN; an infinite PPM structure using (b) ANSYS and (c) analytical [5].

Using five different $\mathbf{r}_{\text {ext }}=\mathbf{r}_{3}-\mathbf{r}_{\mathrm{m} 2}$, where $\mathbf{r}_{\mathrm{m} 2}$ was kept constant while $\mathbf{r}_{3}$ varied, Fig. 4 shows an absolute growth of the axial peak magnetic field value along the axis when $\mathbf{r}_{3}$ was reduced.

\section{Conclusion}

A FEM formulation to determine the magnetic field in a PPM structure with pole piece was developed. A good agreement was observed, in the measurement of the axial magnetic field peak, between the XMAGUN, observed at the center of a PPM structure with six pole pieces and five permanent magnets, the software ANSYS, and the analytical PPM structure modeled as an infinite long PPM structure as well.

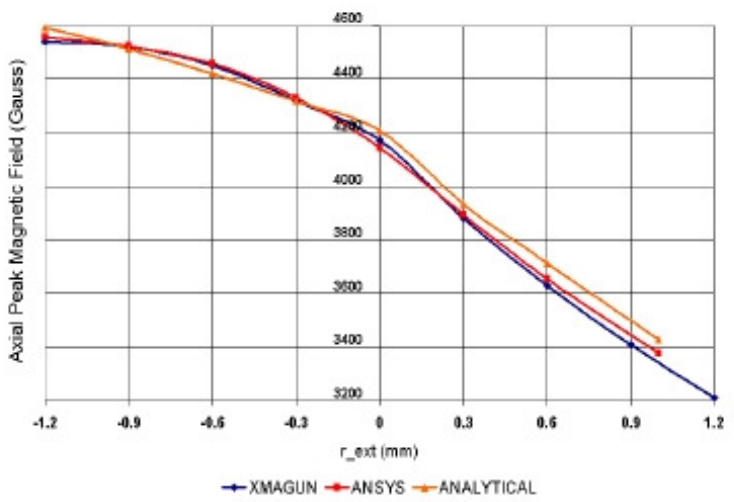

Figure $3-V$ ariation of the axial peak magnetic field using the XMAGUN, the ANSYS and the Analytical values for distinct $\mathbf{r}_{\text {ext }}$.

\section{References}

1. Xavier, C. C., Motta, C. C., The XMGUN Particle Path FEM Code, IEEE Trans. Mag. vol. 46, No. 8, pp. 3281-3284, Aug. 2010.

2. Gilmour, A. S. Jr, Principles of Traveling Wave Tubes, Artech House, 1st edition, 1994.

3. Chang, K. K. N. Optimun Design of Periodic Magnet Structures for Electron Beam Focusing. RCA Review, vol. XVI, p.65-81, Mar., 1955.

4. Sterzer, F.; Siekanowicz, W. W. The Design of Periodic Pemanent Magnets for Focusing of Electron Beams. RCA Review, vol. 28, p.39-59, Mar., 1957.

5. Santra, M.; Kumar, L.; Balakrishnan, J. An Improved Analysis of PPM Focusing Structures Including the Effect of Magnetic Saturation in the Iron Pole Pieces. IEEE Trans. on Electron. Devices, vol. 56, Issue 5, p.974-980, May 2009.

6. Electromanetic Field Analysis Guide, ANSYS Inc., Canonsburg, PA, Sep. 1997. Release 5.4.

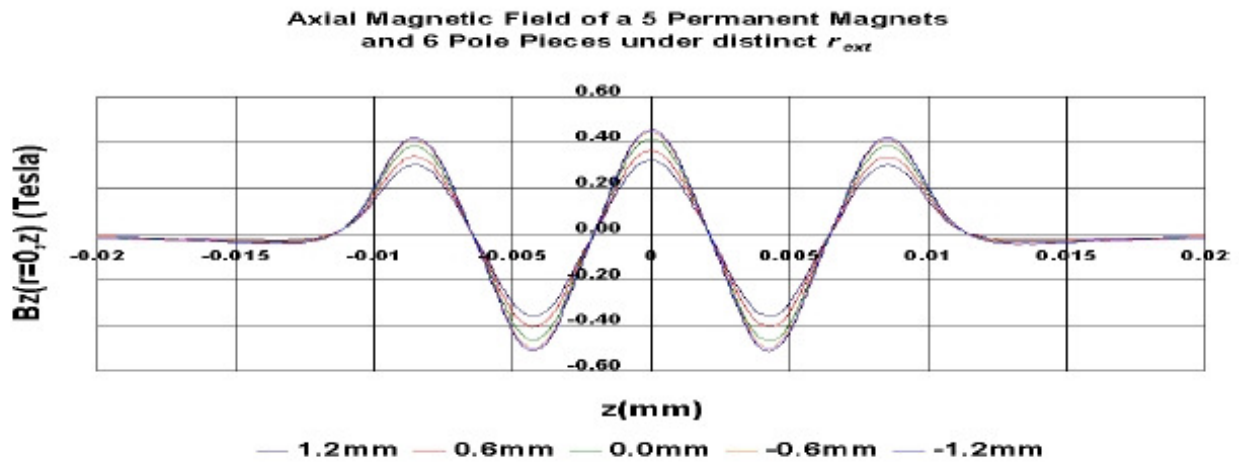

Figure 4 - Axial magnetic field profile along axis for five distinct $r_{e x t}=r_{3}-r_{m 2}$. 


\section{Bibliografia}

[1] B. N. BASU, Eletromagnetic theory and applications in beam-wave electronics. World Scientific, 1st edition, 1996.

[2] HERRMANNSFELDT, W. B. "Egun - An Electron Optics and Gun Design Program," SLAC-331, Stanford, CA, Out. 1988.

[3] HUMPHRIES JR. S. "TRACK", Computational Accelerator Physics, edited by R. Ryne (Am. Inst. of Phys., New York 1994), p.597; "Integrated Software System for High-Power Beam Design", in Beams 94: Proc., 10th Conf. High Power Particle Beams, p. 568.

[4] A. IVANOV, M. TIUNOV, "ULTRASAM-2D Code for Simulation of Electron Guns with Ultra High Precision", in EAPAC 2002: Proc., 8th. European Particle Accelerator Conference, p.1634-1636.

[5] TRUE, R. The Design of Gridded Pierce Guns for Accelerators, IEEE Trans. Nucl. Sci, vol. 32, Issue 5, Oct. 1985, p.2611 - 2613S.

[6] TRUE, R. Gridded Pierce Gun Design and the PPM Focussing of Beams from Gridded Electron Guns. International Electron Devices Meeting, IEEE, p.32-35, 1982.

[7] TRUE, R. A Theory for Coupling Gridded Gun Design with PPM Focussing. Transactions on Electron Devices, IEEE, 31(3):353-362, March 1984.

[8] TRUE, R. Calculation and Design of Grids in Pierce Guns. International Electron Devices Meeting, IEEE, vol. 31(3), p215-218, 1989.

[9] PETILlO, J. EPPLEY, K. PANAGOS, D. BLANCHARD, P. KRUEGER, W. MONDELLI, A. SAIC, T.M. LANL, E.N. RAYTHEON, N.D. PRECISION, S.H.J.F. DEFORD, J. STAR, B.H. NRL, B.L. "The MICHELLE electron gun and collector modeling tool: Theory and design", IEEE Trans. Plasma Sci, vol. 30, p.1238-1264, Jun. 2002.

[10] COCO, S. CORSARO, S. DIONISIO, R. LAUDANI, A. MARTORANA, R. POLLICINO, G. "Electromagnetic analysis by finite elements of electron guns for traveling wave tubes", in IVEC 2004: 5th IEEE International Vacuum Electronics Conference, 2004, p.320-321. 
[11] Petillo, J. TSANG, K. MONDELli, A. "AVGUN: A 3-D Electrostatic Relaxation Particle-in-cell Code With Multiple Grids", in IEEE Int. Conf. on Plasma Sci., 1991, p.211

[12] COCO, S. EMMA, F. LAUDANI, A. PULVIRENTI, S. SERGI, M. "COCA: a novel 3D FE simulator for the design of TWTs multistage collectors", in IEEE Trans. Electron Devices, vol. 48-1, p.24-31, Jan. 2001.

[13] R. BHATT, T. BEMIS, C. CHEN. "Three-Dimensional Theory and Simulation of Nonrelativistic Elliptic Electron and Ion Beam Generation", in IEEE Trans. Plasma Sci., vol.34-2, p.187-193, Abr. 2006.

[14] B. LI, Z. H. YANG, J. Q. LI, X. F. ZHU, T. HUANG, Q. HU, YU LU HU, LI XU, J.N J. MA, LI LIAO, LI XIAO, G. X. HE. "Theory and Design of Microwave-Tube Simulator Suite", in IEEE Trans. Electron Devices, vol. 56-5, p.919-927, Mai. 2009.

[15] QUAN HU, TAO HUANG, ZHONG H. YANG, et al. . "Recent Developments on EOS 2-D/3-D Electron Gun and Collector Modeling Code", in IEEE Trans. Electron Devices, vol. 57-7, p.1696-1701, Jul. 2010.

[16] BIRDSALL, C.K.; LANGDON, A.B. Plasma physics via computer Simulation. Adam Hilger, 1st edition, 1991.

[17] BARKER, R. J.; BOOSKE, J. H.; JR, N. C. L.; G. S. Nusinovich, Modern Microwave and Millimeter-wave Power Electronics. Willey-Interscience, 1st edition, 2005.

[18] GILMOUR, A. S. JR. Principles of Traveling Wave Tubes, Artech House, 1st edition, 1994.

[19] PIERCE, J. R. Theory and Design of Electron Beams, Van Nostrand, New York, 1958.

[20] LANGMUIR, I. The effect of space charge and residual gases on thermionic currents in high vacuum. Phys. Rev., vol. 2, Issue 6, p. 450-486.

[21] LANGMUIR, I.; BLODGETT, K. B. Currents limited by space charge between concentric spheres. Phys. Rev., vol. 24, p.49-59, 1924.

[22] HIGASHI, C. Investigação do processo de obtenção de aluminatos de Bário e Cálcio para construção e caracterização de catodos termiônicos impregnados para aplicação em dispositivos de micro-ondas de potência. Dissertação (Mestrado) - Instituto de Pesquisas Energéticas e Nucleares, São Paulo.

[23] VAUGHAN, J. RODNEY M. "Synthesis of the Pierce Gun", IEEE Trans. on Electron. Devices, vol. 28, Issue 1, p.37-41, Jan. 1981.

[24] MENDEL, J.T., QUATE, C. F., YOCOM, W. H. "Electron Beam Focusing with Periodic Permanent Magnet Fields", Proceedings of the IRE, May 1954, p.800-810. 
[25] MENDEL, J. J.; QUATE, C. F.; YOCOM, W. H. Electron Beam Focusing with Periodic Permanent Magnet Fields, Proc. I. R. E., vol.42, p.800-810, May, 1954.

[26] KREYZIG, E. Advanced Engineering Mathmatics. New York: John Wiley and Sons, 1967.

[27] PÉRIGO, E. A.; FARIA, R. N.; MOTTA, C. C. General Expressions for the Magnetic Flux Density Produced by axxially Magnetized Toroidal Permanent Magnets. Trans. Magn., IEEE, 43(10):3826-3832, Oct. 2007.

[28] JACKSON, J. D. Classical Elctrodynamics, 2nd ed. New York: Wiley, 1975.

[29] GRADSHTEYN, I. S.; RYZHIK, I. M. Tables of Integrals, Series and Products. San Diego, CA. Academic, 1994.

[30] CHANG, K. K. N. Optimun Design of Periodic Magnet Structures for Electron Beam Focusing. RCA Review, vol. XVI, p.65-81, Mar., 1955.

[31] ARFKEN, G. B.; WEBER, H. J. Mathematical Methods for Physicists, 6th ed. San Diego, CA: Elsevier Academic Press, 2005.

[32] OLSON, H. F. Elements of Acoustical Engineering. New York, NY: D. Van Nostrand Co., 1940.

[33] STERZER, F.; SIEKANOWICZ, W. W. The Design of Periodic Permanent Magnets for Focusing of Electron Beams. RCA Review, vol. 28, p.39-59, Mar., 1957.

[34] SANTRA, M.; KUMAR, L.; BALAKRISHNAN, J. An Improved Analysis of PPM Focusing Structures Including the Effect of Magnetic Saturation in the Iron Pole Pieces. IEEE Trans. on Electron. Devices, vol. 56, Issue 5, p.974-980, May 2009.

[35] FORCE, D. A. Calculation of secondary Electron Trajectories in Multistage Depressed Collectors for Microwave Amplifiers. NASA Technical Paper 2664, 1986.

[36] VAUGHAN, J. R. M. A New Formula for Secondary Emission Yield. IEEE Trans. on Electron. Devices, vol. 36, Issue 9, p.1963-1975, Sep. 1989.

[37] VAUGHAN, J. R. M. Secondary Emission Formulas. IEEE Trans. on Electron. Devices, vol. 40, Issue 4, p.830, Apr. 1993.

[38] HUANG T.; YANG, Z. H. et al. Electron Optics Simulator: A Three-Dimensional Finite-Element Electron Gun and Collector Design Tool. IEEE Trans. on Electron. Devices, vol. 56, Issue 1, p.140-148, Jan. 2009.

[39] ZHANG, Y.; LUO, J.; GUO, W. E ZHU MIN. Influence of the Output Parameters on Multistage Depressed Collector Characteristics in a Coupled Cavity TWT, Progress in Electromagnetics Reserch Symposium Proceedings, March 2010 p. 347-350. 
[40] REIMER, L. Scanning Electron Microscope, Physics of Image Formation and Microanalysis. New York: Springer-Verlag, 1985.

[41] KIRSTEIN, P.T. HORNSBY, J. S. An investigation into the use of iteration methods for the analysis of axially symmetric and sheet beam electrode shapes with an emitting surface. IEEE Trans. on Electron. Devices, vol. 11, Issue 5, p.196 - 204, May 1964.

[42] BOERS, J. E. BOERS, J. E. Digital Computer Analysis of Axially Symmetric Electron Guns, IEEE Trans. on Electron. Devices, vol. 12, Issue 7, Jul. 1965, p.425 -435.

[43] HOCKNEY, R. W.; EASTWOOD, J. W. Computer simulation using particles. Taylor \& Francis, Inc., Bristol, PA, USA, 1988.

[44] DAWSON, J. M.; LIN, A. T. Handbook of Plasma Physics - Particle Simulation. Elsevier Science Publishers, 1st edition, 1984.

[45] SILVESTER, P. P.; FERRARI, R. L. Finite Elements for Electrical Engineers. 3.ed. New York, NY.:Cambridge University Press, 1996.

[46] BASTOS, J. P. A; SADOWSKI, N. Eletromagnetic Modeling by Finite Element Methods. New York, NY.: Marcel Dekker, Inc., 2003

[47] IDA, N.; BASTOS, J. P. A. Eletromagnetics and Calculation of Fields. 2nd. New York, NY.: Springer-Verlag, 1997.

[48] LAPIDUS, L.; PINDER, G. F. Numerical Solution of Partial Differential Equations in Science and Engineering. New York, N.Y.: John Wiley and Sons, 1982.

[49] STOER, J.; BULIRSCH, R. Introduction to Numerical Analysis. New York, NY.: Springer-Verlag, 3rd., 2002.

[50] PRESS, W. H. TEUKOLSKY, S. A. FLANNERY, B. P. Numerical Recipes - The Art of Scientific Computing. 3.ed. New York, NY.:Cambridge University Press, 2007.

[51] GOLUB, G. H.; VAN LOAN, C. F. Matrix Computations. 2nd ed. Baltimore, M.D.: Johns Hopkins University Press, 1989.

[52] DevC++. Disponível em http://www.bloodshed.net/dev/index.html. Acesso em 09 de julho de 2010.

[53] STL. Disponível em http://www.sgi.com/tech/stl/index.html. Acesso em 09 de julho de 2010 .

[54] C++/STL. Disponível em http://www.cplusplus.com/reference/stl/. Acesso em 09 de julho de 2010.

[55] JOSUTTIS, N. M. The C++ Standard Lirary: a tutorial and Reference. Indianapolis, IN.: Addison-Wesley, 2008. 
[56] OpenGL. Disponível em http://www.opengl.org/. Acesso em 12 de julho de 2010.

[57] GLUI User Interface. Disponível em http://www.cs.unc.edu/ rademach/glui/. Acesso em 14 de julho de 2010.

[58] EasyMesh - A Two-Dimensional Quality Mesh Generator. Disponível em: http://wwwdinma.univ.trieste.it/nirftc/research/easymesh/. Acesso em 10 jul. 2009.

[59] HUMPHRIES, JR. S. "Numerical Modeling of Space-Charged-Limited ChargedParticle Emission on a Conformal Traiangular Mesh", Journal of Comp. Phis, vol. 125, p. 488-497, 1996.

[60] XAVIER, C. C; MOTTA, C. C. Design and Characterization of a Gridded Electron Gun for Traveling-Wave Tubes. $13^{\circ}$ SBMO - Simpósio Brasileiro de Microondas e Optrônica e o $8^{\circ}$ CBMag - Congresso Brasileiro de Eletromagnetismo, p.565-568, 2008.

[61] XAVIER, C. C; MOTTA, C. C. Design of a Gridded Electron Gun for Traveling-Wave Tubes: an EGUN case study. International 2009 IEEE International Vacuum Electronics Conference - IVEC2009, 2009, Roma. Proceeding of IVEC2009. Piscataway: IEEE, 2009. v. 1., p. 153-154. 2009.

[62] XAVIER, C. C; MOTTA, C. C. Modeling of a Gridded Electron Gun for TravelingWave Tubes. Power Pulse Conference, 2009.

[63] XAVIER, C. C.; MOTTA, C. C. The XMGUN Particle Path FEM Code. IEEE Trans. Magn., 48(8):3281-3284, Aug. 2010.

[64] XAVIER, C. C; MOTTA, C. C. XMAGUN: An Iron Pole Piece PPM Design and Analysis FEM Code. International 2011 IEEE International Vacuum Electronics Conference - IVEC2011 (aceito em Nov. 2010) .

[65] XAVIER, C. C; MOTTA, C. C. A Particle-Path FEM Approach Used on Electron Gun, Magnetic Focusing and Collector TWT Design. MOMAG 2010 - $14^{\circ}$ SBMO - Simpósio Brasileiro de Microondas e Optrônica e o $9^{\circ}$ CBMag - Congresso Brasileiro de Eletromagnetismo - COMPUMAG 2010. p.641-645, 2010.

[66] Electromagnetic Field Analysis Guide, ANSYS Inc., Canonsburg, Set. 1997, Release 5.4 .

[67] EGUN - Óptica de párticulas sob Cargas Espaciais. Disponível em: http://www.egunigun.com/. Acesso em 10 jul. 2009.

[68] GNU. Disponível em http://www.gnu.org/. Acesso em 09 de julho de 2010.

[69] RedBook. Disponível em http://www.opengl.org/documentation/red_book/. Acesso em 12 de julho de 2010. 
[70] FREY, P. J.; GEORGE, P. L. Mesh Generation. Oxford, Hermes Science Publishing, 2000.

[71] BERG, DE M.; KREVELD, M. VAN; OVERMARS, M.; SCHWARZKOPF, O. Computational Geometry. Berlin, Heidelberg: Springer-Verlag, 2000. 